Louisiana State University

LSU Digital Commons

1975

\title{
The Effects of Conventional Soil Sampling Methods on the Engineering Properties of Cohesive Soils in Louisiana.
}

Kenneth Louis Mcmanis

Louisiana State University and Agricultural \& Mechanical College

Follow this and additional works at: https://digitalcommons.Isu.edu/gradschool_disstheses

\section{Recommended Citation}

Mcmanis, Kenneth Louis, "The Effects of Conventional Soil Sampling Methods on the Engineering Properties of Cohesive Soils in Louisiana." (1975). LSU Historical Dissertations and Theses. 2844. https://digitalcommons.Isu.edu/gradschool_disstheses/2844

This Dissertation is brought to you for free and open access by the Graduate School at LSU Digital Commons. It has been accepted for inclusion in LSU Historical Dissertations and Theses by an authorized administrator of LSU Digital Commons. For more information, please contact gradetd@lsu.edu. 


\section{INFORMATION TO USERS}

This material was produced from a microfilm copy of the original document. While the most advanced technological means to photograph and reproduce this document have been used, the quality is heavily dependent upon the quality of the original submitted.

The following explanation of techniques is provided to help you understand markings or patterns which may appear on this reproduction.

1. The sign or "target" for pages apparently lacking from the document photographed is "Missing Page(s)". If it was possible to obtain the missing page(s) or section, they are spliced into the film along with adjacent pages. This may have necessitated curting thru an image and duplicating adjacent pages to insure you complete continuity.

2. When an image on the film is obliterated with a large round black mark, it is an indication that the photographer suspected that the copy may have moved during exposure and thus cause a blurred image. You will find a good image of the page in the adjacent frame.

3. yutuen a map, drawing or chart, etc., was part of the material being photographed the photographer followed a definite method in "sectioning" the material. It is customary to begin photoing at the upper left hand corner of a large sheet and to continue photoing from left to right in equal sections with a small overlap. If necessary, sectioning is continued again - beginning below the first row and continuing on until complete.

4. The majority of users indicate that the textual content is of greatest value, however, a somewhat higher quaiity reproduction could be made from "photographs" if essential to the understanding of the dissertation. Silver prints of "photographs" may be ordered at additional charge by writing the Order Department, giving the catalog number, title, author and specific pages you wish reproduced.

5. PLEASE NOTE: Some pages may have indistinct print. Filmed as received.

Xerox University Microfilms

300 North Zeeb Rcad

Ann Arbor, Michigan 48106 
McMANIS, Kenneth Louis, 1941-

THE EFFECTS OF CONVENTIONAL SOIL SAMPLING

METHODS ON THE ENGINEERING PROPERTIES OF

COHESIVE SOILS IN LOUISIAHA.

The Louisiana State University and Agricultural and Mechanical College, Ph.D., 1975

Engineering, civil

Xerox University Microfilms, Ann Arbor, Michigan 48106 
THE EFFECTS OF CONVENTIONAL SOIL SALAPLING METHODS ON THE ENGINEERING PROPERTIES OF COHESIVE SOILS IN LOUISIANA

\author{
A Dissertation \\ Submitted to the Graduate Faculty of the \\ Louisiana State University and \\ Agricultural and Mechanical College \\ in partial fulfillment of the \\ requirements for the degree of \\ Doctor of Philosophy
}

in

The Department of Civil Engineering

by

Kenneth Louis ficitianis

B.S. University of Southwestern Louisiana, 1963

M.S., Louisiana State University, 1966

August, 1975 


\section{ACKNOWLEDGENENTS}

This dissertation reflects to a large degree the assistance, guid: ance and consultation of many individuals. The author is most grateful to Professor Ara Arman under whose direction and guidance the research and writing was accomplished. I am indebted also to the members of my graduate conmittee who at various times provided insight and consultation: To those staff members of the soils and foundation section of the Louisiana Department of Highways and Division of Engineering Research at Louisiana State University who participated in this study, I would also like to extend a special thanks. 
Acknowledgements.......................................... ii

List of Tables.............................................viii

List of Figures........................................ ix

Abstract............................................... xix

\section{Chapter}

\section{INTRODUCTION}

Soil Sampling Objective and Need for Study.............. 1

Soil Sample Types................................... 3

Sample Type as Governed by Soil Properties.............. 3

II SOIL SAMPLING TECHNIQUES

Block Sampling.................................... 8

Borehole Sampling.................................. 8

Methods of Advancing The Borehole....................... 8

Stabilizing the Borehole.............................. 9

Samplers.......................................... 10

exploration samplers.............................. 10

open drive samplers............................... II

piston samplers................................... 14

core samplers................................... 15

Methods of Forcing Sampler into Soil................... 17

Sampling as a Function of Sampler, Soil and Sample Type..... 17

Storage, Handling, and shipment of Samples.............. is

Current Methods and Equipment Used for Soil Sampling........ 21 
CHAPTER

World Wide.................................. 21

Southern States................................ 24

Louisiana..................................... 25

III SAMPLE DISTURBANCE

Disturbance Prior to Sampling..................... 30

Disturbance During Sampling...................... 32

Disturbance Factors............................. 35

change is stress conditions..................... 37

changes in moisture content and void ratio............ 46

disturbance of soil structure................... 47

chemical changes............................. 48

mixing and segregation of soil constituents...........49

The Effects of Sampling, Handling, and Storage on

Engineering Properties.............................. 49

shear strength............................... 49

modulus of deformation........................... 52

consolidation............................... 52

permeability................................ 52 .

IV PREVENTION, EVALUATION AND CORRECTION FOR SAMPLE DISTURBANCE: STATE-QF-THE-ART

Prevention: Comparative rerformances of Samples

and Sampling Techniques........................... 53

Evaluation of Sample Disturbance.................. 68

Correcting for Sample Disturbance................. 72

v GEOLOGY AND SITE SELECTION....................... 87

iv 


\section{CHAPTER}

VI SAMPLING AND TESTING PROGRAM

Block Samples.................................. 93

Osterberg Samples............................. 96

Thin-Wal1, Open-Drive, Shelby Samples............... 96

Standard Penetration Test and Samples................ 98

Handling and Storage Techniques $s_{s}=\ldots \ldots \ldots \ldots \ldots \ldots \ldots . . \ldots 8$

Testing Program............................... 101

unconfined and unconsolidated-undrained............ 101

remolded samples.............................. 101

consolidation test.......................... 102

classification tests......................... 102

field tests: SPT and field vane test.............. 102

extruding, storage, etc...................... 102

microanalysis, $x$-ray diffraction................ 106

x-ray radiography......................... 106

VII TEST RESULTS AND DISCUSSION

Lake Charles Site................................. 109

l.aplace Site............................... 152

Erwinville Site................................ 168

Houma Site...................................... 175

Morgan City Site............................... 172

Benton Site................................. 187

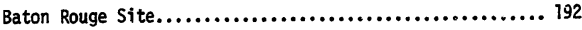

Monroe Site..................................... 196

Larose Site.................................... 201

v 


\section{CHAPTER}

Fillmore Site.................................. 201

Undisturbed Sampling Relative to Soil Fabric......... 201

Sample Protection............................. 206

Sample Storage............................. 211

Extrusion Effects.......................... 216

Radiography (General)

Photoelastic Anaìsis......................... 219

Sample Variations in Cores.................... 219

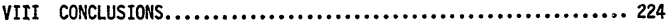

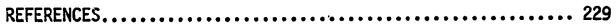




\section{APPENDIX}

A. SEM-EDS Microanalysis of Lake Charles Soil ................ 240

B. $X-R a y$ Radiography Technique.......................... 264

C. Lake Charles Site.................................. 266

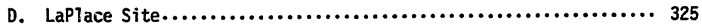

E. Erwinville Site................................... 341

Houma Site...................................... 343

Morgan City Site.................................. 346

Benton Site $. . \ldots \ldots \ldots \ldots \ldots \ldots \ldots \ldots \ldots \ldots \ldots \ldots \ldots \ldots \ldots \ldots \ldots . \ldots \ldots 1$

Baton Rouge Site................................... 352

Monroe Site....................................... 354

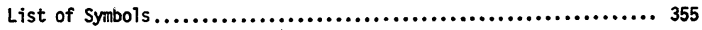

Biography ......................................... 357 


\section{LIST OF TABLES}

No.

\section{Title}

1 Quality Classes for Soil Samples.................... 5

2 Specimen Sizes .................................. 19

3 Stress Ratios for Perfect Sampling................... 83

4 Typical Soil Properties-Lake Charles Site 1,

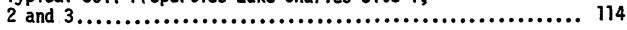

5 Typical Soil Properties-Lake Charles Site 7,

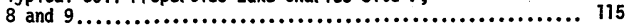

6 Soil Properities-LaPlace Site........................ 154

7 Typical Soil Properties - Erwinville Site............... 172

8 Typical Soil Properties - Houma Site................. 177

9 Typical Soil Properties - Morgan City Site............... 181

10 Typical Soil Properties - Benton Site.................. 189

11 Typical Soil Properties - Monroe Site.................. 198

12 Test of Sample Protection Methods ..................... 209

13 Simulated Field Storage of Extruded Cores $\ldots \ldots \ldots \ldots \ldots \ldots \ldots 210$

14 Typical Extrusion Stresses and Unconfined Compressive

Strength ........................................ 218

15 Statistical Analysis, Sample Classification Compared,

Lake Charles Site.................................. 270

16 Statistica] Analysis, Tests/Sample Size and Type Compared, Lake Charles Site........................ 271

17 Statistical Analysis, Tests/Sample Size Compared.......... 272

18-23 Statistical Data-Lake Charles Site $\ldots \ldots \ldots \ldots \ldots \ldots \ldots . \ldots 273$ - 278

viii 
2 Cumulative Distribution Curves for Proportion of Total Sampling Effort

3 Drive Sampling and Rotary Drilling with Sampler

4 Soil Sample Protective Storage Technique

5 Stress Changes and Deformations of Soil Layers Below Bottom of Bore Hole

$6 \quad$ Fcrces Acting During Sampling 33

7 Zone of Disturbance. 36

8 State of Stress Change Due to Sampling 38

$9 \quad$ Relationship Between $K_{0}, I_{p}$ and OCR 40

10 Perfect Sampling of a Normally Consolidated Clay 42 and an Over-Consolidated Clay

11 Changes in Stress Conditions of Soil Sample 44

12 Measured Pore Pressure vs Time Relationships 45

13 Variation of $U$ Along Length and Diameter . 51

14 Relationship Between Edge Angle and Sample Quality 55

$15 \mathrm{a}, \mathrm{b}$ Influence of Sample Type and Size on Disturbance 67

16 Evaluation of Disturbance 69

17 Preconsolidation Pressure, Casagrande Graphical 74

18 Preconsolidation Pressure, Burmister Method 74

19 Preconsolidation Pressure and Field Curve, 74

Schmertman Method

20 a, b Field Curve For Settlement Interpretation 76

21 Preconsolidation Pressure $\quad 76$

ix 
23 a Cross-Section of Clay Specimen Shaving Portions Disturbed in Preparation For Consolidation Test

$23 \mathrm{~b} \quad$ Determination of Amount of Disturbance in Thin Consolidation Specimens by the Proportioning Method Strength

26 Effect of OCR on Undrained Strength

27 Extrapolation of Field Time-Settlement Curve From Disturbed Laboratory Consolidation Tests Soil Sampling Sites Showing Fissures 
41 Typical Stress-Strain Curves of Triaxial Undrained Compression Test-Lake Charles-30 Ft. Depth Compression Test-Lake Charles-30 Ft. Depth

43 Typical Stress-Strain Curves of Unconfined

Compression Test-Lake Charles - 27' - 30' Depth

44 Specimen From Block Sample Showing Failure Plane

Triaxial Compression Tests on Block Sample

46 Average e $\log \bar{\sigma}$ Curves for Various Sample TypesLake Charles-30 Ft. Depth

47 Determination of the Apparent Preconsolidation Pressure-Lake Charles Site 5, Block 7

48 Field Surve For Lake Charles Site 5, Block 10, $30 \mathrm{Ft}$. Depth

49 Comparison of the Average Coefficient of Coefficient of Consolidation For Different Samples, Lake Charles-30 Ft. Depth ( $\sqrt{+}$. method)

Comparison of the Average Coefficient of Consolidation for Different Samples, Lake Charles $30 \mathrm{Ft}$. Depth (log + method) Layer Wall Samples Relative to Block Samples, Lake Charles 
No.

Titile

Page

60 X-Ray Radiograph of Sltce of Sample Tested to Failure

X-Ray Radiograph of 5 in. Core Showing Shells

150

62 X-Ray Radiograph of Sample Stice with Concretions 151

63 LaPlace Site Summary Profile 153

64 Sampler Influence On Unconfined Shear Strength - 156

Laplace Site

LaPlace Site - Sample Reliability for Osterberg

Piston Sampler

66

LaPlace Site - Sample Reliability for $3^{\prime \prime} \phi$ Shelby

Sampler

158

159

LaPlace Site - Sample Reliability for $5^{\prime \prime} \phi$ Shelby Sampler

68 X-Ray Radiograph of 5 in. Shelby Sample with Shear Planes

162

69

X-Ray Radiograph of 3 in. O.D. LaPlace Site

163

70

X-Ray Radiograph of 3 in. O.D. LaPlace Site

163

71 X-Ray Radiograph of 3 in. O.D. LaPlace Site

165

$72 X$-Ray Radiograph of 3 in. 0.D. LaPlace Site 166

73 Photograph 3 in. 0.D. LaPlace Site 167

74 Summary Profile - Erwinville Site 169

75 Photograph of Erwinville Core $\quad 170$

76 Influence of Sampling and Remolding on Unconsolidated 173 Undrained Compressive Strength - Erwinville Site

77 X-Ray Radiograph of 3 in. O.D. Core - Erwinville 174 Site

78 Summary Profile - Houma Site 176

79 Unconfined Shear Strength, 5" $\phi$ vs 3" $\phi$, Houma Site 178

80 Summary Profile - Morgan City Site 180

xit 
Sampler Influence on Unconfined Shear Strength Benton Site

86 Sumnary Profile and Storage Tezt Results Baton Rouge Site

a) Remolded vs Undisturbed - Baton Rouge Site

b) Lower Sample vs Upper Sample - Baton Rouge Site

89 Sanpler Infliuence on Undrained Shear Strength Monroe Site Site

93 Storage Time vs Preconsolidation Pressure, Lake Charles Site

94 Storage Time Effects on e $\log \bar{\sigma}$, Lake Charles

95 Top of Overdriven Sample 220

96 Photoelastic Siress Patterns During Sampling 221

97 Variation in Sample Core 223

$98 \quad$ Electron Micrographs 245

99 a Electron Micrograph (upper) and Calcium Element 247 Distribution Map (Lower) 
No.

Tftle

Page

99 b Iron Element Distribution Map 248

100 Electron Micrograph (Upper) and Iron Distribution May (Lower)

101 a Electron Micrograph (Upper) and iron Distribution 252 May (Lower)

101 b Sulfur Distribution Map 253

102 a Electron Micrograph (Upper) and Iron Distribution 255

102 b Sulfur Distribution Map 256

103 Electron Micrograph (Upper) and Element May of 258

104 Electron Micrograph-pyrite Crystals and Variable 260

105 Energy Dispersive X-ray Spectrum for Lake Charles 262

106 X-ray Diffraction, Oriented Slide-Lake Charles 263

107 Modified Plasticity Chart, Lake CharTes Sites 1, 2, 267 3, 4 and 5

108 Modified Plasticity Chart, Lake Charles Sites 7, 8, 268 and 9

109 Moisture Content vs Sample Length 269

110 Lake Charles Site, B-1, C-11A (UU Test) 279

111 Lake Charles Site 3, B-9, C-57 (UU Test) 280

112 Unconfined Compressive Test, Lake Charles, Site 4, 281 Block 4

113 Triaxial compressive Test, Lake Charles, Site 4, 282 Block 4

114 Triaxial Compressive Test, Lake Charles Site 4, 283 Block 6

115 Unconfined Compressive Test, Lake Charles, Site 5, 284 Block 7 xiv 
No.

Title

Page

116 Triaxial Compressive Test, Lake Charles, Site 5, Block 7

117 Unconfined Compression Test, Lake Charles, Site 5 , Block 8

118 Triaxial Compressive Test, Lake Charles, Site 5, Block 8

119 Lake Charles Site 7, B-18, C-265, Compression Tests

288

120 Lake Charles Site 7, B-17, C-261A, Compression

121 Lake Charles Site 7, B-12, C-233A, Compression Test

122 Lake Charles Site 7, B-17, C-263A, Compression

123 Lake Charles Site 8, B-20, C-270B, Compression Test

124 Lake Charles Site 8, B-21, C-275A, Compression Test

125 Lake Charles Site 8, B-22, C-280, Compression

294 Test

126 Lake Charles Site 8, B-23, C-285, Compression Test

127 Lake Charles Site 8, B-24, C-290A, Compression Test

128 Lake Charles Site 8, B-24, C-290B Cciapression Test

129 Lake Charles Site 8, B-20, C-271B, Compression Test

130 Lake Charles Site 8, B-21, C-276A, Compression

131 Lake Charles Site 8, B-21, C-276B, Compression Test Test 
133 Lake Charles Site $8, \mathrm{~B}-23, \mathrm{C}-286$, Compression

134 Lake Charles Site 8, B-24, C-29], Compression

135 Lake Charles Site 9, B-25, C-295, Compression

304

136 Lake Charles Site 9, B-25, C-290B, Compression Test

137 Undrained Triaxial Test, Lake Charles, Block Samples

306

138 Triaxial Compressive Strength, Lake Charles, Sites 1 through 9, 27-30 Ft. Depth

139 Triaxial Compressive Strength, Lake Charles, Sites 1 through 9, 30-33 Ft. Depth

140 Comparison of Sample Performance in Consolidation Tests, Lake Charles Sites 1, 2, 3, and 5

141 Comparison of Sample Performance in Consolidation Tests, Lake Charies Sites 5, 7, 8 and 9

142 Compression Carve Variation, Lake Charles, Block Samples

143 Compression Curves, Consolidation Test of $3^{\prime \prime} \phi$ Samples, Lake Charles Sites

144 Compression Curves, Consolidation Test of $3^{\prime \prime} \phi$ Samples, Lake Charies Sites

145 Compression Curves, Consolidation Test of $5^{\prime \prime} \phi$ Samples, Lake Charles Site

146 Compression Curves, Consolidation Test of $5^{\prime \prime} \phi$ Samples, Lake Charles Site

147 Compression Curves, Consolidation Test of Block Samples, Lake Charles Site

143 Compression Curve, Consolidation Test of Block Sample, Lake Charies Site 


\begin{tabular}{|c|c|c|}
\hline$\underline{\mathrm{No}}$ & Title & Pag \\
\hline 149 & $\begin{array}{l}\text { Consolidation Test Data, Lake Charles Sites } 4 \\
\text { and } 5, e_{0} \text { vs } \omega_{n}\end{array}$ & 318 \\
\hline 150 & $\begin{array}{l}\text { Consolidation Test Data, Lake Charles, Sites } 7 \text {, } \\
8 \text { and } 9, e_{0} \text { vs } \omega_{n}\end{array}$ & 319 \\
\hline 151 & $\begin{array}{l}\text { Consolidation Test, Lake Charles, Sites 1, } 2 \text { and } \\
3 \text {, vs } \omega_{i}\end{array}$ & 320 \\
\hline 152 & $\begin{array}{l}\text { Consoliciation Test, Lake Charles, Sites } 4 \text { and } 5 \text {, } \\
\text { vs } \omega_{i}\end{array}$ & 321 \\
\hline 153 & $\begin{array}{l}\text { Consolidation Test, Lake Charles, Sites } 7,8 \text { and } \\
9 \text {, vs } \omega_{i}\end{array}$ & 322 \\
\hline 154 & $\begin{array}{l}\text { Storage Time Versus Undrained Triaxial Strength, } \\
\text { Lake Charles Site }\end{array}$ & 324 \\
\hline 155 & $\begin{array}{l}\text { Moisture Content Variation vs time, Lake Charles } \\
\text { Site }\end{array}$ & 323 \\
\hline 156 & Modified Plasticity Chart, LaPlace Site & 326 \\
\hline 157 & LaPlace Site-e- $\log \bar{\sigma}$ Compression Curve & 327 \\
\hline 158 & LaPlace Site, Unconfined Shear Strength vs Depth & 328 \\
\hline 159 & LaPlace Site, Depth vs Unconfined Shear Strength & 330 \\
\hline 160 & LaPlace $\left(15^{\prime}-18^{\prime}\right) \sigma \cdot-\varepsilon \cdot$ curves & 331 \\
\hline 161 & LaPlace $(18-21) \sigma-\varepsilon$ curves & 332 \\
\hline 162 & LaPlace $(21-24) \sigma-\varepsilon$ curves & 333 \\
\hline 163 & LaPlace $(24-27) \sigma-\varepsilon$ curves & 334 \\
\hline 164 & LaPlace $(27-30) \sigma-\varepsilon$ curves & 335 \\
\hline 165 & LaPlace $(30-33) \sigma-\varepsilon$ curves & 336 \\
\hline 166 & LaPlace $(33-36) \sigma-\varepsilon$ curves & 337 \\
\hline 167 & LaPlace $(36-39) \sigma-\varepsilon$ curves & 338 \\
\hline 168 & LaPlace $(39-42) \sigma^{-} \varepsilon$ curves & 339 \\
\hline 169 & Modified Plasticity Chart, Erwinvilile Site & 341 \\
\hline 170 & $\begin{array}{l}\text { Consolidation Test, Erwinville Site } \\
\text { xyii }\end{array}$ & 342 \\
\hline
\end{tabular}


No. Title Page

171 Modifted Plastictty Chart, Houma Stte 343

172 Unconfined Shear Strength vs Moisture Content, 344 Houma Site

173 Consolidation Test - Houma Site 345

174 Modified Plasticity Chart, Morgan City Site 346

175 Depth vs Unconfined Shear Strength Morgan City 347 Site

176 Depth vs. Natural Moisture Content, Morgan City 348 Site

$177 \quad$ Coefficient of Consolidation vs pressure, $\quad 349$ Morgan City Site, $12^{\prime}-15^{\prime} \mathrm{Ft}$ Depth

178 Coefficient of Consolidation vs Pressure, Morgan 350 City Site $\left(30^{\prime}-33^{\prime}\right.$ Depth)

179 Depth vs Unconfined Shear Strength, Benton Site 351

180 Modified Plasticity Chart, Baton Rouge Site 352

181 Storage Time vs Compression Strength, Baton 353 Rouge Site

182 Modified Plasticity Chart, Monroe Site 
A comprehensive study of the methods and equipment used for soil sampling in Louisiana has been conducted. The effects of various samp1ing and handling methods on the engineering properties of cohesive soils were examined.

The types of samples studied included block samples, 0sterberg samples and thin-wall shelby samples (5-in. and 3-in. dianeter). The selection of the sampling sites was based on an attempt to find solis which would be conducive to a study on sampling and also would be representative of material encountered by soil engineers in this area. The soils sampled in the study varied in geologic age, composition and structure.

The results of the investigation show that a single unique sampling program for all geographic sites in not practical. Variation between and within the test results of the different sample types was found to be significant. It was observed that even samples visually identified as homogeneous specimens exhibited inherent variations in their physical properties. As a result of the study, it was determined that: the soil fabric is a major consideration in selecting the best sampling method. The sampling methods currently used in Louisiana can drastically alter test results of soil properties. The sample size and type does have an effect on Louisiana soils. Specitien from the larger diameter sanples were found to be superior to the smaller diameter samples. The block samples were the least disturbed. Sample storage time has an effect on the properties of the soil and is influenced by the sampling technique.

xix 
In the study, X-ray radiography techniques were used and found to be a valuable non-destructive tool for assessing the extent of sampling disturbance and other anomalies of the sample. 
CHAPTER I

INTRODUCTION

\section{Soil Sampling - Objective of Study}

Soil sampling involves the removal of small pieces of the soil I mass. It is the most common and relied upon method for identification and evaluation of the physical and chemical properties of the material. It is the only means available to the engineer whereby a positive identification of the soil strata is possible. Although soil samples are not always required in every foundation study, most engineers find them necessary when confronted with a project involving a significant economic investment or one which will result in the alteration of the substrata's existing conditions. The results of the tests conducted on the sampled material provide the designer with the criteria on which the foundation design will be based.

Much progress has been made in the testing methods and in the analytical approaches used by soil engineers. The weakest link at this time appears to be lack of confidence in the validity (or accuracy) of the values used as engineering properties or soil constants. The resulting situation is that of the utilization of representative or average soil constants which the designer may feel is conservative (Poplin \& Arman, 1973, pp. 88, 89). The causes of this situation are two fold. The first is due to the inherent variation of soil. The second is due to the alteration of the soil properties of the samples during sampling, handling, and storage.

In natural soil deposits, it is not uncommon to find erratic 
variations of the soils' properties both in vertical and lateral direction.

When sampling is deemed necessary as part of the site investigation, it is important that the quality of the sample be at the level necessary to obtain accurate information. Herein lies a second and important consideration when evaluating data furnished by a. soil testing lab. Regardless of how sophisticated the equipment or techniques used, the quality of the end results, at best, cannot be better than that of the test sample.

With the availability of more and more computer aided design techniques and other powerful tools such as the finite element analysis, engineers are today in a tetter position to take into account the natural variation which may exist in a soil. The problem of sample quality still exists, however.

There is an important need for regional studies to determine those detrimental effects, if any to sample quality which results from standard sampling methods. Such information would be of great value to foundation engineers in their efforts to provide a safe, economic design. "In general terms where undisturbed samples are required because disturbance will affect the value of the property which controls soil behavior in the particular problem, every effort should be made to reduce disturbance to a minimum," (Golder, 1971).

The objective of this study was to determine the effects of conventional soil sampling methods on the engineering properties of cohesive soils found in Louisiana. The objective also included a comprehensive review of the state-of-the-art, an analysis of the effects of 
sampling, sample type and size, sample extrusion, storage and handling methods and the effects of the storage period on the physical properties of the soil. In order to accomplish this a comparative analysis of different sampling and handling methods was conducted. Special emphasis was placed on the effects of current sampling methods employed locally.

\section{Soil Sample Types}

Hvorslev (1949) classified soil samples as either non-representative, representative, or undisturbed. This classification is made by comparing the state of the sampled soil to that as exists in-situ. A non-representative sample is one in which soils from different strata have been mixed. The representative soil sample is one is which there is no change in soil constituents but whose structure, water content or void ratio has been altered. The undisturbed sample, idealiy, represents the in-situ condition. The soil structure, water content, void ratio and mineral composition should not be changed by sampling.

\section{Sample Type as Governed by Soil Properties}

It is not possible to obtain an undisturbed sample in all types of soils. In a sand for example, obtaining an undisturbed sample without changing its density would be very difficult, if not impossible. Although a number of devices and techniques (Bishop sampler, injection process, freezing methods) have been proposed, the nature of a granular material is such that most soil engineers consider an undisturbed sand sample as being unobtainable. As it turns out, in most cases an undisturbed sand sample is not necessary. The results of the standard penetration test (ASTM D-1586) provides a means of estimating the 
density and provides a representative sample. This information will suffice in most cases.

In general, clays or soils exhibiting some degree of cohesion represent the major area of concern whereby undisturbed samples are required. Although it is sometimes difficult, methods and equipment have been devised whereby an acceptable undisturbed sample can be obtained. The quality of the sample will depend upon the environment, methods used, and the properties of the soil.

A more recent system which has been proposed for classifying sample quality according to specific soil properties is shown in Table 1(Ide1, Muhs, and Von Soos, 1971). Some of the conclusions that were drawn as a result of the activities of the Specialty Session on "Quality in Soil Sampling" at the Fourth Asian Regional Conference (A1tchison, Dover, Lang, 1971) are:

1. There is a need for definitions of the quality of soil samples.

2. There is a general acceptance that the specifications for sample quality should be varied according to the purpose for which the sample is used.

3. In practice, only a minor proportion (25\%) of effort is expended on the class of sampling in which any real attempt is made to minimize disturbance.

4. The scheme proposed by Idel, Muhs, and Von Soos for a set of quality classes based on soil properties is generally acceptable, apparently because it fills a recognized need. Although matters of detail require 
TABLE 1

QUALITY CLASSES FOR SOIL SAMPLES

\begin{tabular}{|c|c|c|}
\hline $\begin{array}{l}\text { Quality- } \\
\text { lass }\end{array}$ & $\begin{array}{l}\text { Soil sample } \\
\text { unchainged in }\end{array}$ & Primarily determinable \\
\hline 1 & $Z, w, \gamma, \tau, E_{S}$ & $\begin{array}{l}\text { boundaries of fipe stratification } \\
\text { grain-size distribution } \\
\text { consistency limits } \\
\text { maximum and minimum density } \\
\text { specific gravity } \\
\text { organic matter } \\
\text { moisture content } \\
\text { dry density } \\
\text { porosity, void ratio } \\
\text { compression index } \\
\text { shear strength }\end{array}$ \\
\hline 2 & $Z$,wor & $\begin{array}{l}\text { boundaries of fine-stratification } \\
\text { grain-size distribution } \\
\text { consistency limits } \\
\text { maximum and minimum density } \\
\text { specific gravity } \\
\text { organic matter } \\
\text { moisture content } \\
\text { dry density } \\
\text { porosity, yoid ratio }\end{array}$ \\
\hline 3 & $\mathrm{Z}, \mathrm{W}$ & $\begin{array}{l}\text { boundaries of fine-stratification } \\
\text { grain-size distribution } \\
\text { consistency limits } \\
\text { maximum and minimum density } \\
\text { specific gravity } \\
\text { organic matter } \\
\text { moisture content }\end{array}$ \\
\hline 4 & $z$ & $\begin{array}{l}\text { layer boundaries without fine- } \\
\text { stratification } \\
\text { grain-size distribution } \\
\text { consistency limits } \\
\text { maximum and minimum density } \\
\text { pecific gravity } \\
\text { organic matter }\end{array}$ \\
\hline
\end{tabular}


TABLE 1 (continued)

\begin{tabular}{rlr}
$\begin{array}{l}\text { Quality- } \\
\text { class }\end{array}$ & $\begin{array}{l}\text { Soll sample } \\
\text { unchanged in }\end{array}$ & Primarily determinable \\
\hline 5 & $\begin{array}{l}\text { also Z changes; } \\
\text { uncomplete soil } \\
\text { sample }\end{array}$ \\
\hline$Z=$ & $\begin{array}{l}\text { grain-size distribution and/or Atterberg limits } \\
\text { resp. organic }\end{array}$ \\
$W$ & $=$ moisture content \\
$\gamma$ & $=$ dry density \\
$\tau$ & $=$ shear strength \\
$E_{S}=$ & compression index
\end{tabular}


further discussion, there is a general agreenent

that the scheme provides a good basis for the evaluaition of quality in soil sampling.

The above statements were based on the results of a written questionaire. It is a reflection of 45 sets of answers from individuals involved with soil engineering, representing 27 countries. 


\section{CHAPTER II \\ SOIL SAMPLING TECHNIQUES}

After the decision concerning the need for and type of soil sample has been determined, the best means for accomplishing the task must be selected. The anticipated soil properties, depth and availability of equipment must be considered. Excavation of a hole, large enough for a man to have access to the material is one way. A second would be to drill a small hole to the desired depth and then secure a sample by means of manipulating sampling tools at the end of drill pipe, or wire line.

\section{Block Sampling}

A hand-cut sample is rarely specified unless the accessibility of the soil is near the surface and then only when a large sample or one sensitive to disturbing forces is sought. Hand-cut or bleck samples as they are cormonly cailed, are considered in general to be the best quality.

\section{Borehole Sampling}

The most common method of obtaining soil samples is by means of a borehole. A continuous vertical hole is formed by removing soil to the desired sample depth. Then by using various sampling tools which are designed for certain conditions, the sample is brought to the surface for visual identification and classification, and determination of those engineering properties of interest.

\section{Methods of Advancing the Borehole}

There are several different methods which have been used for 
advancing the borehole. The method chosen isıusually based upon regional geology, the availability of equipment and the experience of local drilling contractors. Boring methods vary from country to country and the results of questionaires concerning this subject have shown that techniques vary from one locale to ancther within the United States (Poplin \& Arman, 1973, Kallstenius, 1965, pp 74,75).

The methods and equipment used in placing a borehole have been discussed in detail by many authors. Those include hand and mechanical augers, the wash boring method, and the rotary drill method.

The rotary drill method offers the greatest degree of flexibility for a variety of subsurface conditions. This technique involves the rotating action of a bit with soil cuttings being flushed out of the hole by means of drilling fluid circulating through the drill stem and up the noie to the surface. When the desired sampling depth is reached, the bit and drill stem are retrieved and replaced by the sampling device. It is then lowered into position and the sample is taken. Quite often, rotary drilling equipment is mounted on a truck. This includes a folding mast, motors, rotary drive mechanism, winches, pump, etc.

\section{Stabilizing the Borehole}

The stability of the borehole can occasionaliy be a problem. Loss of fluid circulation or caving in of the borehole will quite often occur when a granular or sandy soil is encountered. A soft clay has a tendency to close the hole, also. In order to prevent blockage of the borehole, it may be necessary to use some technique which will give the sides of the borehole support. There are two ways of doing 
this. One method is to drive casing pipe beyond the trouble zone. The second involves the use of a drilling mud. This is done by mixing a commercially prepared thixotropic clay such as bentonite with the circulating wash water. The result.is a drilling fluid whose density approaches that of the soil. The thixotropic nature of the drilling fluid produces a coating which tends to prevent flow to or from the hole, thus preventing loss of the circulating fluid.

\section{Samplers}

Once the borehole has been established to the desired sampling depth and the loose soil cuttings have been flushed or removed from the hole, the drilling bit at the end of the drill stem must be replaced by the sampling tool. The sampling tool which will be used will, of course, reflect the type of sample and soil which is to be obtained. Hvorslev (1949) categorized subsurface samples into three basic types: (1) exploration samplers, (2) drive samplers, and (3) core barrels.

\section{Exploration Samplers:}

When little is known about the subsurface conditions at the proposed site, it may be necessary to conduct a reconnaissance survey to determine the location and types of soils present. The resulting information will be the basis on which decisions for a more involved site investigation will be made, if necessary. Since the object is mainly one of identification, representative samples will suffice. These may be taken by nieans of special exploration samplers such as slit tubes or cup samplers. Quite often, however, the samples taken 
are the cuttings obtained with the boring equipment which is used to advance and clean the hole. This includes bailers, sand pumps, and augers. The sample may to some degree be mixed, but the mixing should be confined to a small zone.

In drive sampling, the sampler consists of a cylindrical tube which is forced without rotation into the soil. Upon completion of the drive, the sampler is rotated. This separates the sample from the parent material and is followed by retrieval of the sampler with the sample inside at the surface. Drive samplers are categorized according to the absense or presence of a piston. Thus there are two kinds of drive samplers used; open drive samplers and piston samplers.

\section{Open Drive Samplers:}

The open drive sampler consists of a section of pipe beveled at the lower end and secured to the bottom of the drill pipe at the other. It can be further classified according to wall thickness as being either a (1) thin wall sampler, (2) thick wall sampler or (3) a composite sampler.

Hvorslev (1949) arbitrarily defined a thin wall sampler "as a sampling tube with a wall thickness less than 2.5 percent of the diameter, corresponding approximately to an area ratio* of 10 percent when the inside clearance of the cutting edge is not taken into consideration." The open drive sample is commonly referred to as a "shelby tube.". The term originates from a trade name for hard-drawn, seamless steel tubing, manufactured by the National Tube Company.

*The area ratio is the area of soil displaced by the sampler divided by the cross-sectional area of the sample. 
This term is still used today, but it refers to any type of thin wall steel or brass tubing. Ideally, the thin wall sampler should be connected to the drill pipe by means of a sampler head or adapter which contains a check valve or vents for escape of air or drilling fluid. It is also desirable that the bottom or cutting edge of the tube be sharp and drawn in to allow some clearance, (1/2 to 1 percent of tube diameter, Clark, 1963). The thin wall sampler (ASTM D1587-67) does provide a sampia with a minimum of disturbance, which in most cases is acceptable for practical purposes as being undisturbed. Usage of the thin wall sampler is limited due to its susceptability of being damaged when used in dense soil or that. containing hard objects.

The thick wall sampler has a longer life than that of the thin wall and can be used in a variety of soils. It consists of heavier tubing and is generally provided with a detachable shoe and cutting edge of hardened steel. The most common thick wall sampler used throughout North America and Britain is the standard split barrel sampler or split spoon sampler as it is commonly kncwn. It consists of a thick walled steel tube split lengthwise. The cutting shoe attaches to the bottom and the top is secured with an adapter head containing a ball check valve. The adapter head connects to the bottom of the drill rods. The standard I.D. and O.D. dimensions are 1.4 and 2 inches, al though other sizes are used. This sampler is used in the Standard Penetration Test (ASTM D-1586). In this test, the split barrel sampler is driven 18 inches in three 6-inch increments by a $140 \mathrm{lb}$. hanmer falling 30 inches. The resistance to driving is 
measured by the number of hammer blows required to drive the last 12 inches. The blow count is considered to be a measure of the relative density when used in sands or the consistency in cohesive soits (Tergaghi and Peck, 1968, pp 341 and 347). The structure of the soil sample obtained will be too distorted to be considered undisturbed, but it does provide a yisual examination of the in-place soil. The sample is representive of the material in so far as moisture content, composition and stratification. It has been suggested (Sowers and Sowers, 1970, pp 272, Tergaghi and Peck, 1968, pp 346) that split spoon samples can often be used for unconfined, compression tests if an undisturbed sample is not available.

Normally, thick wall samples are examined in the field with smaller segments being placed in jars to be sent to the lab. If the entire samp?e is to be sent to the lab, a sampler with an initer tube or liner, that is a composite sampler, is used. After the sampling and field testing, the liner can then be removed and the sample sent to the lab intact.

The open drive sampler may not be adequate when trying to obtain an undisturbed sample of a soft cohesive soil. The instability of the borehole in such a material combined with the added outside wall friction produced by the dowmward push of the sampler will tend to cause the soil to enter or flow into the sampler at a rate faster than that of the sampler's thrust. The results can be quite disturbing to tine sample's structure. Assuming that the above does not occur, the problem of retrieving the sample within the open drive sampler still exists. The friction developed between the sample and sampler may not 
be great enough to overcome the sample weight or suction created when attempting to free the sample from the parent material and pull it to the surface.

Piston Samplers:

Piston samplers have been found to be useful in reducing the effects of disturbing forces described above. A piston sampler is a drive sampler with a piston. In taking a sample, the piston should be initially in the advanced position; that is at the sampler's cutting edge. This preyents the entry of cuttings and shavings from the sides of the borehole. After the sampler has been positioned at the bottom of the hoje, the tube is advanced beyond the piston into the undisturbed soil. The piston assists the sampling operation in two ways. First, it prevents the entrance of excess soil into the tube. Second, it heips to hold the soil in the tube. If there is good contact between the piston and the top of the sample, then the sample cannot slip out of the tube without creating a vacuum. Piston rods are used to control the piston's movement. The rods extend up from the sampler through the drill pipe. Piston samplers are further classified according to the operation or control procedure of the piston. There are three techniques used with piston samplers.

A stationary piston is one which functions with the piston secured at a fixed elevation during sampling. The second type of piston sampler is one in which the piston is withdrawn to the top of the sampler just before taking the sample. It is known as a retracted piston sampler. The third type of piston sampler is one in which the piston is free to move. It moves with the top of the sample. 
The length of undisturbed sample which can be taken by the above piston samplers is limited to a few feet. The Swedish foil sampler is a special type of stationary piston sampler which minimizes friction between the sample and the sampler by using thin strips of metal foil which acts as a liner and prevents it from touching the tube. The equipment is complex, but an undisturbed continuous sample of extremely soft and sensitive soil can be obtained with sample length in excess of fifty feet.

The 0sterberg sampler (Figure 1) is a special adaptation of the stationary piston sampler. It is quite popular for use in recovering samples of troublescme soils. It operates hydraulicly, and does not require a piston rod. This sampler uses a second piston called the actuating piston and a pressure cylinder. When taking a sample, a fluid pressure is exerted on the top of the actuating piston forcing it and the sampler downward until it comes in contact with the fixed piston. The fixed piston prevents the sampler from moving forward and thus prevents overdriving of the sample.

\section{Core Samplers:}

If the soil to be sampled is very stiff or brittle, attempts to sample with one of the above drive samplers may prove to be detrimental to both sampler and sample. Under these conditions core drilling is used. It differs from driye sampling in that sampling and advancenent of the borehole are done simultaneously. This is accomplished by providing a stationary sampling tube inside a rotating cutter barrel. The ground-up material is removed by either a circulating drilling 


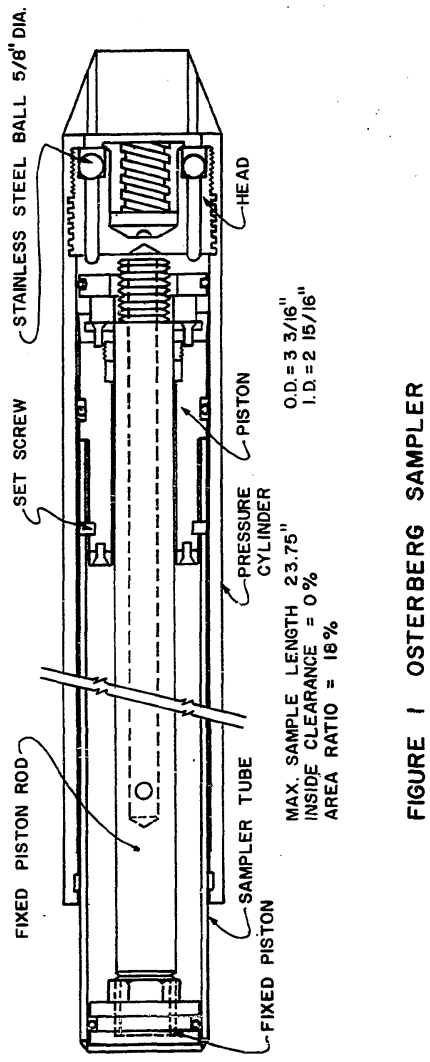


fluid or by air. Two such samplers are the Pitcher and the Denison sampler. The Tams double tube auger uses the same technique of a stationary inner barrel with a rotating outer barrel. The major difference in the Tams sampler is the outer barrel consists of a helical conveyor which removes the cuttings.

\section{Methods of Forcing the Sampler Into the Soil}

Hvorslev (1949) categorized and studied methods which have been used to force a drive sampler into the soil. The results of his findings were that "the speed and continuity of motion with which the sampler is forced into the soil has a great influence on the length and degree of disturbance of the sample obtained." His recommendation for general use in undisturbed sampling is "fast pushing, or a fairly uniform and uninterrupted advance at 0.5 to $1.0 \mathrm{ft}$. per second."

\section{Sampling as a Function of Sampler Soil and Sample Type}

In considering the various types of subsurface material and the methods available for sampling, Golder (1970, pp 7), concluded that "if clays are difficult, sands are more difficult; sands and gravels are almost impossible; and rocks are so deceptively simple." The type of soil encountered and the desired sample classification (i.e. und isturbed, representative, etc.) will dictate the equipment and methods to be used in sampling. Hvorslev (1949) presented a generalized summary of the most advantageous methods of boring and sampling in different subsurface soils. In a study on methods used by the Bureau of Reclamation, Clark (1963) presented his findings on boring techniques and a comparison of the performance of different samplers in various soil 
types. The relative merits of auger boring and rotary drilling were examined in considering the most efficient and economical method for both clays and sands. Use of drilling mud rendered casing unnecessary. Greater accuracy in logging the hole was achieved by air drilling, but this method is not suited for cohesionless material.

The influence and importance of the natural soils fabric should also be considered when planning a site investigation. Rowe (1972) demonstrated that for an adequate site investigation it is essential to first examine, describe and record the fabrics of consecutive soil samples before deciding on the location, quality and sample size. He defined fabric as referring to size, shape and arrangement of solid particles, the organic inclusions and associated voids (i.e. the arrangement of particle groups for example in layers having different particle sizes). In the presentation of his Rankine Lecture, he emphasized the manner in which the fabric of the natural soil should dominate a site investigation in the selection of the quality and size of specimens and how this in turn will influence the drilling technique. The methods used in advancing the borehole were found to have a direct influence on the coefficient of consolidation and the undrained shear strength of soils with a permeable fabric. The recommended minimum specimen size (Rowe, 1972) of natural clay deposits as a function of fabric is shown in Table 2 .

Storage; Hand 1 ing and Shipment of Samples

The generally preferred method of shipping and storing undisturbed samples is in the sampling tube or in liners (Hvorslev, page 153, 1949, Terzaghi and Peck, page 347,1967$)$. It has been considered advantageous 
TABLE 2 SPECIMEN SIZES (ofior Rowe, 1972)

MINIMUM SIZES OF SPECIMENS FROM QUALITY I THIN WALLED PISTON SAMPLES OF NATURAL CLAY DEPOSITS. FOUNDATIONS FOR BUILOINGS, BRIDGES, DAMS, FILLS. STABILITY OF NATURAL SLOPES, CUTS OPEN OR RETAINED.

EXCEPTIONS: DEPOSITS TOO $\left\{\begin{array}{ll}\text { WEAK } & \text { VARIABLE } \\ \text { STRONG } & \text { STONY }\end{array}\right\}$

\begin{tabular}{|c|c|c|c|c|}
\hline CLAY TYPE & MACRO FABRIC & $\underset{\mathrm{m} / \mathrm{s}}{\operatorname{MASS}} k$ & PARAMETER & $\begin{array}{l}\text { SPECIMEN } \\
\text { SIZE, mm* }\end{array}$ \\
\hline \multirow{3}{*}{$\begin{array}{l}\text { NON-FISSURED } \\
\text { SENSITIVITY }<5\end{array}$} & NONE & \multirow{2}{*}{$\begin{array}{c}10^{-10} \\
10-9-10-6\end{array}$} & \multirow{2}{*}{ 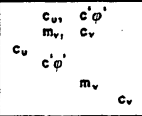 } & \multirow{2}{*}{$\begin{array}{c}37 \\
76 \\
100-250 \\
37 \\
75 \\
250\end{array}$} \\
\hline & $\begin{array}{l}\text { PEDAL, SILT, SAND } \\
\text { LAYERS, INCLUUSIONS. } \\
\text { ORGANIC VEINS }\end{array}$ & & & \\
\hline & $\begin{array}{l}\text { SAND LAYERS } 2 \mathrm{~mm} \\
0.2 \mathrm{~m} \text { SPACE }\end{array}$ & $10^{-6-10-5}$ & $\begin{array}{l}c^{\prime} \varphi^{\prime} \\
m_{v}\end{array}$ & $\begin{array}{l}37 \\
75\end{array}$ \\
\hline SENSITIVITY $>5$ & CEMENTED WITH ANY ABOVE & & $c_{v}, c^{\prime} \varphi^{\prime}, m_{v}, c_{v}$ & $50-250 \div$ \\
\hline \multirow[t]{2}{*}{ FISSUREDT } & PLAIN FISSURES & $10-10$ & $\begin{array}{ccc}c_{v} & & \\
& c^{\prime} \omega^{\prime} & \\
& & m_{r}\end{array}$ & $\begin{array}{l}250 \\
100 \\
75\end{array}$ \\
\hline & $\begin{array}{l}\text { SILT OR SAND FILLED } \\
\text { FISSURES }\end{array}$ & $10^{-9}-10^{-6}$ & $\begin{array}{llll}c_{v} & & & c_{v} \\
& c^{\prime} \varphi^{\prime} & & \\
& & m_{v} & \end{array}$ & $\begin{array}{l}230 \\
100 \\
75\end{array}$ \\
\hline JOINTED & OPEN JOINTS & & $\varphi^{\prime}$ & 100 \\
\hline \multicolumn{2}{|c|}{ PRE-EXISTING SLIP } & & $c_{r} \varphi_{r}$ & $\begin{array}{c}150 \\
\text { OR REMOULDED }\end{array}$ \\
\hline
\end{tabular}

* $75 \mathrm{~mm}$ Samples for continuous Quality 2-4 Samples for fabric examination, STRENGTH AS INDEX TEST, $C_{0}$ AND $C$ ' $\varphi$ FOR INTACT LOW SENSITIVITY.

T SIZE AND ORIENTATION DEPENDENT ON FISSURE GEOMETRY.

\$TUBE AREA RATIO $4 \%$, SAMPLE DIA. $260 \mathrm{~mm}$. 
to use this method as it eliminates disturbances which may result from handling the sample under adverse conditions in the field. The disadvantage of this technique is that field identification and description of the soil must be made from an examination of only the sample ends. Normally the sampling tube is sealed with parafin or other sealing campound. Hvorslev (1949) recommends at least a $3 / 4$ inch thick plug. Special mechanical type sample tube sealers have also been proposed, (Bartlett and Holden, 1968). This has the advantage of quick sealing, unsealing and resealing. For long storage, petroleum jelly is placed between the sample and the sealer.

For those samples which are not taken with a tube or which are not to be stored in a sample tube, Hvorslev (1949) recommended that the sample be preserved in a wax coating of at least 0.1 in. for small samples and $0.2 \mathrm{in}$. for large samples.

In transporting the samples to the testing laboratory, they should be packed in such a way as to prevent vibrations and shock disturbances. Shipment preferably should be with the samples in the upright position in padded crates or on a mattress. Protection against freezing should also be provided for when necessary (ityorslev, 1949).

In storing the samples, it is desirab? e that they be kept in a cool area in the upright position. A humidity room will help in retarding the loss of water.

In order to minimize the danger of internal migration of water and structural or chemical changes within the sample as a result of long storage, it is preferred that the sample be tested as soon as possible. The sample should be extruded from the tube with a close fitting plunger 
in such a way that the sample movement with respect to the tube is in the same direction as it entered (Terzaghi and Peck, 1967, page 347). The sampling tube should be cut into shorter sections (three to six times the diameter) in order to reduce extruding disturbances (Hvorslev, 1949, Terzaghi and Peck, 1967).

Current Methods and Equipment used for Soil Sampling

Most of the sampling techniques described above have been presented in detail by Hvorslev (1949). They represent, along with the more current techniques and equipment mentioned, the approximate state of the art of sampling techniques and recommendations as presented in the literature. The above does not, necessarily, however, reflect the conventional or accepted sampling methods as practiced by all soil engineers.

\section{World Wide:}

As has been stated previously, the quality or degree of disturbance is a function of the soils properties and the sampling techniques. The quality level required will vary depending on the job. In a questionarie addressed to the mamberships of the International Group on Soit Sampling (:.:itchison, Dover and Lang, 1970) the following was asked:

"If for the purpose of this question, four types of soil samples are defined as follows, then in your experience what proportions of each type would on the average, be required:

(a) Disturbed Samples..........

(b) Simple class intact samples (Not seriously disturbed 
chief consideration is to the use of simple apparatus and avoiding delays to boring in order to keep costs low. To include samples from robust open drive samples driven by impact or sliding hammer)..........

(c) Standard class intact samples (Good quality but with some attention to keeping equipment fairly simple and operations reasonably short to avoid excessive costs. Use made of well designed thin walled open and piston samplers, pushed, not hanmered, with reasonably close supervision)..........

(d) Special class intact samples (Highest possible quality with little regard to costs. Research projects, important or critical foundation).........."

Figure 2 represents graphically the results of this question. Results of the median values are:

$$
\begin{array}{lr}
\text { special class intact sampling } & 5 \% \\
\text { standard class intact sampling } & 20 \% \\
\text { simple class intact sampling } & 50 \% \\
\text { disturbed sampling } & \underline{25 \%} \\
& 100 \%
\end{array}
$$

Previously, a survey was taken by this same group to determine the status of undisturbed sampling (Kallstenius, 1965). Representatives from fifteen countries responded.

The results showed that the thin wall, open drive or shelby tube sampler is used most often in obtaining an undisturbed sample. The use 


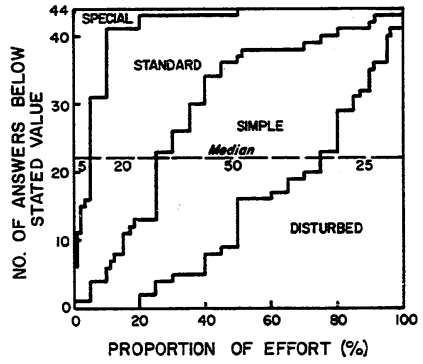

FIGURE 2 CUMULATIVE DISTRIBUTION CURVES FOR PROPORTION OF TOTAL SAMPLING EFFORT EXPENDED AT VARIOUS LEVELS OF SAMPLING: SPECIAL CLASS INTACT, STANDARD CLASS INTACT, SIMPLE CLASS INTACT, AND DISTURBED SAMPLING. 
and frequency of other samplers varies from area to area. Methods of advancing the borehole also vary with geography.

The most commonly used soil sampling technique in the United States is with the thick walled solid or split barrel sampler (Kallstenius, 1965 and Lowe, 1959).

\section{Southeastern States:}

A brief questionaire concerning site investigation procedures was submitted to Chief Engineers of highway departments in Alabama, Georgia, Mississippi, North Carolina, South Carolina and Texas (Poplin and Arman, 1973). The results are as follows:

Drilling Operations

The response indicates a variety of borehole diameters are used ranging from 2 to 8 in. with earth augers, fishtail bits, rotary drills and core drills to advance boreholes. Casings and driller's mud are used to stabilize boreholes excepth when hollow-stermed augers are used.

\section{Field Testing}

Standard penetration tests according to AASHO T-206 are conducted in Alabama, Georgia and Mississippi whereas a nonstandard 100-1b. weight is used to drive a split spoon sampler in South Carolina. Cone penetrometers are used in Florida, Georgia, Mississippi and Texas, each with a local variation. Vane shear testing in the field is indicated in Florida, Georgia, North Carolina and Texas. Unconfined compression tests are run in the field in North Carolina. 


\section{Sampling Procedures}

In most cases, disturbed samples are taken with split-spoon samplers in conjunction with standard penetration tests cited above. Three-inch diameter thin-walled (shelby) tubes are used for collecting undisturbed samples in Alabama, Florida, Mississippi and North Carolina while piston samplers aee utilized in Florida and Georgia. A doublewalled Denison barrel is used in Texas. For apparently uniform material, some states indicated continuous samples are taken for specific conditions while in other instances, intervals of as much as five feet are allowed between samples. Undisturbed samples are sealed in sampling tubes for preservation white in transit to testing laboratory in Florida, Georgia and Texas.

\section{Laboratory Testing}

Routine classification tests are run in every state. Shear strength is evaluated from unsonfined compression tests and undrained triaxial tests most commonly on 2-7/8 inch diameter specimens although smaller sizes are used in saine ca-es. Direct shear tests are used only in Mississippi. One-dimensional consolidation tests are conducted in Alabama, Florida, Georgia and Mississippi using 2.5 inch diameter specimens with thicknesses ranging from 0.5 to 1:.0 inches. Triaxial consolidation tests are conducted only in Mississippi.

Practices in Louisiana:

Most highway procedures have been developed from practical experience in coping with the peculiar problems of the region which account for the broad diversity of practices in current use. Based on 


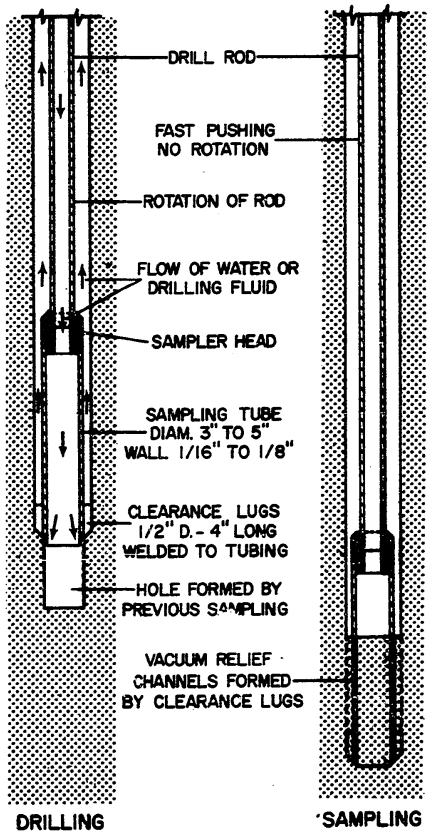

From Horsley, 1949

\section{FIGURE 3 DRIVE SAMPLING AND ROTARY DRILLING WITH SAMPLER}


the response from other state highway departments, practices in Louisiana compare favorably. However, a point by point comparison of the adequacy of methods and practices cannot be made on the basis of a general questionnaire.

A method commonly used in Louisiana for taking undisturbed samples combined the principles of rotary drilling with that of continuous open drive sampling. This technique is utilized by the Louisiana Department of Highways and by most commercial firms in the state. It involves the use of a 3-inch thin wall sampling tube with small lugs welded near the cutting edge. outside the barrel, Figure 3 . The borehole is reamed out by rotating the barrel. The cuttings are removed by pumping a drilling fluid down the drill stem and up the sides of the hole. When the hole has been cleaned out to the desired depth, the sampler is placed on the bottom of the hole and is pushed into the soil approximately thirty inches; Figure 3. . For soft soils or those which are difficult to obtain, the 3 inch Osterberg sampler is used.

When the sample in the tube is retrieved at the surface, it is extruded. The Louisiana Department of Highways field extrudes by means of a hydraulicly operated piston. Some of the commercial firms extrude the sample by pushing it out using hydraulic pressure. This second technique requires skill and probably disturbs the sample more so than one extruded by piston. The sample is extruded into a wooden V-shaped trough.

The method used by the Louisiana Department of Highways (i.e. piston extruded) forces the sample to be pushed out of the sampler in the same direction it entered. The sample movenent relative to the tube is 
reversed when extrusion by hydraulic pressure is used.

After field extruding, the Louisiana Department of Highways drilling squad leader identifies the material and notes this information in his log book. Approximately nine-inch sections are selected and cut for shipment back to the laboratory. The sample is wrapped in an inner plastic sheet and an outer sheet of aluminum foil. It is then enclosed in a plastic bag and placed in specially constructed styrofoam boxes (Figure 4). The boxes are taped securely and placed in a utility truck for shipment. Split spoon samples and other small pieces of disturbed samples are placed in heavy plastic bags which are marked for identification and then secured by tying the open end in a knot.

The methods of packaging the samples used by commercial firms varies from that of the Louisiana Department of Highways. In general, the portion of the sample selected is placed in a paper carton and parafin is poured in the annular space between the sample and the carton. Some of the firms wrap the sample with aluminum foil first. Split spoon and other disturbed samples are placed in sealed jars.

The only other agency which does any. extensive soil sampling in Louisiana for civil engineering purposes in the U.S. Army Corps of Engineers. The overall site investigation techniques employed by the Corps appears to be much more comprehensive. Piston samples of varying size are used along with other sampling equipment. Shipment of the samples is quite often done with samples in the tube. 


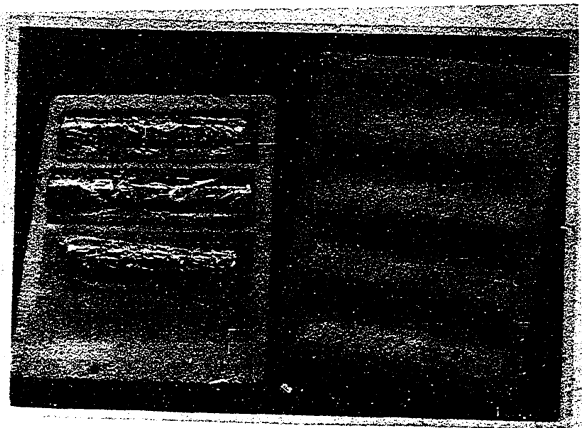

Figure 4 - Soil Sample Protective Storage Technique

Reproduced with permission of the copyright owner. Further reproduction prohibited without permission. 


\section{CHAPTER III}

\section{SAMPLE DISTURBANCE}

In soil sampling, the samples obtained for testing fall into two groups: disturbed and undisturbed. The disturbed samples include those obtained from the split spoon and other heavy wall samplers. The disturbed sample is used for identification purposes and for classification tests.

An undisturbed sample is one which is considered to represent the in-situ properties. It is impossible to obtain a completely undisturbed sample.

In general, the quality of borehole samples is somewhat less than that of hand-cut samples. However, in most cases, the sample required is unaccessible by excavation and must be sampled by means of a borehole.

\section{Disturbance Prior to Sampling}

In the drilling of the borehole, the normal stress at the bottom will be reduced once the soil is removed, Figure 5. For large stress reductions and with low shearing resistance, the soil layers below the borehole will be deflected upwards. It is possible for the distortion of the suil at the bottom of the borehole to extend beyond a distance of three times the borehole diameter (Hvorslev, 1949). Samples from this zone will have a conyex layering and in soft material may show signs of plastic flow. Using a drilling fluid will tend to offset the reduction of stresses resulting from the removal of the soil. 


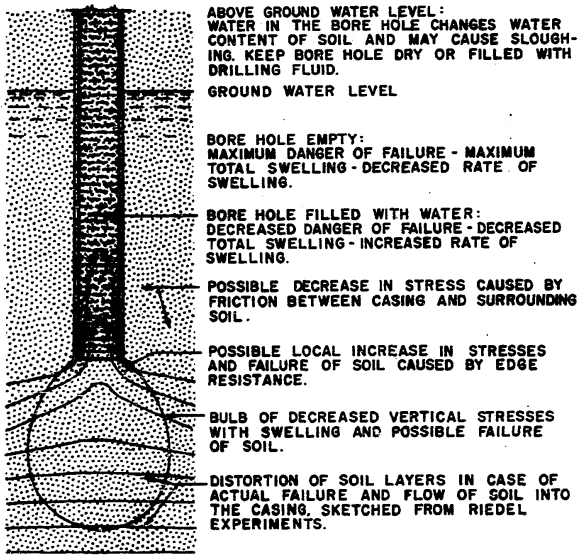

ABOVE GROUND WATER LEVEL:

WATER IN THE BORE HOLE CHANGES WATER ING. KEEP BORE HOLE DRY OR FILLED WITH DRILLING FLUID.

GROUND WATER LEVEL

BORE HOLE EMPTY

MAXIMUM DANGER OF FAILURE - MAXIMUM TOTAL SWELLING - DECREASED RATE OF SWELLINE.

PORE HOLE FILLED WITH WATER : DECREASED DANGER OF FAILURE - DECREASED TOTAL SWELLING - INCREASED RATE OF

POSSIBLE LOCAL INCREASE IN STRESSES AND FAILURE OF SOIL CAUSED BY EDGE

BULB OF DECREASED VERTICAL STRESSES WITH SWELLING ANO POSSIBLE FAILURE DISTORTION OF SOIL LAYERS IN CASE OF THE CASINB SKETCHED FROM RIEDEL EXPERIMENTS

\section{FIGURE 5 STRESS CHANGES}

\section{AND DEFORMATIONS OF SOIL LAYERS BELOW BOTTOM OF BORE HOLE}

After Hoorslev, 1949 
In continuous sampling, additional disturbance to the soil at the bottom occurs when the previous sample is sheared from the parent soil by torsion. There is also an eyen greater reduction of normal stresses with the creation of a vacuun when the soil sample is pulled up. Excessive overdriving of the previous sample, or pushing a closed piston beyond the bottom of the borehole can cause a downward deflection of the soil layers.

\section{Disturbance During Sampling}

The most cormon method of obtaining an undisturbed sample is by drive sampling. Figure 6 ,is a presentation of those forces acting during the sampling operation.

Hvorslev (1949) discussed the disturbance caused by sampling as follows:

"Disturbance during sampling is primarily due to displacement of soil by the walls of the sampler, to friction and adhesion between sample and sampler, and to hydrostatic pressure on top of the sample."

"Displacenent of soil by the sampler walls may cause shear failure in the soil below the sampler or plastic deformations and entrance of excess soil in the sampler. Entrance of excess soil causes distortions and entrance of excess soil in the sampler. Entrance of excess soit causes distortions and increase in thickness of the soil layers. The danger of disturbance and entrance of excess soil increases with wall thickness of the sampler, increasing depth below ground surface, and decreasing velocity of penetration." Thus, for a given diameter and penetration rate, the degree of disturbance can be expressed as an 

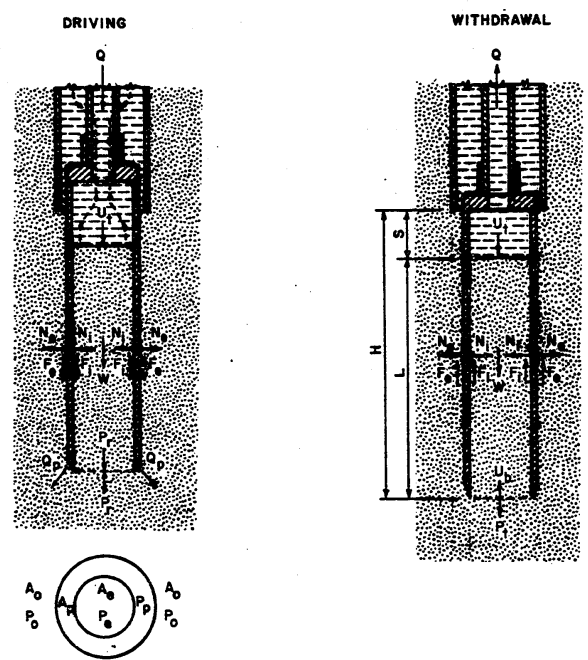

SOIL LOADS BELOW SAMPLER

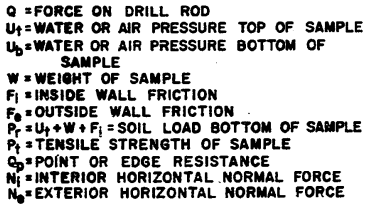

H =DEPTH OF PENETRATION

$L$ = LENGTH OF SAMPLE

$S$ = SHORTENING OR "COMPRESSION" OF

$R=\frac{L}{H}=$ TOTAL RECOVERY RATIO

$r=\frac{d}{d H}=$ SPECIFIC RECOVERY RATIO

$P_{P}=$ AVERAGE UNIT LOAD ON AREA AP

DUE TO $Q_{p}$

$P_{Q}=$ AVERAGE UNIT LOAD ON AREA $A_{0}$

DUE TO $P_{\mathbf{r}}$

\section{After Hvorster}

\section{FIGURE 6 FORCES ACTING DURING SAMPLING}


area ratio,

$$
C(\%)=\frac{D_{w}^{2}-D_{e}^{2}}{D_{e}^{2}}
$$

where $D_{w}$ is the external diameter, and $D_{e}$ is the inside diameter. "Ultimately the inside friction becomes so large that it prevents further entrance of soil in the sampler." The inside friction can be partially overcome by using a sampler with a low coefficient of friction and by making the diameter of the cutting edge somewhat smaller than the rest of the tube. A reduction in the cutting edge diameter provides an inside clearance which is expressed as

$$
C_{L}=\frac{D_{S}-D_{e}}{D_{e}} \times 100
$$

where $D_{S}$ is the inside diameter of the sampler tube and $D_{e}$ is the diameter at the cutting edge. Another means of overcoming the inside friction is to use thin strips of metal foil which acts as a liner for the sample and prevents direct contact between the sample and the sample tube. The Swedish foil sampler operates on this principle (Jakobson, 1954).

The friction build up between the soil and the outside sampler wall has been presented by Arthur and Leo Casagrande as causing serious disturbance to the soil prior to entering the sampler in soils of relatively low sensitivity (Bai1, 1962). Sensitivity here refers to the water-plasticity ratio or liquidity index:

$$
I_{L}=\frac{W_{n}-W_{p}}{I_{p}}
$$


where $W_{n}$ is the natural moisture content, $W_{p}$ is the plastic limit and $I_{p}$ is the plastic index or the difference between the liquid and plastic limit. "The probable explanation for the manner in which sensitivity influences sample disturbance is illustrated in Figure 7. For a clay of low sensitivity, the total friction force that builds up along the outside surface of the sampling tube, while the tube is being pushed into the clay, can reach values which exceed the compressive strength of the clay below the cutting edge." The conclusion was that "in general satisfactory samples were obtained only for clay having a relatively high sensitivity, i.e. for water-plasticity ratios less than 50 percent, the samples were disturbed excessively. Satisfactory as well as excessively disturbed samples were obtained for clay having water-plasticity ratios between 50 percent and 80 percent. The areas of disturbance to which a soil sample may be subjected have been reviewed by Hvorslev (1949) as:

(1) Changes in stress conditions

(2) Change is water content and void ratio

(3) Disturbance of soil structure

(4) Chemical changes

(5) Mixing and segregation of soil constituents

The extent or effect of the above on the sample will depend on the soil properties and the techniques used for sampling. Thus the quality of the undisturbed sample is measured by the absence of the above disturbance factors which may alter the engineering properties of the soil, Table 1. 


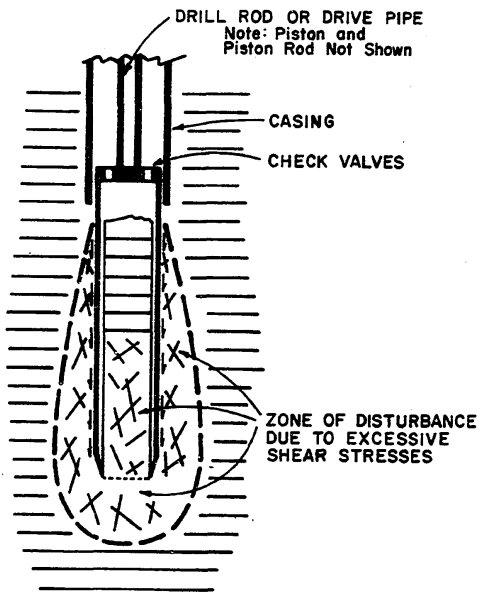

After Cosagrande

FIGURE 7 ZONE OF DISTURBANCE 
Change in Stress Conditions:

The changes in stress conditions involve not only the drilling and sampling operations but also include a change in stress state from an anisotropic to isotropic system. Removal of the sample from the ground to the surface reduces the total stresses to zero. The tendancy of the sample to rebound will produce negative stress values in the pore water.

The amount and severity of disturbance to the sample will determine how close the resulting isotropic effective stress approaches that of the anisotropic in-situ conditions.

Prior to sampling, the stresses acting on a soll element at a depth $z_{1}$, below ground sarface are as shown in Figure 8 . The total vertical stress is $\sigma_{v c}=\gamma^{z_{1}}$, where $\gamma$ is the unit weight of the overburden soil. The total horizontal force is $\sigma_{h o}$ and in general is not equal to $\sigma_{v c}$. If the soil element is below the water table, the pore pressure is $u_{0}=\gamma_{w} z_{z}$ where $\gamma_{w}$ is the unit weight of water and $z_{z}$ is the distance below ground water table. The effective stresses acting on the element are

$$
\begin{gathered}
\bar{\sigma}_{v c}=\sigma_{v c}-u_{c} \\
\text { and } \quad \bar{\sigma}_{h o}=\sigma_{h_{0}}-u_{0}=k_{0} \bar{\sigma}_{y_{0}}
\end{gathered}
$$

where $\bar{\sigma}_{v o}$ is the effective vertical stress, $\bar{\sigma}_{\text {ho }}$ is the effective horizontal stress. $K_{0}$ is the coefficient of earth pressure at rest.

For normally consolidated soils, $\mathrm{K}_{0}$ is approximately 0.6 or can be estimated by (Jaky, 1948),

$$
k_{0}=1-\sin \phi^{\prime}
$$



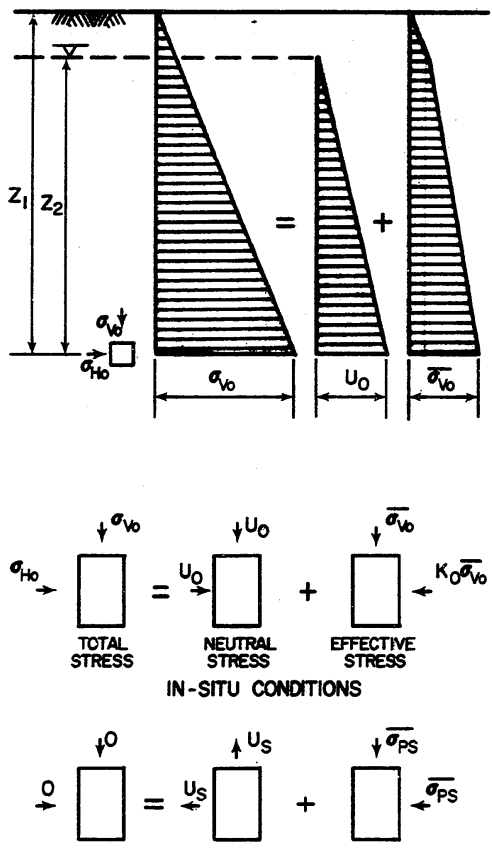

HYYROSTATIC STRESS STATE AFTER SAMPLING

FIGURE 8 STATE OF STRESS CHANEE DUE TO SAMPLING 
in which $\phi^{\prime}$ is the angle of shearing resistance for effective stresses. For over consolidated soils, $K_{0}$ may be larger than one. Relationships between the plastic index, $I_{p}$, the overconsolidation Ratio, OCR $=\bar{\sigma}_{C / \bar{\sigma}_{\mathrm{VO}}}$, and $K_{0}$ have been presented by Brooker and Ireland, 1965, Figure 9.

Once the sample has been removed from the ground, the stress state is altered as shown in Figure 8 . With consequential release of overburden stresses, there is a tendancy for the soil to rebound or expand. This results in a hydrostatic state of stress with a negative pore pressure equal and opposite to the effective stress and a zero total stress.

If there were no other disturbances to the sample except that of stress relief and assuming that the pore pressure is capable of maintaining the negative pressure required, the effective stress, $\bar{\sigma}_{\text {ps }}$ for the "perfect sample" can be derived as follows:

For a change in the major principal stress, $\Delta \sigma_{1}$ and a change in minor principal stress, $\Delta \sigma_{3}$, Skempton, 1954, has shown that the corresponding change in pore pressure, $\Delta u$, can be expressed as

$$
\Delta u=B\left[\Delta \sigma_{3}+A\left(\Delta \sigma_{1}-\Delta \sigma_{3}\right)\right]
$$

For saturated soils, $B=1$, and $A_{0}$ is the pore pressure coefficient. For a reduction of the deviator stress $\left(\sigma_{1}-\sigma_{3}\right)$, and

$$
\Delta u=\Delta \sigma_{3}+A_{0}\left(\Delta \sigma_{1}-\Delta \sigma_{3}\right)
$$

For normally consolidated soils, $K_{0}<1, \Delta \sigma_{1}=\Delta \sigma_{v}$, and $\Delta \sigma_{3}=\Delta \sigma_{h}$.

From Figure 10,

$$
\bar{\sigma}_{\mathrm{ps}}=-\mathrm{u}_{\mathrm{s}}
$$




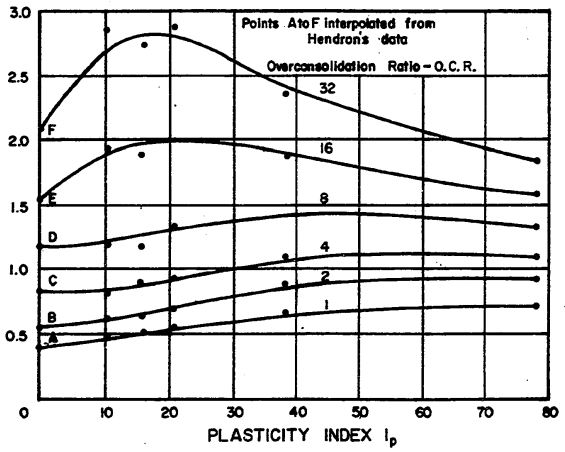

FIGURE 9 RELATIONSHIP BETWEEN $K_{0} i I_{p}$, AND OCR FROM BROOKER AND IRELAND 
Thus

$$
\begin{gathered}
\Delta_{u}=u_{0}+\sigma_{p s}^{3} \\
\Delta \sigma_{v}=\sigma_{v c}=\sigma_{p s}^{3}+u_{c} \\
\Delta \sigma_{n}=\sigma_{h c}=\sigma_{h c}^{3}+u_{c}
\end{gathered}
$$

Substituting into the above, the isotropic effective stress acting on a "perfect" sample of normally consolidated clay is (Figure 10):

$$
\bar{\sigma}_{\mathrm{pS}}^{3}=\bar{\sigma}_{\mathrm{vo}}\left[K_{0}+A_{0}\left(1-K_{0}\right)\right]
$$

For a heavily overconsolidated soil, $K>1$, the horizontal stress is larger than the vertical stress and the isotropic effective stress acting on the "perfect" sample is (Figure 10):

$$
\bar{\sigma}_{\mathrm{ps}}=\bar{\sigma}_{\mathrm{vo}}\left[1+A_{0}\left(K_{0}-1\right)\right]
$$

The problem of stress release has of recent been studied extensively by laboratory testing (Ladd \& Lamb, 1963; Skempton \& Sowa, 1963, Noorany and Seed, 1965, and Davis and Poulos, 1967). This has been accomplished by creating in the laboratory "field elements" whose stress history has been that of consolidation under $K_{f}$ conditions. After the final in-situ conditions have been established, one sample is tested for determination of the "field" undrained strength. The axial and lateral stresses on a second sample are released under undrained conditions. This simulates a "perfect" sample, i.e. one which is free from mechanical disturbance but whose state of stress has been changed from that of anisctripic to hydrostatic loading. The "sampled" element is then tested under undrained conditions. The result of such tests have shown the undrained 


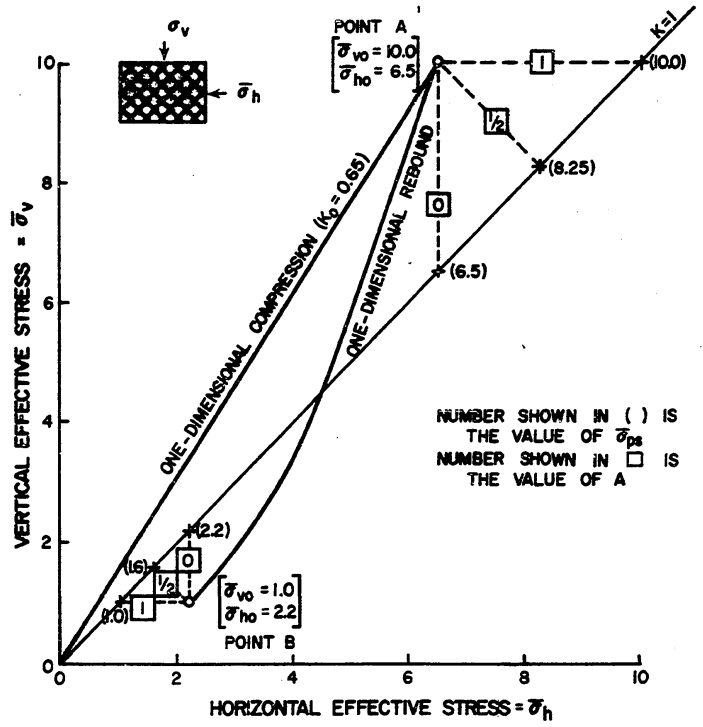
cloy.

The one-dimensicnd compression and rebound arves simulate $K_{0}$ for the Lendon

\section{FEITE 10 PERTECT SAMPLMG OF A NORMALLY COMSOLDATED CLAT AND AN OMER-CONSOLDATED ClaY}

From Ladd and Lambe, 1963. 
compressive strength of the perfect sample to be somewhat lower than the corresponding field element. The compressive strength ranged from $1 \%$ - $2 \%$ lower for soils of low sensitivity to $5 \%-10 \%$ and as much as 18\% lower for the more sensitive soils. The effective stress path of the "field" element and the "perfect" sample is significantly different. At failure, however, there was only a small difference between the effective stresses of the "perfect" sample and the "field" element.

In actual sampling Ladd and Lamb (1963) have found that the actual effective stress, $\bar{\sigma}_{\mathbf{r}}$ (residual effective stress), measured on moderately sensitive clays after actual sampling to be much smaller than $\bar{\sigma}_{\mathrm{ps}}$ ' Figure 11. Test data on the tube sampies show average values of the ratio of $\bar{\sigma}_{\mathrm{ps}} / \bar{\sigma}_{\mathrm{r}}$ to range between 2.8 to 5 . Stress release has been indicated as the reason for the discrepancy between undrained strength values as determined in the laboratory on undisturbed samples and the results of in-situ tests such as the field vane (Adams and Radinakrishna, 1970).

Schjetne (1971) discussed pore pressure changes during sampling of a sensitive clay and a plastic low sensitive clay. Measurements were taken using a hypodermic needle piezometer connected to a vibratingwire pore pressure transducer which was built into the piston of a NGI fixed piston sampler. The measured pore pressure versus time relationships are shown in Figure 12, for the two clays. A total stress release did not occur until the tube was renoyed from the sampler. The measured negative pore pressure at this point was sma!? \{approximately 20 percent of overburden stress) and it later dropped to zero. The release 


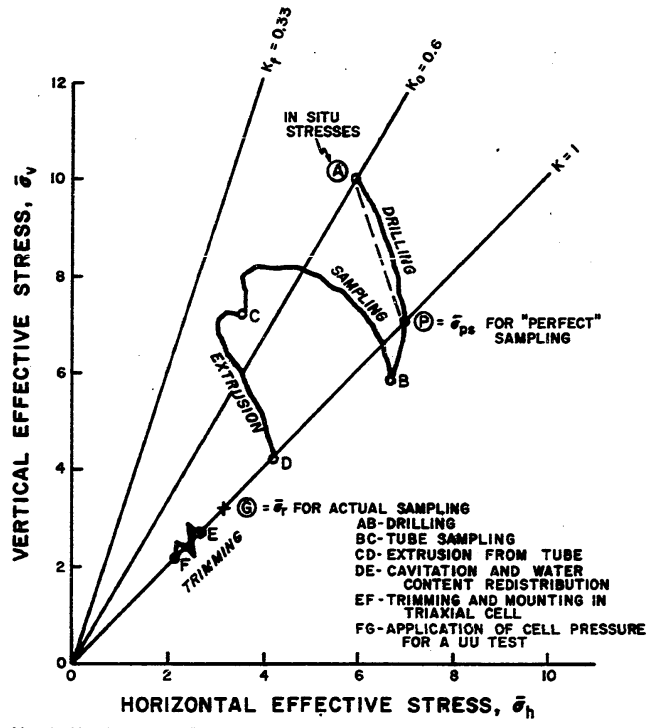

After Lodd and Lombe, 1963

FIGURE II CHANGES IN STRESS CONDITIONS ACTING ON A SOIL SAMPLE 

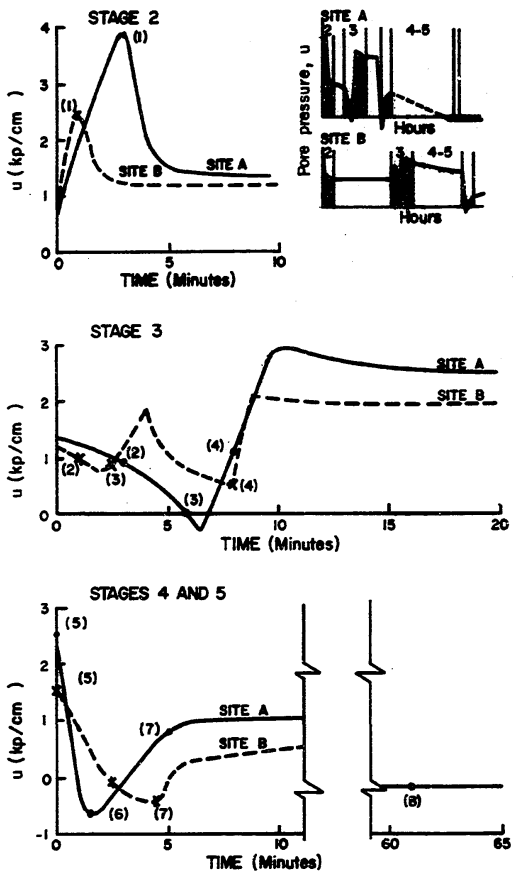

SITE A: Seneitivive ctoy

SITE Bi Plastic, low sensitive clay
(1) The wholi neacle is pressed out
(2) Piston is relecosed
(3) Cutting of the somple stonts
(4) Cutting of the sconple finished

(5) Lifting storts

(6) $20 \mathrm{~cm}$ lifted

(7) $80 \mathrm{~cm}$ lifted

(8) The coose the ground

\section{FGUTE 12 MEASURE PORE PRESSURE VS. TME RELATENGHPS After Schjotne}


of pore pressure was credited to swelling caused by the free water in the remolded material along the tube walls. Since this is a time dependent phenomenon, it was recommended that for minimum disturbance, the sample be trimmed and prepared for testing as quickly as possible after the cutting of the sample in the ground.

Changes in Moisture Content and Void Ratio:

In a non-gaseous saturated soil, a change in void ratio will also involve a change in moisture content. In a gaseous or non-saturated soil a change in void ratio will not necessarily have a corresponding change in moisture content or yice versa.

Changes in volume and moisture can occur prior to sampling, during the sampling operation and after the sample has been removed. The removal of the soil above the sample will be accompanied by a tendency to expand. In driving the sample, the sheared sides will result in a change of pore pressure at the walls of a saturated soil and may involve an increase or decrease in volume.

Sample recovery ratio is the length of sample recovered to the length of the sampler stroke. A recovery ratio of one would tend to indicate no major change in volume. However, there is aiso the possibility that compaction of the soil may be offset by the entrance of excess soil or a swelling of the soil layers which have been deflected downward and stretched.

Use of a drilling mud will help in maintaining overhead pressure on the sample prior to sampling. There may in some cases be reason for concern of sample contamination or changes in moisture content. For 
non-saturated soils or soils above the water table, a drilling fluid should not be used.

Using a bentonite slurry as the drilling fluid while sampling material under a high pore pressure, Fuquay (1968) ran a test as a check to make sure that soil samples were not being contaminated by the slurry. A bright blue dye was mixed with the drilling fluid on one borehole. An examination showed that there was no dyed slurry found in any part of the sample except in the normally disturbed portion of an inch or so at the top.

Moisture content and volumetric changes can also take place after sampling and prior to testing. The method of storing, handling and transportation and the emyironment under which it takes place will influence these changes. Volumetric changes during this period can be checked by measuring and weighing the samples after sampling and just before test preparations.

Disturbance of Soil Structure:

Soil structure disturbance can take place before, during and after the actual sampling. Normally the disturbance before sampling is confined to the top portion of the sample. Using the proper sampler can reduce the structural distortion during sampling, but when the sample is separated from the subsoil, the bottom portion may be disturbed. Structural disturbance may result in different forms such as turn down of layering at the sample edge, planes of failure, distortion or change in thickness of soil layers, etc. The more drastic-structural disturbances can be observed visually by slicing a sample lengthwise and allowing 
half of it to dry slowly.

Not all of the structural disturbances can be visually observed, however. The soil's micro-structure may be disturbed and the physical properties changed even when there is no visible distortion, planes of failure or change in thickness.

\section{Chemical Changes:}

Chemical changes in soil samples include oxidation, contamination of the drilling fluid, and reaction between the storage containers and the soil. The problem of chemical changes are intensified by the presence of acids, alkaline in the pore water, and organic material in combination with exposure to air and metal samplers or containers. Samples should be stored in containers inade of inert material or ones coated with lacquer.

Mixing and Segregation of Soil constituents:

Improper cleaning of the borehole and the use of open drive samplers are causes for mixing and segregation of soil constituents. This normally affects only the top portions of the sample and is easily determined by slicing and observing the distorted structure. 
THE EFFECTS OF SAMPEING; : HANDEING; AND: STORAGE; ON ENGIHEERING PROPERTIES

Shear Strength:

The sensitivity ( $U$ undisturbed/ $U$ remolded) of a soll has been used qualitatively in considering the effect of sample disturbance. The higher the sensitivity, the greater the possible sample disturbance. Based on this, the strength properties obtained from samples of sensitive soils might be expected to be conservative or on the low side of the in-situ value. This is generally true for the unconsolidated-undrained (UU, Q or quick) test. Disturbance does not always reduce the strength of a soil, however. The unconfined compressive strength of a remolded stiff fissured clay is higher than that of the undisturbed sample. Hvorslev, (1949, pp 193) discusses the following cases in which disturbances of the sample may result in unconservative values of strength parameters.

"In case of the consolicated quick and slow tests, the decrease in void ratio during the initial consolidation and during the test itself will be increased by an initial disturbance of the soii structure, as indicated in the discussion of consolidated tests. This additional decrease in void ratio will cause an increase in strength which will counteract and may even exceed the decrease in strength caused by the particles. Therefore, for some soils and certain stress conditions, a distrubance of the soil structure may cause results of consolidated quick and slow tests to be on the unsafe side for practical applications." 
Sample disturbance normally is the result of shear deformation. The effect of this shear strain is to make the clay more compressible. In the UU test the more compressible structure results in a jore pressure build up which leads to a lower strength for the undisturbed sample. In the CU test, the shear strength is increased since the pore pressure build up during shear will be smaller as a result of having previously been consolidated to a more stable state. Thus, the shear strains resulting from sampling disturbances tend to increase the conpressability of sensitive soils. In a dilatant soil, shear strains tend to cause an increase in volume, (Hirschfield, 1960). In the consolidated-undrained test or the consolidated-drained test, a reduction in moisture content and void ratio occurs.

The soils engineer is confronted with the decision of either testing at the natural moisture content (and void ratio) with an effective stress lower than in-situ or consolidating to the existing field overburden stress, but at a moisture content (and void ratio) smaller than the inplace conditions. It is generally believed that the unconfined or unconsolidated-undrained strength test underestimates the in-situ undrained strength while the consolidated-undrained test results are too high.

Qualitatively, disturbance variation within the sample has been discussed in terms of the sampling operation. The variation of disturbance can also be demonstrated quantitatively using engineering test results conducted on different portions of the sample. Figure 13 demonstrates the variation of the unconfined compression strength along the sample length and its diameter. 
RELATIVE STRENGTH IN \% RELATIVE STRENGTH IN \%

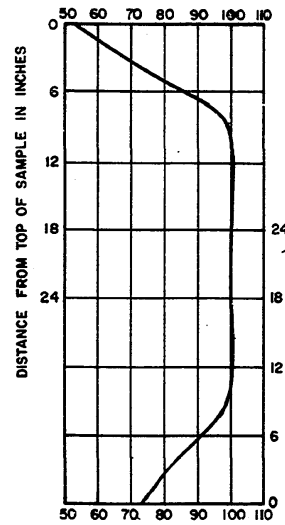

A-RELATIVE STRENGTH OVER LENGTH

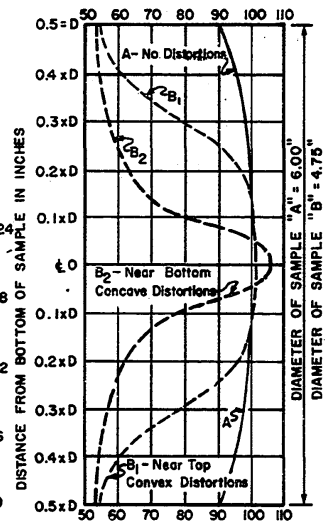

B-RELATIVE STRENGTH OVER DIAMETER

From Hworsev

FIGURE I3 VARIATION OF UNCONFINED COMPRESSION STRENGTH ALONG SAMPLE LENGTH AND DIAMETER 
A reduction in strength due to disturbances for soils of low sensitivity may involve a moderate decrease only. However, the effect on the corresponding deformations may be quite pronounced. It turns out that the most seriously affected property of a soil due to disturbance is the modulus of elasticity (or modulus of deformation).

\section{Consolidation:}

Disturbance of the soil structure will generally cause a pressurevoid ratio curve to be displaced dowmward. When the sample is reloaded, the recompression and the straight portion of the curve will be rounded, thus obscuring the stress history, preconsolidation pressure and decreasing slightly the slope of the virgin compression part of the curve.

\section{Permeability:}

The structural disturbance causing a change in density and void ratio will also result in a corresponding change in the permeability. Estimates concerning settlement rates can deviate drastically from the performance in the field if tests are conducted on samples with excessive disturbance.

Chemical changes induced in the sample by exposure to reactive materials can significantly change the results of Atterberg tests for some soils. The response of the soil to the chemical change will depend on the mineralogy, presence of organic material, pore fluid, etc. 
CHAPTER IV

PREVENTION, EVALUATION AND CORRECTION FOR SAMPLE DISTURBANCE:

STATE-OF-THE-ART

Prevention: Comparative Performances of Samples and Sampling Techniques

The first step in producing an undisturbed sample is to use sampling methods which cause the least possible disturbance. There is some disagreement among investigators as to what is the best method or methods. Most would agree that this does require some consideration of the inplace soil properties. Block sampling generally is considered to yield the least disturbed sample. It is rareiy economically feasible, horrever. Most sampling is done by means of a bore hole. The performance of different samples in a variety of soils have been studied and compared by several investigators. It has been noted by Terzaghi and Peck (1967, p. 307) that "if tube samples have been taken on a given job it is always desirable to investigate the extent to which the consistency of the clay has been affected by the sampling operation."

Recommendations for the geometric design of drive samplers for minimizing disturbance have been presented by Hvorslev, 1949, 1948.

In comparing different types of piston samplers, Jakobson (1954) reported that there was a great difference in the shear strength of samples obtained. These were nine variations of piston samplers used in his study. These included differences in geometry such as length, area ratio, cutting edge angle, core retainers, and methods of operation such as metal foils, pneumatic operation, etc. The results of this study did not indicate an adyantage in using an extremely small area ratio or 
cutting edge. However, Jakobson made a point of reconmending that large area ratios or edge angles not be used.

The highest values of shear strength were obtained with samples taken by the pneumatic piston sampler. The most important difference between this sampler and the others in the study was in the velocity and continuity of the drive during sampling. Based on a comparison with the field vane test, a decrease of about $10 \%$ in shear strength occurred with the best samples taken from moderate depths (13 M). At greater depths the decrease in the unconfined shear strength was greater. This decrease was attributed to stress release and it was concluded that even if the sample is perfect, a loss in shear strength will occur and vary with the depth.

In studies concerning the relationship between the angle of the cutting edge of piston samplers and the unconfined compression strength at the Swedish Geotechnical Institute, the angle of the cutting edge was found to be the most important single influence on sample qualtiy (Kallstenius, 1957). Figure 14 presents the results of tests with varying cutting edge angles. It was also proposed that criteria for the cutting edge angle may replace Hvorslev's area ratio concept.

Kal1stenius $(1963,1971)$ considered several areas of disturbance in a study involving different types of piston samplers, sampling techniques and testing. Variations of clay samples were taken from different sites in Sweden with piston samplers. Geometric differences in the samplers and different sampling techniques were examined. Internal and external friction were found to be a major source of disturbance. For the reast disturbance the sampler tube surface should be hard, 

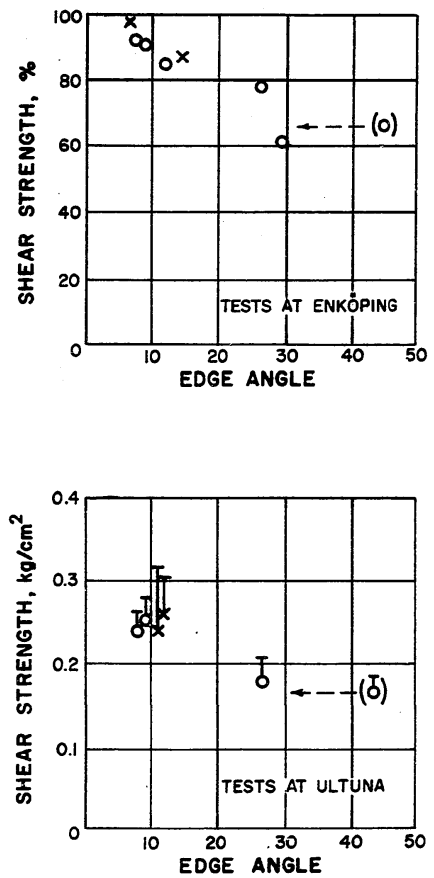

- no clearance

$X$ WITH CLEARANCE

T INCREASE IN STRENGTH WHEN

DEPTH IS INCREASED FROM

10 TO $15 \mathrm{~m}$

FROM KALLSTENIUS, 1957

FIQURE I4 RELATIONSHIP BETWEEN EDGE ANGE AND SAMPLE QUALITY: UNCONFINED COMPRESSTON TEST ON SAMPLES OBTAINED WITH PISTON SAMPLERS 
smooth and noncorrosive. A small inside clearance was also recommended. The greatest clearance (1.4\%) used gave somewhat lower strength values than did the smaller clearances. The greater inside clearance was found to be detrimental to swelling soils and those with fissures.

The influence of the punching speed used while sampling was examined. A punching speed of $15 \mathrm{M} / \mathrm{Min}$ resulted in a decrease in strength of $10 \%$ relative to the average observed at $8 \mathrm{M} / \mathrm{Min}$. Observation of the punching force required was found to be an aid in detecting disturbance by friction.

In transporting soil samples, they should be protected from frost and shocks. Soft vibrations normally were found to be nondetrimental to clays. Deformation was found to be of serious concern to high quality samples as it may lead to water migration or other secondary effects. The effects of time or storage resulted in general in a weakening of the samples' strength.

In preparing the sample for testing, Kallstenius recomnended that the trimmed surface area should be as small as possible in relation to the test specimen. The overall results of this study showed the sampler type to have a considerable influence on test results.

Strength tests conducted on $\mathbf{1 . 5}$ in diameter specimen from 4-in. open-drive sampler taken in boreholes fell well below the lower limit of block strength values in the stiff fissured London clay (Ward, Marsland, and Sammuels, 1965). The block strength was about 30 percent stronger than the borehole samples. The secant modulus of the block samples was many times greater than the open-drive borehole sample values. However, borehole samples obtained by rotary-coring methods compared 
favorably with the upper limit of the block sample value of strength and modulus. Ward (1957) attributed the sampling disturbance of the stiff London clay to the opening up of laminations and fissures.

Holtz (1963) comented on several detrimental characteristics of the sampling operation and made suggestions as to how some may be overcome. He noted the effects of remolding of the sides of the sample. Rather than use the diameter of the sample as extruded from the tube for testing, he suggested that a large enough sample be taken so that remolded material on the sample sides could be removed by trimming. Densification can also be a problem when sampling loose unsaturated material. The remedy is the use of short drives with samples having adequate clearance. Double barrel core samples or hand-cut samples are often required for the elimination of the above.

In sampling unsaturated expansive clays or loose, unsaturated soils, changes in moisture can haye drastic effects on the strength properties. Deep sampling should either be done with a heavy drilling mud or compressed air in a double core-barrel drilling operation with the inner barrel extended into the soil. Hand-cut samples are desirable for shallow exploration.

Coates and McRostie (1963) found the results of shear tests on sensitive Leda clay to be moderately affected by the sample diameter. The sampling operation was found to be very important, however. They concluded that samples from piston samplers in general yield a 25 percent higher strength test yalues than open tube samples. However, the variation between different piston samplers was as much as 40 percent. Shear test on block samples were significantly higher (50 to 200 percent) 
than those from borehole samples. A sumary of the sampling investigation was presented by coates (1963) as foliows:

1. Block Specimen -- in to tests $50 \%$ to $80 \%>2$ in. piston in UU tests $200 \%>2$ in. piston

2. Piston Samplers $-31 / 2$ in. diam. in $U$ tests $25 \%>2$ in. shelby

2 in. diam. in $U$ test 0 to $25 \%>2$ in. shelby

$37 / 2$ in. diam. preconsolidation $15 \%>2$ in. shelby

3. Field Vane -- vs UU tests $40 \%$ to $70 \%>2$ in. shelby ys CU tests $\quad=2$ in. piston

4. Pocket Penetrometer -- ys UU on 2 in. shelby $=2$ in. shelby vs UU on block $40 \%<$ block

Consolidation tests on an artificially sedimented residual limestone clay were performed under "in-situ" and "sampled" conditions (Leonards and Altschaeffl, 1964). Agreement between results of the two tests occurred when a good piston sampler was used for sampling and no more than 15 min. elapsed between the time of unloading and the time when the effective stress prior to unloading was reapplied in the oedometer. Thus, it was recommended that for high quality sampling the time duration between stress release resulting from sampling and reapplication of stress in the oedometer be minimized. Even the best sampling techniques resulted in excessive disturbance in the case of leached (but not highly 
sensitive) clays.

There was a substantial difference between values of $c_{v}$ for the "in-situ" and "sampled" specimen of the artificially sedimented clay. The $c_{v}$ values of the "sampled" specimen were approximately 50 percent lower than those of the "in-situ" tests for an effect stress value less than the preconsolidation pressure.

Peck (Terzaghi and Peck, 1967) compared the unconfined compressive strength of 2-in. tube samples with that of hand-cut samples in Chicago clays of various consistencies. The tube samples yielded a compressive strength of approximately 75 percent that of the hand-cut sample. Complete remolding reduced the strength to 30 percent of the block strength.

Lo et al (1969), 1971) found that for a stiff fissured clay, the effect of sample size is the single most important factor in influencing the shear behavior. The effects of sample distrubance, strain rate of compression, anisotropy, laboratory specimen size, and confining pressure on the modulus of deformation were investigated in the laboratory using 2 in. inside diameter open-drive shelby tube samples and one cubic foot block samples. Field plate loading tests were also conducted. In comparing the results of the borehole and block samples, sample disturbance was by far the most overiding factor in modulus variation. The value of the block samples modulus was 4 to 7 times that of the borehole samples, except in the case of shallow depths. The block samples from different depths $(10,15$ and $20 \mathrm{ft}$.) showed the modulus to increase with depth while results of the borehole samples did not show this trend. 
Conlon and Isaacs (1970) made a comparative study of the effects of sampling and testing techniques on shear strength using block samples, 5,3 , and 2 in. tube samples. The tube sample strength was in general less than the block samples. The fatlure strains in the block samples were smaller and showed less scatter than those of the tube samples.

A comparative study of the performance of soil samples with special emphasis on determining the reduction in shear strength of deep penetration marine samples off the Louisiana coast when using a wire line operated drive sampler was conducted by Emrich (1970). The study included two sizes (2.25 and 3-in.) of a wire line operated sampler. This equipment was developed for use with boat drilling. Attached to the sampler is a sliding weight of approximately $175 \mathrm{lbs}$. (300 $\mathrm{lb}$. for the 3-in. sampler), having a maximum vertical travel of 10 feet. A 3-in. thin walled open drive sampler operated by pushing along with a hydraulically activated $3-$ in. stationary piston sampler was also used in the study which was conducted on land in soils similar to those offshore.

Sample distrubance resulting from the wire line sampling technique significantly affected the shear strength. Most of this distrubance was thought to be the results of the percussion method of driving the sampler. Tube diameter influenced sample disturbance somewhat as the 3 -in. wire line strengths were approximateiy 5 to 10 percent greater than those of the 2.25 wire-line samplers. The highest strengths were measured on samples from the hydraulically operated piston sampler. Emrich found the relationship between sampler types to be constant over substantial ranges of depth and strengtins and suggested that an 
appropriate correction factor could be applied to the wire line samples for simtlar soils.

Using block samples as reference, Eden (1970) compared the test results of four types of piston samplers in Leda clay $\left(S_{t} \geq 20\right)$. The samplers used were the Swedish foil sampler, the Norwegian piston sampler, the standard Swedish piston sampler and the Osterberg hydraulic sampler. The in-situ strength of the clay was also measured with the field vane. The relative quality of the samples was determined by comparing the measured preconsolidation pressure and the undrained shear strength. The results of the test values from the samplers feil far short of those of the block. Only 4 of 35 preconsolidation tests equaled or exceeded the block test values. Similarly, on 6 of 240 undrained strength tests results equaled or exceeded those of the block. In many of the tests the piston tube samples amounted to only half the value of the block. The field vane did not provide a more reliable test method. The most divergent results came from samples obtained with the Swedish foil sampler.

Bozozuk's (1970) studies of a quick $\left(s_{t}=17\right)$ marine clay indicated that size (5-in. and 2-in. core diameter) and storage effected the quality of the sample. In general, for specimens trimmed from 5-in. diameter cores, the measured strain to failure in strength tests was smaller and the pore pressure parameter was greater than those of the 2-in. diameter cores. The larger core also generated a higher preconsolidated pressure in consolidation tests. Storage reduced the measured preconsolidation pressure (4.8 percent), indicating that consolidation tests should be conducted as soon as possible after sampling. 
Rowe $(1972,1970)$ discussed the requirement for large (260im) diameter samples in order to provide relevant laboratory consolidation and strength data on clay soils which exhibit a fabric in layers, varves, silt, and organic inclusions or fissures. Large clay samples with permeable fabric can show coefficients of consolidation $10^{3}$ to $10^{4}$ times larger than those on smaller conventional samples. Permeable fabric leads to water content changes and softening during drilling and sampling from dry holes below the water table. This can be reduced by using a driliing fluid.

The undrained strength of fissured clay was shown to decrease with larger samples and improve representation of soil fabric. Good quality samples were achieved by using a $260 \mathrm{~mm}$ thin-walled flush-tube piston sampler with an area ratio of 6 percent. It was necessary to handle and extract organic clays under water to prevent oxidation of rootlet channels which causes variation in permeability.

In comparing the results of laboratory tests on block samples and samples using the Norwegian Piston sampler, LaRochelle and Lefebvre (1970) found that Champlain (Leda) clay was severely disturbed by thinwalled tube sampling. The sampling disturbance can be traced to the strain resulting from change in volume consecutive to the intrusion of the sampling tube into the soil. Triaxial tests have shown that the lateral strains necessary to destroy rale "cementation bonds" on block samples are smaller than those resulting from use of the thin-wall sampler. It was suggested that in order to get an acceptable undistrubed sample of cemented clay, that a special type of sampler will have to be developed with an area ratio much smaller than 10 percent. 
Milovic (1970) presented test results on Shelby, piston and block samples of two sensitive $\left(S_{t}=10\right.$ and 15$)$ slightly overconsolidated clays. The results clearly indicated a significant influence of the sampling method on the undrained shear strength, consolidation, and the elastic properties. The effect was pronounced even at shallow depths. The results obtained on the Shelby and piston specimen were systematically lower than those obtained from the block specimen.

In another sampling study, Milovic (1971) compared block samples and Shelby tube samples of a loess whose initial density was low and water content high. The elastic moduius, $E$, the unconfined strength, $u$, the compressibility, $\dot{K}$, and preconsolidation pressure $P_{c}$, determined from Shelby specimen were higher than those obtained from blocks (i.e. unconservative).

Test results on loess (Milovic, 1971):

\begin{tabular}{lc} 
Property & Shelby/Block \\
\cline { 2 - 2 } Unconfined Compression, u & 1.86 \\
Young's Modulus, E. & 1.82 \\
Compressibility, K & 1.87 \\
Preconsolidation pressure, $P_{c}$ & 1.58
\end{tabular}

A comparison of consolidated undrained triaxial test on a sensitive, cemented Leda clay sampled by six different sampling methods was reported by Raymond, et. al (1971 a, b). Of the sampling methods used, the results in order of least disturbance were;

1) Block Sampling

2) Osterberg Sampling 
3) Swedish piston Sampling

4) Shelby piston Sampling with sharp cutting edge ( $5^{\circ}$ taper)

5) Shelby piston sampling

6) Shelby open tube sampling

The samples were removed from the shelby tubes by cutting the tube with the sample, with a power saw. However, there was some evidence that vibrations associated with this procedure caused disturbance to the sensitive clay in the tube. However, the length of the sample tube was such that jacking the sample out without cutting caused more dìsturbance.

Using a consolidation pressure less than the preconsolidation pressure required to cause collapse of the cementation bonds increased the value of $E_{u} / C_{u}$. The optimum consolidation pressure depends on the sample disturbance. The pore pressure coefficient, A, for samples consolidated below the preconsolidation pressure showed a consistent value except at low consolidation pressures. Sampling with $50 \mathrm{~mm}$ (2-in.) shelby tubes caused considerable disturbance to the cementation bonds which resulted in lower strengths at low confining pressures, but higher unsafe strengths at higher confining pressures which were less than the preconsolidation pressures.

Morgenstern and Thomas (1970) found bilock samples to be more disturbed than samples taken with a Shelby tube or Pitcher sampler in a stiff clay. Contrary to expectations, the block samples had lower strengths and higher permeabilities than the borehole samples. However, the block samples were taken under adverse conditions. They were 
obtained at the face of a tunnel between the cross arms of the cutting mole using a compressed air jackhanmer equipped with a clay spade bit. They weighed between 30 to 50 pounds.

In a study of the effects of groundwater levels on stress history of a clay till deposit, Sodeman and Kir (1970), found that the prediction of the preconsolidation pressure depends on the degree of overconsolidation and the degree of sample disturbance. Block samples and different size tube samples were obtained. Laboratory test results showed the e-log $\bar{\sigma}$ curves to be directly influenced by the method of sampling, sampler dimensions and size of the test specimen. The larger specimen consistently showed less disturbance.

Lang (1971) made measurements of the forces acting on an open-drive, thin-walled sampler in a stiff clay. Using two different methods, he determined that the ratio of peak forces (inside force/outside force) was 0.48 and 0.28 , respectively. The average surface shear stress in contact with the soil was 0.64 times the shear strength of the soil. The peak axial stress on the soil core had a mean value of 13.4 times the shear strength of the soil. Strength tests on pairs of samples cut from the sample tube sample indicated a higher strength for the lower specimen. The difference in strength between the lower and upper specimen was attributed to the sampling process.

In an earlier paper concerned with experimental sampling, Lang (1967) found that in all cases (14) the secant modulus to be greater in specimen cut from the lower part of the tube sample. In twelve of the fourteen tests a similar condition existed for the peak strength.

The deformation of a tube soil sample during extrusion was measured 
by Sone (1971). He found that in an alluvial clayey silt that the extruding pressure required as much as ten times larger than the unconfined compressive strength and that the extruding strain was almost equivalent to the failure strain in the unconfined compression test. The extruding force and average soil strain was smaller for sampler tubes with inside clearance. The largest strains occurred at the bottom where the extruding force was applied. Unconfined compressive tests on samples cut from the lower portions was 10 to 20 percent smaller than of the upper part.

Shackel (1971) used nuclear techniques to study changes in bulk density that occurred within soil samples during sampling and extruding. Most of the disturbance in bulk density was the result of jacking the sampler into the parent soil. The subsequent extrusion of soil from the sampler resulted in only minor changes in the profile of bulk density.

For the most part, a surmary of the findings of various investigators on the influence of sample type and size on disturbance is graphically represented by Figure 15 . The hand-cut block sample gives the best representation of inplace conditions. The next most important criteria for samplers of similar type is size. The large tube sizes yield a sample of higher quality than smaller tube diameters. This is not in the form of higher strengths, however. It has been demonstrated (Milovic, 1971, Rowe, 1970, 1972) that sampling disturbance can actually result in an increase of strength for some soils.

Comparison of open drive samplers to piston samplers indicate that the latter provides the least disturbed sample, Figure 15b. In a number of studies (Jakobson, 1954, Leonards and Altschaeff1, 1964, Eden, 1970, 


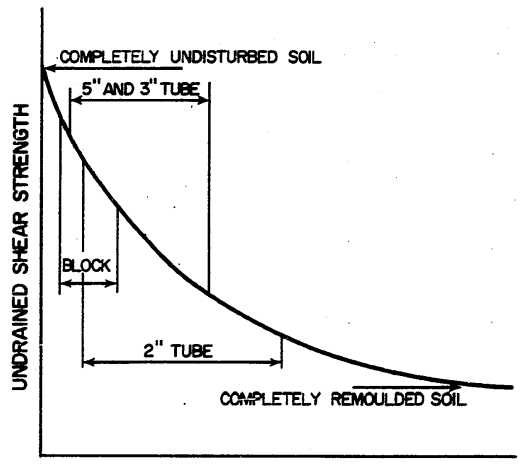

a. DEGREE OF DISTURBANCE

After Conion and isoocs INCREASING $\longrightarrow$

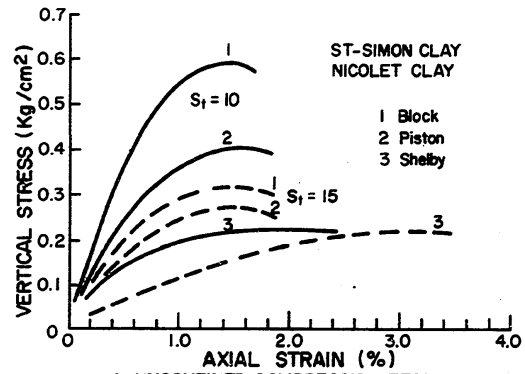

After Milovic

b. UNCONFINED COMPRESSION TEST

FIGURE I5 INFLUENCE OF SAMPLE TYPE AND SIZE ON DISTURBANCE 
Raymond, et. a1, 1971) the hydraulically operated piston sampler (Osterberg sampler) appears to outperform mechanically operated piston samplers.

\section{Evaluation of Sample Disturbance}

A measure of sampling disturbance, using the results of the e-log $\bar{\sigma}$ curve has been proposed by several investigators (Schmertman, 1955, Bartlett and Holden, 1968, Bromham, 1971). These are based upon deviation of the laboratory undisturbed e-log $\bar{\sigma}$ curve from that of the extrapolated field curve, which will be discussed subsequently. Schmertman defined the degree of disturbance as (Figure 16);

Degree of Disturbance $=$

$$
\frac{\Delta e}{\Delta e_{\max }} \times 100 \%
$$

Bartlett, Holden and Bromham have used disturbance factor, $x$, Figure 16 .

$$
\left.X=100 \frac{P_{C}-P_{L}}{P_{C}-P_{r}}\right)
$$

in practice, $P_{r} / P_{c}$ is small and in the limit as $P_{r} / P_{c} \rightarrow 0$, then

$$
x=100\left(1-\frac{P_{L}}{P_{C}}\right)
$$

The second definition has the advantage of not requiring a test on à remolded sample.

In evaluating the quality of consolidation samples, Burmister (1950) 


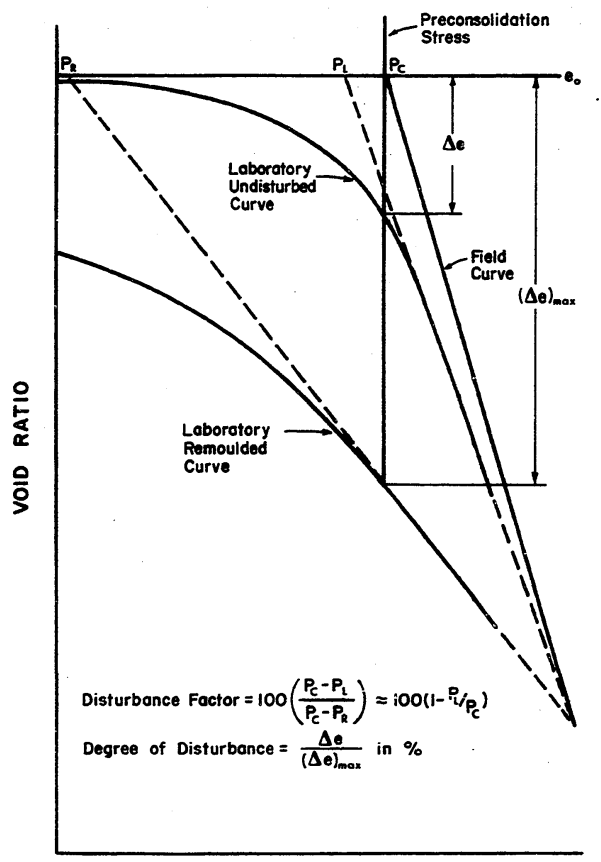

PRESSURE (log scale)

FIGURE 16 EVALUATION OF DISTURBANCE 
suggested an examination of the shape of the e-log $\bar{\sigma}$ curve. This may be judged by a small initial compression under the initial load which results in a relatively flat recompression curve, and by a relative sharp break of this curve in the region of the natural stress.

Since the previous stress history and preconsolidation load are among the factors which govern shear resistance, disturbance to these would modify to some degree the shear resistance.

In the unconfined compression test, Rutledge (1944) observed that the effect of sampling disturbance was more severe on the modulus of elasticity than on the compressive strengths. He concluded that serious sample disturbance is indicated if, (a) the stress-strain curve is nonlinear for the first 30 percent of the compressive strength, or (b) the stress-strain curve falls close to that for the same soil remolded.

Skeopton and Henkel (1957) observed that for a normally consolidated clay the ratio of shear strength to effectiye overburden correlated closely with the plasticity index. Computation of this ratio, $C_{u} / P_{0}$, can be used as a check on the reliability of sampling and testing results.

Arthur and Leo Casagrand (Ball, 1962) found the liquidity index to be a good indicator of sampling disturbance. It was found that, in general, excessive disturbance will occur when the sampler is driven into a soil whose liquidity index is less than 50 percent.

Other investigators (Saiki, 1971; Sangrey, 1971) haye experienced limited success in correlating strength with properties of the remolded soil. Most of these have made use of the plastic index, sensitivity, and liquidity index. 
Mechanical or Structural Disturbance

One of the quickest and easiest methods for deternining the extent of excessive structural disturbance is to slice the core and allow it to dry very slowly in a humtd roon (Terzaght, 1940; Horsiev, 1949). As the moisture in the soil eyaporates, a point is reached which enhances color variations within the soil. At that point, the structural characteristics are most pronounced and some of the more dramatic forms of sampling disturbances, such as bent layering, can be seen. .

Some of the more subtle forms of mechanical or structural disturbance cannot be obseryed visually. Yet, their influence on laboratory tests can be most detrimental. Small shear strains can result in a breaking of particle bonds and reorientation of particles. The effect of such changes to the microstructures have been studied by means of thin sections (Mitche11, 1956), and clay particle parallelism using $X$-ray diffraction techiniques (Quigley and Thompson, i966; Barden and Sides, 1971). Such methods and equipment are for the most part not available to most soil labs and the results of such studies at the present time are limited in application to most analyses on the effects of sampling.

In order to study structural disturbance by the slow drying technique, the sample must be split and dried. This destroys the sample insofar as its use for undisturbed testing. Another drawback in this method is that it presents a picture of the material on only one plane of the core and this will be speared somewhat. Another technique which shows great promise in its application to soil investigations is that of $\mathrm{X}$-ray radiography (Krinitzsky, 1970). 
Using X-ray radiography in a geological and geotechnical investigation of varved soil, Kenney and Chan (1972) discussed frequent damage to 2 in. open-drive undisturbed samples in the form of transyerse cracks between varves. This was analyzed as having been caused during the sampling process and was the result of large frictional forces created between coarse-grained soil and the sampling tube. Extruding the sample from the tube tended to mask or hide the cracks by smearing and by partially closing then. It was believed that the prevention or at least reduction of this type of disturbance can be accomplished by using sampling tubes with positive clearances at the cutting edge and treated inner surfaces.

Residual effectiye stress measurement after sampling has been proposed as a quantitative method for determining the quality or the extent of sampling disturbance. Ladd and Lambe (1963) used $\sigma_{p s} / \sigma_{r}$ as a means of gaging stress release. Nelson, et. al, (1971) proposed that a more useful indicator for the degree of disturbance, $D_{d}$, should be defined as

$$
D_{d}=\frac{\bar{\sigma}_{p s}-\bar{\sigma}_{r}}{\bar{\sigma}_{p s}}
$$

For a perfect sample $D_{d}=0$ and for a completely disturbed sample $D_{d}=1.0$.

\section{Correction for Sample Disturbance}

It has been recormended by Terzaghi and Peck (1967), that when undisturbed tube samples are taken, it is a good idea to determine the extent and nature of the disturbance resulting from the sampling methods 
used. Idea lly, such a study would involve a comparison of the methods used to those which would produce the least disturbance, i.e. block sampling. Then, if a correlation can be established, a correction factor may be applied to the test results of tube samples in similar soils. This is, of course, not always possible unless the material in question is near the ground surface and the expense of such a study can be economically justified. In most foundation analyses, this is not the case.

Corrective methods for sampling disturbance of solls in general have come about from observation of test results on undisturbed and remolded samples and utilize some method of extrapolation.

One of the earliest and most popular methods proposed for determining the preconsolidation load was by Casagrande (1936). In this method, a horizontal and tangent line are drawn through the point on the e logo curve representing minimum curvature, Figure 17. A line is then drawn, bisecting the angle formed. The virgin, or straight line, portion of the compression curve is then extended until it intersects the bisecting line. The stress at this intersection is an approximation of the preconsolidation pressure.

Burmister (1951) used a characteristic triangle, Figure 18, formed by rebounding and reloading the consolidation sample. The preconsolidation pressure is found by projecting the virgin curve back and then moving the characteristic triangle between it and the initial portion of the e logo curve until the vertical leg marịs tia precorsolidation pressure.

In a study of the deviation of consolidation test results due to sample disturbance, Schmertman (1955) proposed an al ternate quantitative 


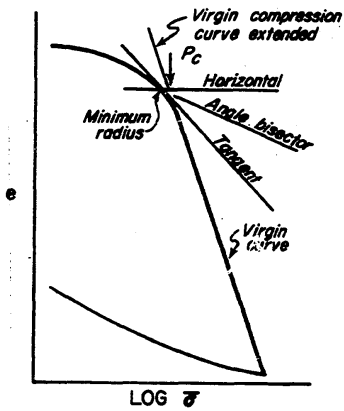

FIGURE 17 PRECONSOLIDATION PRESSURE, CASAGRANDE GRAPHICAL CONSTRUCTION

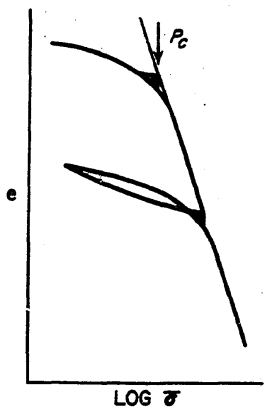

FIGURE 18 PRECONSOLIDATION . PRESSURE, BURMISTER RETHOD

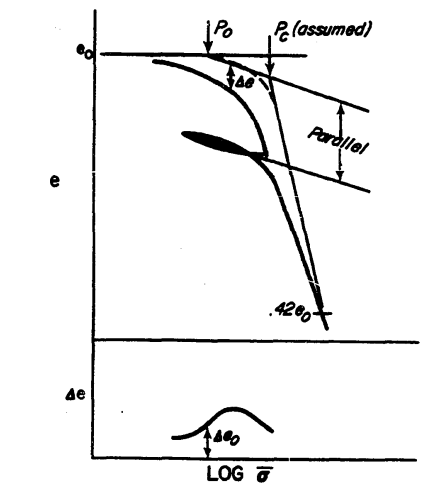

FIGURE 19 PRECONSOLIDATION PRESSURE AND FIELD CURVE, SCHMERTMAN METHOD 
method for determining the preconsolidation pressure and location of the field curve, Figure 19. Using the procedure of laboratory loading, rebound and reloading a line parrallel to the rebound curve through the point whose coordinates correspond with the initial void ratio, $e_{0}$, and the existing overburden pressure, $P_{0}$, is assumed and plotted on the line parallel to the rebound curve. A field virgin line is then drawn by connecting this point with the laboratory curve at $0.42 e_{0}$. The void ratio reduction ( $\Delta \mathrm{e})$ between the assumed field curve and the laboratory curve is plotted against $\log \bar{\sigma}$. This procedure is repeated, assuming different values of $P_{c}$. The correct preconsolidation pressure and field curve will be the one which yields the most symmetrical void ratio reduction plot.

A procedure recommended by Leonards (1962) for estimating ultimate settlements in overconsolidated deposits is as follows:

1. Obtain the best possible samples.

2. Consolidation tests are performed using reduced pressure increments until the virgin curve is reached, then rebound to the existing overburden pressure and reload using conventional load increments.

3. Estimate the probable range of preconsolidation pressure, Figure 20.

4. If the curve has a well-defined break, use the Casagrande method for estimating the preconsolidation pressure; otherwise use the Burmister or Schmertman method. Determine a most probable value of $P_{c}$.

5. Draw a line from the point $\left(p_{0}, e_{0}\right)$ parallel to the slope 


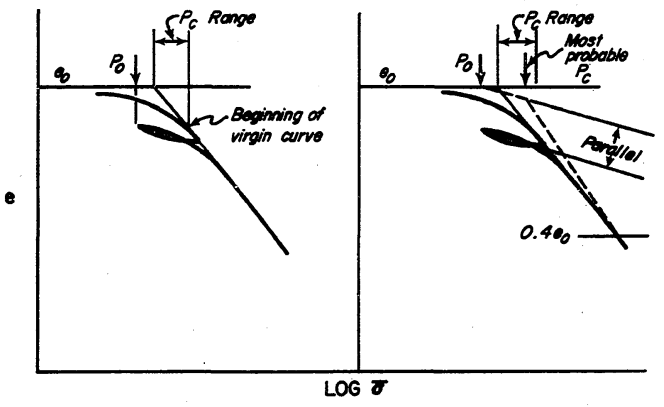

(a)

(b)

FIGURE 20 FIELD CURVE FOR SETTLEMENT NTERPRETATION OF OVERCONSOLIDATED SOIL

After Leonords, 1962

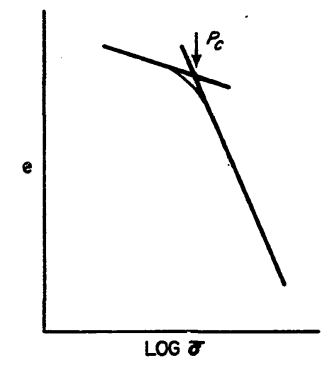

FIGURE 21 PRECONSOLIDATION PRESSURE

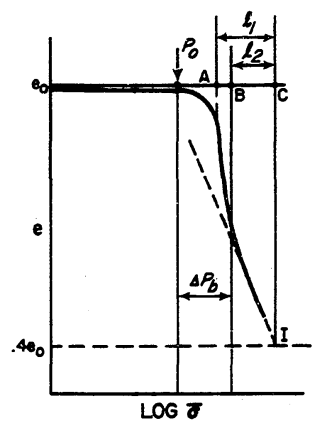

FIGURE 22 FIELD CURVE FOR A SENSITIVE CLAY After Terzaghiand Peck, 1967 
of the rebound curve and plot $\cdot \mathrm{p}_{\mathrm{c}}$ on this line. Connect this point with $0.4 e_{0}$ on the laboratory consolidation curve.

6. Use the field curye (dashed line) to compute settlement.

Another technique proposed (Sowers and Sowers, 1970, Zeevaert) for estimating the preconsolidation pressure from the compression curve is accomplished by extending the initial flat portion of the curve and the steep or virgin section, Figare 21. The intersection of these lines define the preconsolidation pressure, $P_{c}$ :

. A method for approximating the field curve of an extra sensitive soiv has Eeen presented by Terzaghi and Peck (1967). Unlike parabolic e-logo curyes of ordinary clays, the shape of the compression curve for sensitive clays will upon reaching some effective stress value turn down abruptly, Figure 22. With additional load, the slope of the compression curye will decrease until it eyentually stabilizes and follows a more or less straight line. This behavior has been credited to the growth of bonds between the clay particles along with the possibility of overconsolidation effects.

The field curve is drawn as shown in Figure 22. The lower portion of the compression curve is extended to a point where the void ratio is equal to $0.4 \mathrm{e}_{0}$. By extending the steep portion of the laboratory curve till it intersects the horizontal line at $e_{0}$, point $A$ is located. If the bond strength, $p_{b}$, is known or can be estimated reliably, this value is added to the effective overburden pressure, $P_{0}$, and is plotted as point $B$ on the horizontal line at $e_{0}$. The field curve is located in such a way that the ratio of the horizontal distances between the field 
curye and the yertical line IC and the laboratory curve and the line IC is equal to

$$
\frac{1}{1_{1}}=\frac{B C}{A C}
$$

If the bond strength is unknown, it is recormended that $p_{0}+\Delta p_{b}$ be taken as that at point $A$.

In an investigation of those factors which have an influence on laboratory consolidation tests, YanZelst (1948) found that the amount of disturbance (by yolume) due to sample triming is approximately constant for different sample thickness. That is, in general test specimen are distrubed to a constant depth irrespective of their thickness. Planing the top and bottom faces of a consolidation specimen was found to be the greatest disturbance in the laboratory preparations. Circumferential trimming was found to be relatiyely small when compared to the other. In general, the effects of other factors such as friction and swelling were much smaller compared to distrubances in sample preparation.

By computing a disturbance factor, based on sample thickness, Figure 23, corrections can be made to thin specimen data.

The existing undrained shear strength of a soil is generally determined under one of two conditions in the laboratory. One mehtod is to test the sample at its natural moisture content (and void ratio) but with an effective stress lower than exists in-situ. This would involve the unconfined (U) or the unconsolidated-undrained or quick (UU) tests. A second alternative is to consolidate the sample to the field overburden 


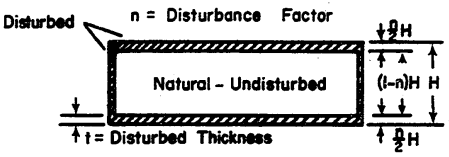

\section{A. CROSS SECTION OF CLAY SPECMEN SHONHG PONTIONS DISTURBED IN FREPARATION FOR CONSOLIDATION TEST}

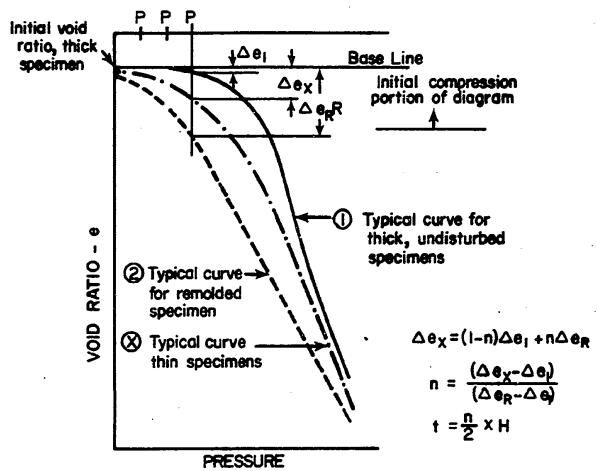

B. DETERMINATION OF. AMOUNT OF DISTURBANCE IN THIN CONSOLIDATION SPECIMENS BY THE PROPCRTIONING METHOD

After Von Zelst

\section{FIGURE 23}


stress but a moisture content (and yoid ratio) smaller than the inplace soil. This would be the consolidated undrained test (CU). Generally, the first test conditions yield a strength value which is too low, while that of the second is on the unsafe side.

If the strength of a soil is plotted against void ratio, e, the resulting diagram is similar to the $e-10 g \bar{o}$ curve of the consolidation test. In order to correct the strength yalues obtained from the $\mathrm{CU}$ test, Casagrande and Rutledge (Hvorslev, 1949, page 194) have suggested that the approximate in-situ strength of the soil may be extrapolated using techniques similar to those for the determination of the preconsolidation pressure, Fìgure 24.

Another extrapolation method for projecting field shear strength has been proposed by Calhoun (1956). It combines the VanZelst (1948) hypothesis on sample disturbance as a function of the ratio of surface area to volume writh the Casagrande-Rutledge (Hvorslev, 1949) hypothesis for shear strength eyaluation. In this method, the plot of laboratory compressive strength versus void ratio is corrected to obtain a field curve. The correction is based on the amount of disturbance of samples of various sizes and on remolded specimen.

Schmertman (1956) suggested a modification of Calhoon's (1956) technique. Instead of relating disturbance to the results of consolidation tests of varying thickness, he suggested that the e-logo field curve be constructed using his procedure (Schmertman, 1955). Then plotting two curves of compressive strength versus the void ratio for the undisturbed and remolded soil, he determines their point of intersection, Figure 25. A field curve of the compressive strength versus 

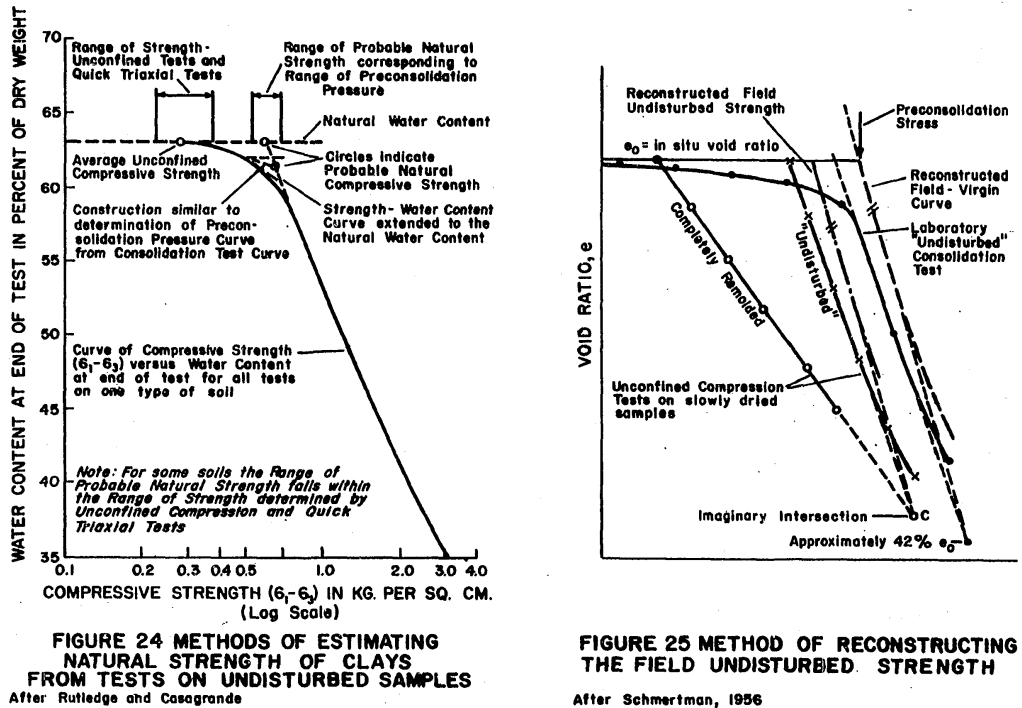

FIGURE 25 METHOD OF RECONSTRUCTING THE FIELD UNDISTURBED. STRENGTH

After Schmertman, 1956 
void ratio is drawn through this point of intersection and parallel to the consolidation field curye.

A method for adjusting the undrained strength (UU and CIV) of tube samples of moderately sensitive, plastic clays which do not posses significant cementation has been proposed by Ladd and Lambe (1963). The corrected strength is the result of adjustments wich account for the reduction of the residual pore pressure, $\bar{\sigma}_{r}$, due to sampling operations from that which would have resulted from perfect sampling, $\bar{\sigma}_{p s}$. Observations of UU tests results suggest that the samples behave as overconsolidated specimens. Using this concept, Ladd and Lambe suggested that the ratio $\bar{\sigma}_{\mathrm{ps}} / \delta_{\mathrm{r}}$ be taken as an overconsolidation ratio for correcting the UU strength. This requires that a relationship between the overconsolidation ratio and the undrained shear strength be established from the results of CIU tests. Then, by measuring $\bar{\sigma}_{r}$ and calculating $\bar{\sigma}_{r}$ an equivalent overconsolidation ratio is established and the undrained strength corresponding to perfect sampling is determined, Figure 26. Typical values of stress values for perfect sampling were given by Ladd and Lambe and are shown in Table 3.

Methods proposed for correction of CIU tests, based on the concept of perfect sampling, require values of Hvorslev's parameters.

A correction for the undrained shear strength as proposed by Noorany and Seed (1965), requires the solution of

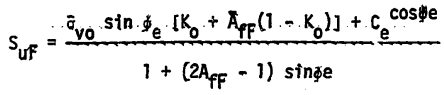




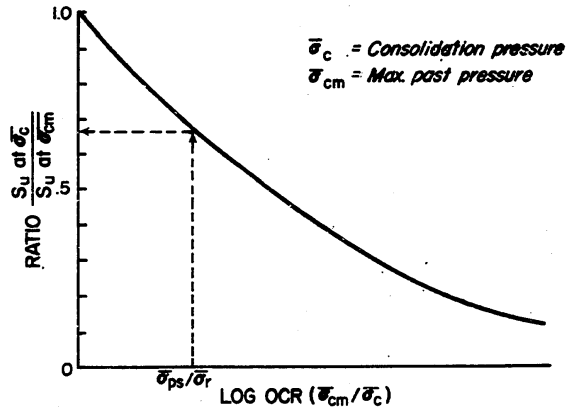

FIGURE 26 EFFECT OF OCR ON UNDRANED STRENGTH After Ladd and Lambe, 1963

TYPE OF SOLL

K

$A_{U}$

$\bar{\tau}_{\text {ps }} / \bar{\sigma}_{\mathrm{vO}_{0}}$

NORMALLY CONSOLIDATED

$\begin{array}{llll}\text { Clayey silt } & 0.4 \text { to } 0.5 & -0.1 \text { to } 0 & 0.35 \text { to } 0.5 \\ \text { Lean clay } & 0.5 \text { to } 0.6 & 0.1 \text { to } 0.2 & 0.55 \text { to } 0.7 \\ \text { Plostic clay } & 0.6 \text { to } 0.7 & 0.2 \text { to } 0.3 & 0.65 \text { to } 0.8\end{array}$

HEAVILY OVERCONSOLDATED

Piastic clay

$\sim 2.5 \sim 0.3 \sim 2$

\section{TABLE 3 STRESS RATOS FOR PERFECT SAMPLING}

After Ladd and Lambe, 1963 
In this equation, the effective overburden $\bar{\sigma}_{\text {vo }}$ can be easily evaluated; the coefficient Ko may be determined experimentally, or calculated ( $K_{0}=1-\sin . \bar{\sigma}$, normally consolidated); the shear strength parameters $C_{e}$ and $\phi_{e}$ can be measured in the laboratory using undisturbed samples of high quality (studies by Noorany and Seed indicated that $C_{e}$ and $\phi_{e}$ are not altered by a small degree of disturbance.).

The estimation of the correct value for the field pore pressure coefficient $\bar{A}_{\mathrm{fF}}$, however is difficult. It was found that the difference for in-situ and perfectly sampled soil was as large as $100 \%$. A lab procedure technique was discussed by Noorany and Seed (1965) which gives an approximate value for $\dot{A}_{\mathrm{fF}}$.

Bavis and Poulos (1967) tested artificially created Kaolin soil samples in the laboratory under simulated conditions of field, perfect sampling, undisturbed sampling, partially disturbed samples, and fully remolded. The results of experimental investigations on one dimensional consolidation properties showed trends similar to those reported by Rutledge (1944) and Schmertman (1955) and conffirmed the validity of correcting on the basis of degree of disturbance from e-logō curves. The deformation properties (drained and undrained) obtained from tests on specimen reconsolidated under hydrostatic conditions are likely to be significantly different from true field properties. In order to minimize sampling disturbance effects, it was recommended that specimens be reconsolidated under conditions as close as possible to the original field conditions prior to testing.

Adams and Radhakrishna (1971) proposed that the effects of suction loss on CU test results can be overcome by consolidating the sample under 
Ko conditions to the estimated yertical stress or the equivalent isotropic stress for perfect sampling. It is believed that the volume changes that will occur under the reconsolidation will be approximately equal to the amount of swelling which took place during sampling.

For correcting UU tests, Adans and Radhakrishna presented a method based on the change in moisture content due to swelling. This is determined from a swelling curve obtained in an oedometer or triaxial test. The strength is then corrected from the unique strength versus moisture relationship for the soil in question.

Whth increased disturbance, Schmertman (1955) observed a systematic decrease in permeability. He presented a method of correction for timesettlenent curves using a graphical extrapolation technique. In this method, several time-settlement curves are drawn using different undisturbed samples from the zone in question. The degree of distrubance for each is determined from the laboratory e-logo curve. The field curye is extrapolated as shown in Figure 27. Davis and Poulos (1967) yerified the validity of this extrapolation technique on laboratory simulation of "fie!d" and sample specimen. 


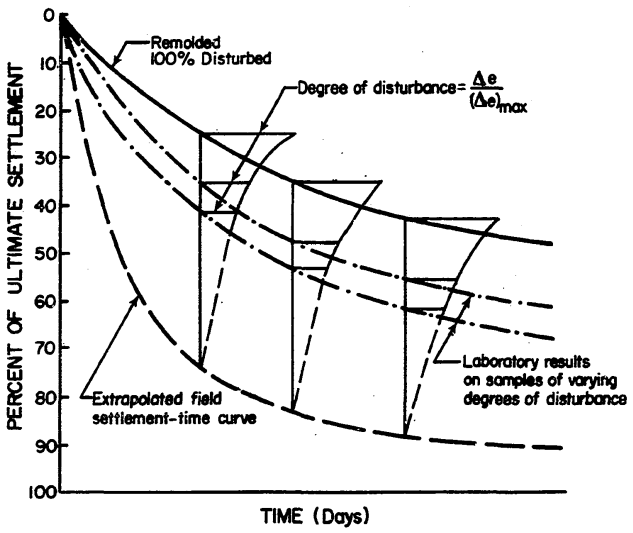

FIGURE 27 EXTRAPOLATION OF UNDISTURBED TIME - SETTLEMENT CURVE FROM DISTURBED LABORATORY CONSOLDATION TESTS 
CHAPTER V

GEOLOGY AND SITE SELECTION

Louisiana is situated in the physiographic province known as the Gulf Coastal plain. The entire terrain is composed of sedimentary material of the Cenozoic Era. The soils of Louisiana were primarily transported and deposited in water during the early Tertiary and Quaternary periods under conditions involving marine, deltaic, and continental environments. The thickness of strata and type of sediment of an area are the results of sea level fluctuations and structural movements, both local and regional. The major structural features which have influenced the geology of the area include the Gulf Coast geosyncline, the Mississippi Structural Trough, several uplift zones and many fault zones.

\section{Sampling Sites}

The sampling sites selected for this study are shown in Figure 28. The geological history and origin of the materials at the different sites is somewhat different. The selection of the sites was based on an attempt to find soils which would be conducive to a study on sampling and also would be representative of material encountered by soil engineers in this area.

The geographical location and the depth to which the samples were taken is such that most of the material is confined to the Recent and late Pleistocene deposits. In general, the deposits sampled were formed during the Wisconsin glacial stage by the development of deltaic 
FIGURE 28

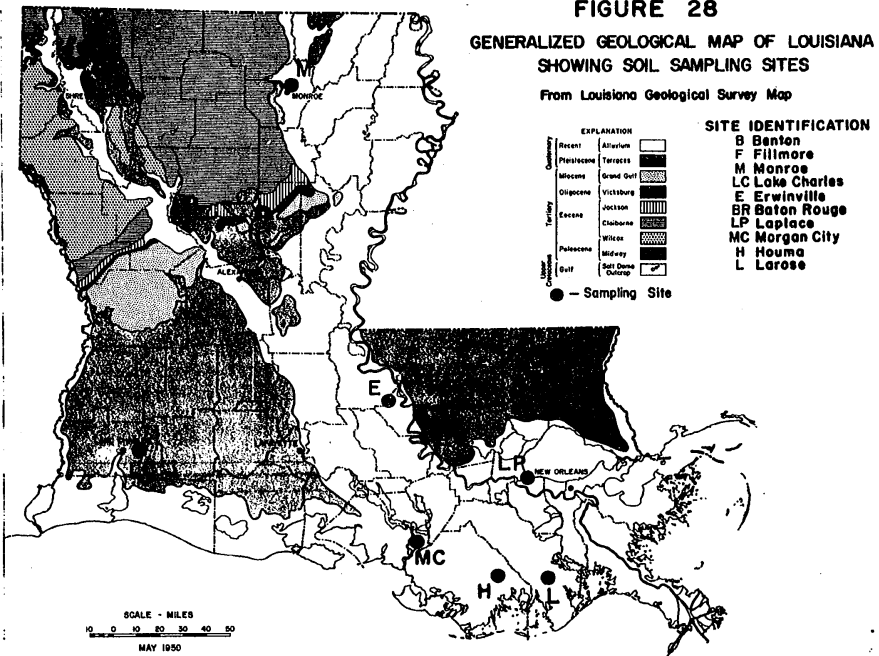


plains of the Mississippi and other rivers. in response to eustatic fluctuations of sea level and other hydrologic factors.

These pleistocene terrace deposits and the soils associated with them compose large areas of the State of Louisiana. They are uaually recognizable, even when they are overlain by more recent material, because of lower sea leyel periods, the material was subjected to thousands of years of consolidation, dessication, oxidation and erosion. The terraces have been warped downward toward the gulf and uplifted to the north (Fisk, 1956). The surface materials of these deposits are characterized by the following:

(1) They are very stiff, shear strength normally exceeds 1000 psf.,

(2) The moisture content is low at the terrace surface,

(3) They are commonly oxidized and are typically reddishbrown, tan, or yellow in color,

(4) They commonly contain calcareous concretions or iron oxide bands.

Three of the sampling sites selected were located in these soils; the Lake Charles site, the Baton Rouge site and the Benton site. The Lake Charles site, in southwest Louisiana (Sec. 30, T. 9S., R. 7W.) was in an area where extensive excavation was in progress. The excavated soil was being used as a fill material for the I-10 highway embankment. In the pit, three distinct zones or layers could be seen and the beginning of a fourth in some areas. The top three zones were fissured throughout. The soil in the bottom or fourth zone was more uniform and did not appear to be dessicated. The open: 
pit made it possible to obtain hand-cut samples in the deeper material. The Benton site, located in northwestern Louisiana is also located in soil of the Pleistocene Prairie Terrace. The material consists of a stiff fissured brown clay overlain by approximately five feet of a soft clay. The Baton Rouge (Sec. 82, T. 7S., R. 1E.) samples also consisted of stiff brown fissured clay from the Pleistocene Prairie Terrace.

The other sampling sites were in more recent materials of alluvial origin. The engineering significance of alluvial deposits has been discussed by Kolb and Shockley, 1957. The clays exhibit a high plasticity, high natural moisture content, very compressible and a low strength, especially in the youngest soils. These soils provide a poor foundation for road embankments, levees and flood control structures. In order to distribute the load properly and obtain a stable structure deep foundations are often required for bridges and multistory buildings. Six of the sites are situated in these alluvial soils. They include the Houma, Morgan City, Larose, Erwinville, LaPlace and Monroe sites.

The Houma, Morgan City and Larose sites are within Recent Deltaic Plains, figure 29, of southeast Louisiana. The Erwinville site is northwest of Baton Rouge (Sec. 23, T. 6S., R. 10E.), located in a backswamp area. Many cypress tress and roots are found throughout this area.

The LaPlace site, northwest of New Orleans (T 11S., R 8E.), is located in an area where the depositional environment is that of alluvial floodwaters in combination with the brackish waters of Lake Pontchartrain. The Soil consists of layres of soft clays and silts 


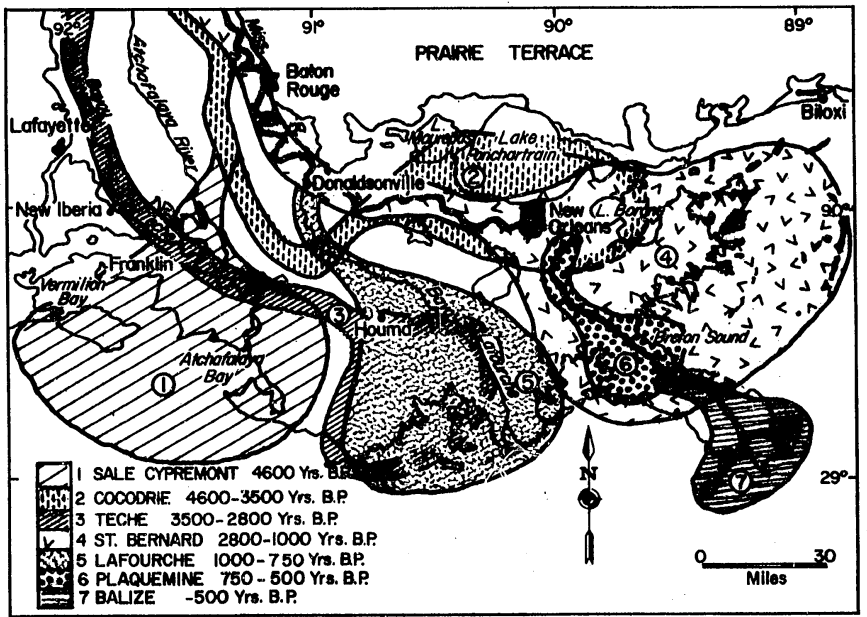

FIGURE 29 SUCCESSION OF MISSISSIPPI DELTAS

After Kolb and Ven Lopik, 1968. 
with scattered shells and organic material present.

The Monroe site is situated in the alluvial fan of the Quachita River in northeast Louisiana. The soils are stiff fissured silty clays. 
CHAPTER VI

SAMPLING AND TESTING PROGRAM

In order to isolate and determine the effects of sampling, several different sampling techniques and sample sizes were used in this study. These included what is nomally considered to be the best samples (i.e. block or hand-cut samples), thin-wall piston samples, thin-wail open drive samples ( $3^{\prime \prime}$ O.D. and $5^{\prime \prime}$ O.D.), and thick-wall open drive samples. The sampling was conducted through the cooperation and assistance of the Louisiana Department of Highways.

\section{Block Samples}

Block samples are not among the conventional types normally taken. They do offer a sample of high quality and one which can be used as a standard in a study of relative sampling disturbance.

Due to the problems of a normally high water table, the inavailability of excavating equipment and shoring requirements, block samples were not taken at all sampling sites. Block samples were taken at two of the sampling sites, however. These included the Lake Charles and Erwinville sites where the inplace material was being excavated and equipment was available.

At the Lake Charles site, samples were taken at depths of 15, 27 and 30 feet below ground level. Material from the site was being excavated for a highway embankment fill. A multi-level pit with several terraces had been dug. The deepest part of the pit was approximately 20 feet in depth. The pit was for the most part kept dry by pumping. 
A backhoe was used to excayate the surface material and to form a bench from which the block sample would be taken. Using the bucket of the backhoe, a trench, three feet deep, was dug on two sides of an 18 to 24 inch wide bench of soil. Then using shovels; knives and at the $15 \mathrm{ft}$. level, chain saw, a column of soil was isolated. After removing approximately 6 inches of the more disturbed soil along the edges, a $12^{\prime \prime} \times 12^{\prime \prime} \times 12^{\prime \prime}$ cube was produced. The top of the sample was marked and the exposed surfaces were wrapped in aluminum foil and waxed. Several layers of aluminum foil and wax were applied to the sample. The thickness of the waxed wrapping exceeded a quarter of an inch. The sample was identified and marked. An open ended plywood box was then placed around the sample, Figure 32. The inside dimensions of the box were $14^{\prime \prime} \times 14^{\prime \prime} \times 14^{\prime \prime}$. The annular space between the box was filled and packed with saw dust. The top cover was then placed on the box. Then using a sharp shooter shovel, the column of soil was disengaged from the parent material below the bottom of the box. The box with the sample was turned upside down and the bottom was trimmed, wrapped and waxed. The bottom of the box was then secured. The sample and the box number were logged in a field book.

At the $30 \mathrm{ft}$. depth, one cubic foot and smaller samples were taken. The smaller samples ranged from 10 inches to 6 inches on a side. These were wrapped and waxed as the larger samples, but were placed in styrofoam ice chests and packed with saw dust.

The second site where block samples were taken was Erwinville. This site is within the Big Riyers Industries Complex where lightweight aggregate is produced. Two block samples were taken at approximately the 


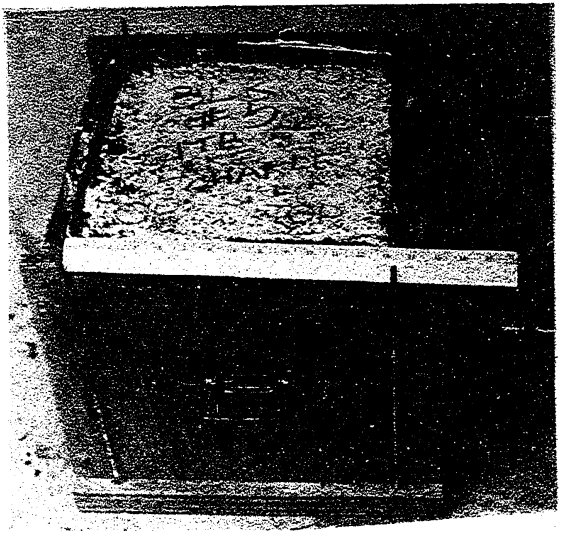

Figure 30 - Block Sample Packaging and Storage Method 
$6 \mathrm{ft}$. depth. The techniques used were the same as Lake Charles except that a dragline unit was used on the initial excavation. Block sampling in the Erwinville soil was yery difficult due to the multiple slickenslided nature of the material and the many roots present.

\section{Osterberg Samplers}

The 0sterberg sampler, Figure 7 , is a hydraulically operated, fixed-piston sampler. It is used locally as a means for obtaining samples in soft soils which cannot be secured by the more cormon shelby tube. The sampler size used by most comtrercial firms and the Louisiana Department of Highways is three inches in diameter. The Osterberg samplem was used at one sampling site in this study.

\section{Thin-Wall, Open-Drive, Shelby Samples}

The most common means of obtaining undisturbed samples in Louisiana is the 3-inch thin-wall Shelby tube. In the initial stages of this study, the thin-wall sampler used did not have a sharp cutting edge, nor was inside clearance provided. This is one of the common types of thin-walled tubes used in Louisiana. Later sampling tubes used hac dimensions which conformed to ASTM D1587-67. These were 3-inch $(76.2 \mathrm{~mm})$ diameter core barrels, with 0.065 inch $(1.65 \mathrm{~mm})$ wall thickness, and 36 inch $(0.96 \mathrm{~m})$ in length. In addition, there are four $1 / 4^{\prime \prime} \times 1 / 4^{\prime \prime} \times 4^{\prime}$ lugs welded near the cutting edge which is a deviation from ASTM requirements. Since much of the soil in Louisiana is somewhat soft, the hole is advanced and reamed out by rotating and washing through the sampler tube. This is the purpose of the lugs. Some of the commercial firms use lugs which extend beyond the cutting edge. Once the 


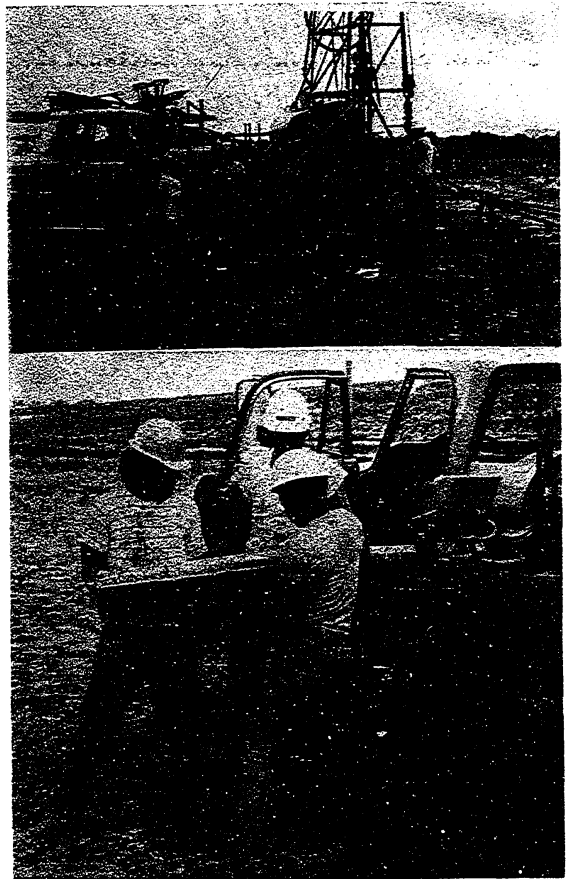

\section{Figure 31 - Truck Mounted Drilling Rig (Upper) and Field Extrusion of Sample (Lower)}


hole is at the desired depth, the sampler is placed on the bottom and the sample is taken by a straight continuous push.

For the purpose of comparison, a 5-in. 0.D. sampler was also used. This size sample is commonly used by the corps of Engineers, but is an uncommon size for the Louisiana Dept. of Highways and for most commercial firms in this area. The borehole was advanced by means of a fish-tail bit, followed by sampling with the 5 -in. shelby tube.

\section{Standard Penetration Test and Samples}

Sampling was also done in conjunction with the standard penetration test, ASTM 1586-67. These samples are taken with a thick-wall split barrel sampler and with percussion driving. In this study, these samples were used for moisture contents, classification tests and in the stiff soils were used in unconfined compression tests as a somewhat lower bound value for sample quality.

\section{Handiing and Storage Techniques}

All tuhe samples taken for this study were secured by personnel and equipment of the Louisiana Department of Highways. Undisturbed samples were, for the most part, extruded in the field using normal operating procedures as practiced by L.D.H. The major difference between these techniques and some of the commercial firms, involves the method and direction of extrusion as discussed below.

As part of a study on the effects of extruding, a number of 3-in. samples were sealed in shelby tubes and sent to the laboratory for testing. Some of these were extruded and tested in the lab immediately, 
others were stored in a moisture room for later extrusion and testing. Methods used for packaging the field extruded samples also varied somewhat. The three inch extruded samples were identified in the field and wrapped with a plastic and an aiuminum foil sheet. The wrapped sample was then placed in a specially made styrofoum box, Figure 4 . The box is taped shut and marked for identification. In the initial phases of this study, only aluminum foil was used for wrapping the sample. In later sampling, the samples were first wrapped in plastic.

The five inch shelby tube samples are not commonly used in Louisiana. Initially, the samples were extruded in the field, cut into 9 or 10 inch lengths and wrapped in aluminum foil. They were then placed in an open-ended metal cylinder, with an inner rubber membrane, Figure 33. The membrane was then inflated with air to give a snug fit around the sample. The ends were then capped with 6" $\times 6^{\prime \prime}$ wooden boards which were held in place with threaded rods. In the later phases of this study, the five-inch samples were wrapped in saran wrap, aluminum foil and coated with a thin layer of wax. The ends of the sample were then placed in two half-gallon cartons.

After field extrusion and packaging, the samples were placed in a utility truck for transport back to the lab. Normally, the maximum length of time that any sample will be stored in a truck is five days. During this study, the length of storage time in the truck did not exceed three days.

Those samples which were not tested immediately were placed in a $100 \%$ humidity room. Most of the laboratory testing on undisturbed samples was completed within two weeks. In order to determine the effects of 


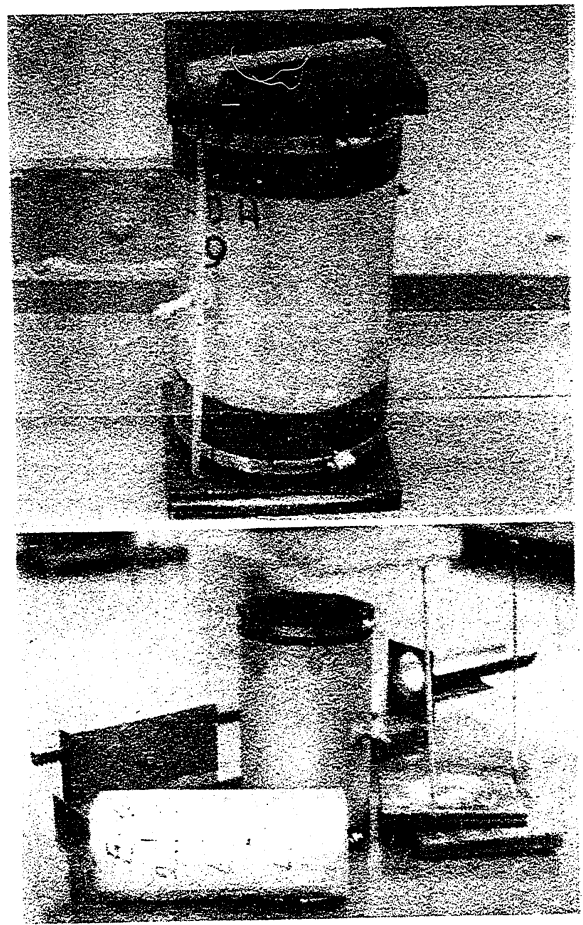

Figure 32 - Five Inch O.D. Sample Packaging and Storage Method 
long term storage, a number of the samples were set aside for testing at a future date. This was done primarily to study the effects of storage time on the moisture content, strength of the specimens, as well as any chemical changes which may occur.

\section{Testing Program}

Approximately 1800 samples were taken during this study. In excess of 6500 laboratory tests were conducted. In addition to laboratory tests, over 1700 in-situ tests were conducted.

The engineering properties of the undisturbed samples were determined using conventional test procedures and equipment. These included the undrained compressive strength (unconfined and triaxial), consolidation tests, classification tests, field and laboratory vane tests and the standard penetration test.

The unconfined compressive strength (U), ASTM D 2166-66, and the unconsolidated-undrained (UU), ASTM D 2850-70, tests were used in testing the sample's strength. Evaluation of the undrained shear strength is generally required for most in-place foundation analysis. Therefore; an evaluation of sampling effects on these tests were of major interest. A strain rate of $0.05 \mathrm{in./min.} \mathrm{was} \mathrm{used} \mathrm{and} \mathrm{in} \mathrm{most} \mathrm{cases} \mathrm{failure} \mathrm{oc-}$ curred within ten minutes. In the UU test, a chamber pressure equal to the effective overburden stress was used.

Sample sizes used included, $2.8 \mathrm{in}$. and 1.4 in. diameters for undisturbed samples and $2.5 \mathrm{in.}$ and $1.4 \mathrm{in}$. diameters for remolded samples. A height to diameter ratio of two or greater was used. Remolding was accomplished by completely destroying the structure of the specimen (by hand kneading) and then by placing the soll in a 2.5 in. diameter cylinder. 
It was loaded with a static load, forming a cylindrical soil specimen. This procedure resulted in producing specimen with moisture content and density similar to that of the original specimen $( \pm 5 \%)$. Some of the stiffer soil was very difficult to remold, so in some cases the highly disturbed spiat spoon samples were used in leiu of complete remolding.

The one-dimensional consolidation test, ASTM D 2435-70, was run on samples from five of the sampling sites. Results of this test also provide additional information for analyzing the strength tests. Two diameter sizes of oedometers were used, 2.5 and $4.4 \mathrm{in.} \mathrm{Both,} \mathrm{the}$ fixed and floating ring oedometer were employed. Ring height varied from $3 / 4$ in. to 1 in.

Classification tests included the liquid and plastic limits which were determined according to ASTM D 423-66 and D 424-59. In preparing the samples for classification tests, the ASTM D 2217 procedure was foilowed. Particle size analyses was conducted by the ASTM D 422-63 procedure.

Field tests conducted were the standard penetration test and the field vane test. The ASTM D 1586 procedures were used in conducting the standard penetrazion test. The field vane test was made with the Nilcon vane borer according to ASTM D 2573. The test was conducted in a borehole in stiff soils. For recent alluvial soils, it was possible to push the vane to the desired depth without using a borehole. The speed of rotation in testing was approximately 6 degrees per minute.

A series of tests oriented for studying the effects of extruding, storage and lengthwise sample variation was conducted on a number of 3-inch shelby samples. The soil samples were taken by Louisiana Dept. 


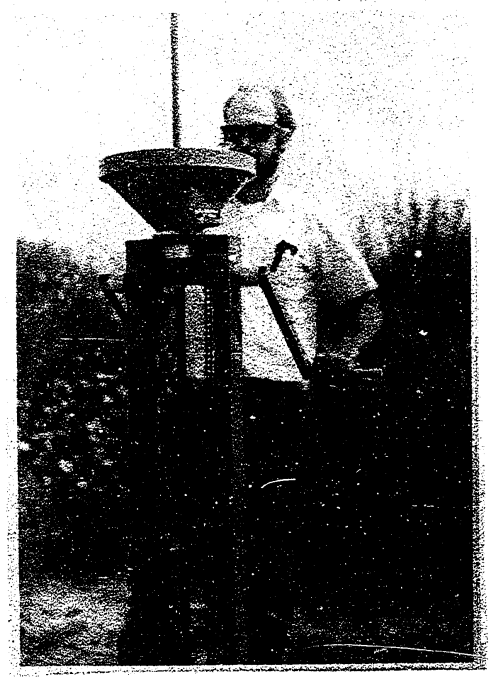

Figure 33 - Field Vane Test with Nilcon Vane Borer 
of Highway field crews and delivered to the L.S.U. Soils Laboratory in the sample tube with the ends sealed. Some of the samples were extruded and tested as soon as receiyed, others were stored in the $100 \%$ humidity room for future testing.

Prior to extrusion, the seals were remoyed and the sample length in the tube was measured. The force required to extrude the samples was originally measured by means of a load cell. It was later found possible to obtain steadier, more consistant measurements by reading gage pressure on a hydraulically operated pump, Figure 34 . The extruding force was increased slowly until the maximum load was reached. Movement of the sample was measured at both ends, using extensionmeter gages. The measurements obtained gave the sample movenent corresponding to an extruding force. After removal from the sampler tube, the extruded. length was measured and the sample cut into segments for engineering tests and/or $X$-ray radiographs.

The effect of leaving the core samples in a utility truek over a period of days with temperatures exceeding $100^{\circ} \mathrm{F}$ was simulated in the lab. Sections of undisturbed cores were renoved and an initial moisture content, ASTM D 2216, was determined. The remaining portion of the core was rewrapped using the methods employed by L.D.H. The sample was then placed in a styrofoam box and taped. The boxes were put in a laboratory oven set at $110^{\circ} \mathrm{F}$ for a period of five days. This was to simulate a like storage period and conditions in a utility truck such as might occur in the summer months. At the end of the five-day oven storage, the samples were removed and moisture contents were determined. Variation from the initial values were compared with test results of the natural 


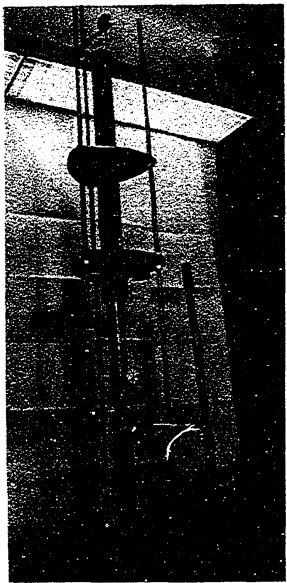

Figure 34 - Extrusion Test Set-Up 
variation of simitar soils.

The results of engineering tests on the Lake Charles samples from the $30 \mathrm{ft}$. depth indicated a brittle material and cementation was suspected. Thus, Materials Evaluation Laboratory, Inc. of Baton Rouge, La. was commissioned to conduct a study of the micro-structure of the soil from this area and depth. The scanning electron microscope and an energy dispersive $X$-ray microprobe (SES-EDS) were used in performing a microanalysis of the soil. The SEM-EDS photographs provide elemental distribution maps which show where chemical species occur and their associations. The methods and techniques used are given in the appendix A. An identification of the major clay minerals present in the Lake Charles soil was also made using X-ray diffraction.

Mechanical disturbance of soil samples was studied using the methods of slow drying and $X$-ray radiography. In the slow drying method, the sample is sliced and set aside for some period of time. Eventualiy, as the sample dries, a point is reached where the color or tone variation between layering becomes most distinct. At this point, structural details of the sample and disturbance can be better observed visually. A more recent method for studying soil structure, which was used in this study, is X-ray radiography. It is possible to observe discontinuities such as fissures or shear planes. Several different radiographic techniques were used in a study of structural disturbance. Radiographs were made of (1) soil cores in the 3-in. shelby tube prior to extruding, (2) extruded cores, and (3) core slices. Due to roundness, edges of the unsliced samples are not clear. In order to enhance the edge layering, some of the extruded cores were packed in a fine clay 
filler. This compensated for the decrease in sample thickness near the edges. Details of the equipment used, film, time and instrument settings used are given in Appendix B. 
CHAPTER VII

\section{TEST RESULTS AND DISCUSSION}

As was noted by Hvorslev (1949, p. 205), it is very difficult, if not impossible, to arrive at definite conclusions concerning sample disturbance when dealing with natural soils. Not only do the geology of geographic sites vary but the random soil structure of the individual site results in a wide yariation in properties. This fact, which for soils is the rule rather than the exception, has been expressed and documented by many authors. In this study, the lack of homogeneity of Louisiana soils was also a fact to be reckoned with. As an example, Figure 109 of Appendix $C$ shows the variation of moisture content within two cores from the Lake Charles sampling site. Visually, the soil from the depths represented by ti:ese cores appeared to be fairly homogenous. However, the variation in moisture content, in the horizontal and vertical direction does seem significant. So, it can be seen that in the evaluation of test data, consideration must be given to several parameters. In comparing test data in this study, the depth, distance between boreholes, grain size results, atterberg tests and the natural moisture content were all taken into consideration for comparative studies.

The overall effect of soil sampling on the engineering properties of Louisiana soils, no matter how random these properties, was the objective of this study. Therefore, the sampling sites were chosen because the soil at these locations was typical or representative of soils in different parts of the state, Figure 30 . These sampling sites 
are beleived to be typical of soils found oyer wide areas in Louisiana and the neighboring Guif Coast states.

\section{LAKE CHARLES SITE}

\section{Location}

The largest number of samples and duplicate samples was secured in an area east of Lake Charles, Louisiana.

At the time of sampling, the area was being excayated for use as a fill material in the I-10 highway construction. The excavation depth was approximately twenty-two (22) feet. The natural grade elevation is approximately fifteen (15 ft. MSL) above mean sea level in this area.

\section{Geology}

A11 samples were obtained from the Pleistocene Prairie Terrace, Figure 30. The soil was oxidized to a depth of twenty-four (24) feet below ground. There were five distinguishable zones or strata, Figures 35 and 36.

The soil from the surface to approximately a nine foot depth was composed of a mottled, yellow and gray silty clay with $1 / 8$ inch iron oxide pellets. From a depth of nine to fifteen feet, the material consisted of a stiff red fissured clay. In some areas burrowing animals had formed a network of channels which had been filled with a clean white medium sand. In other areas, red silt pockets were common. Many slickensides were observed in samples from this depth.

Between fifteen and twenty-seven to thirty feet, a fissured, stiff, gray streaked, brown, silty-clay was found. The gray appeared to be 
STANDAFD

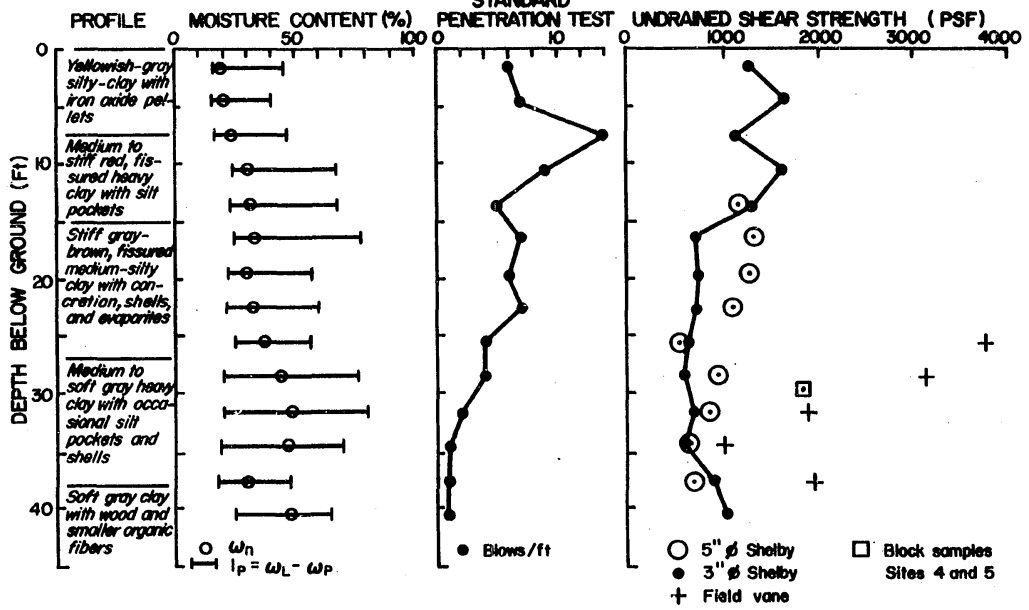

FIGURE 35 SUMMARY PROFILE - LAKE CHARLES (SITES I, 2, AND 3 ) 


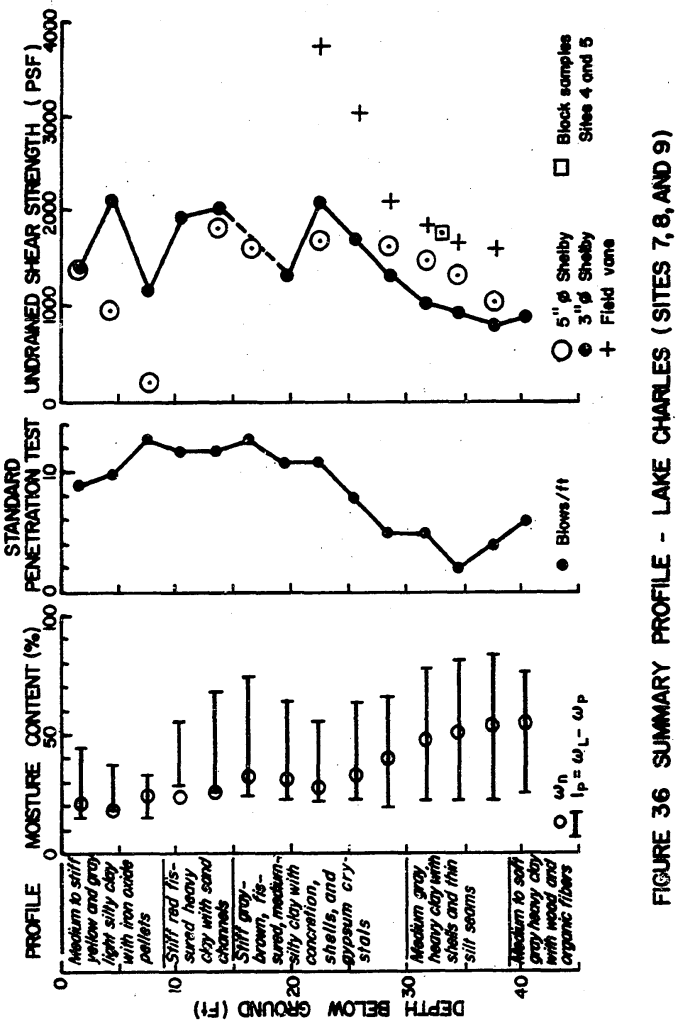


material which had filled fissures formed in the brown during periods of extreme dessication. Failure along a gray seam or plane was common. A natural slide which had occurred along an excavated pit was blocky in ñature with failure occurring along gray fissure planes.

Gypsum crystals were abundant at a depth of fifteen feet.

Below twenty-seven or thirty feet, a fairly uniform, medium, gray clay was encountered. It contained, however, thin silt seams, isolated silt pockets and shells within the clay matrix. Below thirty-nine feet, the gray clay contained wood and organic fibers.

The type of shells found were those common to a marine bay environment. They included; crassostrea, mercenaria, mulinia and the most common was the rangia cuneata. Most of these occurred at depths between fifteen and thirty-nine feet.

An X-ray diffraction analysis with oriented slides was conducted on specimens from the twelve and thirty-three foot depths. The X-ray diffractogram of the thirty-three foot depth is shown in Appendix A, Figure 106. It is typical of the results from the twelve foot depth, also. The major clay minerals present are montmorillonite and kaolinite.

A microanalysis of the soil fabric and presence of cementitious compounds was also conducted on samples from the thirty foot depth and is presented in Appendix A. The results of this study showed there to be an abundance of pyrite crystals. This has resulted in a disruption of the bedding producing a more homogeneous but irregular fabric.

This possibly explains the brittle-like nature of the clay at this depth. Unlike some of the more sensitive Canadian clays, the Lake Charles material had a liquidity index of approximately 0.5 and does not become 
"quick" or liquid with the complete breakdown of the clay particle structure. Perhaps this is because a large portion of the space between clay particle voids is occupied by the pyrite crystals. Thus the diagenetic crystal growth creates an irregular and somewhat unstable clay structure, but prevents the moisture in the voids from exceeding the liquid limit of the clay.

\section{Sampling and Field Tests}

Sampling and field tests were conducted at a number (10) of the sites within the Lake Charles sampling area. Sampling consisted of 3-in. shelby tubes, 5-in. shelby tubes, and block samples. Continuous tube samples were taken to a depth of forty-two feet. Hand-cut block samples were taken at four sites, ranging in depths of $15 \mathrm{ft} ., 27+\mathrm{ft}$. and $30 \div \mathrm{ft}$. below ground.

Field testing consisted of the standard penetration test and the field vane test. The SPT test was performed at three foot increments from natural grade to a depth of forty-two feet below ground. The insitu vane shear strength was determined between a depth of twenty-four and forty-two feet. Representative test values for the Lake Charles site are shown in Figures 35 and 36.

An examination of Figures 35 and 36 demonstrates the effects of the soils properties, sample type, sample size, and storage time on the peak strength of the soils encountered. Samples from sites 1, 2, and 3 were tested after long storage periods (i.e., exceeding 3 months). For the most part, samples from sites 7,8 , and 9 were tested within one to fourteen days after sampling. 


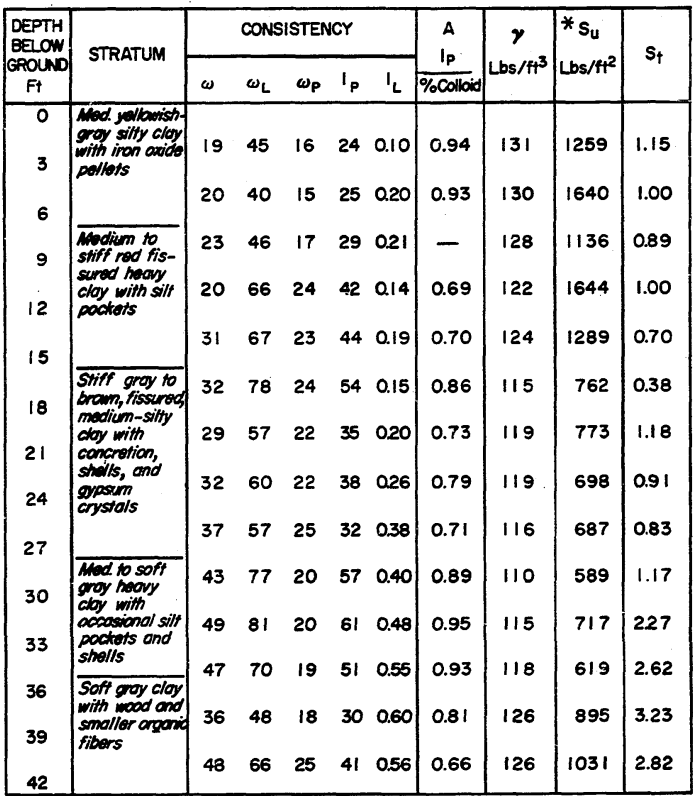

* 3" $\varnothing$ Shelby tube somples

TABLE 4 TYPICAL SOIL PROPERTIES-LAKE CHARLES SITES I,2, AND 3 


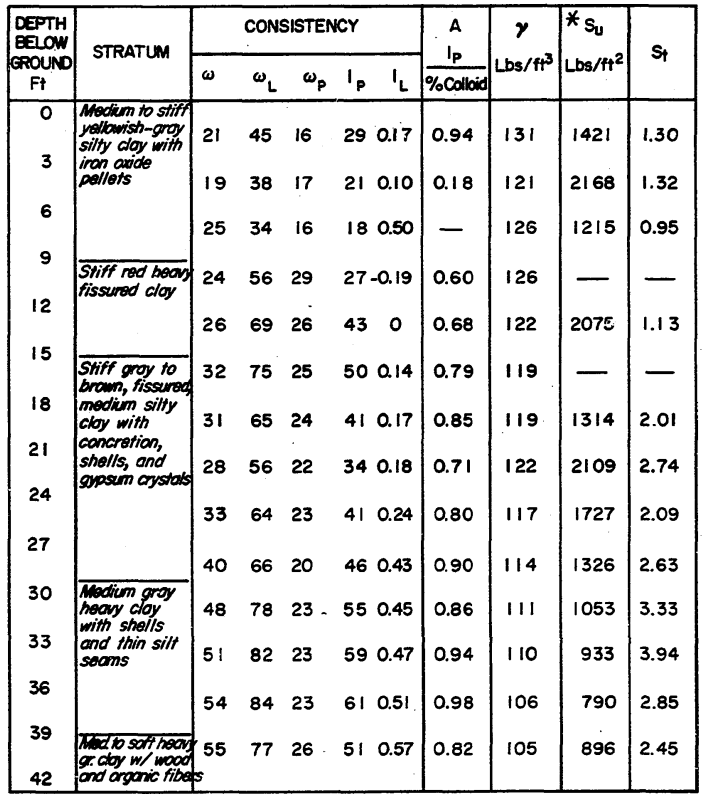

$* 3^{\prime \prime} \varnothing$ Shelby tube somples

TABLE 5 TYPICAL SOIL PROPERTIES-LAKE CHARLES SITES 7,8, AND 9 
The response of the in-situ soil to sampling is a function of the sampling technique and, also, it is directly related to the consistency and structure of the soil. In the upper stratas ( 0 to $27 \mathrm{ft}$.) the secondary structure consisting of fissures and slickensides was found to have the greatest influence on the soil strength. The effect and degree of structural disturbance which occurred during sampling varied according to the sample size and technique. In general, however, the strength of the 3-in. shelby tube sample exceeded that of the five inch diameter. Block samples secured at the $15 \mathrm{ft}$. depth failed along fissure planes during attempts to trim down to a smaller size, Figure 37. This was attributed to stress release and possibly migration of moisture toward and along the fissure planes.

The relationship between the test results from different sample types appears to vary. For example, above the $27 \mathrm{ft}$. depth, undrained shear strength of the five inch tube samples at sites 7,8 and 9 are somewhat smaller than those found from tests on three inch shelby tube samples. Below $27+$ depth, the five inch shelby tube specimen strength is greater than that of the 3-in. shelby specimen. The techniques used for the two sample sizes was the same from the ground surface to the deepest sample obtained. The response of the in-situ soil to sampling is a function of the sampling technique and also, it is directly related to the consistency and structure of the soil. The secondary structure of the soil from the surface to $27 \mathrm{ft}$. or $30 \mathrm{ft}$. consisted of many fissures and siickensides, Figure 38.

Sampling with the smaller shelby tube (3-in.) has a tendancy to increase the shear strength over that obtained with the large diameter tube 


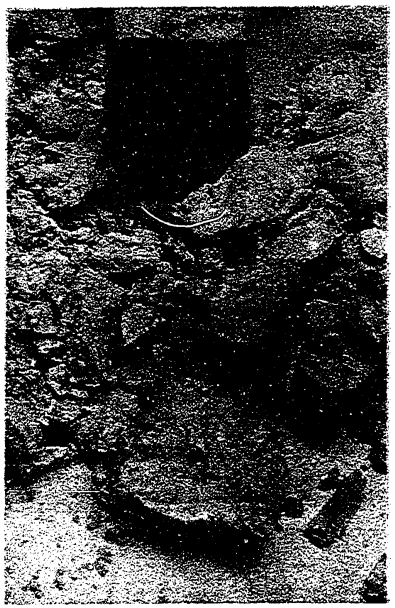

Figure 37 - Lake Charles Site, Fissured Block Sample - 15 Ft. Depth 


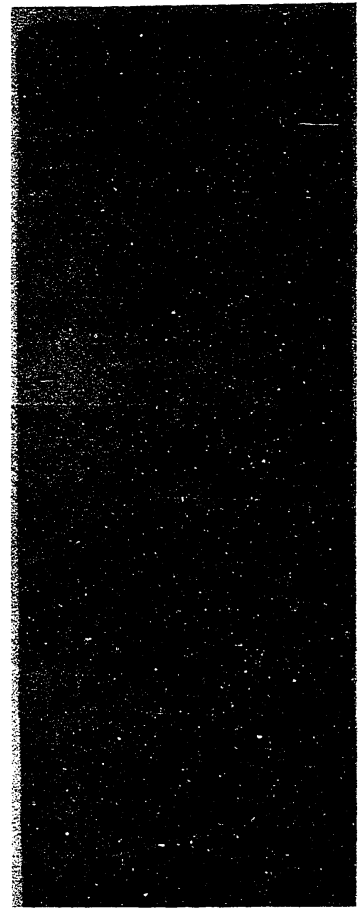

Figure 38 - X-Ray Radiograph of Si ice From 3" O.D. Sample Showing Fissures - Lake Charles, 9-12 Ft. Depth 
in the upper fissured stratas, Figure 36. This is attributed to remolding effects of the fissures in the soil. In several cases, the remolded shear strength exceeded that of the undisturbed strength (note the $S_{t}$ values in Tables 4 and 5 ).

The effects of prolonged storage, however, seem to be greater on those samples experiencing the greatest degree of structural disturbance or remolding (i.e., 3-in. O.D.). The samples from sties 1, 2, and 3 were tested after long storage periods (i.e. 3+ months). Those from sites 7,8 , and 9 were tested within 15 days. There is a greater reduction with time of the strength for the 3-inch samples as compared with the 5-inch samples, Figure 35 and 36. Krinitzsky (1970) observed by means of radiographs that "stratification and the pre-existing fractures and voids contributed to a disintegration of specimen."

At the $30 \mathrm{ft}$. depth below ground, the material consisted of a medium to soft gray clay. Silt seams, silt pockets and shells suspended in the clay matrix were also present. However, the strength was determined by the clay with failure occurring along a thin shear plane at an angle of $45^{\circ}$ to $50^{\circ}$ from the horizontal. Approximately fourteen block samples were taken from sites 4 and 5 at this depth.

To verify the validity of comparing the test results from sites 4 and 5 to those samples taken from sites 7, 8, and 9, a statistical analysis was conducted, Appendix $C$. In this analysis, the natural moisture content, $w_{n}$, the liquid limit, $w_{1}$, and the percent clay, $\% c l$, were compared. The results indicates that blocks obtained from sites 4 and 5 at a depth of $27+$ and $30+$ respectively, correspond to the $30 \mathrm{ft}$. 
to $36 \mathrm{ft}$. depth at sites 7,8 , and 9 . Thus indicating a dip in the soil strata toward the southwest.

Once the validity of comparing the samples was established, a statistical analysis was used in comparing the peak strength test results from different samples. The results of the analysis is as follows:

\begin{tabular}{|c|c|c|c|}
\hline Depth & $3^{11 \phi}$ & $5^{\prime \prime} \phi$ & Block \\
\hline $30^{\prime}=36^{\prime}$ & 1980 psf & 2892 psf & $3593 \mathrm{ps}$ \\
\hline
\end{tabular}

The 3-inch shelby sample had an average strength of $55 \%$ that of the block or a $45 \%$ reduction as a result of sampling techniques and size. The average 5-inch shelby sample had a strength of $80 \%$ that of the block or a $20 \%$ reduction as a result of the sampling operation. The average strength test results on block samples were equal to the inplace vane shear strength.

The sensitivity of this clay, according to the sample type is

$\begin{array}{llll}\text { Depth } & 3^{\prime \prime} \phi & 5^{\prime \prime} \phi & \text { Block } \\ 30^{\prime}-36^{\prime} & 2.9 & 4.2 & 5.2\end{array}$

An investigation based on test data from the commonly used 3-inch diameter shelby tube would indicate a moderately sensitive soil. Using larger samples, (i.e., 5-in. diameter shelby and block samples), the clay is seen to be a sensitive soil.

A comparison of the effects of sample tube size for sites 7,8 , and 9 is given in Appendix $C$ and is reviewed here: 


\begin{tabular}{|c|c|c|}
\hline Depth & 3"d & $5 " \phi$ \\
\hline $27-30$ & 2652 psf & 3275 psf \\
\hline $30-33$ & 2105 & 2995 \\
\hline $33-36$ & 1865 & 2651 \\
\hline $36-39$ & 1580 & 2052 \\
\hline
\end{tabular}

Typical stress-strain curves are presented in Appendix C. The shape of the stress-strain curves was influenced to a degree by the magnitude of the confining stress, $\sigma_{3}$, Figures 39 and 40 . In most triaxial tests performed on tube samples obtained from the thirty foot depth, the stress-strain curve consisted of a steep initial modulus extending from the origin to a point or knee where it changes to a less steep curve until a peak load was reached and the load dropped off, Figures 41 and 42 . This shape was most pronounced in the three inch samples and somewhat less in the five inch samples. The triaxial tests on the block samples produced a very steep, brittle stress-strain curve, Figures 41 and 42.

Unconfined tests did not result in this unique shape for the stressstrain curve of any sample, Figure 43 . Thus the shape of the triaxial stress-strain curve is believed to be the results of partial structural damage to the soil from sampling. The additionai iateral support of the confining stress helps to prevent, initially, the movement and rearrangement of the soil particles whose contact points have been disturbed while sampling ard are less stable. A fabric study of the soil indicated a tendency toward an unstable open structure arrangement of particles, Appendix A. This being the result of diagenetic growth of pyrite 


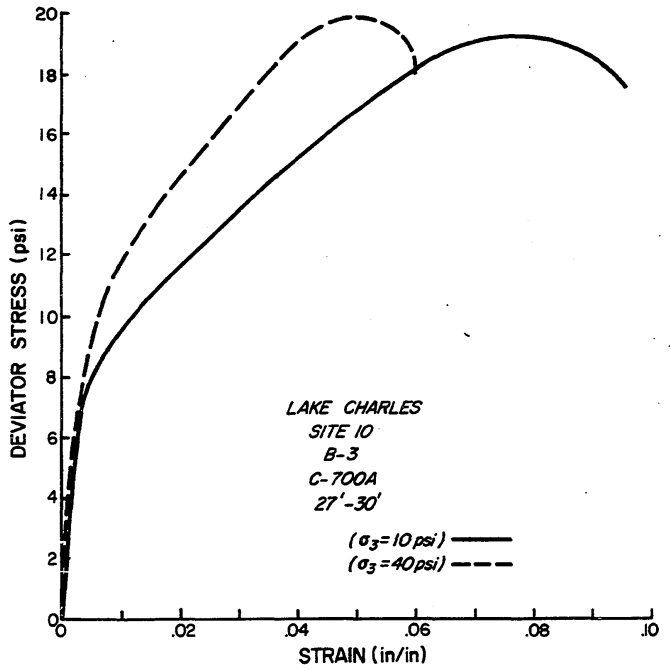

FIGURE 39 CONFINING PRESSURE INFLUENCE ON UNCONSOLIDATED - UNDRAINED TEST 


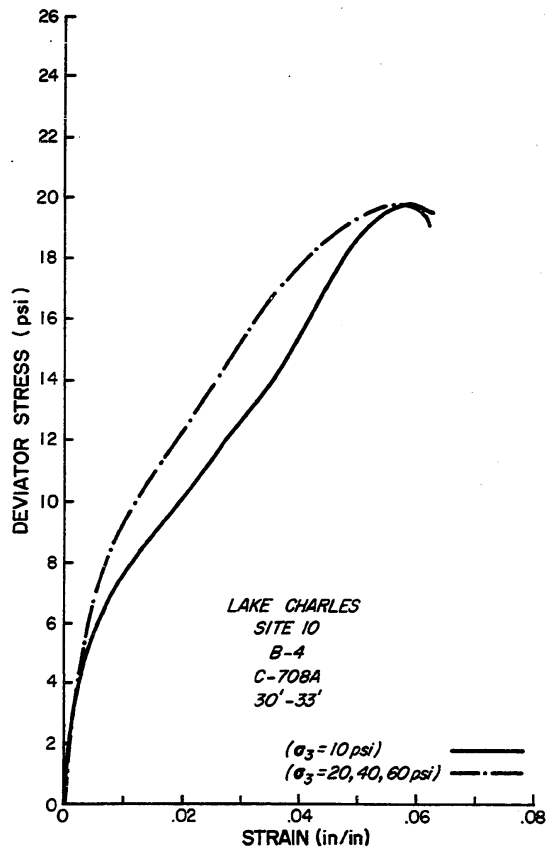

\section{FIGURE 40 CONFINING PRESSURE INFLUENCE ON UNCONSOLIDATED-UNDRAINED TEST}




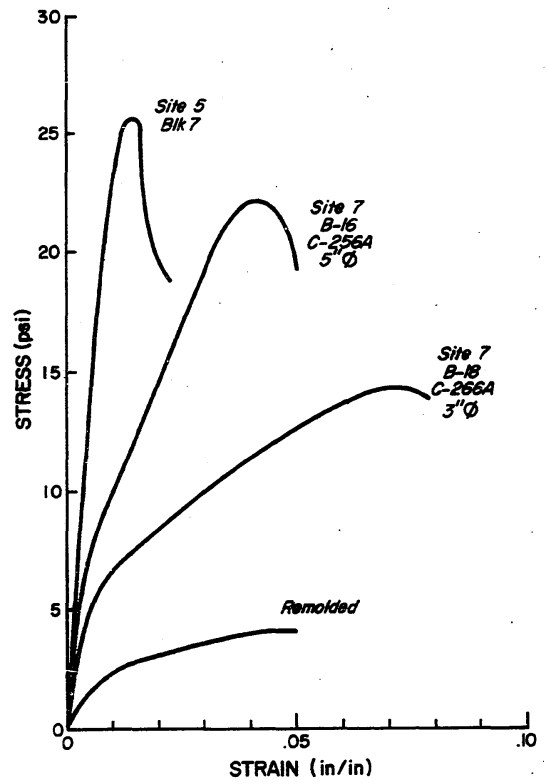

FIGURE 41 TYPICAL STRESS STRAN CURVES FOR TRIAXIAL UNDRAINED COMPRESSION TEST LAKE CHARLES-30' DEPTH 


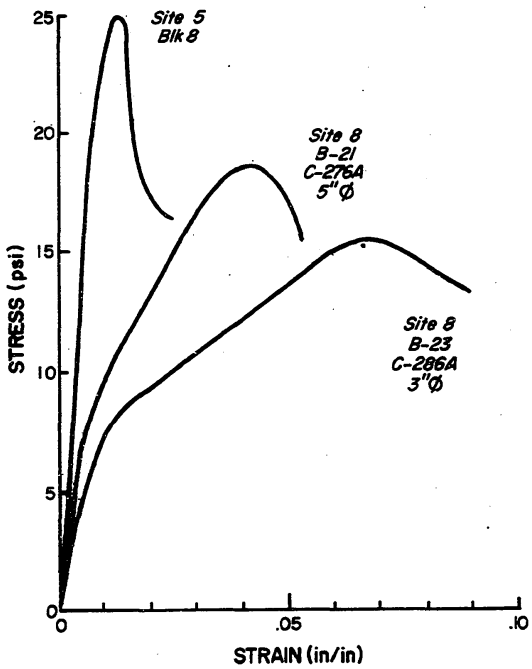

FIGURE 42 TYPICAL STRESS-STRAN CURVES FOR TRIAXIAL UNDRANED COMPRESSION TEST LAKE CHARLES- 30' DEPTH 


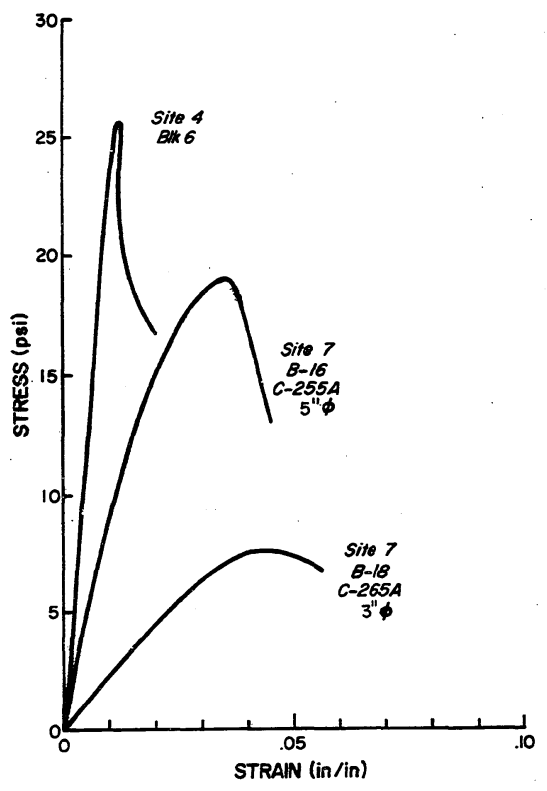

FIGURE 43 TYPICAL STRESS-STRAIN CURVES FOR UNCONFINED COMPRESSION TEST LAKE CHARLES-27'-30' DEPTH 
crystals in between the particles. In sampling, some percentage of these contacts are disturbed and particles are rearranged. As the load is applied, the point of contact between particles which have been disturbed is not as stable as those between the undisturbed particles. A confining pressure has the effect of preventing particle movement and results in a steeper modulus for the initial parts of the curve. A confining pressure provides a greater modulus in all cases, however, Appendix $C$. Thus the distribution and transfer of load within the tube sample varies from that of the undisturbed structure in that it is more of a gradual break-down of the structure. Failure of the block sample occurred at small strains (i.e., within $1 \%$ to $2 \%$ ) under loads larger than that of the tube samples. Failure was always along a distinct plane making an angle of $45^{\circ}$ to $50^{\circ}$ from the horizontal. Figure 44 . This would indicate a sudden collapse of the structure.

Two specimen, 1.4 inches in diameter, from a block sample were tested. One of these was trimmed with a wire saw. The other was cut to size by pushing a tube with a sharp cutting edge through a segment of the block sample. The results of the tests on these samples and that of a remolded sample are presented in Figure 45. The peak strength of the specimen trimmed with the tube was reduced by more than $30 \%$ that of the sample trimed with a wire saw and the stress-strain relationship was similar to those tube samples obtained in the field (i.e. a reduction of the modulus of deformation.

Typical oedometer compression curyes for some of the individual samples tested are presented in Appendix C. Figure 46 is a comparison of the performance of different sample types in the consolidation test. 


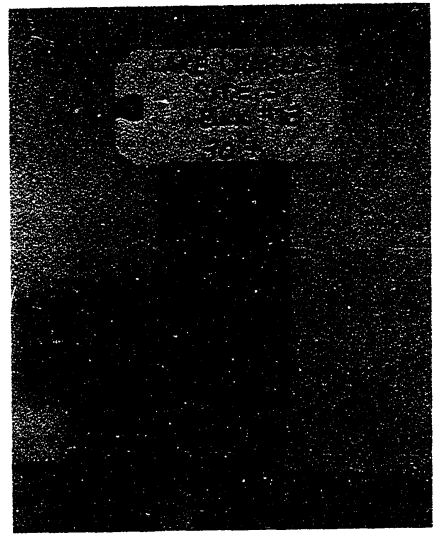

Figure 44 - Specimen From Block Sample Showing Failure P.lane 


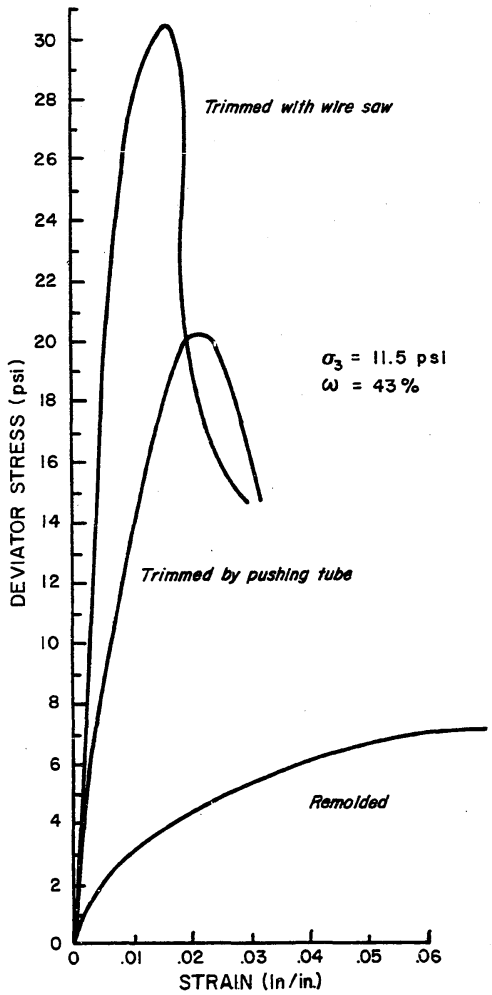

FIGURE 45 TRIAXIAL COMPRESSION TEST ON BLOCK SAMPLES, LAKE CHARLES, SITE 4, BLK NO. 5, 27 FT. DEPTH. 


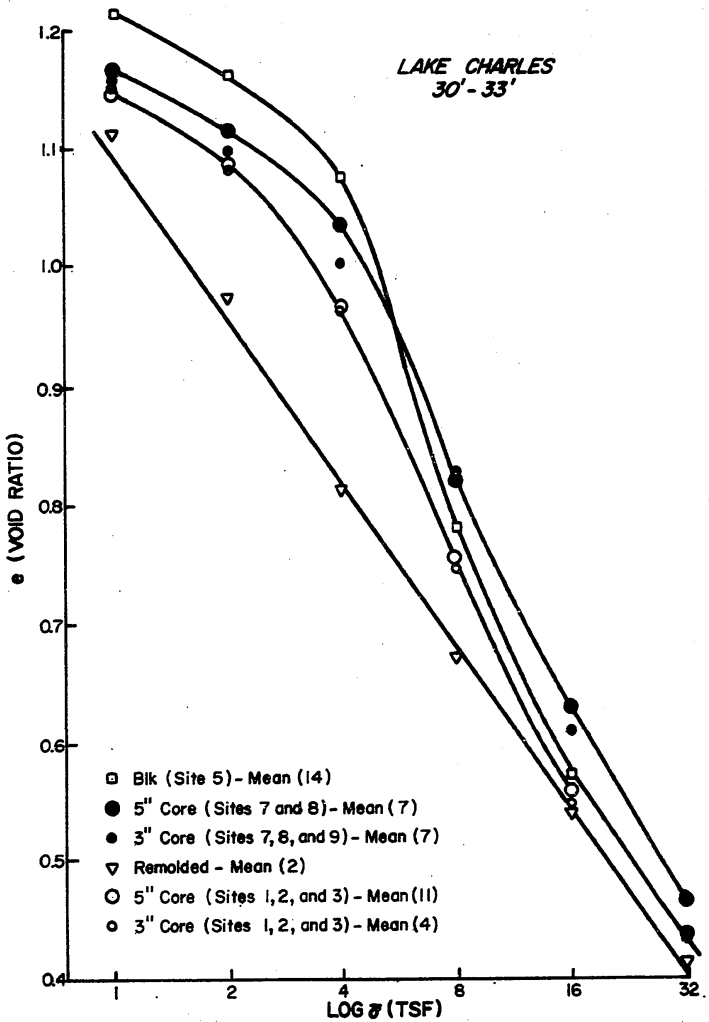

FIGURE 46 AMERCE O-LOGJ CURVES FOR VMOUS SMMVE TYPES LAKE CHARLES - 30 FOOT DEPTH 


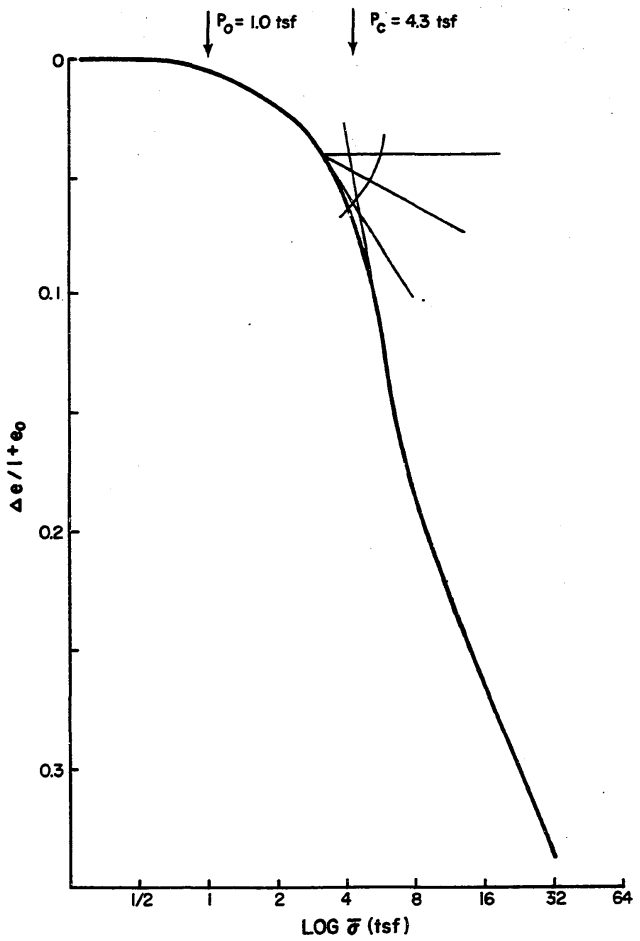

\section{FIGURE 47 DETERMINATION OF THE APPARENT PRECONSOLIDATION PRESSURE-LAKE CHARLES SITE 5, BLOCK 7}


The detrimental effects of long term storage on the block samples was either very small or non-existent. Structural disturbance of the soil was minimized with block sampling and therefore, storage and time did not result in any deterioration. It would appear that the secondary disturbance effects resulting from storage and time are directly related to the initial sampling which disturbs the bonding and structure of the soil particles. With the soil structure damaged and with the el imination of the overburden, i.e. stress release, the sample undergoes a slow relaxation, the negative pore pressure is reduced and the residual stress which resulted after sampling is also reduced with time. The sample becomes soft and more compressible.

\section{Field Curve}

Deviation of the lab e logo curve from that of the field curve is the result of disturbances which occur during sampling, handling and storage, and sample preparation for testing. The difference between the curves for the different sample types and sizes reflects the disturbance occurring during sampling. For all practical purposes, the handling storage and sample preparation for testing was the same for all samples. The different sample protection techniques have been previously discussed.

The uniqueness of the compression curve was such that none of the more traditional techniques for estimating a field curve seemed applicable. A combination of methods suggested by Terzaghi and Peck, Casagrande, and Leonards was applied to the results of a test on a block sample, Figure 48. Although it is believed that sampling 


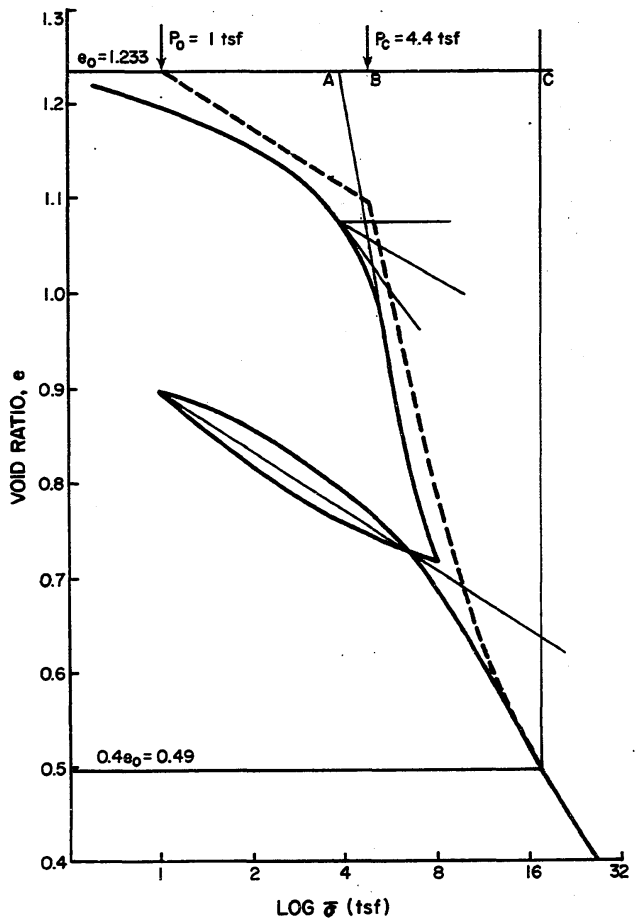

FIGURE 48 FIELD CURVE FOR LAKE CHARLES SITE 5, BLOCK 10, 30 FOOT DEPTH 
disturbance is minimized for block samples, the effects and disturbances resulting from stress release, handling and sample preparation can not be avoided.

Figures 49 and 50 are plots of the average coefficient of consolidation $\left(c_{v}\right)$ for the square root of time (Taylor) and the log of time (Casagrande) method. As in the compression curve, loads in excess of 4 tsf resulted in a drastic reduction of $c_{v}$. This corresponds to the collapse of the soil structure. These results indicate the effects of sampling techniques and the extent of disturbance relative to the block samples are measurabie and quite significant. For this clay, the size and sampling technique are most important.

To demonstrate the effect of sample size on the settlement analysis, a 100 inch thick layer of the type of clay occurring at the $30 \mathrm{ft}$. depth was used. Figure 51 presents the magnitude and variation in settlement predictions for the different samples. These are computed using average test results. The error in settlement prediction made from test results of samples obtained by the 3-inch and 5-inch thin-wall tubes relative to the block samples are shown in Figure 52.

The existing overburden stress for this clay is 1 tsf. For an increase in 1 tsf, (i.e. $\bar{\sigma}=2$ tof), the percent error for predicting the magnitude of the settlement based on 3-inch and 5-inch sample test data is $+83 \%$ and $+59 \%$ respeciively. As the original soil structure is altered by increase loading, the magnitude of the error or difference decreases.

Evaluation of Disturbance - Lake Charles

A disturbance ratio was calculated for each incremental loading of the average test results for the 5 and 3 inch shelby tubes. The 


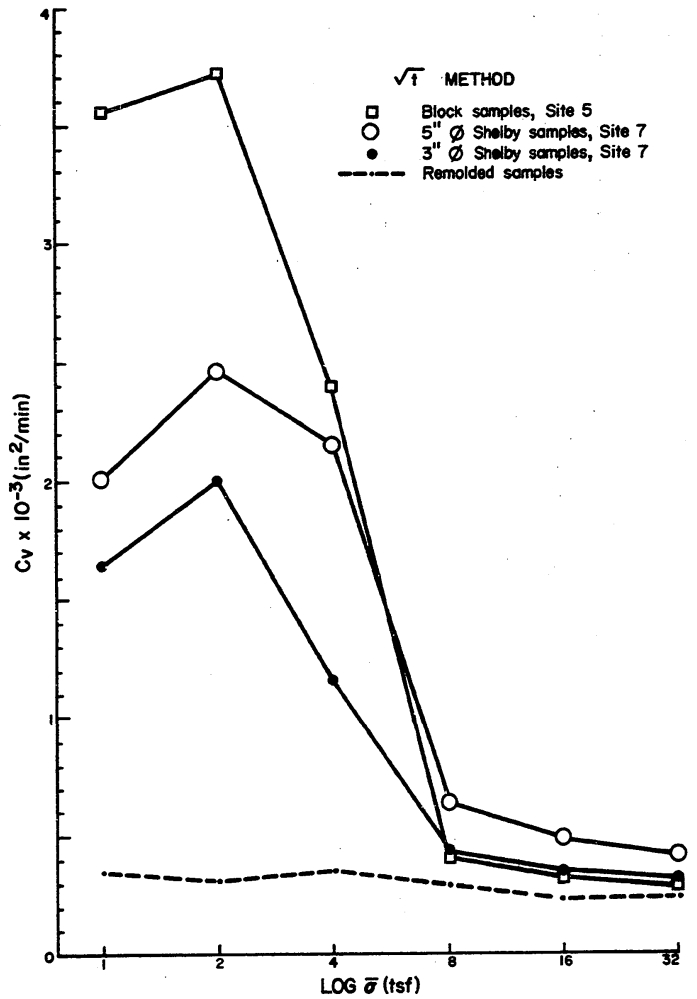

FIGURE 49 COMPARISON OF THE AVERACE COEFFICIENT OF CONSOLIDATION FOR DIFFERENT SAMPLES LAKE CHARLES - 30 FOOT DEPTH 


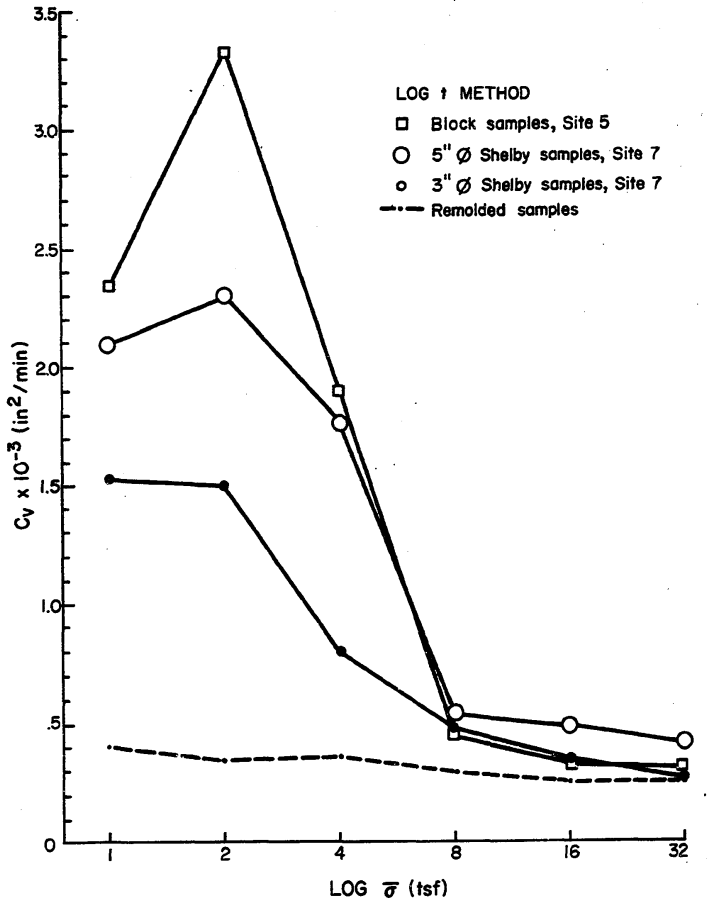

FIGURE 50 COMPARISON OF THE AVERAGE COEFFICIENT OF CONSOLIDATION FOR DIFFERENT SAMPLES

LAKE CHARLES-30 FOOT DEPTH 


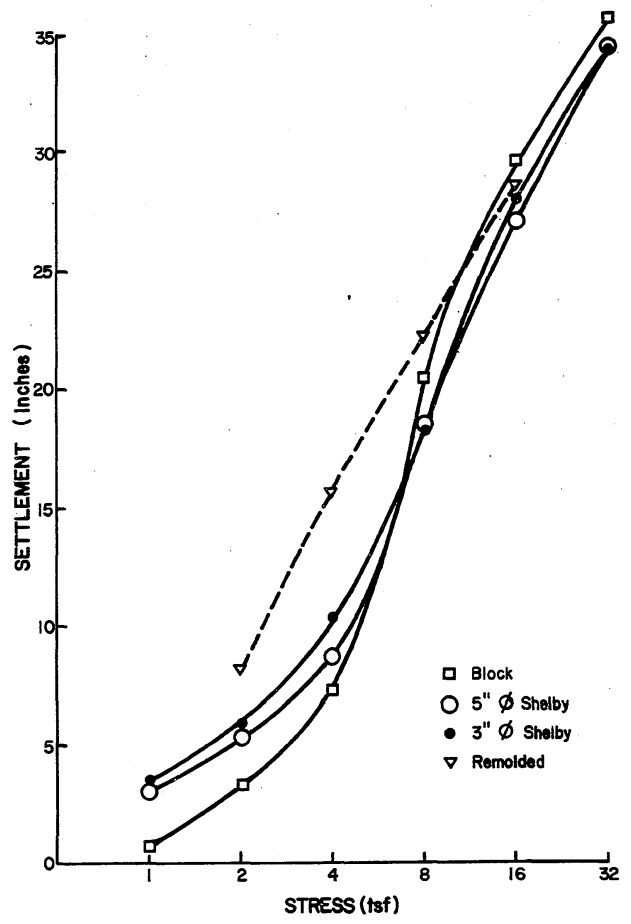

FIGURE 51 SETTLEMENT PREDICTIONS OF A 100 INCH CONSOLIDATING LAYER

LAKE CHARLES SITES 7,8, AND 9 - 30 FOOT DEPTH 


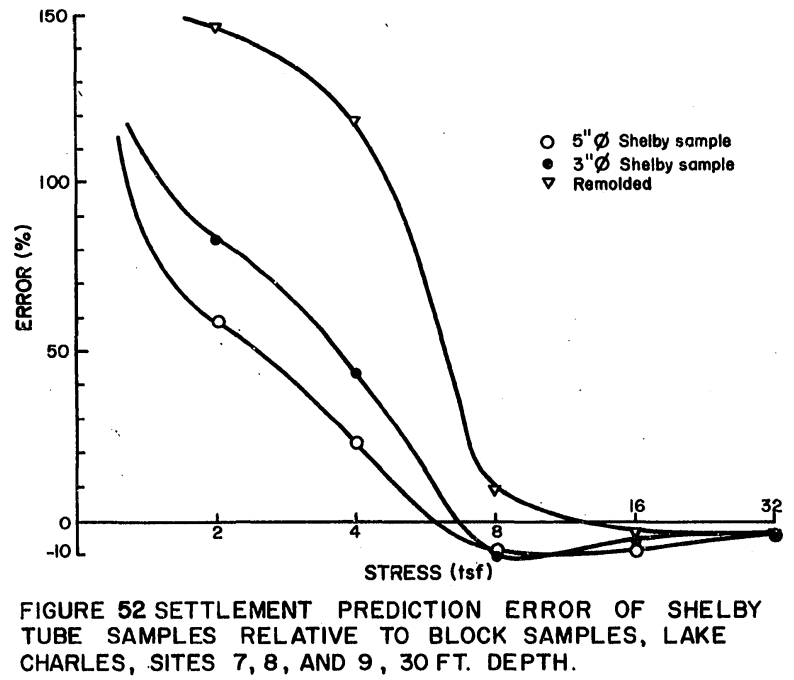


disturbance ratio was defined as the difference in void ratio between the tube sample and that of the block sample divided by the difference between the void ratio of the block sample and the remolded sample, Figure 46. This assumes that the disturbance of the soil structure of the block sample is minimum (0\% disturbed) and that of the remolded sample is maximum (100\% disturbed). A plot of the disturbance ratio for each load increment is shown in Figure 53, $a$ and $b$. Distance from the zero line is a measure of deviation from the block samples' performance.

The residual stress for the 3-inch diameter thin-wall shelby tubes was determined indirectly by means of the oedometer test. Computations for the degree of disturbance as defined by Ladd and Lambe, 1963, are as follows:

$$
\begin{aligned}
\bar{\sigma}_{\mathrm{v}} & =12.5 \mathrm{psi} \\
\text { OCR } & =\frac{\bar{\sigma}_{c}}{\bar{\sigma}_{\mathrm{v} 0}}=\frac{53.9}{12.5}=4.3 \\
I_{\mathrm{p}} & =60 \\
\mathrm{~K}_{0} & =1.2 \text { (Brooker \& Ireland, 1965) } \\
A_{u} & =1 / 4 \text { to } 1 / 2 \text { (Skempton \& Bjerrum, 1957) }
\end{aligned}
$$

For perfect sampling,

$$
\begin{aligned}
\bar{\sigma}_{\mathrm{ps}} & \left.=\bar{\sigma}_{\mathrm{vo}}\left[\mathrm{K}_{0}+A_{\mathrm{u}}\left(1-\mathrm{K}_{0}\right)\right]\right] \\
& =12.5[1.2+0.3(1-1.2)] \\
& =14.3 \mathrm{psi}
\end{aligned}
$$

The residual stress (oedometer readings), $3^{\prime \prime} \phi$ shelby tubes

$$
\bar{\sigma}_{\mathrm{r}}=3.2 \mathrm{psi}
$$

The degree of sample disturbance 

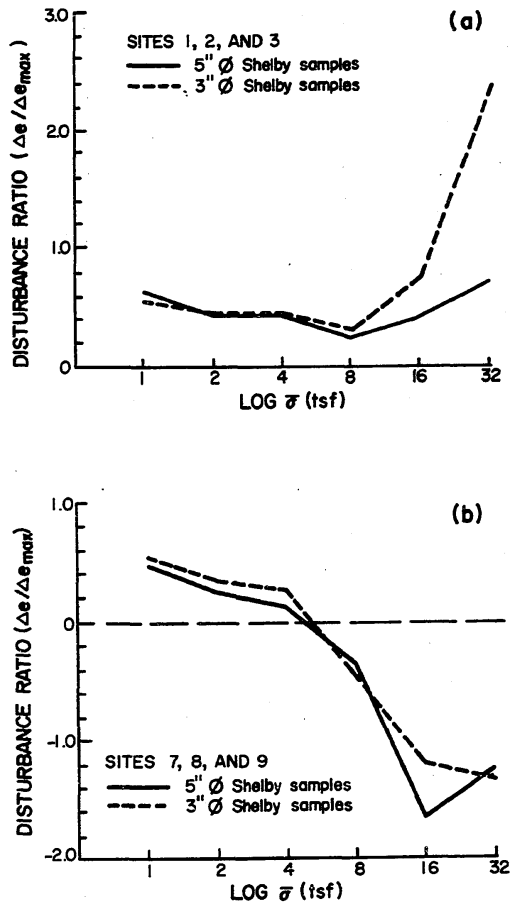

FIGURE 53 DISTURBANCE RATIO VS. LOAD LAKE CHARLES - 30 FOOT DEPTH 


$$
\begin{aligned}
D_{d} & =\frac{\delta_{p s}-\bar{\sigma}_{r}}{\bar{\sigma}_{p s}} \\
& =\frac{14.3-3.2}{14.3} \\
& =80 \%
\end{aligned}
$$

The use of radiography as a method for determining the nature and extent of distortion on clays has been demonstrated by Krinitsky (1970). Its application in the study of sample quality and sampling disturbances proved to be an invaluable aid. Not only from the stand-point of sample distortion which resulted from the sampling operation, but also as a means of validating the uniformity of geologic features in samples.

The most common sample distortion resulting from sampling was a turning down of the layering at the edges. A comparison of the block samples to that of the tube samples is shown in Figures 54, 55, and 56. The degree of disturbance or sample quality is most noticeable when comparing the radiographs of the block samples with those of the 5 and 3inch, thin-wall tube samples.

A second type and more serious distortion was the occurrence of failure planes. Radiographs revealed many that could not be detected visually, Figure 57.

Figure 58 shows a radiograph of a 5 -inch core which is quite seriously disturbed. This sample was later sliced, photographed and $X$-raved, Figure 59. 


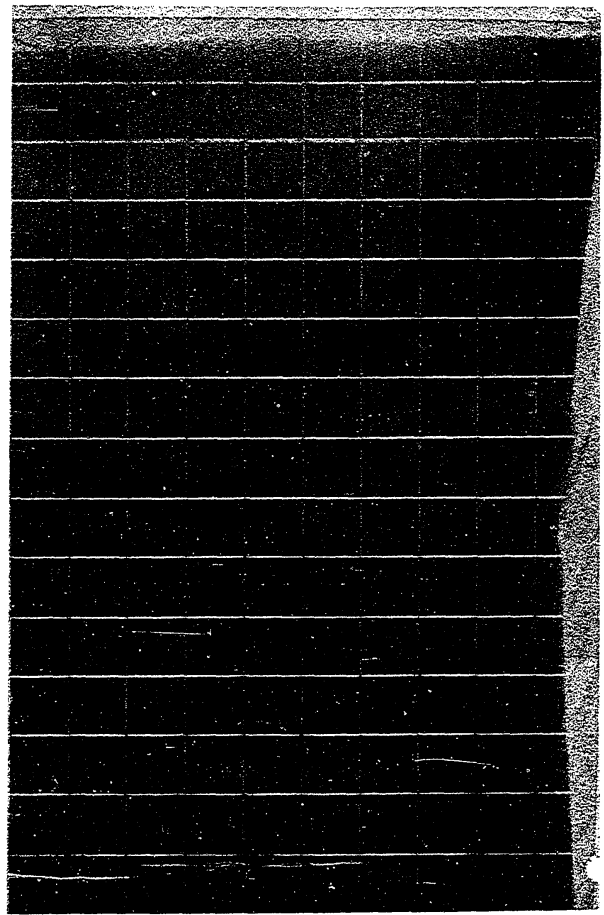

Figure 54 - X-Ray Radiograph of Block Sample, Lake Charles Site 


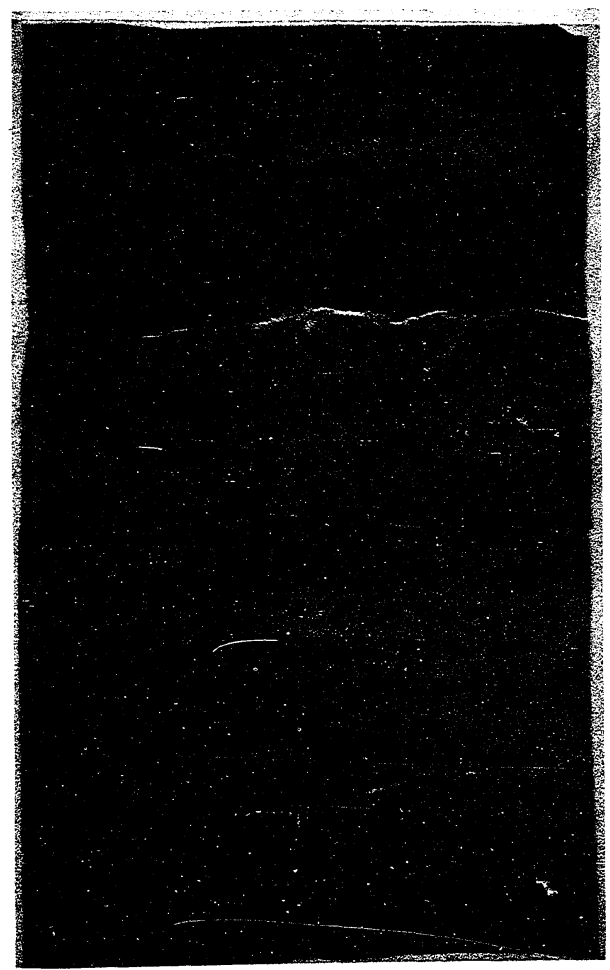

Figure 55 - X-Ray Radiograph of Slice From $5^{\prime \prime}$ O:D. Sample 


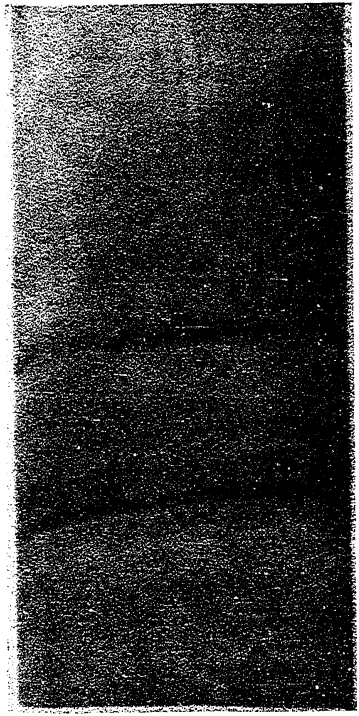

Figure 56 - X-Ray Radiograph of Slice From 3" O.D. Sample 


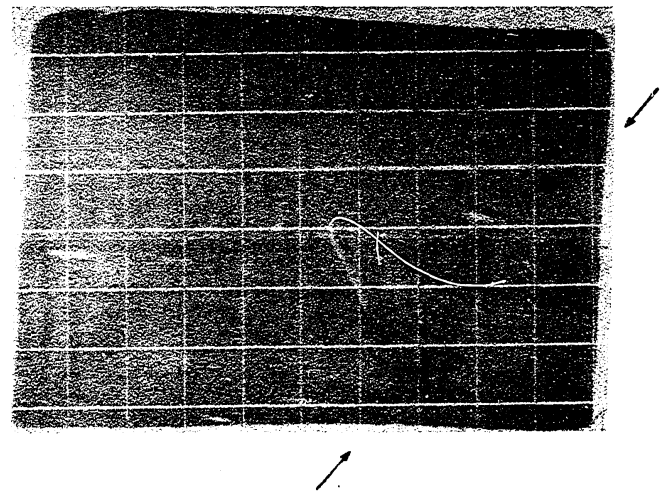

Figure 57 - X-Ray Radiograph of $5^{\prime \prime}$ O.D. Sample With Shear Plane 


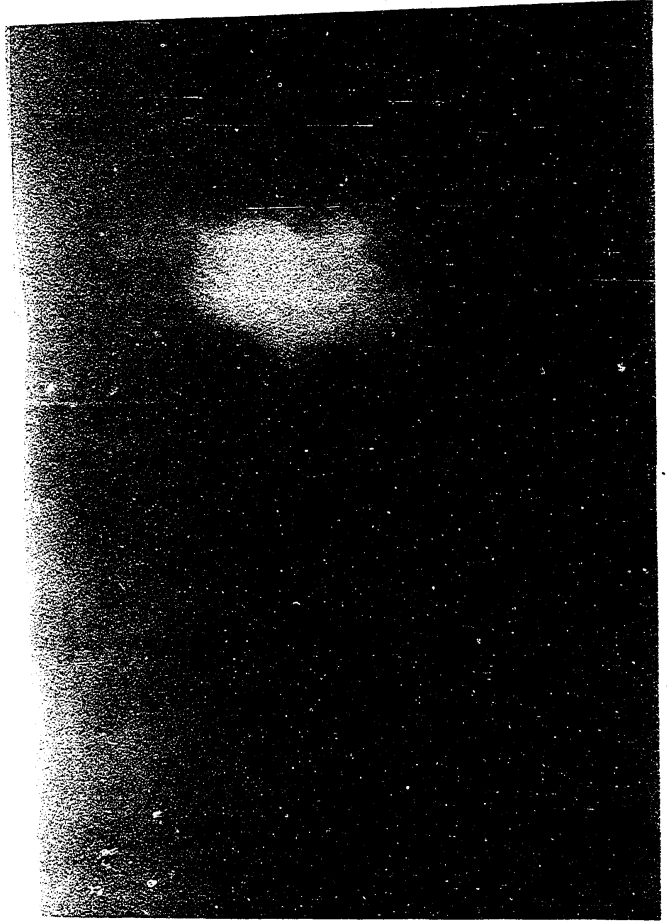

Figure 58 - X-Ray Radiograph of 5" O.D. Core 


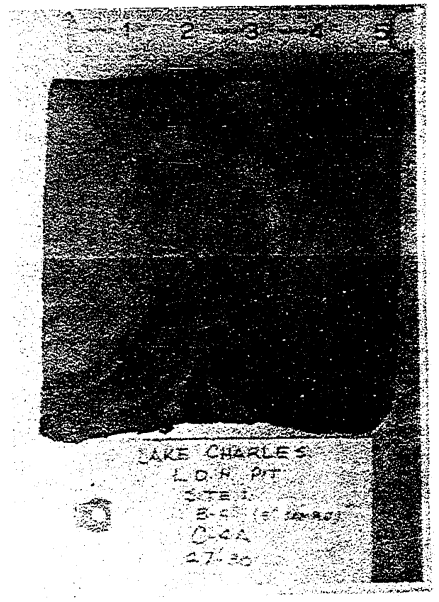

Figure 59 - Photograph of $5^{\prime \prime}$ O.D. Core Sice 
Radiography was found to be a valuable tool for the selection of samples tested. Figure 60 shows the failure plane in a sample tested in the unconsolidated undrained triaxial test. Note the shell in the failure plane. The peak strength for this particuiar sample was $40 \%$ greater than for other samples tested from this location.

The effects and presence of geologic features such as shells, concretions, and naturally occurring fissures are also enhanced and can be studied in radiographs, Figures 61,62 , and 38 . 


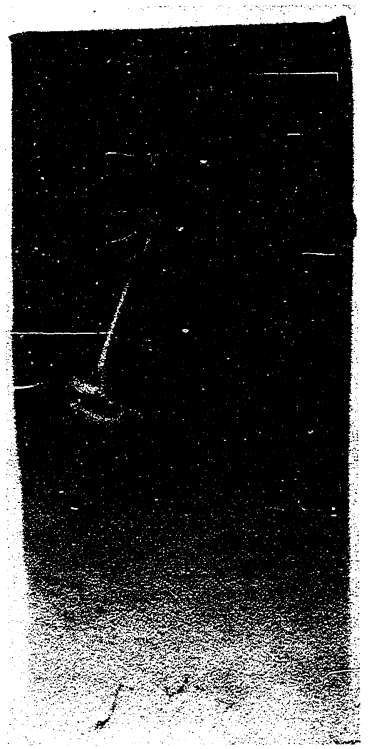

Figure 60 - X-Ray Radiograph of Slice of Sample Tested to Failure 


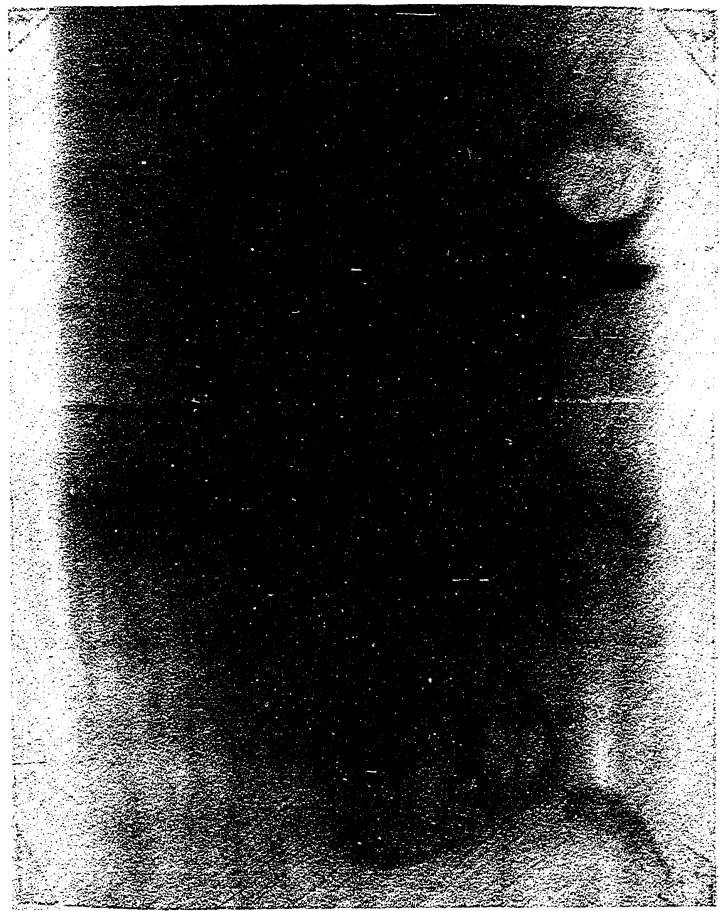

Figure 61 - X-Ray Radiograph of $5^{n}$ 0:D. Core Showing Shells 


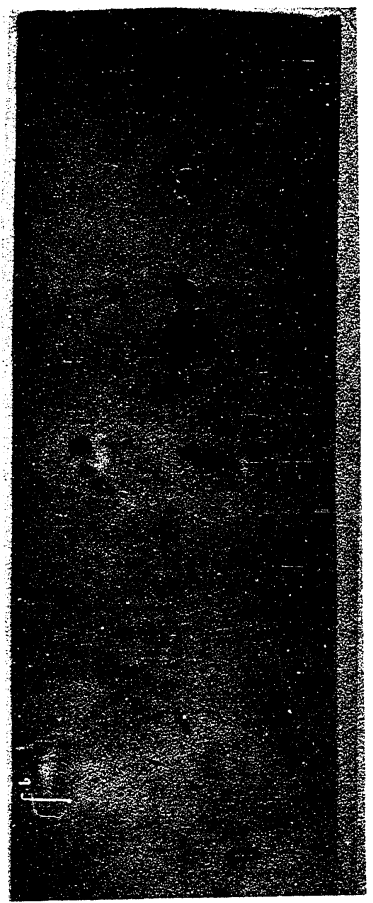

Figure $62^{-}$- X-Ray Radiograph of Sample Slice With Concretions 


\section{LAPLACE SITE}

\section{Location and Geology}

The LaPlace sampling site is located on the southeastern corner of the Ponnet Carre Spillway; approximately one hundred yards west of Lake Ponchartrain, Figure 30. The soil consists entirely of recent material. The depositional environment was that of alluvial floodwaters in combination with brackish marine conditions. Thus the material was varved with alternating layers of organic clay and silt and traces of shells. Due to the proximity of the leyee system of the spillway the top fifteen feet consisted of material artificially placed. The natural material was very soft and difficult to handle. Several samples were lost while lifting them in the borehole. The natural moisture content of the soil was approximately that of the liquid limit, Figure 63 .

\section{Sampling and Field Testing}

The samplers used consisted of the 3-inch shelby tube, the 5-inch shelby tube and the 3-inch Osterberg sampler. There were two variations of the 3-inch shelby tube used with respect to the cutting edge. One had a beveled and sharpened cutting edge. The other was squared off at the cutting edge. The cutting edge of the 5-inch shelby tube was beveled and sharpened. As previously mentioned, several samples were lost in the sample recovery phase due to the softness of the soil. This was especially true for the 5-inch shelby samples.

The standard penetration test and the field vane test were conducted. The results of the laboratory tests and the field tests are reviewed in Figure 63. Typical values of the soil properties are presented in 


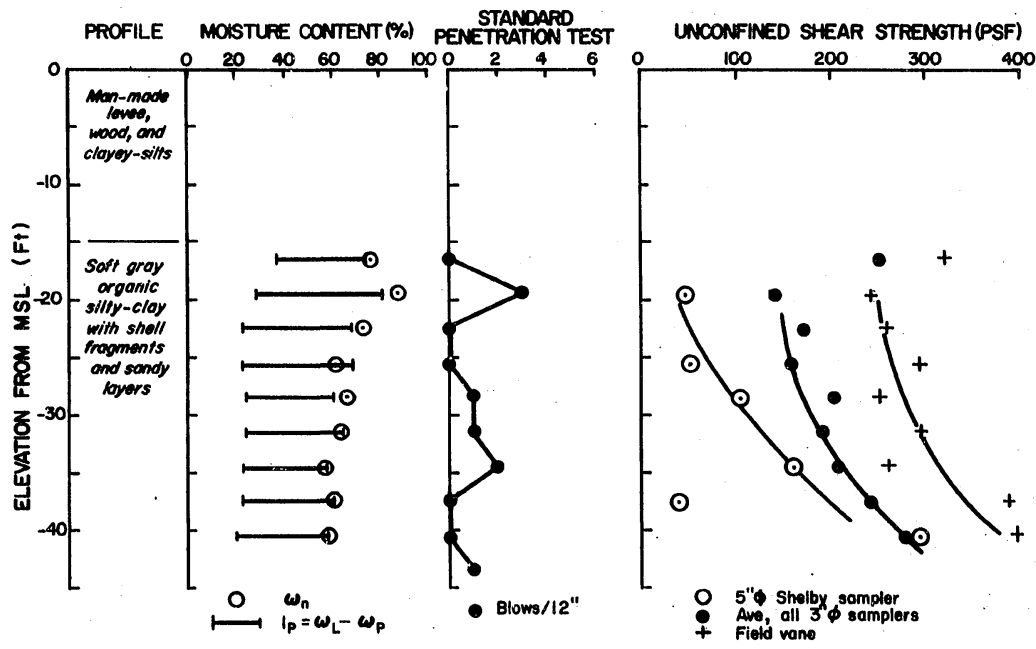

FIGURE 63 SUMMARY PROFILE - LAPLACE SITE 


\begin{tabular}{|c|c|c|c|c|c|c|c|c|c|c|}
\hline \multirow{2}{*}{$\begin{array}{c}\text { DEFTH } \\
\text { EELOW } \\
\text { EROUND } \\
\text { Ff } \\
\end{array}$} & \multirow{2}{*}{ STRATUM } & \multicolumn{5}{|c|}{ CONSESTENCY } & \multirow{2}{*}{$\frac{A_{p}}{\% \text { colloid }}$} & \multirow{2}{*}{$\begin{array}{c}\gamma \\
\omega / f t^{3}\end{array}$} & \multirow{2}{*}{$\begin{array}{c}S_{u^{*}} \\
L \mathrm{~L}_{\mathrm{ft}}{ }^{2}\end{array}$} & \multirow{2}{*}{$\begin{array}{l}S_{t}^{* *} \\
L b / f t^{2}\end{array}$} \\
\hline & & $\omega$ & $\omega_{L}$ & $\omega_{p}$ & $I_{P}$ & $I_{L}$ & & & & \\
\hline $\begin{array}{l}0 \\
3 \\
6\end{array}$ & $\begin{array}{l}\text { Mon-mode } \\
\text { leves, wood, } \\
\text { orgenics, ond } \\
\text { cloyey-silts } \\
(M L-O L)\end{array}$ & & & & & & & 92 & & \\
\hline 16 & & & 48 & 38 & 10 & & & & & \\
\hline 18 & $\begin{array}{l}\text { soft groy } \\
\text { organic } \\
\text { silty -cloy }\end{array}$ & 77 & 78 & 27 & 51 & 0.98 & 0.77 & 98 & 284 & 2.8 \\
\hline 21 & $\begin{array}{l}\text { with sholl } \\
\text { frogments } \\
\text { and thin }\end{array}$ & 88 & 82 & 29 & 53 & 1.11 & 0.78 & 95 & 142 & 2.8 \\
\hline 24 & $\begin{array}{l}\text { sendy strotios } \\
(C H)\end{array}$ & $\begin{array}{l}73 \\
62\end{array}$ & 69 & $\begin{array}{l}23 \\
23\end{array}$ & $\begin{array}{l}46 \\
46\end{array}$ & 0.85 & $\begin{array}{l}0.78 \\
1.05\end{array}$ & $\begin{array}{l}101 \\
99\end{array}$ & $\begin{array}{l}246 \\
263\end{array}$ & $\begin{array}{l}4.9 \\
5.3\end{array}$ \\
\hline 30 & & 67 & 61 & 25 & 36 & 1.16 & 1.24 & $9 \mathrm{l}:$ & 207 & 3.8 \\
\hline 33 & & 64 & & & & 0.97 & 0.84 & & 189 & 3.4 \\
\hline 36 & & 58 & 59 & 23 & 36 & 0.97 & 0.84 & 104 & 192 & 1.9 \\
\hline 39 & & $6 i$ & 59 & 23 & 36 & 1.06 & 0.75 & 99 & 294 & 2.2 \\
\hline 42 & & 59 & 59 & 21 & 38 & 1.00 & 1.00 & 103 & 310 & 3.1 \\
\hline
\end{tabular}

* Averoge $S_{U}$ from Osterberg sampler

**Remolded $S_{U}$ from lab vane

\section{TAQLE 6 SOLL PROPERTIES- LAPLACE STE(TYPICAL VALUES)}


Table 6.

\section{Test Resuilts}

Unconfined compressiye tests were run on the samples. Plots of the stress-strain relationship for the different samples are presented in Appendix D. The Osterberg samples out performed both the 5-inch and the 3-inch shelby samples. The unconfined shear strength versus depth for the individuai sample and the field vane results are shown in Figure 158 and 159 of Appendix D. The resu?ts of the osterberg samples compared favorably with the field vane tests.

The unconfined shear strength of the different sample types were plotted against one another in comparing the sampler influence, Figure 64. The diagonal line represents equal shear strengths. As can be seen, the osterberg samples provided strengths greater than all other samples. The 3-inch shelby tube with the square cut was the next best. This was followed by the 3 -inch beveled shelby and the 5-inch beveled shelby tube which had the lowest strengths.

It is believed that since the material was so soft and had a tendency to flow under pressure, that the reason the squared off shelby tube out-performed the beveled tubes was due to the sample being more restricted in the first. With no clearance space, as provided for by the beveled tube, there was less room for the material to flow. Also, without the clearance space, the sample was held tighter when it was recovered up the hole. Due to the size and weight of the sample and with the clearance provided, many of the 5-inch samples were lost when they were being pulled from the hole. This was also true of some of the 3-inch beveled shelby samples. 

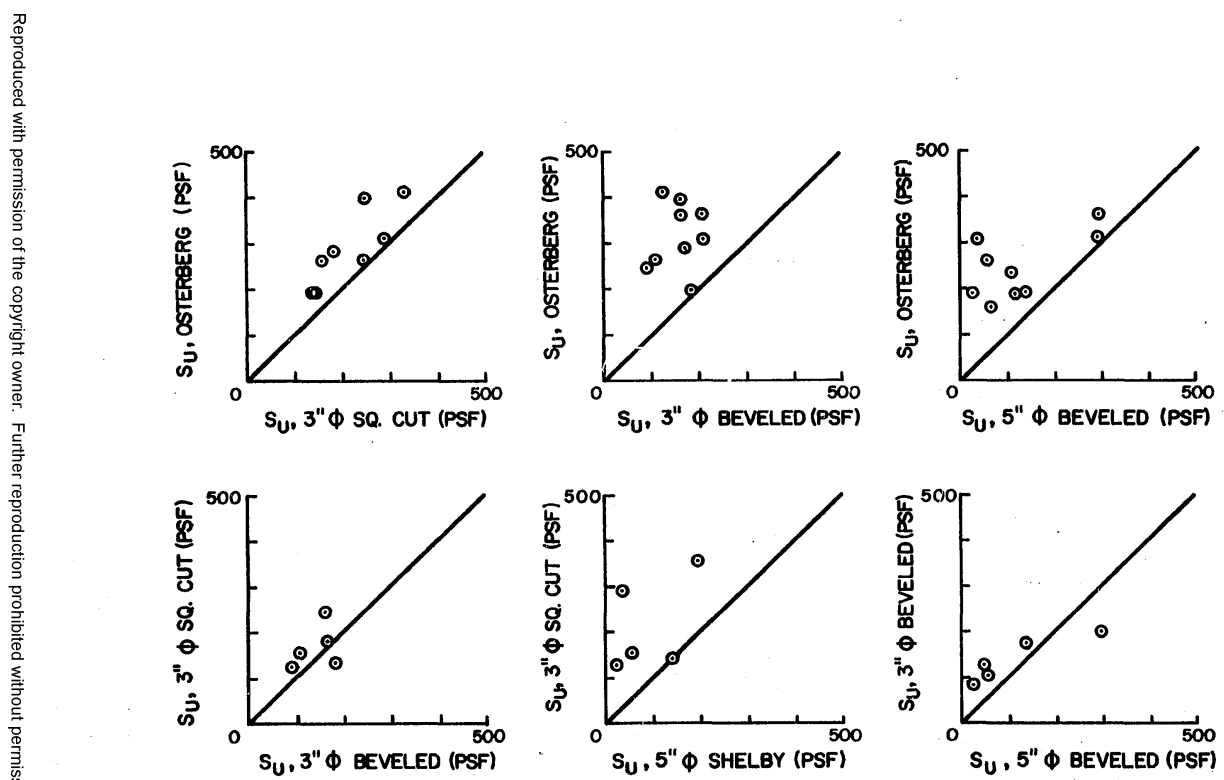

FIGURE 64 SAMPLER INFLUENCE ON UNCONFNED SHEAR STRENGTH - LAPLACE SITE 
Al though the osterberg sampler was beveled, the sampling drive of this hydraulically operated sampler was much faster than the punching drive of the shelby tubes. It also has the advantage of the fixed piston. This helps to prevent the entrance of excess soil and eliminates distortion during recovery.

Sample reliability which was defined by Skempton and Henkel (1957) as a function of the plastic index has been plotted for the different sample types in Figures 65, 66, and 67. The performance of the osterberg sampler gave good agreement with this relationship. The others did not perform as well.

The results of a consolidation test on a 3-inch sample is shown in Figure 157 of Appendix D. The soil is normally consolidated or slightly under-consolidated.

Unconfined compression tests show that a piston type sample is required in a soil such as found at the Laplace site. A piston sample should be used, even if an open-drive sample will provide a sample. The tendency of most sampling personnel is to use the easiest and most productive instrument; that being the open-drive shelby for local sampling crews. However, quality must be considered and this points out the need fora qualified individual (knowledgeable equipment wise and in the area of soil mechanics) to plan on the spot sampling technigues to be used

\section{Radiographs}

The distortion of the soil layers was quite yisible with the aid of radiographs. This largely consisted of turned down edges and shear planes, although mixing and flowing of the sample was also observed.

Figure 68 is a radiograph of a 5 -inch shelby sample with several 


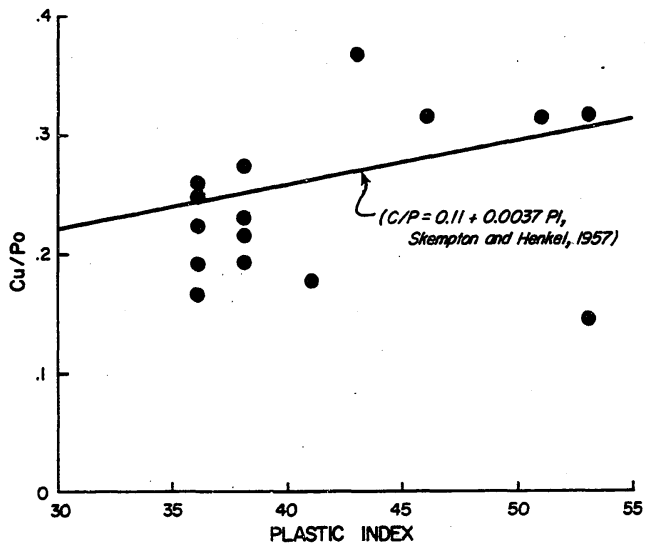

FIGURE 65 LAPLACE SITE SAMPLE RELIABLLITY FOR OSTEREERG PISTON SAMPLER 


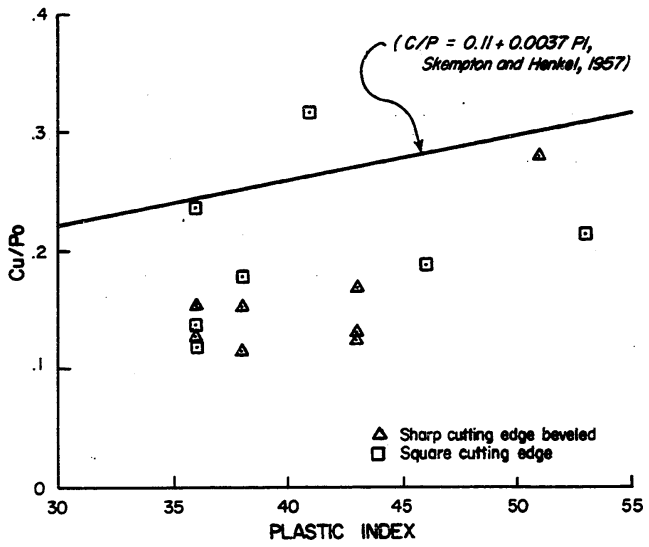

FIGURE 66 LAPLACE SITE SAMPLE RELIABILITY FOR $3 " \phi$ SHELBY SAMPLER 


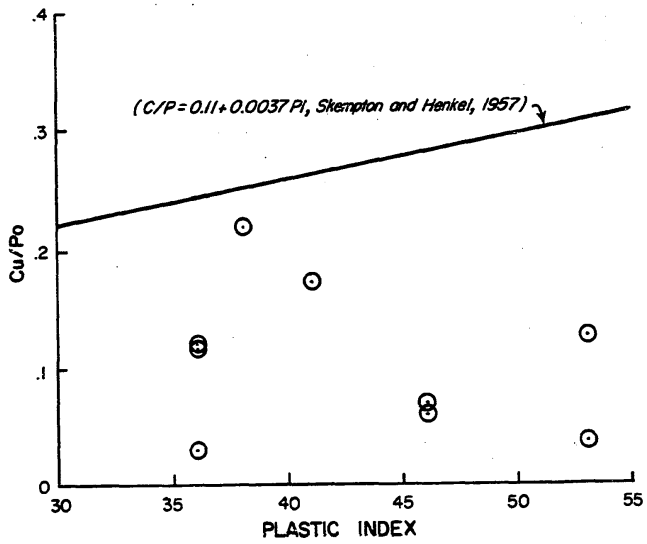

FIGURE 67 LAPLACE SITE SAMPLE RELIABLLITY FOR 5 " $\$$ SHELBY SAMPLER 
shear planes and some edge turndown.

Figures 69,70 and 71 show layering that is bent in 3-inch samples. Shear planes can be seen in Figure 69.

A severe case of sample distortion with soil flow and mixing is shown with a radiograph in Figure 72 , and a photograph in Figure 73 . 


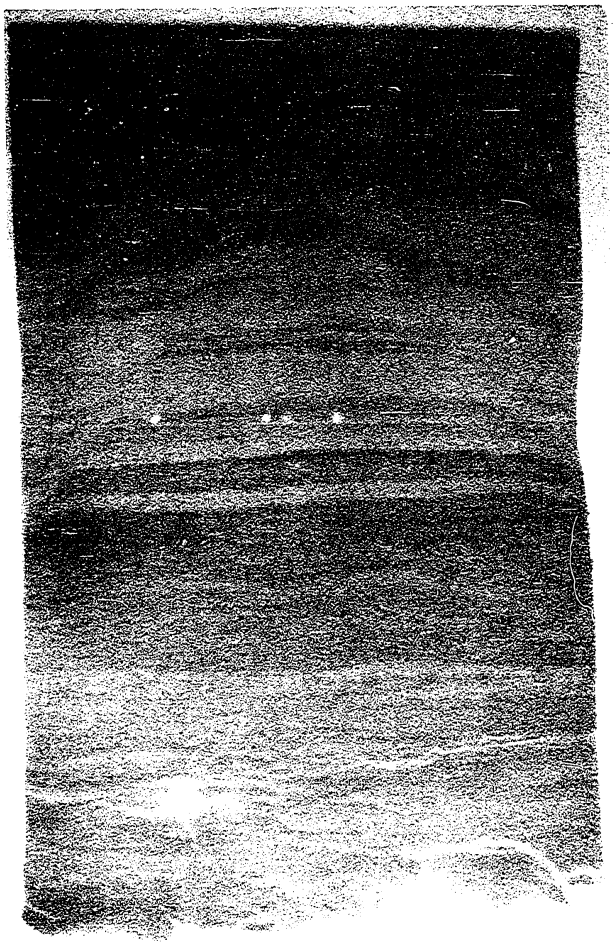

\section{Figure 68 - X-Ray Radiograph of 5-inch Shelby Sample with Shear Planes}




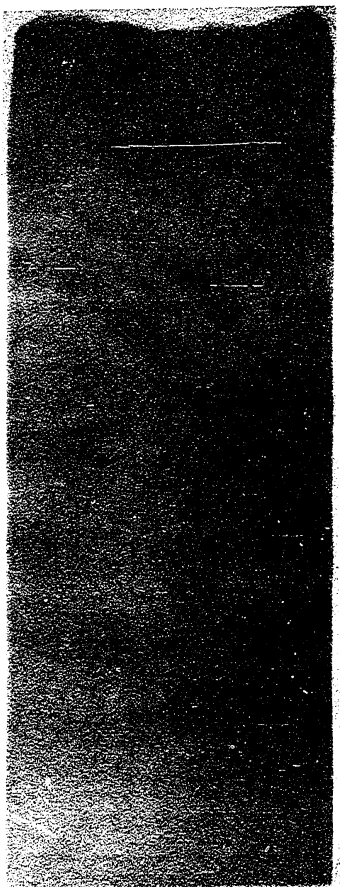

Figure 69 - X-Ray Radiograph - 3" 0.D., LaPlace Site 


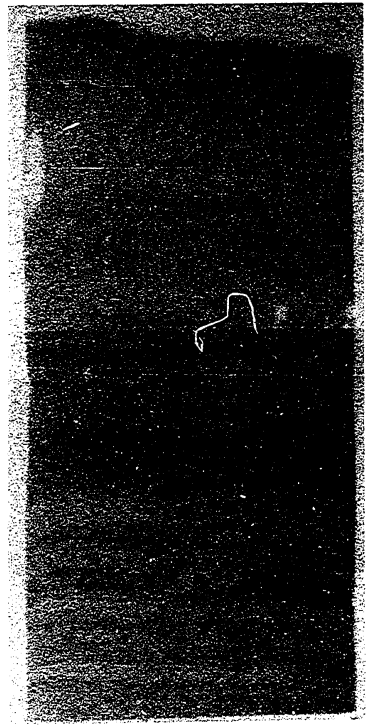

Figure 70 - X-Ray Radiograph - 3" 0.D., LaPlace Site 


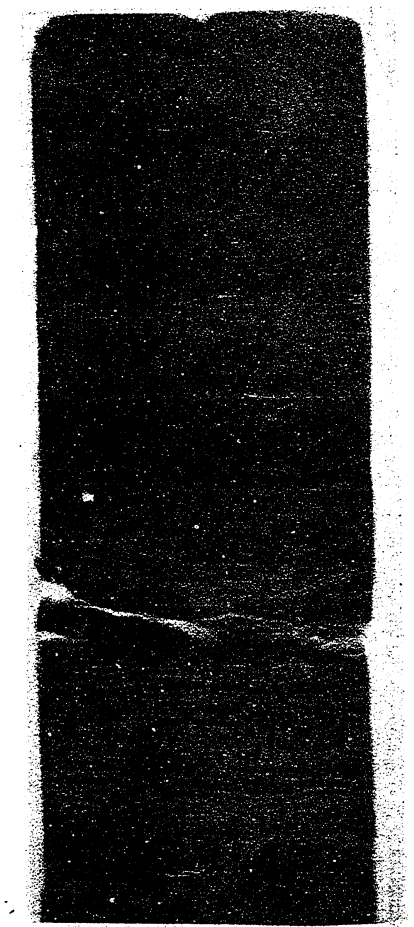

Figure 71 - X-Ray Radiograph - 3" 0.D., LaPlace Site 


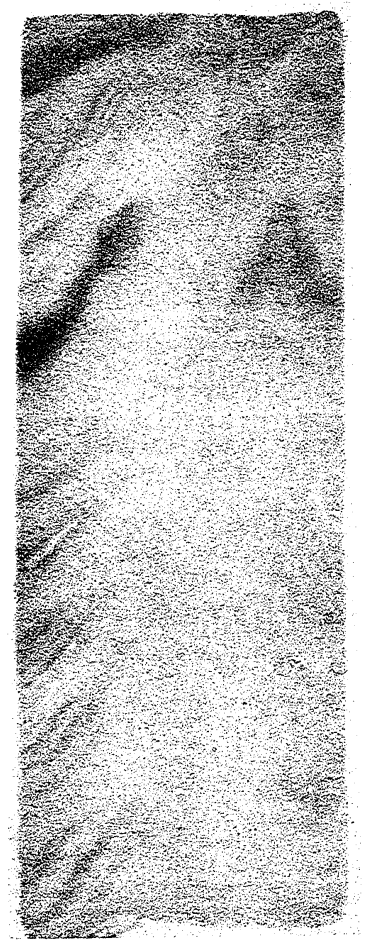

Figure 72 - X-Ray Radiograph - 3" O.D., LaPlace Site 


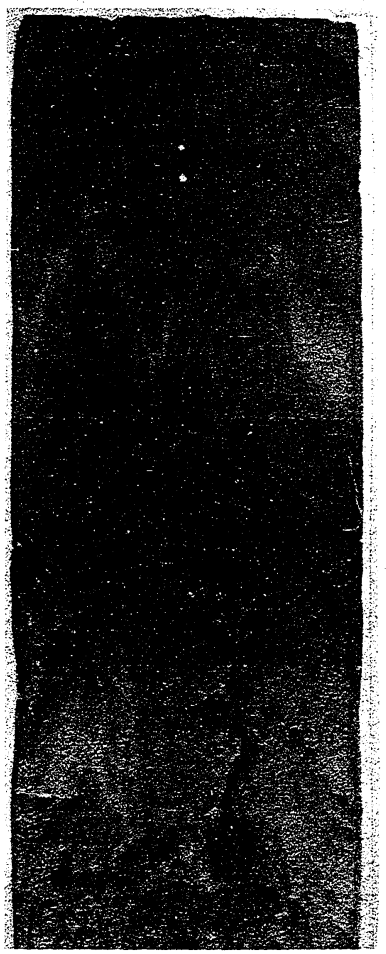

Figure 73 - Photograph - 3" $0.0 .$, LaPlace Site 


\section{ERWINILLE SITE}

\section{Location and Geology:}

The Erwinville sampling site was located off highway U.S. 190, approximately fifteen miles west of Baton Rouge, Figure 30. The depositionai environment of this material was that of a recent backswamp. Many roots, large and smal1, of old cypress trees were encountered. As seen in Figure 74, the top thirty feet of the soil consisted of a mottled gray clay with multiple slickensides. The material below thirty feet was a soft silty clay.

The clay in the top thirty feet contained many hairline fissures. It was possible to separate parts of a sample down to very small pieces, and each time the exposed soil consisted of a smooth though irregular, shiny surface, Figure 75. One explanation for this type of phenomena is syneresis, (Terzaghi and Peck, 1967, page 17). This involves a removal of water from the soil during dry periods with the aid of plant roots.

\section{Sampling and Field Tests}

Open drive continuous shelby tube samples, both 3-inch and 5-inch diameter, were taken to a depth of forty-two feet. A block sample was also secured from an approximate depth of fourteen feet below the ground. It was very difficult to cut block samples due to the many roots and slickensides present throughout the soil. The acquisition of two block samples were attampted, but only one was obtained. When the latter sample was uncrated in the lab and trimming was attempted, it fell apart along shiny surfaces.

The standard penetration test was conducted continuously at three 168 
STANDARD

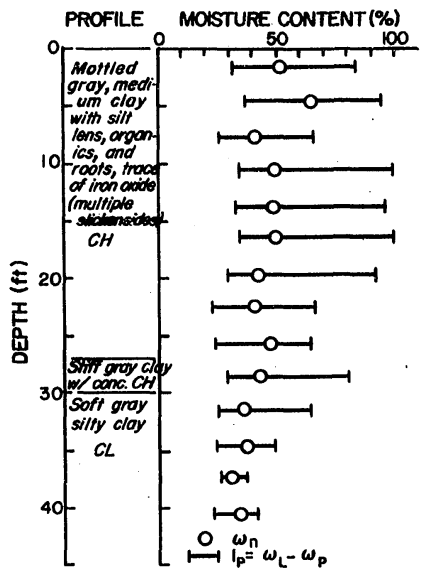

PENETRATION TEST UNDRANED TRIAXIAL STRENGTH (PSF)
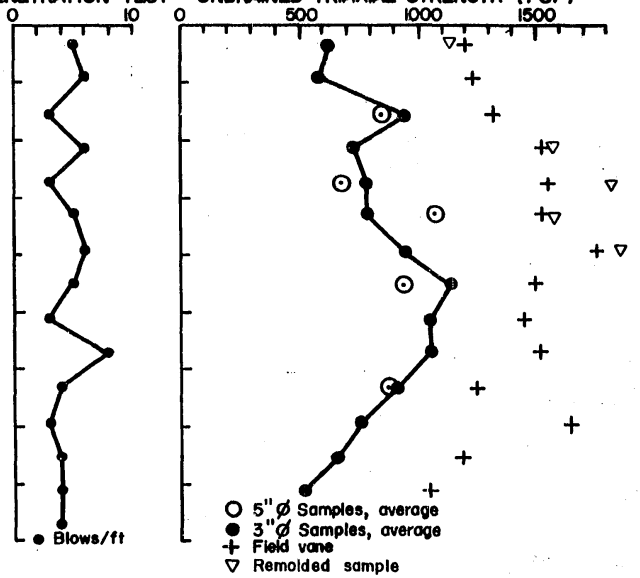

FIGURE 74 SUMMARY PROFILE - ERWMNVILLE SITE 


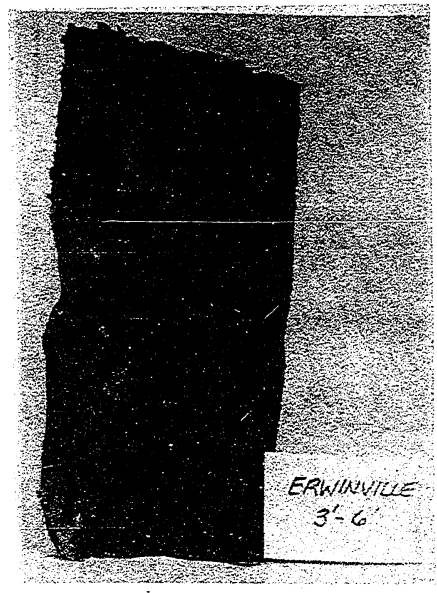

Figure 75 - Fissure Planes, Erwinville Sample 
feet increments to a depth of forty-two feet. The field vane test was also run to the same depth.

\section{Test Results}

Test results for the soil profile is presented in Figure 74 and Table 7. As will be noted, the soil properties were improved by remolding. A plot of the remolded shear strength versus the shear strength of the 5-inch and 3-inch samples is shown in Figure 76. A plot of the shear strength of 5 -inch diameter specimens versus the shear strength of the 3-inch diameter specimen shown in this figure, though neither shows an advantage here.

The shear strength of this soil was definitely governed by the secondary structure (i.e., the multiple slickensides). It seems plausible then that any sampling method used which tends to remold the soil structure should definitely improve its strength in laboratory tests. Actually remolding provided strengths comparable to those obtained in the field vane test, Figure 74.

A consolidation test, Appendix E, Figure 170, shows the soil to be overconsolidated.

\section{Radiographs}

The results of X-ray radiographs indicated that the soil structure is homogenous. That is, the distribution of fissures did not seem to be oriented in any particular manner. Structural disturbances were not obvious. Radiographs of 3-inch diameter core is presented in Figure 77. 


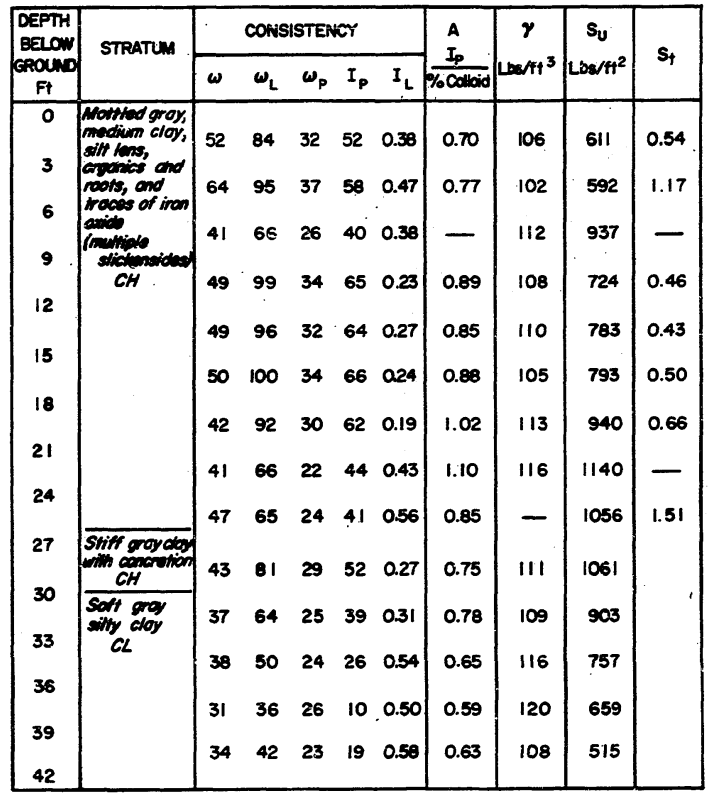

TAELE 7 TYPICAL SOIL PROPERTES - ERWINVILLE SITE 

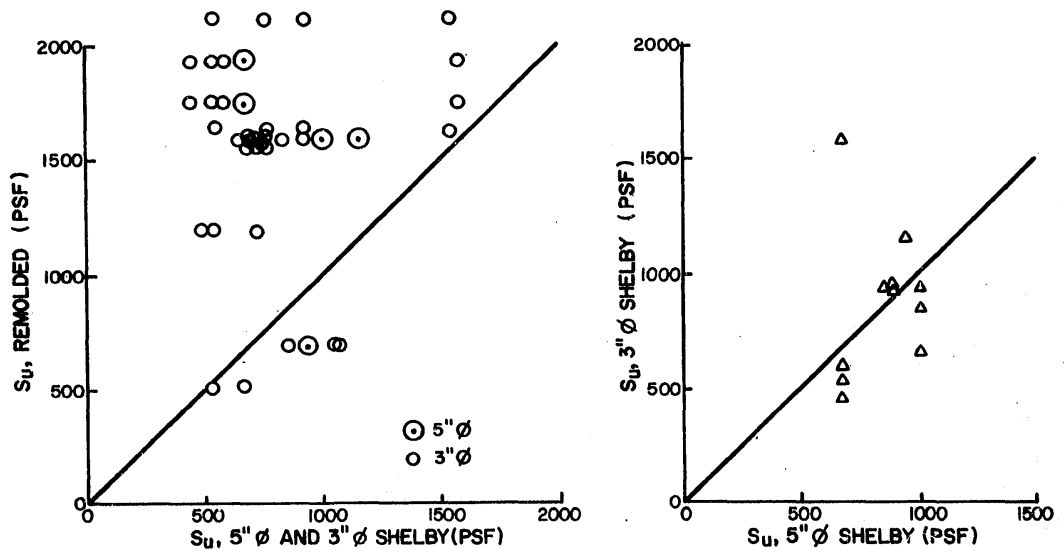

FIGURE. 76 INFLUENCE OF SAMPLING AND REMOLDING ON UNCONSOLIDATED-UNDRAINED COMPRESSIVE STRENGTH 


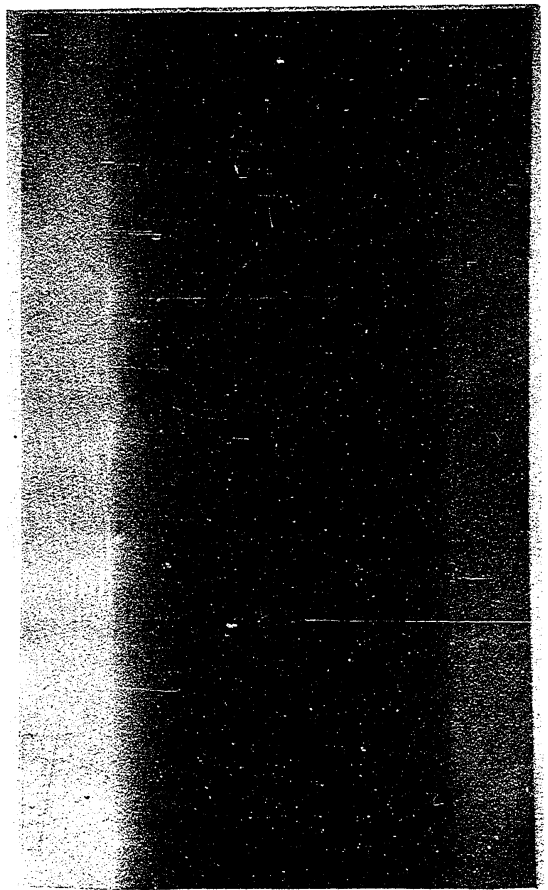

Figure 77 - X-Ray Radiograph of 3" 0.D. Core - Erwinville Site 
HOUNA SITE

\section{Location and Geology}

This site is siturated in a recent deltaic plain near Houma, Louisiana, Figures 30 and 31 . The soil consisted of organic clays and silty clays. The soil had a tendency to separate into lumps and peds. When the soil was squeezed, the response was somewhat "spongy" in nature.

\section{Sampling and Field Tests}

Continuous sampling to a depth of forty-two feet was done with 3inch and 5-inch shelby tube samplers. The standard penetration test was performed at three foot increments to the same depth. The field vane test was also conducted.

\section{Test Results}

The results of the laboratory tests and the field tests are presented in Figure 78 and Table 8. According to strength tests, the soit ranged from an insensitive to a moderately sensitive soil.

Figure 79 is a plot of the unconfined shear strength of the 3-inch shelby tube samples versus the unconfined shear strength of the 5-inch shelby tube samples. Each point represents average test results. There appears to be an increase in strength for the 3-inch samples. 
STANDARD

PROFILE MOSTURE CONTENT (\%) PENETRATION TEST UNCONFINED SHEAR STRENGTH (PSF)

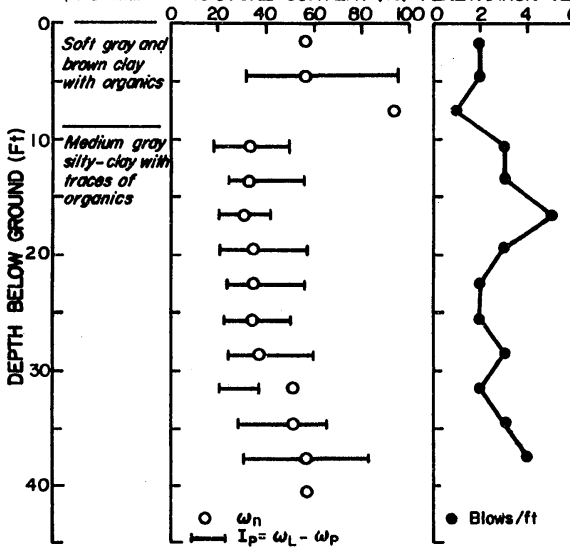

400

800

1200 1600

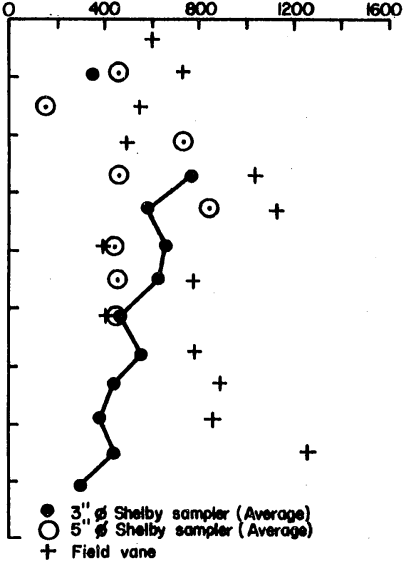

FIGURE 78 SUMMARY PROFILE - HOUMA SITE 


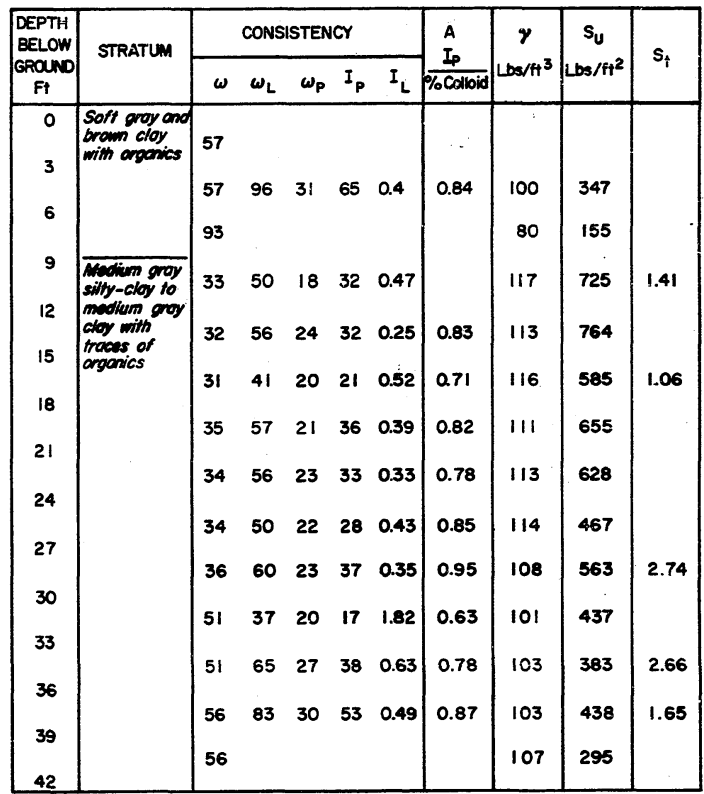

TABLE 8 TYPICAL SOIL PROPERTES - HOMMA STTE 


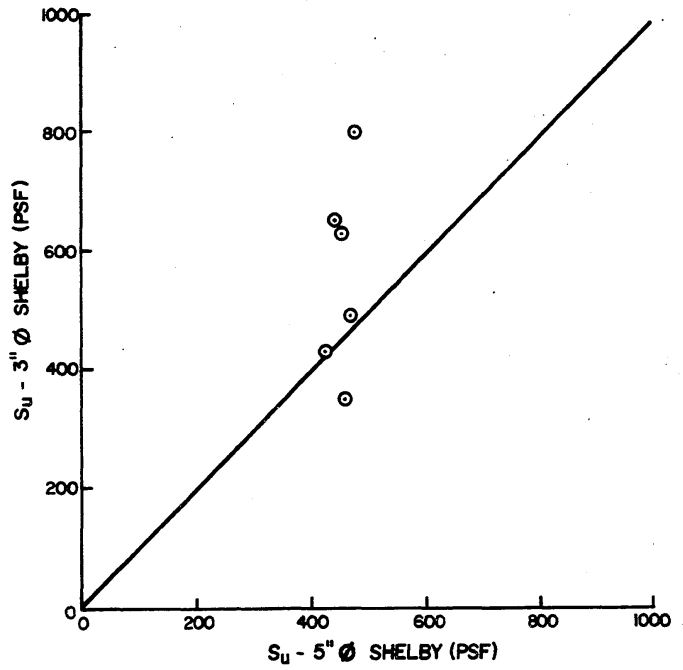

FIGURE 79 HOUMA UNCONFNED SHEAR STRENGTH: $5^{\prime \prime} \varnothing$ SHELBY VS $3^{\prime \prime} \varnothing$ SHELBY 


\section{MORGAN CITY SITE}

\section{Location and Geology}

Located within the recent deltaic plain of the Atchafalaya Basin, this site was approximately seven miles east of Morgan City, Louisiana, Figure 30 . The material consisted of backswamp deposits of clays and silty clays. The percentage of clay size particles ranged from 20 to $55 \%$. Silt size particles ranged from 44 to $80 \%$. The structure or fabric of the soil had a grainy texture.

\section{Sampling and Field Tests}

Five-inch and three-inch thin-wall shelby tube samples were secured in adjacent boreholes. The standard penetration test was conducted at three feet increments from the surface to a depth of forty-two feet. The field vane test was also conducted at three feet increments to a depth of forty-two feet.

\section{Test Results}

Laboratory testing consisted of the unconfined compression test, consolidation tests and classification tests. The soil profile and average test results are presented in Figure 80 and Table 9.

The sensitivity of the soil ranged from 2.75 to less than one for test results on three inch samples. This was an insensitive soil, when sensitivity is measured by alteration of the structure (i.e., undisturbed to remolded strength). However, there is a significant difference between the average undisturbed sample strength and the field vane 
STANDARD

PROFILE MOISTUAE CONTENT (\%) PENETRATION TEST UNCONFINED SHEAR STRENGTH (PSF)
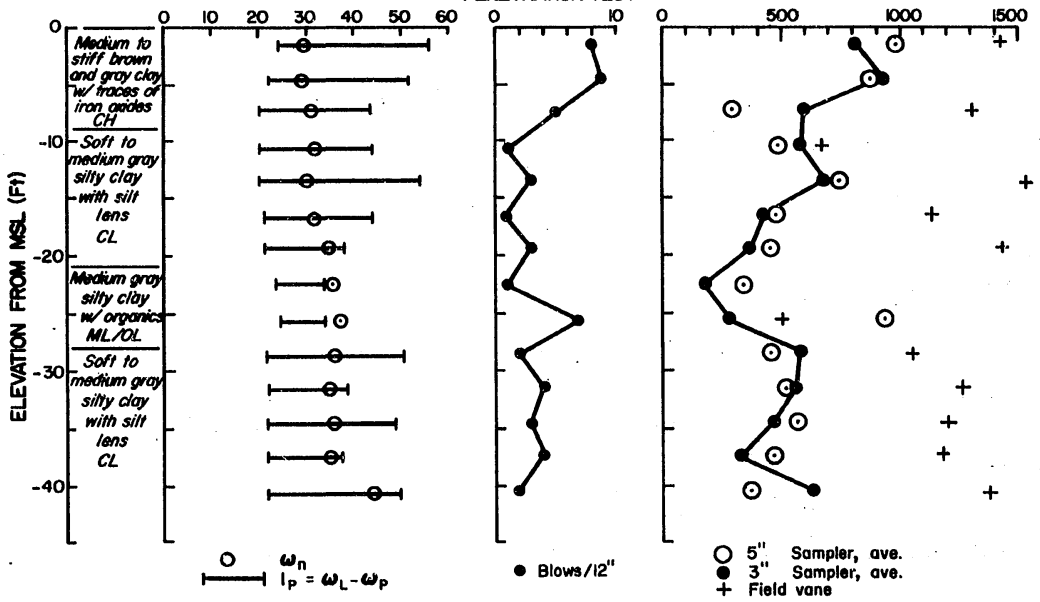

FIGURE 80 SUMMARY PROFILE - MORGAN CITY SITE 


\begin{tabular}{|c|c|c|c|c|c|c|c|c|c|c|}
\hline \multirow{2}{*}{$\begin{array}{c}\text { DEPTH } \\
\text { EELOW } \\
\text { EROUND } \\
\text { Ft }\end{array}$} & \multirow{2}{*}{ STRATUM } & \multicolumn{5}{|c|}{ CONSISTENCY } & \multirow{2}{*}{$\frac{I_{p}}{\% \text { Colloid }}$} & \multirow{2}{*}{$\begin{array}{c}\gamma \\
L b / f t^{3}\end{array}$} & \multirow{2}{*}{$S_{L S / f t^{2}}{ }^{*}$} & \multirow{2}{*}{$s_{t}$} \\
\hline & & $\boldsymbol{\omega}$ & $\omega_{L}$ & $\omega_{p}$ & $I_{P}$ & $I_{L}$ & & & & \\
\hline 0 & \multirow{3}{*}{ 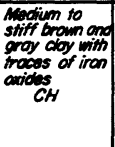 } & $29^{\circ}$ & 56 & 24 & 32 & 0.16 & 0.76 & 120 & 815 & 0.91 \\
\hline \multirow{2}{*}{6} & & 28 & 52 & 22 & 30 & 0.20 & 0.97 & 123 & 925 & - \\
\hline & & 31 & 43 & 20 & 23 & 0.48 & 0.68 & 120 & 595 & 1.32 \\
\hline 9 & Solft to & 32 & 44 & 20 & 24 & 0.50 & - & 119 & 585 & 0.93 \\
\hline 12 & silty clay & 30 & 54 & 22 & 32 & 0.25 & 0.82 & 120 & 683 & 0.90 \\
\hline 15 & & 32 & 44 & 21 & 23 & 0.47 & 0.79 & 121 & 423 & 0.77 \\
\hline 18 & & 34 & 38 & 21 & 17 & 0.76 & 0.77 & 116 & 356 & 1.12 \\
\hline 21 & $\begin{array}{l}\text { Modium gray } \\
\text { silty slay }\end{array}$ & 36 & 34 & 23 & 11 & 1.18 & 0.61 & 120 & 183 & 一 \\
\hline 24 & $\begin{array}{c}\text { with argonics } \\
M L / O L\end{array}$ & 37 & 34 & 24 & 10 & 1.30 & 0.56 & 113 & 285 & 1.08 \\
\hline 27 & Soft to & 36 & 51 & 22 & 29 & 0.48 & 0.84 & 112. & 589 & 2.07 \\
\hline 30 & $\begin{array}{l}\text { silty cloy with } \\
\text { silt lons }\end{array}$ & 35 & 39 & 22 & 17 & 0.76 & 0.65 & 113 & 563 & 1.40 \\
\hline 33 & & 36 & 49 & 22 & 27 & 0.52 & 0.75 & 117 & 464 & 1.96 \\
\hline 36 & & 35 & 38 & 22 & 16 & 0.81 & 0.91 & 119 & 323 & 2.75 \\
\hline 39 & & 44 & 50 & 22 & & 0.79 & - & 112 & 635 & 2.62 \\
\hline
\end{tabular}

* Averoge $S_{U}$ for $3^{\prime \prime} \varnothing$ Shelby sompler.

\section{TABLE 9 SOIL PROPERTIES - MORGAN CITY (TYPICAL VALUES)}


strength.

A significant amount of scatter in strength test data from undisturbed samples is shown in Figure 175 of Appendix E. As can be seen in Figure 176 of Appendix E, the moisture content of the Morgan City samples yaried widely. Whether this can be attributed to sample disturbance and/or to natural variation may be debatable. However, it does seem to strongly suggest that such a soil, while not sensitive to structural disturbance, is sensitive to changes in moisture content. Rowe, 1972 , pp 197, 198) discusses sensitivity of some silty clays as being a function of permeability and change in moisture content more so than mechanical shear. He also observed that permeable fabrics caused wide scatter in the undrained strength.

The results of consolidation tests on samples from the $9-12 \mathrm{ft}$. depth are shown in Figures 81,82 , and 83 , respectively. The samples from the $12 \pm \mathrm{ft}$. depth indicated overconsolidation ratios of between 2 and 7. The three and the five inch shelby samples for the 12 $15 \mathrm{ft}$. depth gave almost identical results, Figure 82 . This was not the case for the samples from the $30 \mathrm{ft}$. depth, Figure 83 . At first glance, the e $\log \bar{\sigma}$ curve would indicate a greater degree of disturbance of the 5 inch shelby samples. That is, a greater degree of remolding as a result of sampling and testing techniques. However, an examination of the coefficient of consolidation, $c_{v}$, shows the 5 inch shelby values to be greater than that of the 3 inch shelby. This is contrary to what should occur as a result of remolding.

The preconsolidation pressures as shown by the two curves in Figure 83 also disagree. That of the three inch sample is more than 

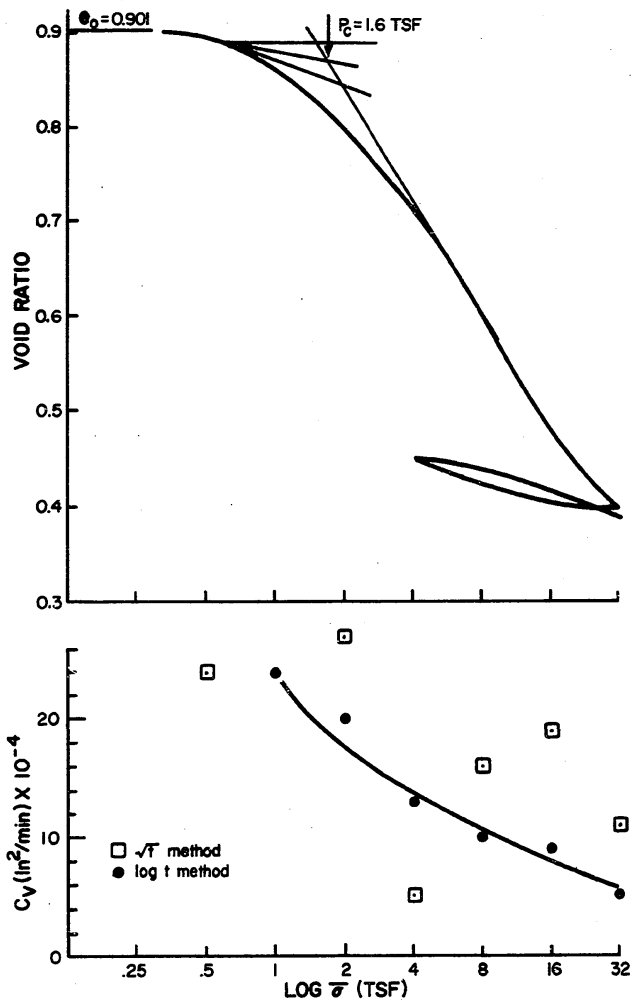

FICURE 81 CONSOUDATION TEST - MOREN CITY STE $3^{\prime \prime} \emptyset$ SHELBY SAMPLE $\left(9^{\prime}-12^{\prime}\right.$ DEPTH) 

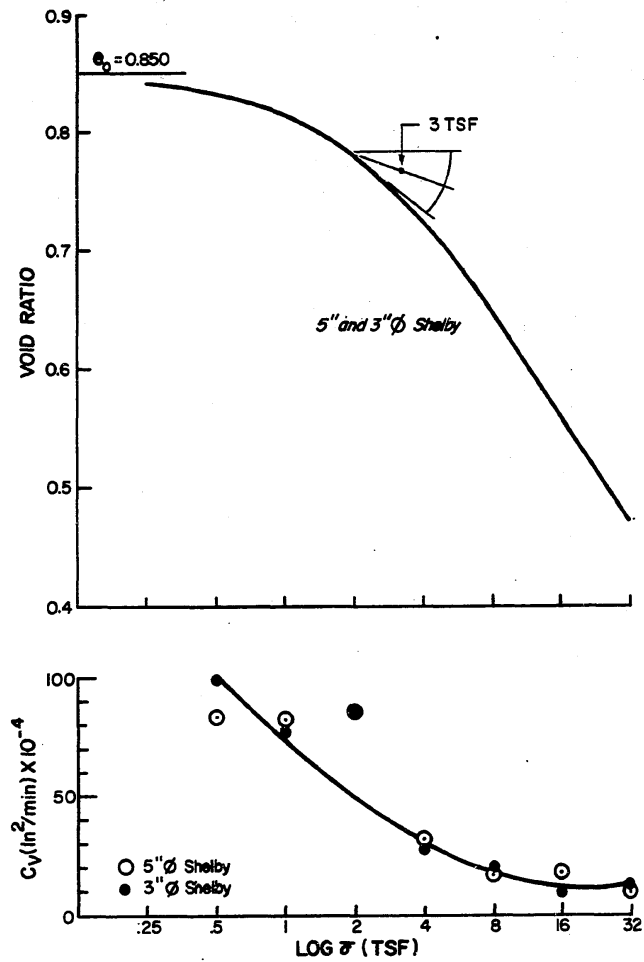

FIGURE 82 CONSOLIDATION TEST - MORTAN CITY SITE (12'-15' DEPTH) 

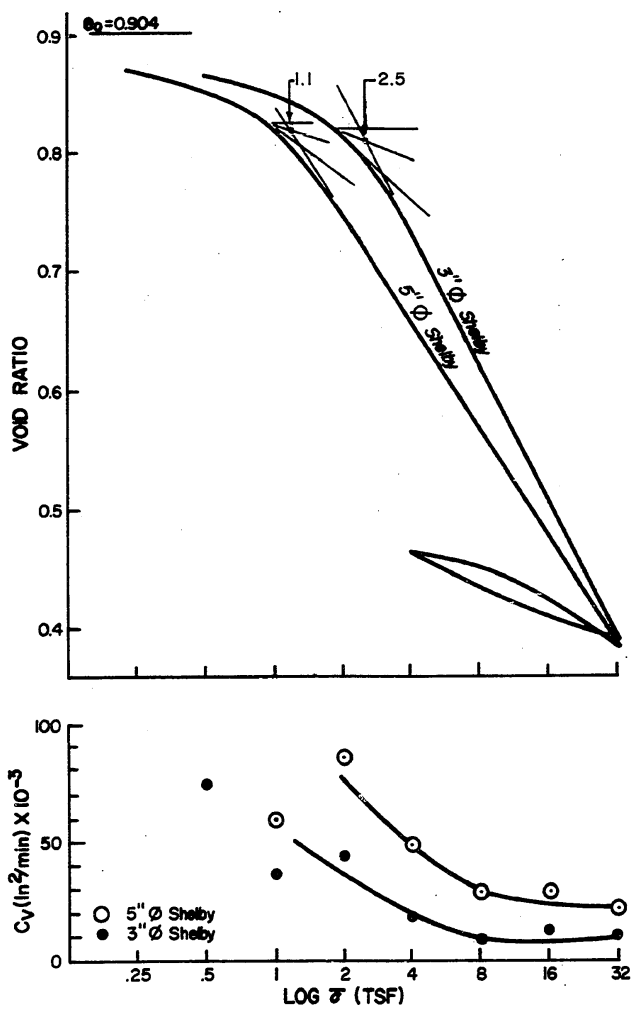

FIGURE 83 CONSOLIDATION TEST-MORGAN CITY SITE (30'-33' DEPTH) 
twice the value obtained from the test on the five inch sample. The five inch preconsolidation pressure of 1.1 tsf is approximately equal to the existing overburden and would indicate that the soil at this depth is a normally consolidated or perhaps a slightly overconsolidated soil. For this depth and considering the fact that the soil is a recent deltaic material, it appears that the preconsolidation pressure computed from the 5 inch thin-wall tube sample is more acceptable than that of the three inch sample.

In sampling, the permeable fabric of the soil lends itself to a greater degree of remolding by the three inch shelby sample. The remolding tends to increase the preconsolidation pressure and may, in some cases, increase the shear strength. The coefficient of consolidation at the 30 foot depth is greater by more than a factor of ten, than that of the specimen from the twelve foot depth.

Thus, as emphasized by Rowe, 1972, a detail description of the fabric may be quite relevant in selecting the type of samples and testing program. It is aiso a major consideration in assesing sampling disturbance. Additional test data for the Morgan City site is presented in Appendix $\mathrm{E}$. 


\section{BENTON SITE}

\section{Location and Geology}

Located in Bossier Partsh, north of Benton, Louisiana, this site consisted of soil of the Pleistocene Prairie Terrace, Figure 30. Broad, relatively flat expanses of Fluviatile Terraces in this area are commonily referred to as "Oak Flats". These areas are known for their retention of water for long periods after rains.

In general, the Pleistocene Terrace soils in Bossier Parish exhibit a profile development as a result of downward leaching of clays, the top zone tends to be silty and at lower levels, where the clay collects or concentrates, claypan results. Below the claypans, clays and grey silt lens are found.

\section{Sampling and Field Testing}

Both 3-inch diameter and 5-inch diameter tubes were used to secure samples at this location.

The standard penetration test was conducted at 3 foot increments from the surface to a depth of $\mathbf{4 2}$ feet. SPT samples were secured and sent to the laboratory. Profile data is given in Figure 84 and Table 10.

\section{Test Resuits}

Moisture content of this soil was approximately equal to the plastic limit. Atterberg tests, grain size and unconfined compression tests were conducted on samples obtained from depths ranging between 18 and 27 feet. This was a yery stiff brown fissured clay. Strength 


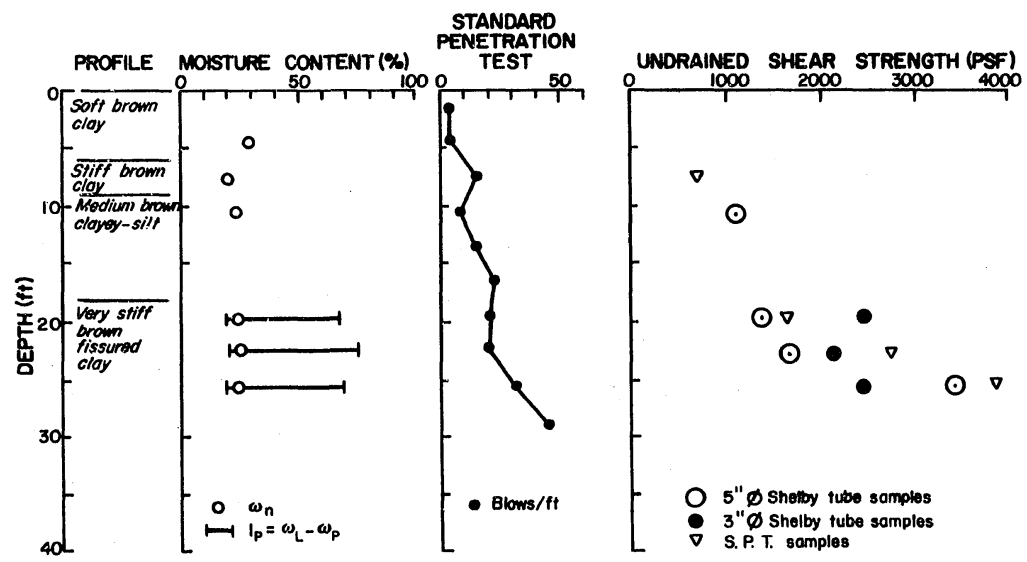

FIGURE 84 SUMMARY PROFILE - BENTON SITE 


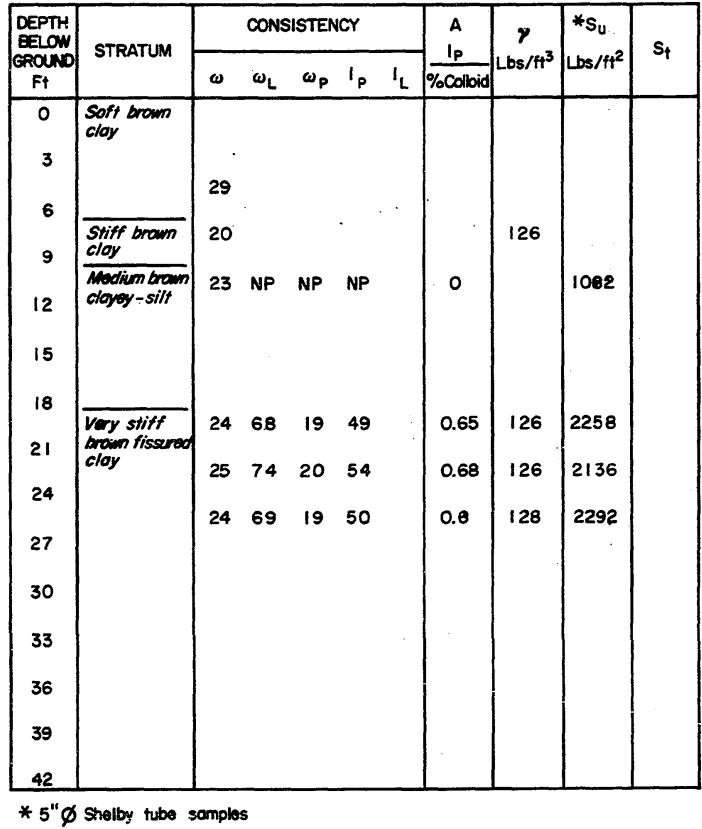

TABLE 10 TYPICAL SOIL PROPERTIES-BENTON SITE 
tests were conducted on 5-inch diameter, 3-inch diameter and split spoon samples. As the split spoon samples are obtained with a heavy wall sampler, which is percussion driven, the remolding effect of sampling is obviously much greater than those of the shelby tubes.

A comparison of the sampler influence on the unconfined shear strength of samples obtained with the split spoon, 3-inch shelby tube, and 5-inch shelby tube at the Benton site is presented in Figure 85 . The diagonal line is the equal strength line. Note that the split spoon samples gave strengths greater than the 3 and 5 -inch diameter samples and that the 3-inch sample strength was larger than the 5-inch sample. Thus, the remolding effects of sampling on this stiff fissured clay is one of increasing the unconfined shear strength. Additional laboratory test data is presented in Appendix E. 

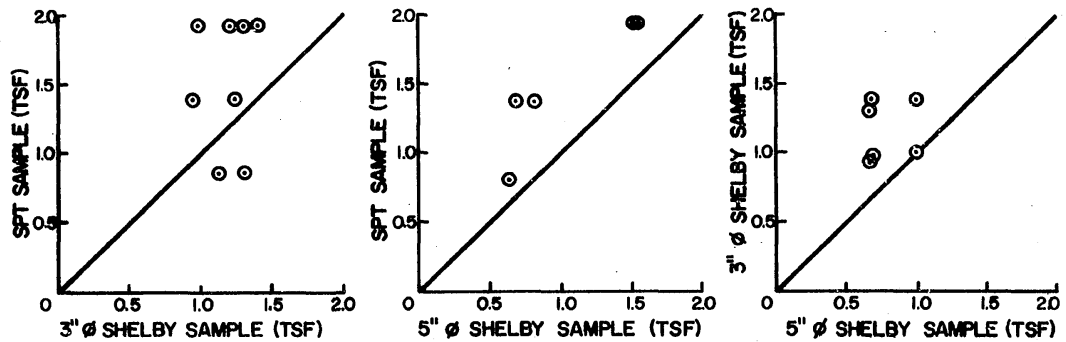

FIGURE 85 SAMPLER INFLUENCE ON UNCONFINED SHEAR STRENGTH-BENTON SITE 


\section{BATON ROUGE SITE}

\section{Location and Geology}

Several boreholes were placed in the Louisiana Department of Highways yard at the central testing laboratory in Baton Rouge, Figure 30. The material sampled was of the pleistocent Prairie Terrace and consisted of a stiff brown fissured clay with silt lens and traces of iron oxide.

\section{Sampling}

A series of 3 -inch thin-wall samples ranging from a depth of 23 to 32 feet were secured from three boreholes. Much of the material above this depth consisted of silts or was artificially placed fill material. All of the samples were taken with the 3-inch shelby tube.

\section{Test Results}

At the Baton Rouge site, the initial intention was to study the effects of storage time on the compressive strength. However, the response of the material was dominated by the occurance of fissures and slickensides. The effects of storage of this soil tended to be masked by the macro-structure.

Four sets of tests were conducted. These included unconfined compression strength run at different storage periods and a remolded series. The storage periods included:

1. Four to six hours after sampling,

2. One week of storage in the moisture room, and

3. One month of storage in the moisture room. Profile data and test results are presented in Figure 86. 


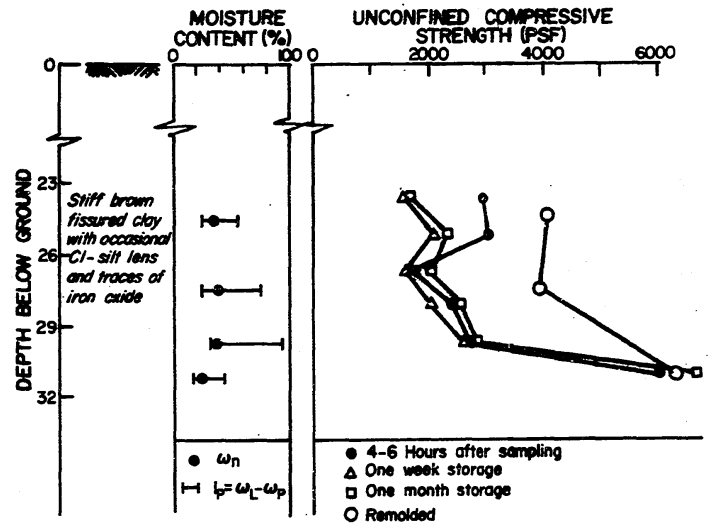

FICURE 86 SUMMARY PROFLE AND STORAGE TEST RESULTS BATON ROUGE SITE 
A comparison of the remolded strength to that of the undisturbed conpressive strength is shown in Figure $87 a$. The diagonal 1 ine represents equal strength. Remolding of the fissured material increased the strength. In Figure $87 \mathrm{~b}$, the undisturbed upper and lower. sample are compared. The lower sample strength was somewhat greater than that of the upper sample strength. This indicates the possibility of a greater degree of remolding to the lower portion of the sample. This would seen logical since the friction forces at the wall of the sampler increase with penetration depth. Thus the stress intensity at the lower portions of the sample is higher than that near the top surface of the sample, Figure 6. Lang (1971) also found that test specimen from the lower portion of the sample of a stiff clay consistently yielded higher strength test results than those from the upper portion. However, he did not indicate that the stiff clay was fissured.

Additional test data is given in Appendix E. 


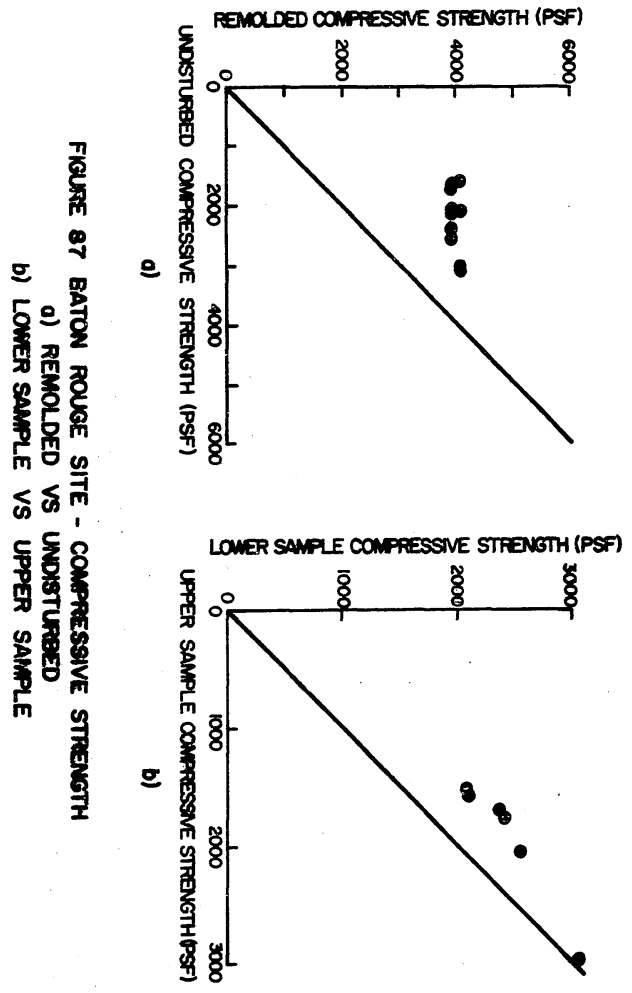


MONROE SITE

\section{Location and Geotogy}

This sampling site is located northeast of Monroe, Louisiana. As shown in Figure 30 , the surficial material is recent alluvium. These soils are characteristically gray or brown in color and are believed to have been transported and deposited by the Quachita River as an extensìve alluvial fan. This recent alluvium overlaps the Pleistocene Prairie Terrace which outcrops just to the north in Morehouse Parish. Soils of the Prairie Terrace are highly oxidized and are a reddish brown color.

\section{Sampling and Field Testing}

Five-inch and three-inch diameter shelby tube samples were secured. The standard penetration test was conducted at 3-foot intervals to a depth of 42 feet. The SPT samples were retained for laboratory tests.

\section{Test Results}

The soil profile is shown in Figure 88, and the soil properties are given in Table 11. Unconfined compression test and the undrained triaxial tests were used in testing the soil. As indicated in the soil profile of Figure 88 , the materiai was a stiff fissured soil. However, for the confining pressures used $\left(\sigma_{3} \simeq \sigma_{0}\right)$, there did not seem to be any effect on the shear strength of one test technique as opposed to the other.

A comparison of sampler influence on the average undrained shear strength, Figure 89, appears to indicate an increase in strength as a result of sample disturbance, or remolding. Note that the shear strength 


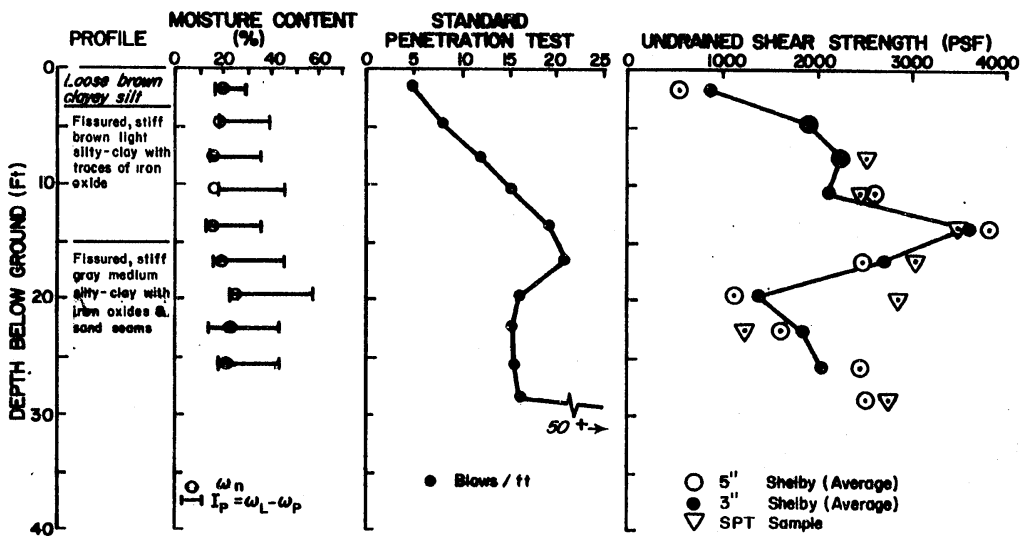

FIGURE 88 SUMMARY PROFILE - MONROE SITE 


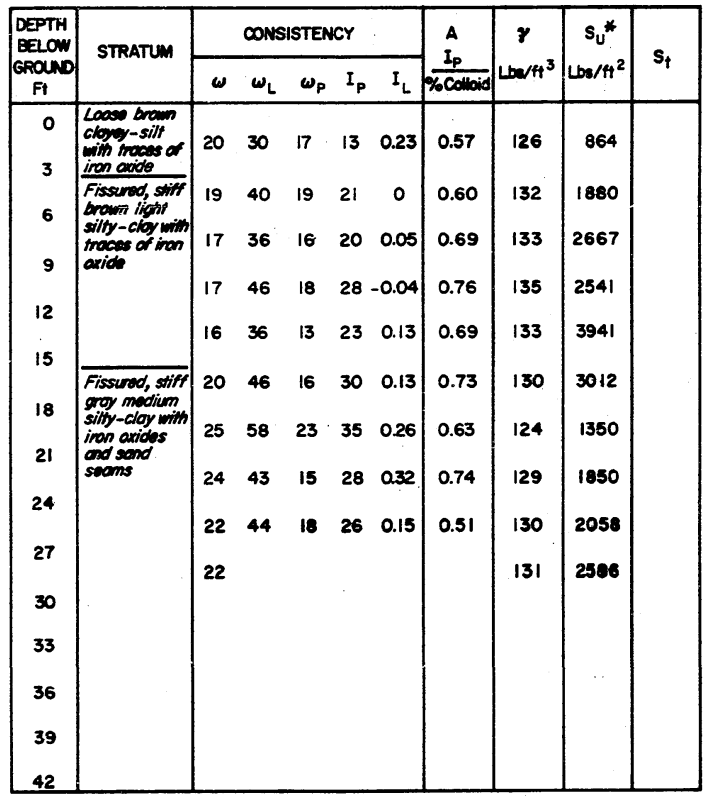

* Average $S_{U}$ for $3^{\prime \prime} \varnothing$ Shelby sompler

TABLE II TYPICAL SOIL PROPERTIES - MONRCE SITE 

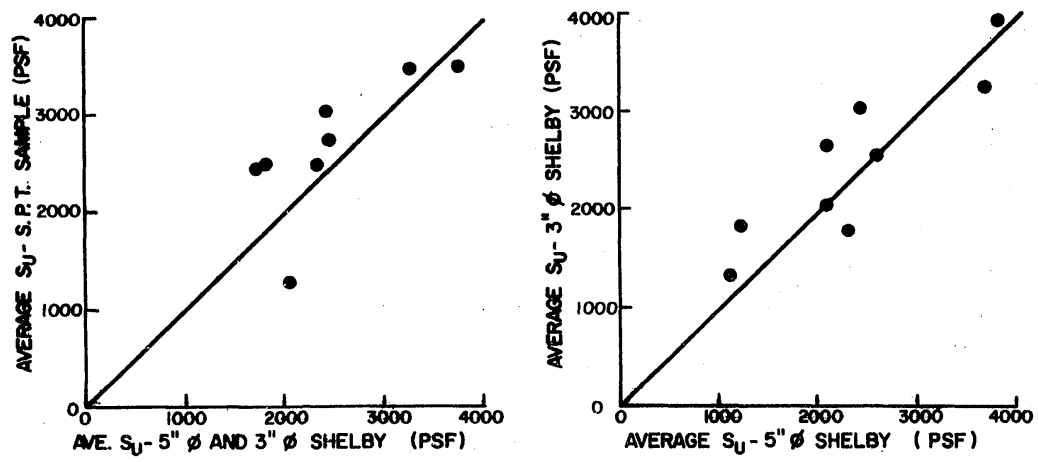

FEURE 89 SAMPLER INFLUENCE ON ANERAGE UNDRAMED SHEAR STRENGTH MONROE SITE 
of the SPT samples exceed somewhat that of the 3-inch and 5-inch samples and that there seems to be a slight increase of strength of the 3 -inch over the 5-inch samples. This is attributed to the remolding of the fissured material. 
LAROSE SITE

This site is located southwest of New Orleans and east of Houma in Lafourche Parish, Figure 30. The sampled soil consisted of a Recent natural levee deposit. Figure 90 is a radiograph of a 3-inch core sample and indicates a caotic flow of the silt material. The pattern is such that this is attributed to sampling disturbance or flow of the material during sampling.

\section{FILLMORE SITE}

The Fillmore site is located approximately fifteen miles east of Shreveport. The soil is of the Tertiary Wilcox formation. This is a stiff layered soi1, Figure 30. Radiographs of the cores show many vertical cracks, Figure 91. It is believed that the drag along the inside surface of the sample tube caused these cracks. The stiffness and brittleness of the soil was such that vertical fracturing of the layers occurred rather than bending.

\section{UNDISTURBED SAMPLING RELATIVE TO SOIL FABRIC}

In addition to the geologic formations to which the individual sites were identified with, it was observed that the response of the soil was related to the type of soil structure or fabric. Samples tested in this study were categorized such that the effects of sampling on soils within a group is similar. For the sampling sites inyestigated, the soils are grouped as follows: 


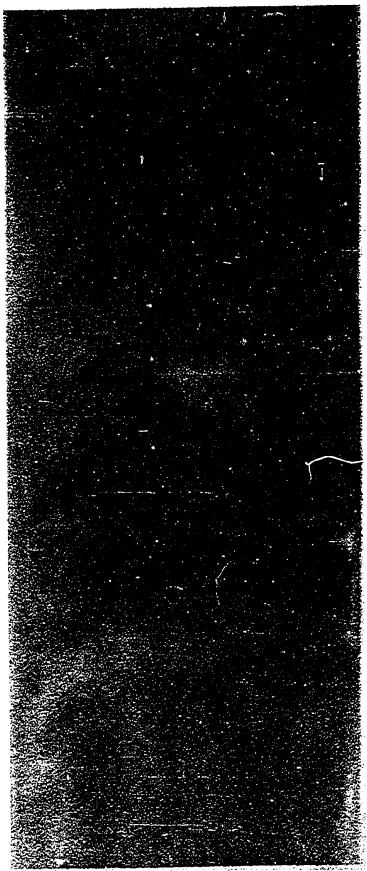

Figure 90 - X-Ray Radiograph - 3" O.D. Core - LaRose Site 


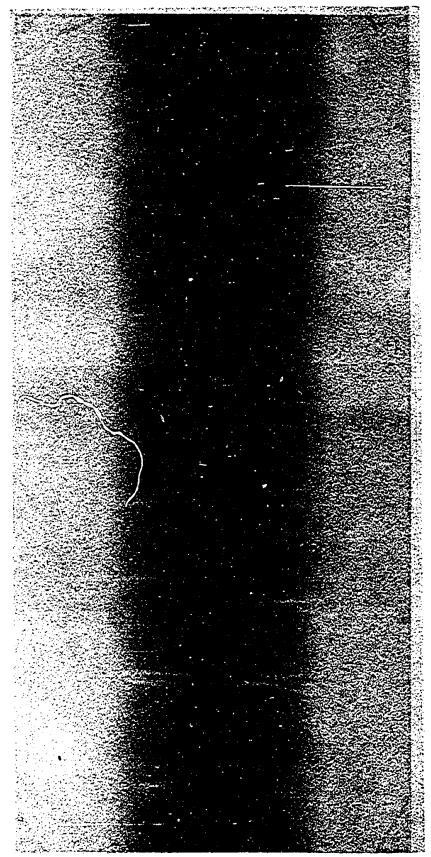

Figure 91 - X-Ray Radiograph - 3" 0.D. Core - Fillmore Site 
Fabric or Soil Structure/Geology

$$
\begin{gathered}
\text { Stiff-fissured clay } \\
\text { Pleistocene }
\end{gathered}
$$

Multiple slickensided clays Recent Backswamp

Permeable Fabric silty-ciays \& clayey silts Recent Deltaic

Soft, varyed silts and clays Recent aluyial-marine

Homogeneous, Irregular clay fabric Pleistocene
Site

Baton Rouge

Benton

Lake Charles (0-27 ft.)

Monroe

Erwinvilie

Horgan City

Houma

Laplace

Lake Charles $(30 \pm f t$.

In general, the response of the stiff fissured Pleistocene clays to sampling was one in which some degree of smearing or remolding of the fissures took place. As a result, unconfined tests and triaxial tests at lower chamber pressures yeilded greater strengths for the more disturbed samples. These values, however, are probably lower than the actual in-place strength which exists with the confining pressure and support of the intact soil strata. But, for a slope stability or trenching problem, the disturbances or remolded fissures may yield strength values too high for design.

The nature of the fissures and their orientation is the governing criteria of the test performance of these samples. Sampling disturbance in such a material appears to be secondary although prolonged storage of samples may result in a stress relaxation at the interface of the fissures. An in depth study of the effect of confining pressure was 
not conducted in this program of research, though a relationship surely exists. It is common practice in local soils laboratories to use the remolded strength of fissured soils for most engineering problems. As discussed, the Recent backswamp soil of Erwinville has a macrostructure consisting of a network of slickensided surfaces. The samples could be readily pulled apart into smalier and smaller lumps. These were separated by shiny planes of weakness or slickensides. This material did contain many roots which offered some degree of reinforcement. As with the stiff Pleistocene soils, remolding or sample disturbance increased the unconfined strength. The overall test results are primarily dependent on the slickensides with the sampling disturbance of a secondary consequence. However, in comparing the test results on a 5-inch sample which is trimed down for testing to a 2.8 inch diameter with that of a 2.8 inch sample (untrimed), tested as extruded from the $3^{\prime \prime}$ sampler, the smaller untrimed sample should on the average produce slightly higher strength values. This would be the result of the smeared periphery of the smaller samples edges.

The grainy texture of the Morgan City-Houma site in combination with the higher silt percentage produced a soil which was permeable in nature. Such a soil is sensitive to moisture content variations which may be altered as a result of the sampling operation. The results of tests on these soils did show erratic results.

The soft varved layers of silts and clays found at Laplace were subject to drastic distortion in sampling. Test results from different samples, strongly shows the pneumatic piston sampler to be the best in securing good quality samples. The piston samples compared quite 
favorably with the field vane test results. The soft, silty clays occuring between the silt and the silty-sand layers was quite fluid. Structural disturbance in sampling ranged from caotic flow of the soil to shearing of the layers as a result of drag on the sampler walls.

The macrostructure of the Lake Charles soil at 30 feet consisted of a heavy grey clay matrix with scattered shells and silt seams. However, the engineering properties of this soil were governed by the microstructure of the clay. The growth of pyrite crystals had altered the clay particles arrangement yielding an irregular and unstable fabric or one with a random pattern throughout the soil. As a result, the clay structure was sensitive to sampling techniques and size. Block samples were far superior to the more common 3-inch shelby sample.

\section{Sample Protection}

Two methods of sealing the extruded cores were to be compared. Identical samples were either completely imersed in melted paraffin or wrapped first in household polyethylene film and aluminum foil and then sealed in household polyethylene bags. All samples were transported in specially-molded styrofoam boxes (Figure 4).

The coating of undisturbed samples with paraffin has been accepted as one method of preserving sample integrity. However, earlier laboratory observations indicated that eyen experienced and carefur technicians had difficuities in renoving the hardened paraffin without damage to the samples, Also noted was sweating under the paraffin. A sample from a depth of 40 . feet has a body temperature of about $65^{\circ} \mathrm{F}$, $\left(18^{\circ} \mathrm{C}\right)$. Then it is urapped in foll and dipped in hot paraffin $\left(49^{\circ} \mathrm{C}\right)$, 
considerable sweating results, with an increase of moisture content in a zone adjacent to the outer surface of the sample. The potential sudden effects of water migration on the pore pressure and moisture distribution, as well as the homogeneity of the soil, would be highly undesirable.

The use of aluminum foil and plastic film as a protective coating, instead of paraffin, was studied.

Approximateiy 100 tube samples (about 18-inches long) of three types of soils were sliced lengthwise immediately after sampling to make three specimens. One of these, to be used for determining the natural moisture content, was wrapped in a plastic bag. The others were used to determine the effectiveness of two protective coatings. One slice, after being wrapped in foil, was placed in a 6-inch round ice cream carton which in turn was filied with melted paraffin (the usual field procedure). The other specimen was wrapped in aluminum foil and sealed with household plastic film. The three specimeno from one sample were then placed in a clear plastic bag that was partially sealed with a twist-wire tie and sent immediately to the laboratory in a styrofoam ice chest.

The natural moisture contents were determined immediateily upon arrival to the laboratory. Both the paraffin-coated and the foil/ plastic-wrapped specimens were stored at 100 percent humidity and at $72^{\circ} \mathrm{F},\left(22^{\circ} \mathrm{C}\right)$. After random storage periods of 14 to 33 days, the two specimen of a set were tested for moisture content from each whole stice.

The results indicated that the foll/plastic wrapping maintained the 
moisture content of a specimen Just as well as the paraffin coating (Table 12). After these tests, the Louisiana Department of Highways adopted the use of foil/plastic protection instead of paraffin. Samples are stored and transported in a specially designed insulated styrofoam container (Figure 4).

\section{Simulated Field Storage}

Earlier observations had shown that sampling crews usually remain in the field about five days before bringing samples to the laboratory. These samples were first extruded in the field, wrapped, placed in the special styrofoam boxes (Figure 4) and they were stored in covered trucks. The temperature in the storage part of these trucks often rose to and remained at $110^{\circ} \mathrm{F}\left(43^{\circ} \mathrm{C}\right)$ for about ten hours each day.

To study the effect of such storage on moisture content, 10-inch long samples (3-inch diameter) were brought in plastic bags to the laboratory immediately after extrusion. A 1/2-inch thick specimen was cut from the middle for determining the natural moisture content. The remaining two end sections (about 4.5-inches long) were then rewrapped and placed in the styrofoam containers. One set of containers was kept in a forced-draft oven at $110^{\circ} \mathrm{F}\left(43^{\circ} \mathrm{C}\right)$; the other set, at $72^{\circ} \mathrm{F}\left(22^{\circ} \mathrm{C}\right)$ and 100 percent humidity. After 5 days, the specimens were removed and the moisture contents determined from the whole 4.5-inch length.

Because no appreciable difference is moisture content among the three sets was found, it is evident that the storage methods and the two protective coatings caused no changes in the moisture content (Table 13). Thus any obseryed differences in the moisture content of samples are inherrent -- probably due to silt and calcareous intrusions, etc. 
TABLE 12

TEST OF SAMPLE PROTECTION METHODS

(Typical Soft and Stiff Heavy Clays)

14-31 Days at $72^{\circ} \mathrm{F}$ and 100 Percent Humidity

AVERAgE MOISTURE CONTENT (Percent)

Natural

29

27

39

35

39

51

53

57

22

22

24

64

67

19

21

17

13

12

\section{Paraffin-Coated}

26

29

37

35

38

48

54

53

21

24

19

64

65

16

21

18

20

13

12

Foil-Plastic Wrapped 
TABLE 13

SIMULATED FIELD STORAGE OF EXTRUDED CORES

\begin{tabular}{|c|c|c|c|}
\hline & Natural & 5 Days at $110^{\circ} \mathrm{F}$ & $\begin{array}{l}5 \text { Days at } 72^{\circ} \mathrm{F} \text { and } \\
100 \text { percent humidity }\end{array}$ \\
\hline $\begin{array}{l}\text { Heavy Clay } \\
\text { Heavy clay } \\
\text { Heavy clay } \\
\text { Heavy clay } \\
\text { Heavy clay } \\
\text { Heavy clay } \\
\text { Heavy clay } \\
\text { Silty Clay }\end{array}$ & $\begin{array}{l}56 \\
69 \\
69 \\
66 \\
67 \\
64 \\
64 \\
19.3\end{array}$ & $\begin{array}{l}63 \\
63 \\
69 \\
69 \\
71 \\
64 \\
64 \\
19\end{array}$ & $\begin{array}{l}62 \\
71 \\
70 \\
66 \\
65 \\
67 \\
63 \\
14\end{array}$ \\
\hline $\begin{array}{l}\text { Light } \\
\text { Silty Clay } \\
\text { clay } \\
\text { clay } \\
\text { clay } \\
\text { Clay } \\
\text { clay } \\
\text { Clay }\end{array}$ & $\begin{array}{l}29 \\
23 \\
56 \\
69 \\
66 \\
67 \\
64\end{array}$ & $\begin{array}{l}29 \\
23 \\
63 \\
70 \\
69 \\
72 \\
64\end{array}$ & $\begin{array}{l}30 \\
- \\
- \\
- \\
-\end{array}$ \\
\hline
\end{tabular}




\section{Long-Termi Storage}

The effects of long storage times on the shear strength and consolidation characteristics were determined from three types of samples: 12-inch hand-cut cubes, 5-inch cores and 3-inch cores. All samples were sent to the laboratory immediately after protective coatings had been applied. Initial testing was performed on 2.5-inch diameter cylindrical specimens trimmed from identical companion samples to determine the moisture content, unconfined compressive strength, undrained triaxial shear strength, and consolidation characteristics without long term storage effects. The remining samples were stored for different times at $72^{\circ} \mathrm{F}\left(22^{\circ} \mathrm{C}\right)$ and 100 percent humidity in the field-applied wrappings.

In the case of the unstored samples, the initial (4 to 7 days) undrained triaxial shear strengths of specimens from the 5-inch cores were slightly lower than those from the large hand-cut blocks. Specimens from 3.0 inch cores had much lower strengths (Figure 92). Such effects must be attributed to disturbances of the outer zones during tube driving and core extrusion.

At the end of randomly-chosen periods, the stored samples were remoyed from their containers, trinmed to cylindrical specimens (2.5inch dianeter), and tested for confined compressive strengths, undrained triaxial shear strength, and consolidation characteristics. Only samples with similar moisture contents, densities, and classifications were used.

Up through the first ten days of storage, the decrease in shear strengths for specimens from the three sizes of samples was small -practically indiscernable. Howeyer, the specimen strength of both the 


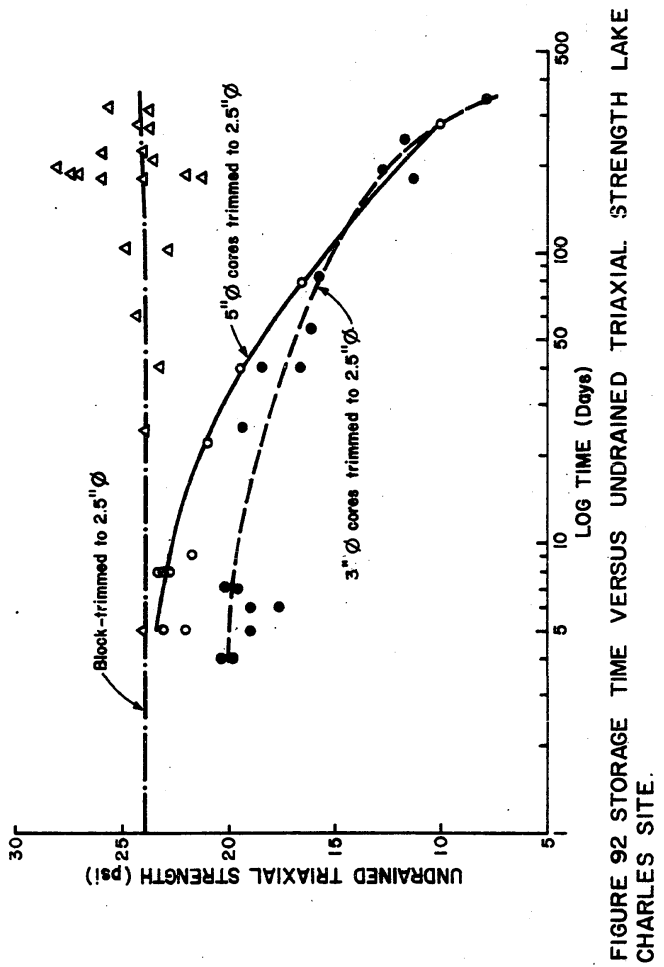

Reproduced with permission of the copyright owner. Further reproduction prohibited without permission. 
3-inch and 5-inch cores deteriorated at an increasing rate after the first ten days (Figure 92).

Any attempt to analyze this strength deterioration versus time numerically would be of no value and might be misleading, because each type of soil reacts differently to storage time as well as other disturbances. However, it is of the utmost importance to know that extended storage affects the strength and that it should be avoided. The derivation of a universal correction factor or formula does not appear feasible due to all the variables involved.

The relaxation of overburden stresses, changes in pore pressure, and unavoidable migration of water within the sample, as some of the reasons for changes in the measured soil characteristics, are demonstrated by the lack of strength reduction in specimens from tire block samples (Figure 92). The results agree with those of Kallstenius (1971).

Extended storage times also bring about a reduction of the preconsolidation pressure by as much as 30 percent (Figure 93), for specimens from the tube cores. By contrast, no change occurred in the block samples, except for some scatter after 100 days. Bozozuk (1970) found much less reduction, only 4.8 percent.

Evidence of disturbance in 3-inch cores is shown in Figure 94. The void ratio/log pressure curves approach those obtained from the same soils after thay had been remolded and compacted under static loads that approximated the original overburden pressures.

The average moisture contents during extended storage remained unchanged. Conceivably, some change in moisture content or dry density should also occur. However, all determinations of these properties 


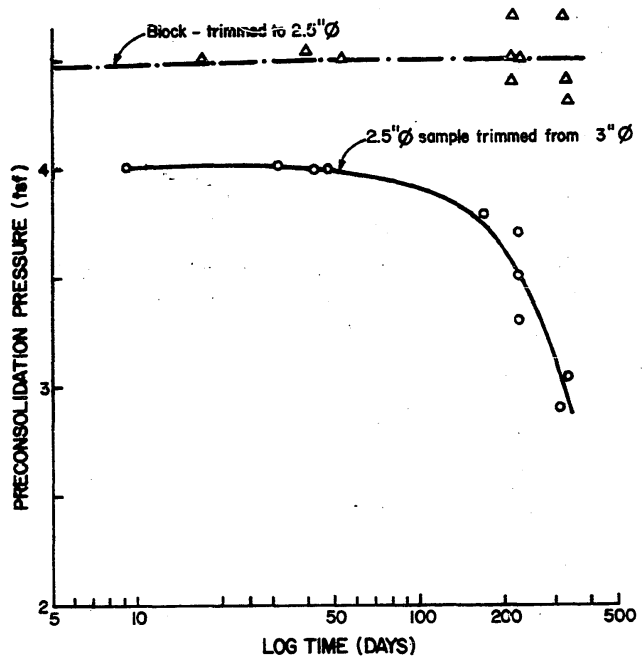

FIGURE 93 STORAGE TIME VERSUS PRECONSOLIDATION PRESSURE, LAKE CHARLES SITE 


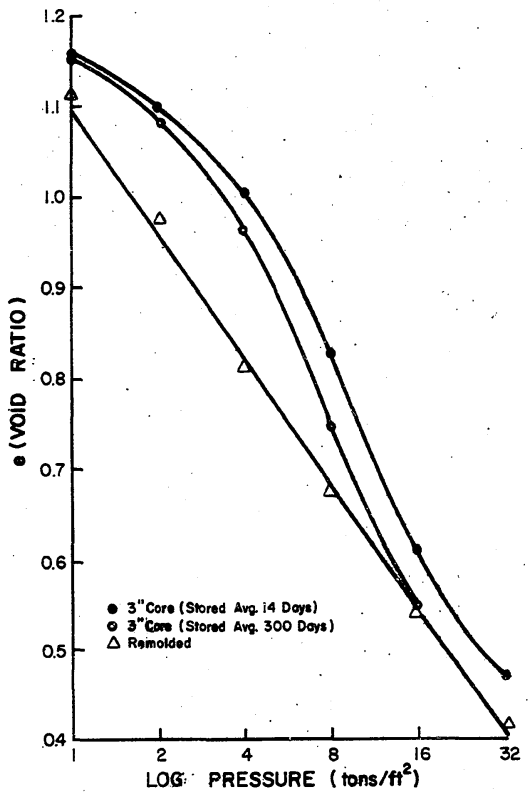

FIGURE 94 STORAGE EFFECTS. LAKE CHARLES SITE 
showed only small variations due to natural inherent scatter.

\section{Extrusion Effects}

Several methods are used to extrude soil cores frem sampling tubes. Pressurized water, as well as hydraulic rams, are used in the field or laboratory. Each method affects the soil properties, depending on the soil type, its condition, and the type of sampling tube, etc.

Several replicate samples were obtained with a 3-inch thin-walled tube from each type of soll deposit. Some cores were hydraulically extruded in the field and placed in a protective coating. Others were sealed in the tubes. All samples were transported without delay to the laboratory.

The field-extruded samples were tested for unconfined compressive strength after being radiographed.

The sealed samples were used to determine the extrusion pressure and the resulting strains. At first, strain cells attached to the piston of the hydraulic ram were used to determine the extrusion forces. More consistent results were later obtained with a calibrated pressure gage attached to the oil cylinder. The displacement at the ends of the cores were measured with two extensiometers.

After a core has been extruded, a portion of it was trimmed and tested for unconfined compressive strength. Another section was sliced for $\mathrm{X}$-ray radiography. Some test specimens were also radiographed before the unconfined compression test.

During the core extrusion, the end of the sample in contact with the piston began to show measurable displacements before the opposite 
end. Thus internal displacements were occurring within the tube. The maximum strain (the strain at the piston end before steady movement at the opposite end) varied from 0.001 to 0.005 . The average strain was 0.003 (Table 14).

In all cases, the applied stress exceeded the unconfined compressive strength of the soit to a maximum of 900 percent. This is somewhat less than the 1340 percent measured by Lang (1971).

A serious type of disturbance shown by radiographs was failure plane patterns in some of the untested clays (Figures 57 and 68). These failure planes occurred at intervals along the longitudinal axis of some specimens.

To determine if the failure planes had occurred during either sampling or extrusion, radiographs of specimens in tubes were also made. However, because of parallax effects caused by the roundness of the sample and shadowing of the high-intensity $X$-rays necessary to penetrate the steel tubes the tests were inconclusive. Thus it could not clearly be determined when these failures occurred. However, edge turning colid be observed in the radiographs of unextruded cores--an indication that at least some of the edge distortion took place during tube driving, which is to be expected. Howeyer, it is more likely that most of the failure planes appeared during extrusion because the sample was in compression.

It was observed in the field, that in driving the sample tube, it was not uncormon to see the rear end of the truck-mounted rig lift off the ground. This technique, which was utilized by the field crews in insuring that a full length of sample was secured, raised the question 
TABLE 14

TYPICAL EXTRUSION STRESSES AND UNCONFINED COMPRESSIVE STRENGTHS (Heavy Stiff Clay at 35-foot Depth)

\begin{tabular}{ccccc}
$\begin{array}{c}\text { Sample } \\
\text { Length } \\
\text { (inches) }\end{array}$ & $\begin{array}{c}\text { Max. Extrusion } \\
\text { Stress } \\
\text { (psi) }\end{array}$ & $\begin{array}{c}\text { Max. Extrusion } \\
\text { Strain }\end{array}$ & $\begin{array}{c}\text { Unconfined Comp. } \\
\text { Strength* } \\
\text { (psi) }\end{array}$ & $\begin{array}{c}\text { Unconfined Comp. } \\
\text { Strength** } \\
\text { (psi) }\end{array}$ \\
\hline 22 & 69 & 0.005 & 17 & - \\
33 & 150 & 0.004 & 12 & 14 \\
32 & 137 & 0.004 & 20 & 18 \\
33 & 94 & 0.003 & 20 & 19 \\
33 & 129 & 0.003 & 14 & - \\
33 & 159 & 0.003 & 20 & - \\
25 & 78 & 0.001 & 6 & - \\
33 & 198 & 0.003 & 28 &
\end{tabular}

*Laboratory-Extruded

**Field-Extruded 
of oyerdriving. Figure 95 shows the top of a laboratory extruded sample which was overdriven. Note the knob at the top which is formed where the soil, under pressure, was forced into the adapter head at the top of the sampler. This technique used by some of the fieid crews could account for the formation of failure planes occurring in some of the samples.

\section{Photoelastic Analysis}

To obtain a qualitative analysis of the stress patterns developed during sampling, a photoelastic analysis was performed with a thin-wa1led tube that had two opposite $90^{\circ}$ arcs of the wall removed.

A gelatin/water mixture was poured into a 4-foot $\times$ 5-foot $\times$ 3-inch glass-walled tank with cross polorizing filters on the walls. After the gelatin had set, a tube sampler was slowly driven in by hand. The developed stress patterns (resulting from bi-refringence of gelatin) were recorded on color movie film and color still photographs (Figure 96). These patterns, covering the full volume of the driven tube, were very similar to the bent layers in soft soils that had been observed in the radiographs (Figure 72). However, no failure planes developed.

Although this experiment showed that disturtion occurs during sampler driving, it did not disprove the earlier-stated contention; friction due to adhesion of the soil to the tube wall increases the distortion during extrusion.

Variations in 36 -Inch Long Cores

Ftgure 97 shows the erratic physical yariations along a typical 


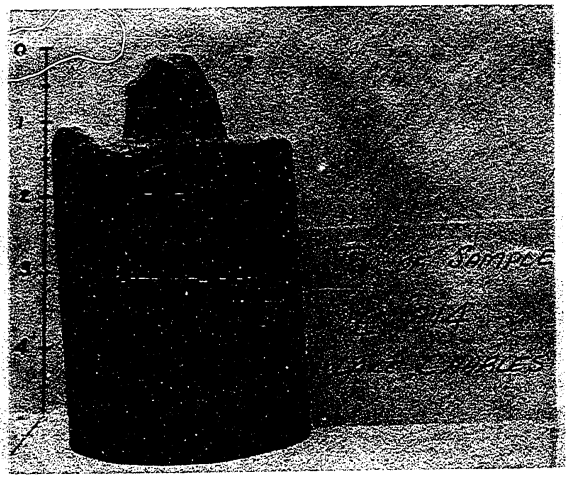

Figure 95 - Top of Overdriven Sample 


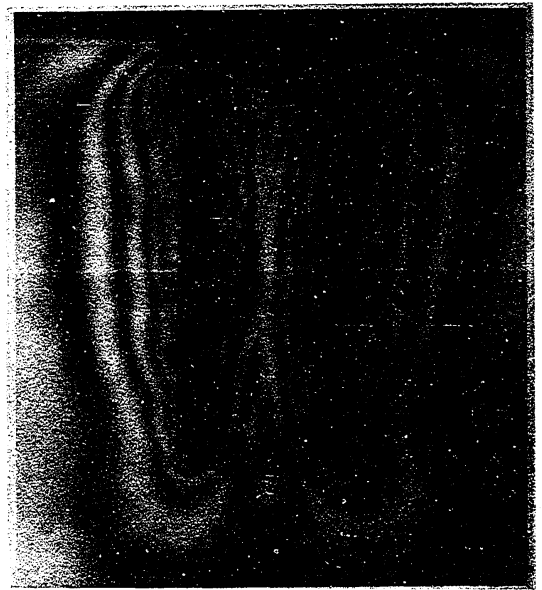

Figure 96 - Photoelastic Stress Patterns During Sampling 
36-inch long tube sample obtained from a soil that is locally considered to be uniform. (It should be noted that the core was classified as a silty clay for its full length.) All the specimens showed similar variations in the Atterberg 1 twits. With the unconfined compressive strength varying from 1100 to 2700 psi, the arbitrary selection of a representative single specimen from this sample could result in either underdesign or overdesign.

It should be emphasized that some of these yariations are probably due to sampling and extrusion disturbance. However, slickensides not visible to the naked eye, very thin sand and silt layers, calcareous nodules, and marine shells were observed in radiographs of parts of these specimens. 


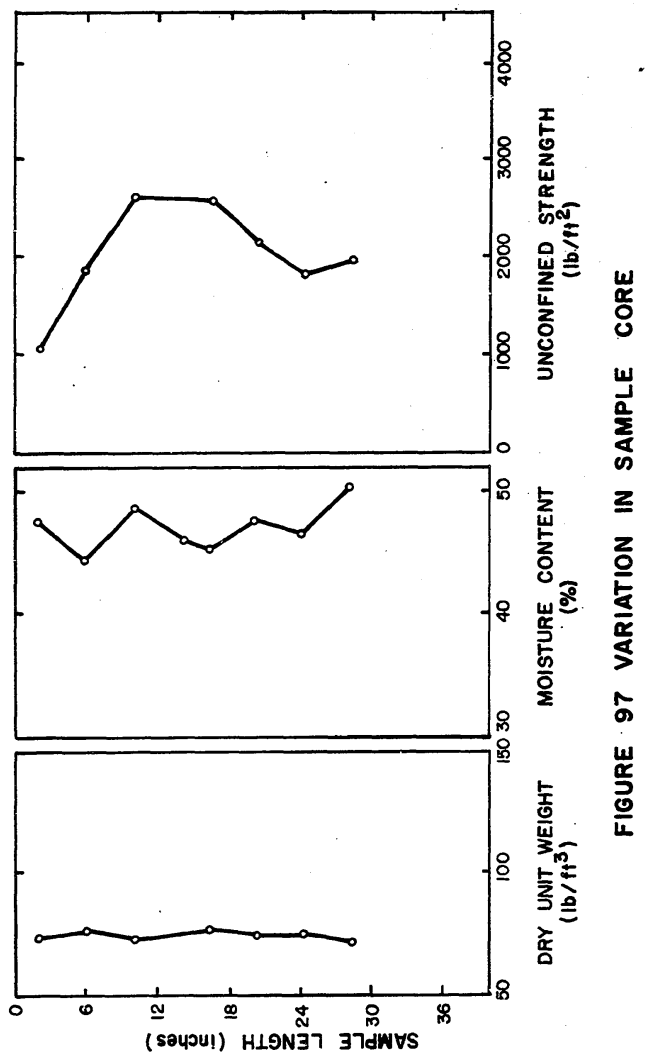

Reproduced with permission of the copyright owner. Further reproduction prohibited without permission. 


\section{CONCLUSIONS AND RECOMMENDATIONS}

The following conclusions are made based on the results of this study;

1. Engineering properties of soils studied showed significant inherent variations. Thus, in selecting representative data for design purposes it is of utmost importance to determine the predominant characteristics of soils rather than characteristics of individual specimens.

2. The extent and nature of the sampling disturbance occurring is a function of the soil type and the sampling techniques used. Consideration must be given to the fabric of the soil when selecting the proper sampling tool.

Disturbance caused by sampling a fissured material has a tendency to remold the discontinuous surfaces. This occurs more so in the smaller tube samples. The effect of stress release on a fissured material is one of separation of the fissures. Thus, the tendency of one disturbing factor in combination with the other is a partial compensation. However, in unconfined compression tests and undrained triaxial tests with low to moderate (approximately that of the effective overburden stress), failure does occur along 
existing fissures. Thus the effects of stress release appears to be most critical on such test results. It is the effects of sampling on the macro-structure (i.e. fissures) that is of interest here.

For soft soils (i.e. high moisture contents or soils which have a tendency to flow, a piston sampler should be used. Field tests such as the shear vane device should also be conducted with the sampling of soft soils when possible.

In sampling soils with a permeable fabric (i.e. a high silt and sand content) there is a danger of altering the natural moisture content.

For soils in which failure occurs in the microstructure (such as the Lake Charles site at the 30foot depth), disturbance due to sampling is in the form of an alteration of the clay particles or a weakening of the particle binding.

3. Larger samples minimize the sampling disturbance. Whenever practical, large (5-inch) diameter samples should be obtained and trimmed down to 2.5 inches or 1.4 inches in diameter to eliminate the distorted outer sections of the specimens.

In many cases, there in no advantage of a larger sample over the more common three-inch shelby tube sample. However, if there is a question concerning the sample quality, a series of larger samples should 
be taken for comparison.

Block samples provide the least disturbed soil sample.

4. Current sampling methods and equipment used in Louisiana can drastically al ter the test results of soil specimens, particularly the results of strength and consolidation tests. As much as 55\%, (Lake Charles), decrease in strength was noted in this study. Variation of the shape of the $\mathrm{e} \log \bar{\sigma}$ curve between sample types was also observed to be significant and resulted in large discrepancies in settlement predictions in some instances.

The stress-strain relationship of the soil is also greatly affected by sample disturbance. The modulus of elasticity was found to be dependent on the type of compression test ( $U$ or $U U$ ) for the tube samples. This was not the case for the less distrubed hand-cut block samples.

5. The methods of storing the samples in polyethelene plastic film and aluminum foil offers satisfactory protection for the cores provided they are stored in containers protecting them from impact and kept in a $100 \%$ humidity room.

Long-term storage of soil cores causes serious deterioration of the strength characteristics and a lowering of the measured preconsolidation pressure 
of the soil. Soil cores should be tested within 15 days after sampling to eliminate deteriorating effects of long-term storage.

The severity of stress relaxation and moisture migration increases with time and is to a great extent a secondary effect of the structural disturbance which occurs during the sampling phase.

6. For the soilis studies, extrusion of the cores required stress levels much higher than the strength of the soils being extruded. Soil reorientation as well as internal failures may take place during sampling and extrusion.

7. X-ray radiography is a useful tool in determining the extent of disturbances as well as the presence of anomalies within soil cores. X-ray radiography results should be made part of the soil testing in critical foundation design projects.

8. In-situ testing should be used as a means of verification and selection of design data.

The following recormendations are presented as considerations for further study:

1. Additional comparative analysis with piston and other sampling devices is needed. Currentiy the Osterberg sampler is used in securing soft clays which are dirficult to obtain with an open drive sampler. It is quite possible that some of the sample 
disturbance occurring in the sampling of

medium clays could be eliminated by using a piston sampler.

2. The formulation of a class or quality designation of sample type based on local needs is desirable. Such a system would be useful to engineers as a means for specifying the type of sample which would yield the uniformation needed. It would also help to clarify to the sampling crew and testing laboratory the time and effort to be devoted toward obtaining that information. A system such as that presented in Table I along with suggested sampling methods for obtaining such samples would be most valuable.

3. A thorough review of the safety factors and other design criteria used by designers in light of the findings of this study should be made. Consideration for the magnitude of the sample disturbance resulting from sampling, handling and storage time and its significance on design is of utmost importance. 


\section{REFERENCES}

Adams, J.I. and Radhakrishna, H.S., "Loss of Strength Due to Sampling in a Glacial Lake Deposit," A.S.T.M. Special Technical Publication 483,1970

Atchison, G.D., Dover, J.D. and Lang, J.G., Seminar by Correspondence on 'Quality in Soil Sampling', Proceedings of Specialty Session, Vol. II, Quality in Soil Sampling, Fourth Asian Regional Conference, ISSMFE, Bangkok, 1971

Ball, D.G., "Prudential Center Foundation," Boston Society of Civil Engineers, July, 1972

Barden, L., and Sides, G., "Sample Disturbance in the Investigation of Clay Structure," Geotechnique 21, №. 3, 1971

Bartlett, A.H. and Holden, J.C., "Sampling and in-Situ Testing Equipment Used by the Cosntry Roads Board of Victoria for Evaluating the Foundation of Bridges and Embankments, A.R.R.B., Proceedings, Vol. 4, Part 2, 1968

Bozozuk, M., "Effect of Sampling, Size and Storage on Test Results for Marine Clay," A.S.T.M. Special Technical Publication 483, 1970 Bromham, S.B., "The Measurement of Disturbance in Samples of Soft Clay," Proceedings, I.G.0.S.S., Fourth Asian Conference, I.S.S.M.F.E., Sangkok, 1971

Burmister, D.M., "The Application of Controlled Test Methods in Consolidation Testing," Symposium on Consolidation Testing of Soils, A.S.T.M., Special Technical Publication 126, page 83, 1951 Calhoun, M.C., "Effect of Sample Disturbance on the Strength of a Clay," A.S.C.E. Transactions, paper No. 2827,1956 
Casagrande, A., "The Determination of the Preconsolidation Load and Its Practical Significance," Proceedings, First International Conference on Soil Mechanics and Foundation Engineering, Vol. I, page 60,1936

Clark, K.R., "Mechanical Methods of Undisturbed Soil Sampling," Symposium on Soil Exploration, A.S.T.M. Special Technical Publication No. 351,1963

Coates, D.F., and McRostie, G.C., "Some Deficiencies in Testing Leda Clay," A.S.T.M. Special Technical Publication 361, p. 459, 1963

Coates, D.F., "Discussion on Test Interpretation and Errors," A.S.T.M. Special Technical Publication 361, p. 416, 1963

Coleman, James M. and Sherrood M. GagTiano, "Cyclic Sedimentation In The Mississippi River Deltaic Plain," Transactions of the Gulf Coast Association of Geological Societies, 14th Annual Convention, 1964

Conlon, R.J. and Isaacs, R.M.F., "Effect of Sampling and Testing Techniques on the Shear Strength of a Glacial-Lacustrine Clay from Welland, Ontario," A.S.T.M. Special Technical Publication 483, 1970

Davis, E.H. and Poulos, H.G., "Laboratory Investigations of the Effects of Sampling," Civil Engineering Transactions, Australia, Vol. CE9 pp. 86-94, 1966

Eden, W.J. "Sampler Trials in Oyerconsolidated Sensitive Clay," A.S.T.M. Special Technical Publication, 483, 1970

Emrich, K.J., "Performance Study of Soll Sampler for Deep Penetration Marine Borings, A.S.T.M. Special Technical Publication 483, 1970 
Fisk, H.N., "Nearsurface Sediments of the Continental Shelf off Louisiana, Proceedings of the Eighth Texas Conference on Soi1 Fiechanics and Foundation Engineering, Austin, Texas, 1956

Fisk, H.N., "Geology of Avoyelles and Rapids Parishes," Geological Bulletin No. 18, Dept. of Conseryation, Louistana Geological Survey, 1940

Fuguay, Garth A., Discussion, Journal of Soil Mechanics and Foundation Engineering Division, A.S.C.E., pages 592-596, March, 1968 Golder, H.0., "The Practice of Sampling Soil and Rock," Sampling of Soil and Rock, A.S.T.M. STP 483, American Society for Testing and Materials, pp. 3-9, 1971

Hirschfield, R.C., "Effect of Sample Disturbance on Shear Strength," A.S.C.E. Research Conference on Shear Strength of Cohesive Soils, pp. 1078-1079, June, 1960

Holtz, W.G., "Effect of Sampling Procedures on Strength of Natural Clays in Terms of Total and Effective Stresses; Discussion on Test Interpretations and Errors," A.S.T.M. Special Technical Publication 361 , p. 417,1963

Hvorslev, M. Juut, Subsurface Exploration and Sampling of Soils for Civil Engineering Purposes, American Society of Civil Engineers, Soil Mechanics and Foundations Division, November, 1949 Hvorslev, M.J., "Foundation Exploration: A Review of Methods and Requirements," Proceedings, Second International Conference on Soil Mechanics and Foundation Engineering, Vol. II, June, 1948 Idel, K.H., Muhs, H. and Von Soos, P., Proposal for 'Quality-Classes' in Soil Sampling in Relation to Boring Methods and Sampling Equipment, 
Proceedings of Specialty Session, Vol. II, Quality in Soll : Sampling, Fourth Asian Regionalt Conference, ISSMFE, Bangkok, July, 1971 Jakobson, B., "Influence of Sampler Type and Testing Method on Shear Strength of Clay Samples," Swedish Geotechnical Institute Proceedings, No. 8, 1954

Jones, P., Turcan, A.N, Jr., and Sicibitzke, H.E., "Geology and Ground Water Resources of Southestern Louisiana," Geological Bulletin No. 30, Dept. of Conseryation, Louisiana Geological Survey, 1954 Kallstenius, T., "Secondary Mechanical Disturbance; Effects in Cohesive Soil Samples, Proceeding of Specialty Session, Quality in Soil Sampling," Fourth Astan Conference, International Society for Soil Mechanics and Foundation Engineering, Bangkok, July, 1971 Kallstenius, T. (Convener), "Appendix II - Report of Sub-committee on Problems and Practices of Soil Sampling," Proceedings, 6th International Conference on Soil Mechanics and Foundation Engineering, Montrea], Canada, 1965

Kallstenius, T., "Studies on Clay Samples Taken With Standard Piston Sampler," Proceeding 21, Swedish Geotechnical Institute, 1963 Kallstenius, T.K.E., Specialty Session on Techniques of Field Measurement and Sampling, Proceedings, Fourth International Conference on Soil Mechanics and Foundation Engineerings, London, 1957 Karol, R.H., "Use of Chemical Grouts to Sample Sands," A.S.T.M. STP 483, 1970

Kenney, T.C., and Chan, H.T., "Use of Radiographs in a Geological and Geotechnical Investigation of Varved Soil," Canadian Geotechnical journa1, 9, 195, 1972 
Kolb, C.R., and VanLopik, J.R., "Geology of the Mississippi Riyer Deltaic Plain Southeastern Louisfana," Technical Report No. 3-483, U.S. Army Engineer Waterways Experiment Station, Corps of Engineers, Juty, 1958

Kolb, C.R. and Shockley, K.G., "Mississippi Valley Geology-Its Engineering Significance," Journal of Soil Mechanics and Foundation Div. A.SSC.E., Vol. 83, No. SM3, July, 1957

Krinitzsky, E.L.; Radiography in the Earth Sciences and Soil Mechanics, Plenum Press, New York - London, 1970

Ladd, C.C., and Lambe, T.K., "The Strength of 'Undisturbed' Clay, Determined from Undrained Tests," A.S.T.M. Special Technical Pub1ication No. 361,1963

Lang, J.G., "Forces on an Open-Drive Sample in Stiff Clay," Proceedings, I.G.O.S.S. Fourth Asian Conference, I.S.S.M.F.E., Bangkok, July, 1971

Lang, J.G., "Longitudinal Variation of Soil Disturbance Within Tube Samples," Fifth Australia-New Zealnad Conference on Soil Mechanics and Foundation Proceedings, 1967

LaRochelle, P., and Lefebyre, G., "Sampling Disturbance in Champlain Clays," A.S.T.M. Special Technical Publication 483, 1970 Leonards, G.A. (editor), Foundation Engineering, McGraw-Hill Book Co., Inc., 1962

Leonards, G.A. and Altschaeffi, A.G., "Compressibility of Clay," Journal of the Soil Mechanics and Foundation Division, A.S.C.E., Vol. 90 , No. SM5, September, 1964

Lo, K.Y., Seychuk, J.L., and Adams, J.I., "A Study of the Deformation 
Characteristics of a Stiff Clay," A.S.T.M. Special Technical Publication 483, June, 1970

Lo, K.Y., Adams, J.I., and Seychuk, J.L., "The Shear Behavior of a Stiff Fissured Clay," Froceedings of the Seventh International Conference of Soil Mechanics and Foundation Engineering, Mexico, 1969 Lowe, J. III, "Current Practices in Soil Sampling in the United States," Highway Research Board Special Report, ㅊo. 60, 1969 Milovic, D.M., "Effect of Sampling on Some Loess Characteristics," Proceedings I.G.0.S.S., Fourth Asian Conference, I.S.S.M.F.E., Bangkok, Juiy, 1971

Milovic, D.M., "Effects of Sampling of Some Soil Characteristics," A.S.T.M. Special Technical Publication 483, 1970 Mitchell, J.K., "The Fabric of Natural Clays and Its Relation to Engineering Properties," Proceedings Highway Research Board, Vol. 35 Mohr, H.A., "Exploration of Soil Conditions and Sampling Operations, Graduate School of Engineering, Harvard University, 1940 Morgan, J.P. (Ed.), Deltaic Sedimentation-Modern and Ancient, Society of Economic Paleontologies and Mineralogists, Special Publication, No. 15, November, 1970

Morgenstern, N.R. and Thomson, S., "Comparative Observations on the Use of the Pitcher Sampler in Stiff Clay," A.S.T.M. Special Technical Publication 483, 1970

Nelson, J.D., Brand, E.W., Moh, Z.C., and Mason, 1.D., "The Use of Residual Stress to Define Sample Quality," Proceedings, I.G.0.S.S., Fourth Asian Conference, I.S.S.M.F.E., Bangkok, July, 1971 
Newcombe, R. Jr., Page, L.U., and Sloss, R., "Water Resources of Natchitoches Parish, Louisiana," Nater Bulletin No. 4, Department of Conservation, Louisiana Geological Survey and Louisiana Department of Public Works, Juiy, 1963

Noorany, I., and Seed, H.B., "In-situ Strength Characteristics of Soft Clays," A.S.C.E. Journal of Soit Mechanics and Foundation Engineering Division, SM2, March, 1965

Poole, J.L., "Grand-Nater Resources of East Carroll and West Carroll Parishes, Louisiana," Louisiana Depaxtment of Public Morks, Baton Rouge, Louistana, November, 1961

Poplin, Jack K., and Arman, Ara, "Phase I: Preliminary Evaluation of Procedures for Collection \& Assimilation of Soils Information for Hìghways in Louisiana," L.S.U., Diyision of Engineering Research, June, 1974

Quigley, R.M., and Thompson, C.D., "The Fabric of Anisotropically Consolidated Sensitive Clays," Canadian Geotechnical Journal, Vol. III, No. 2, 1966 .

Raymond, G.P., Townsend, D.L., and Lojkasek, M.J., "The Effect of Sampling on the Undrained Soil Properties of a Leda Soil," Canadian Geotechnical Journal, 8, p. 546, 1971

Raymond, G.P., Townsend, D.L. and Lojkasek, M.J., "Evaluation of Sample Quality on Undrained Soil Properties," Proceedings, I.G.0.S.S., Fourth Asian Conference, I.S.S.M.F.E., Bangkok, Juiy, 1971 Rowe, P.W., "The Relevance of Soil Fabric to Site Investigation Practice," Geotechnique 22, No. 2, 1972

Rowe, P.W., "Representative Sanpling in Location, Quality, and Size," 
A.S.T.M. Special Technical Publication 483; 1970

Saiki, K.M., "Some Useful Properties of Soil to Evaluate the Sample Quality of Unsaturated Volcanic Ash," Proceedings, I.G.0.S.S.,

Fourth Asian Conference, I.S.S.M.F.E., Bangkok, July, 1971

Sangrey, D., "Obtaining Strength Profiles and Depth for Marine Soil

Deposits Using Disturbed Sample," A.S.T.M. Special Technical

Publication 501, 1971

Schjetne, K., "The Measurement of Pore Pressure During Sampling,"

Proceedings I.G.0.S.S., Fourth Asian Conference, I.S.S.M.F.E., Bangkok, 1971

Schmertman, J.H., Discussion: Sample Distrubance, A.S.C.E. Transactions,

Paper 2827, page 940, 1956

Schmertman, J.H., "The Undisturbed Consolidation Behavior of Clay,"

A.S.C.E., Transactions, Paper No. 2775, page 1201, 1955

Shackel, B., "Some Aspects of Sampling Disturbance Observed Using a

Nuclear Method," Proceedings, I.G.0.S.S., Fourth Asian Conference,

I.S.S.M.F.E., Banglok, July, 1971

Skempton, A.W., and Sowa, V.A., "The Behavior of Saturated Clays During

Sampling and Testirig," Geotechnique, Vol. XIII, No. 4, December, 1963

Skempton, A.W. and Henkel, D.Y., "The Post-Glacial Clays of the Thames

Estuary at Tilbury and Shellhaven," Proceedings, Third International

Conference on Soil Mechanics and Foundation Engineering, Vol. 1, 1957

Skempton, A.M., "The Pore-Pressure Coefficients A and B," Geotechnique, Vol. IV, No. 4, 1954 
Skempton, A.W., "Notes on the Compressibility of Clays," Quart. J. Geol. Soc., London, C, pp. 119-135, 1944

Soderman, L.G., and Kim, Y.D., "Effects of Groundwater Levels on Stress History of the St. Clair Clay Till Deposit," Canadian Geotechnical Journal, 7, 173, 1970

Sone, S., "The Deformation of a Soil Sample During Etrusion from a Sample Tube," Proceedings, I.G.0.S.S., Fourth Asian Conference, I.S.S.M.F.E., Bangkok, July, 1971

Sowers, G.B., and Sowers, G.F., Introductory Soil Mechanics and Foundations, 3rd Edition, Macmillan Co., New York, 1970

Terzaghi, K., and Peck, R.B., Soil Mechanics in Engineering Practice, 2nd Edition, John Wiley \& Sons, Inc., New York, 1967

Terzaghi, K., "Sampling, Testing, and Averaging," Proceedings, Purdue Conference on Soil Mechanics and Its Applications, Purdue University, Lafayette, Indiana 1940

Tipsworth, H.L., Setzer, F.M., and Smith, F.L. Jr., "Interpretation of Depositional Environment in Gulf Coast Petroleum Exploration From Paleocology and Related Stratigraphy," Transactions of the Gulf Coast Association of Geological Societies, Vo1. XVI, 1966 Van Zelst, T.W., "An Investigation of the Factors Affecting Laboratory Consolidation of Clay," Proceedings, Second International Conference on Soil Mechanics and Foundation Engineering, Vol. VII, June, 1948

VonSoos, P., "Influence of Type of Soil Upon the Accessibility of Soil Sample Quality, Proceedings of Specialty Session, Vol. 1, Quality in Soil Sampling, Fourth Astan Regional Conference, I.S.S.M.F.E., Bangkok, July, 1971 
Ward, K.H., Marsland, A., and Saruels, S.G., "Properties of the London Clay at the Ashford Common Shaft: In-situ and Undrained Strength Tests," Geotechnique, Vo1. 15, No. 4, p. 327, 1965

Ward, K.H., "Technique of Field Measurement and Sampling Session,"

Proceedings of the Fourth International Conference on Soil Mechanics and Foundation Engineering, London, 1957

Zeevaert, L.; Foundation Engineering for Difficuit Subsoil Conditions, Van Nostrand Reinhold Publication

Arman, A., Poplin, J.K., and Ahmad, N., "A Study of the Vane Shear," Proceedings, Specialty Conference on In-Situ Measurement of Soil Properties, June, 1075 
APPENDIX 
APPENDIX A

\section{MICROANALYSIS}

\section{LAKE CHARLES SITE}

Strength tests on block samples from the Lake Charles site resulted in a very distinct, sudden failure at ultimate load. Due to the brittleness of the material, cementation of the soil's structure was considered. Materials Evaluation Laboratory Inc. of Baton Rouge, La. was cormissioned to conduct a microanalysis of this soil. Two cube specimen, inarked for proper orientation, from block sample No. $4(27+\mathrm{ft}$.) were furnished for this study. The following is the report.

\section{INTRODUCTION}

The microanalysis of soils can be very useful in interpreting differences in their physical behavior. The soils may be well laminated or heterogeneous at the sub-micrometer level and thereby influence the strength at failure and the direction of shear-propogation. Well-bedded clay rich materials are much weaker parallel to the planes of orientation. Microscopic changes in composition may introduce an additional heterogeneity and produce an unpredictable behavior. Accumulations of calcium carbonate or iron oxide may cement the soil matrix compenents and form a rigid framework.

In this study, the scanning electron microscope and an energy dispersive X-ray microprobe (SEM-EDS) have been used to perform a microanalysis of soil from the vicinity of Lake Charles, Louisiana. One of the chief goals was the identification of cementitous compounds. The 
chief advantage in using this type of instrument for this study lies in its ability to provide "pictures" of chemical differences. That is, the SEM-EDS provides pictures in the form of elemental distribution maps which show where the chemical species occur and what they are associated with. The accompanying photomicrographs demonstrate the utility of the technique and the concentration of iron as an iron sulfide in the soil sample labeied Lake Charles.

\section{MATERIALS AND METHODS}

Two samples were received in the form of cubes approximately 4 inches in size. The soil cubes were wrapped in cellophane and aluminum foil and had been dipped in wax to preserve their field moisture. They remained sealed until the time of sampling for microanalysis.

The cubes of soil were sampled with $5 / 8$ inch cork borer perpendicular to the top surface and parallel to it about one-half of the way down on one side. This provided two continuous cores approximately 10 centimeters long which were trimmed with a razor blade to produce a 4 millimeter by 4 millimeter by 10 centimeter piece for microanalysis. Representative sections about 1.5 centimeters in length were then dried by critical point drying techniques and then coated with a thin layer of gold or carbon prior to examination in the SEM-EDS.

Critical point drying was used because it is the least disruptive of drying methods. That is, it minimizes the possibility of the rearrangement of soil particles as water is removed. Gold was applied to those samples which would be used for microtextural analyses in order to obtain the best quality images of the soil particles. However, gold interfers 
with $X$-ray observations so the samples used in microprobe determinations were coated with carbon. The image quality produced by the carboncoated soils is not as high as the gold coated ones, but the sacrifice is necessary for good $X$-ray results. Both specimen coating techniques were employed on the samples and the entire coring operation was repeated in order to insure the representative nature of the observations.

Two types of pictures were produced in the SEM-EDS. The continuous tone photographs are secondary electron images of the specimen surface and illustrate at high magnifications the arrangement of the soil particles, or the micro-texture. The photographs exhibiting patterns formed by dots are elemental distribution inaps. Each dot represents an area on the specimen where an $X$-ray characteristic of a selected element was produced. For example, there are several photos which illustrate by clusters of dots where surphur, or iron, or calcium are present. The $X$-ray maps are produced at the same magnification as the accompanying electron images so that one can relate an observed element concentration to morphological features.

In al1, stubs containing pieces of 4 different samples were examined.

Sample 1 - Cube No. 1

A - section perpendicular to top

B - section perpendicular to top

C - section perpendicular to one side of cube

Sample 2 - Cube No. 1 second core of above

$A$ - section perpendicular to one side of cube

B - section perpendicular to top 
C - section perpendicular to top

Sample 3 - Cube No. 2

A - section perpendicular to top

B - section perpendicular to top

C - section perpendicular to one side of cube

Sample 4 - Cube No. 2 second sample of above

A - section perpendicular to one side of cube

B - section perpendicular to top

C - section perpendicuiar to top

\section{RESULTS}

The results of this study are presented in the following figures. The captions are expanded and explain the major observations as well as some of the interpretations formed during the investigations. 
Figure 98. Magnification 2000X. Electronmicrographs of Sample 2 (above) and 4 (below) illustrating the texture of the soils. A gold coating was applied in order to obtain the best secondary electron image. There is evidence of horizontal layering of flake-shaped clay particles in both samples. The layering is disrupted in some areas by vertical planar surfaces and some in varying orientations. A slightly curved surface resembling those formed by slickensides is present near the upper right-hand margin of the top photo. There is a slight indication that layering is more perfectly developed in samples 1 and 2 and that formation of iron sulfide crystals has disrupted the bedding in samples 3 and 4 . 


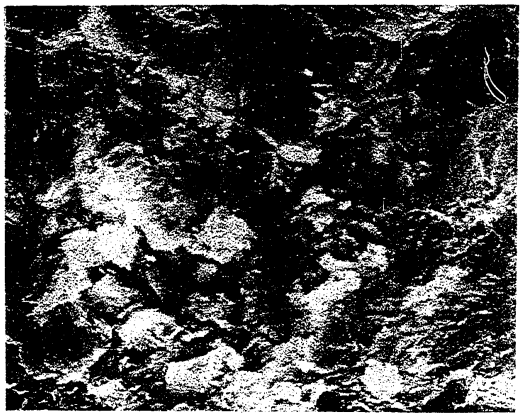

\section{$5 \mu \mathrm{m}$}

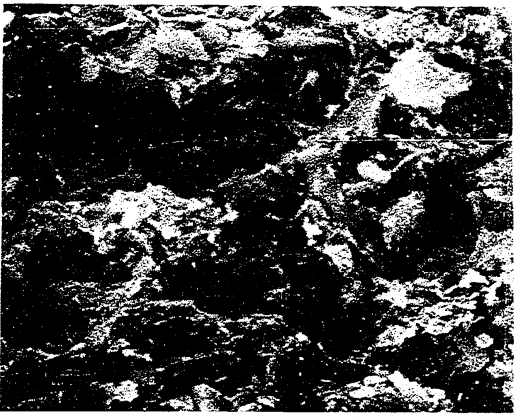

Figure 98 - Electron Micrograph 
Figure 99. Magnification 2000X. Electron micrograph (upper, 99a) and calcium (lower, 99a) and iron (99b) element distirbution maps. Horizontal layering and some non-parallel curved surfaces are present in the soil. Calcium is uniformly distributed at low levels throughout the sample. The same is generally true for iron, but one small spherical grain can be seen. This is probably an iron oxide because no other elements were detected on closer examination. This was sample \#2A. 


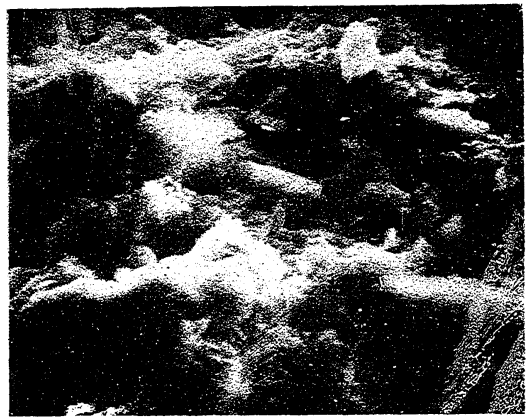

$\stackrel{5 \mu \mathrm{m}}{\longrightarrow}$

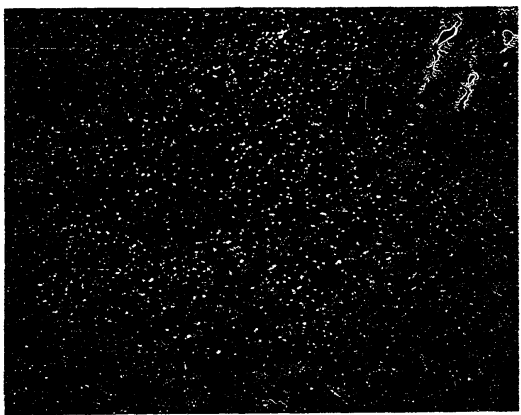

Figure 99a) - Electron Micorgraph (Upper) and Calcium Element
Distribution Map (Lower) 


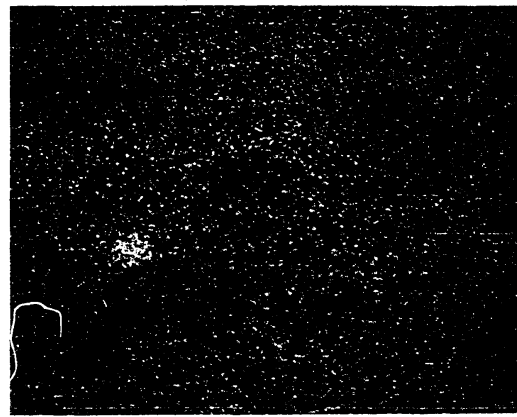

$5 u \mathrm{~m}$

Figure 99b) - Iron Element Distribution Map 
Figure100. Magnification 2000X. Electron micrograph (upper) and iron distribution map (lower) of sample \#2C. Layering is prominent with the top of the sample to the left. Even though this specimen was taken from a core at $90^{\circ}$ to the previous photo, there is no apparent change in texture. The bedding is dominant. The iron distribution is uniform and the element is present at low leveis throughout. 


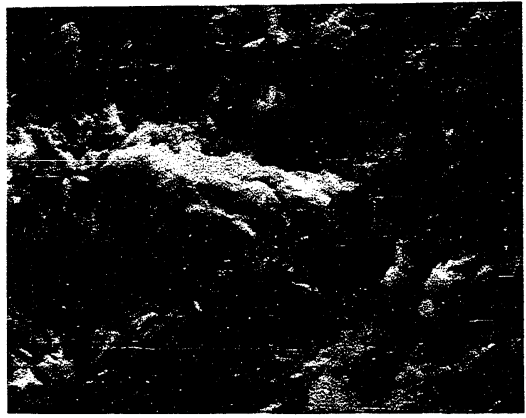

$\stackrel{5 \mu m}{\longrightarrow}$

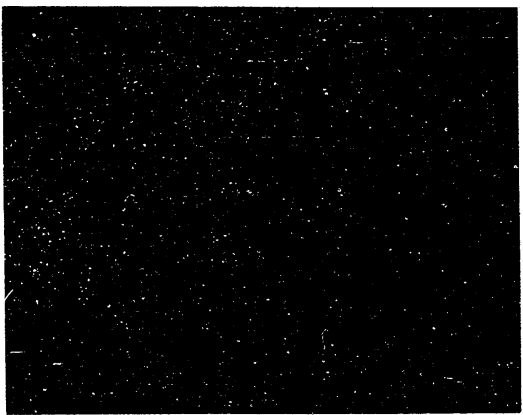

Figure 100 - Electron Micrograph (Upper) and Iron Distribution Map (Lower) 
Figure 101. Magnification 2000X. Electron micrograph (top, 101a) and iron (lower, 10la) and sulfur lower, 101b) distribution maps from a typical area on sample 4 . There is an apparently large number of clay flakes oriented perpendicular to bedding and in the plane of the photograph. Samll clusters of $1-2$ micrometer particles are present and particularly well-developed near the right margin just above the center. The iron and sulfur maps show accumulations of these elements to be coincident with the above. There is some iron and sulfur present in the remainder of the sample but both occur at low levels. The areas of concentration represent places where pyrite crystals have formed and judging by the amount of disruption of the parallel bedding in these areas, they probably formed after the clay was deposited. They could serve as textural modifiers and change the failure of the samples. 


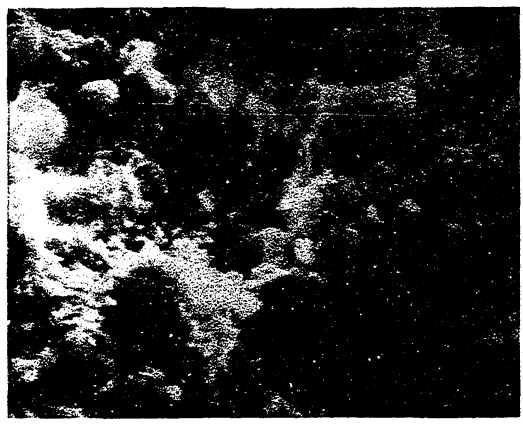

$\stackrel{5 \mu \mathrm{m}}{\longrightarrow}$

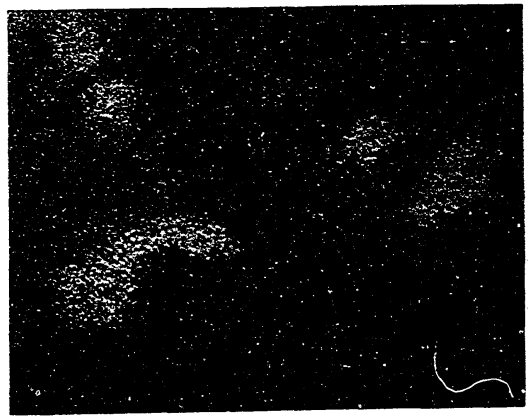

Figure 101a) - Electron Micrograph (Upper) and Iron Distribution Map (Lower) 


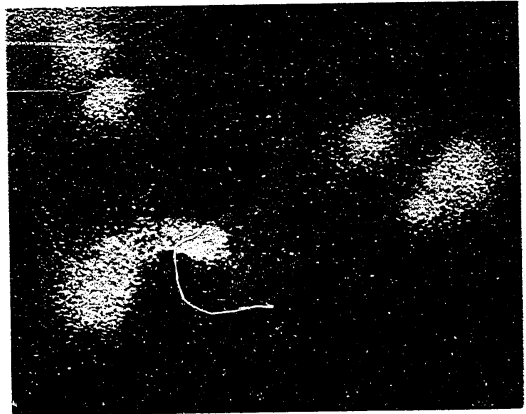

$5 \mu \mathrm{m}$

Figure 101b) - Sulfur Distribution Map 
Figure 102. Magnification 2000x. In some areas the pyrite crystals are almost as abundant as the clay particles. A crystal about 10 micrometers in diameter is present in this electron micrograph of sample \#4A. Iron (lower, 102a) and sulfur (102b) distribution maps confirm the identity of this crystal and others as pyrite. There is sorre indication that iron is more evenly distributed than sulfur and may occur independent of pyrite crystals. The crystals appear to be cubes truncated by octahedra, although the one right of center may be the pyritohedron. 


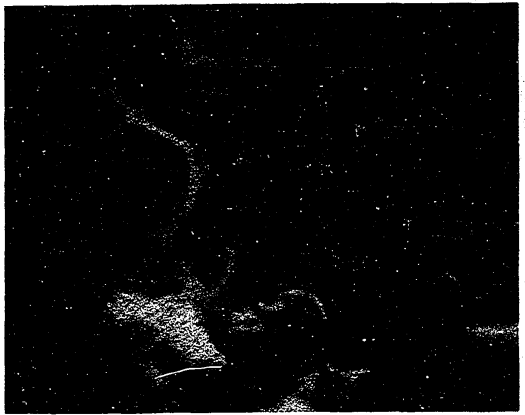

sum

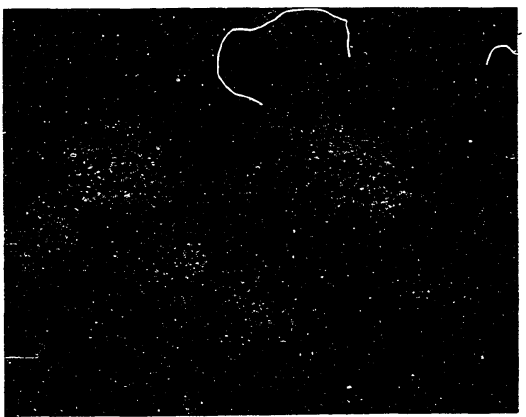

Figure 102a) - Electron Micrograph (Upper) and Iron Distribution Map (Lower) 


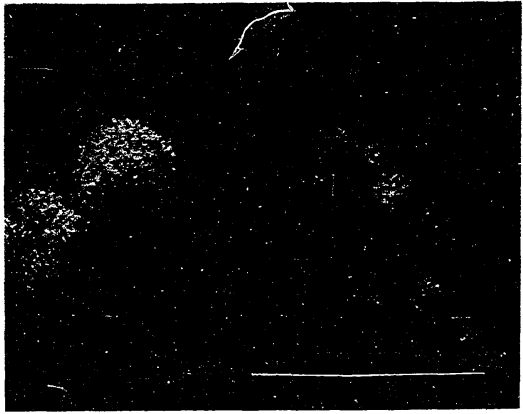

$\stackrel{5 \mu \mathrm{m}}{\longrightarrow}$

Figure 102b) - Sulfur Distribution Map 
Figure 103. Magnification 5000X. Well developed planar surfaces perpendicular to bedding and pyrite crystals are apparent in sample $\# 4 \mathrm{~B}$. The presence of the pyrite crystals is accentuated in the sulfur distribution map. The presence of a gold coating produces an abnormally high background levef in the element map of sulfur, but the area of crystal formation are evident. 


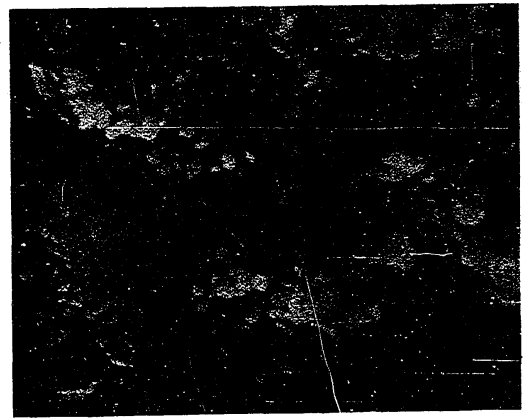

$\stackrel{2 \mu \mathrm{m}}{\longrightarrow}$

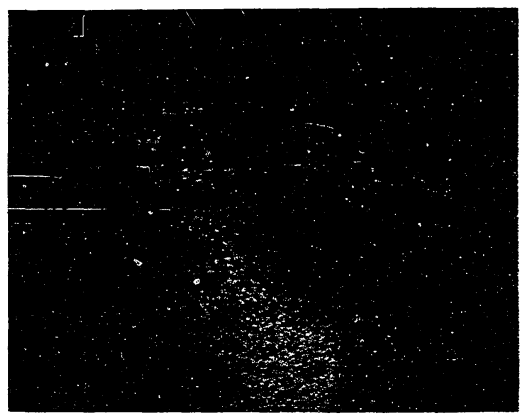

Figure 103 - Electron Hicrograph (Upper) and Element Map of Sulfur (Lower) 
Figure 104. Magnification 5000X (top) and 10,000 (10wer). Wel1 developed pyrite crystals and variable clay fabric are illustrated in these micrographs of samples $4 B$ and $4 A$, respectively. The individual crystals in the lower photo are less than one-half of a micrometer. In the lower part of this phow parallel flakes of clays are oriented perpendicular to bedding. A cluster of pyrite crystals and a quartz grain are evident in the upper photo. 


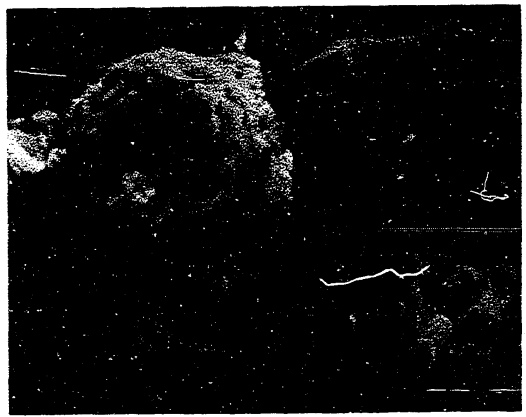

$\stackrel{2 \mu \mathrm{m}}{\longrightarrow}$

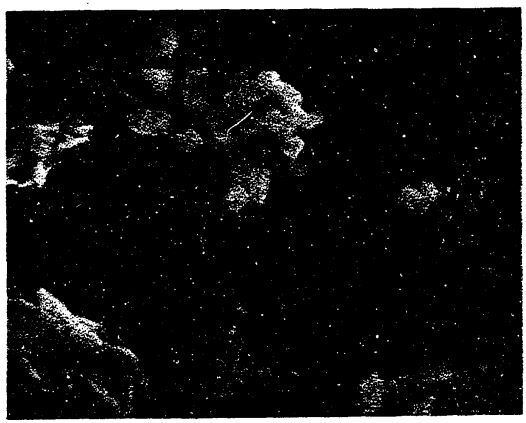

$1 \mathrm{\mu m}$

Figure 104 - Electron Micrograph - Pyrite Crystals and Variable Clay Fabric 
Figure 105. Energy dispersive $X$-ray spectrum illustrating the chemical elements present. This was the more chemically diverse sample. Elements present include aluminum, silicon, sulfur, potassium, caloium, titanium, and iron. The aluminum and silicon are the major elements associated with the clay minerals in the soils. Iron and sulfur are associated as micro-crystals of pyrite. 
-

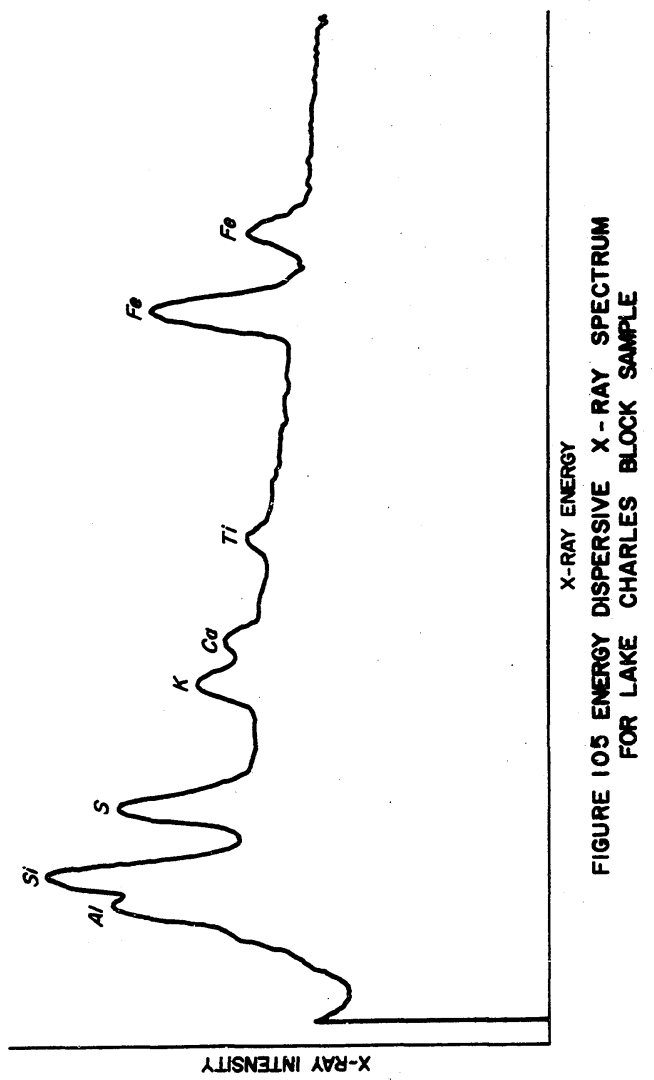




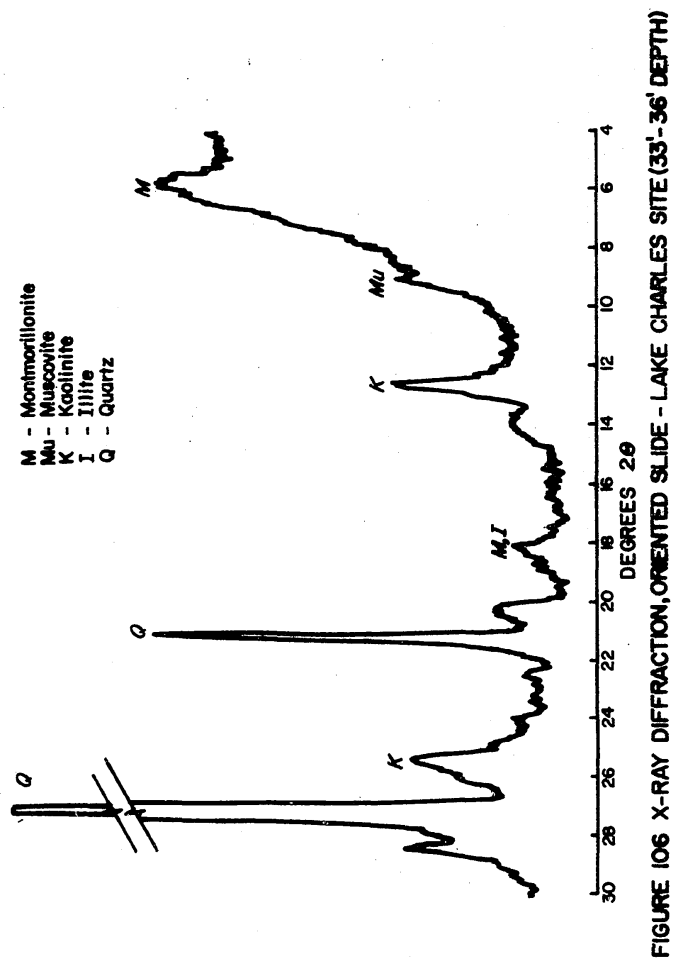




\section{APPENDIX B}

\section{X-Ray Radiography Equipment and Techniques}

Two different $X$-ray machines were used during this study. These were the Picker X-ray machine $(\max 200 \mathrm{kv}$, max 15ma) and the PhilipsNorelco X-ray machine $(\max 300 \mathrm{kv}, \max 30 \mathrm{ma})$. The Philips-Norelco machine had an additional advantage in that the $\mathrm{X}$-ray tube is not enclosed as is the Picker michine. Thus in addition to having a higher voltage potential there is no sample size limitation with the PhilipsNorelco as there is with the Picker machine.

Two types of film were used, Kodak AA industrial film and Kodak type $M$ industrial X-ray film. The size of the film is 8 in. $\times 10$ in. sheets and is loaded in GAF ANSCOFLEX film holders for X-ray exposure.

Soil samples were $X$-rayed under three different conditions. These included core slices in which a $3 / 8$ in. to $1 / 2$ in. siab was cut from the center of a core, extruded cores, and 3-in. shelby sampler tives with the sample enclosed. In order to enhance the edges of radiographs made of uns?iced cores, they were occasionally packed in a fine, uniform, dry clay. This prevented over-exposure of the $f i l m$ in the area of the thinner edges which was projected.

The settings and equipment used in producing the radiograph were as follows:

\section{Picker X-ray Hachines}

Sample Film Voltage Current Exposure Time

$\begin{array}{ccccc}\begin{array}{c}\text { soil slab on glass } \\ \text { plate }(1 / 4)^{\mathrm{u}}\end{array} & M & 65 \mathrm{kv} & 10 \mathrm{ma} & 1 \mathrm{~min} . \\ \text { extruded core } & M & 150 \mathrm{kv} & 10 \mathrm{ma} & 4 \mathrm{~min} .\end{array}$


Philips-Norelco X-ray: Machines

\begin{tabular}{lccccc}
\multicolumn{1}{c}{ Samples } & Film & Voltage & Current & Exposure Time \\
$\begin{array}{l}\text { soil slab on glass } \\
\text { plate }\end{array}$ & AA & $100 \mathrm{kv}$ & $10 \mathrm{ma}$ & $8 \mathrm{sec}$. \\
$\begin{array}{l}\text { extruded core } \\
\text { core in tube }\end{array}$ & AA & $150 \mathrm{kv}$ & $10 \mathrm{ma}$ & $30 \mathrm{sec}$. \\
& $M$ & $150 \mathrm{kv}$ & $10 \mathrm{ma}$ & $4 \mathrm{~min}$.
\end{tabular}

The distance from the X-ray source to the film was $100 \mathrm{~cm}$.

After exposure, the film was developed at $68^{\circ} \mathrm{F}$ in a Kodak X-ray film developer with the following times:

$\begin{array}{lr}\text { Kodak KLX Developer } & 8 \mathrm{~min} . \\ \text { Stop (water) } & 5 \mathrm{~min} . \\ \text { Kodak KLX Fixer } & 10 \mathrm{~min} . \\ \text { Wash (water) } & 20 \mathrm{~min} . \\ \text { Dry } & 30 \mathrm{~min} .\end{array}$

Drying was accomplished by blowing hot air over the film sheets. The hot air helps to minimize streaking by residual water.

In printing a positive from the $X-r a y$, the contact method was used. Prints were made with Kodak Polycontrast rapid RC paper, F/MW type. Exposures varied with each $X$-ray but were usually 30 second exposures. The developer used was Dektol with indicator stop bath and Edwal Industrial fixer. Most prints were air dryed for flatness. 


\section{APPENDIX C}

\section{LAKE CHARLES SITE}

\section{6}

Reproduced with permission of the copyright owner. Further reproduction prohibited without permission. 
Location: LAKE CHARLES

Site: $1,2,3,4$, and 5

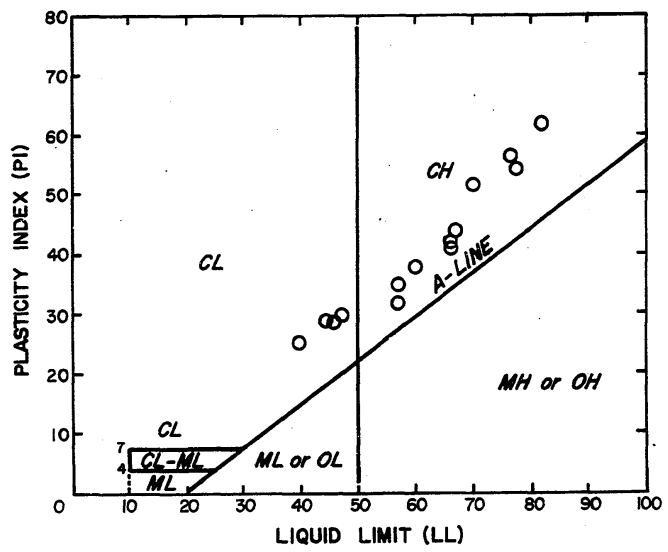

FIGURE 107 MODIFIED PLASTICITY CHART

WITH

UNIFIED SOIL CLASSIFICATION SYSTEM

(AFTER USER ISG3) 
Location: LAKE CHARLES Site: 7,8 , and 9

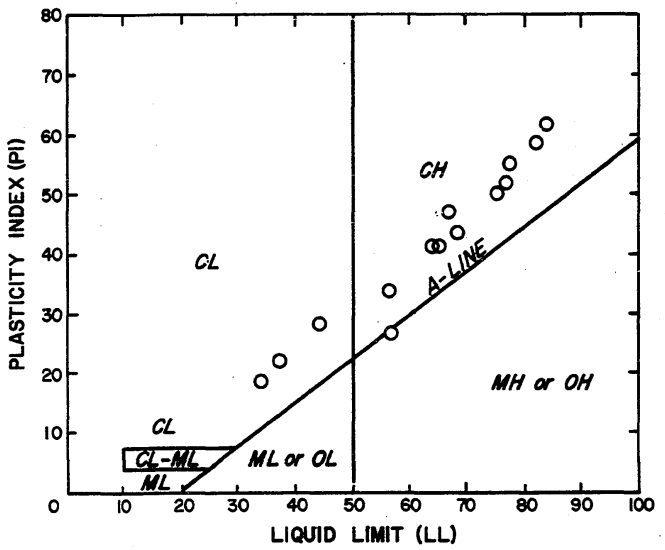

FIGURE 108 MODIFIED PLASTICITY CHART WITH

UNIFIED SOIL CLASSIFICATION SYSTEM

(AFTER USBR 1963) 


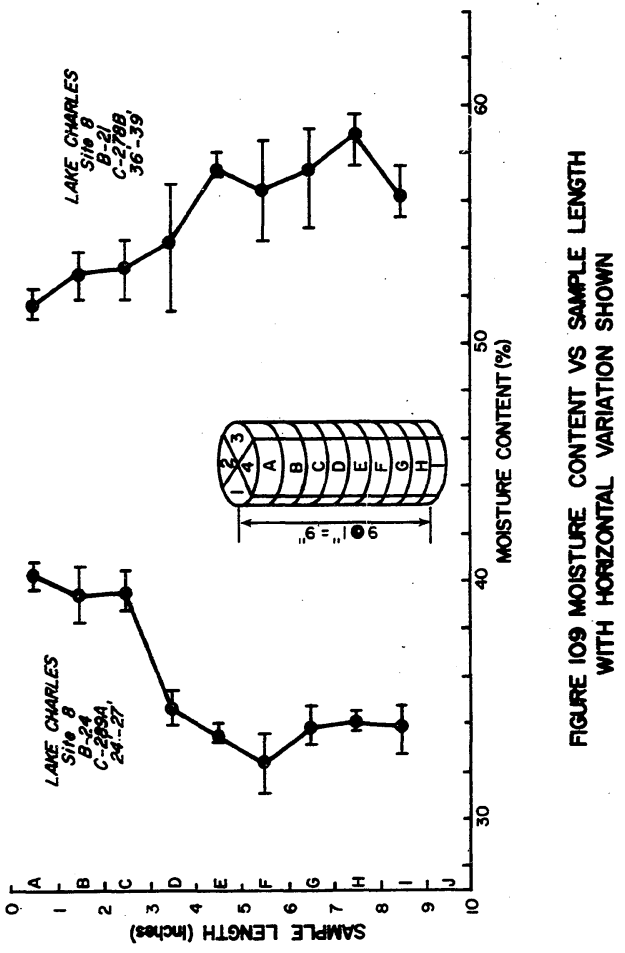


SITE: LAKE CHARLES $(4,5,7,8,89)$

SAMPLE CLASSIFICATION COMPARED: $3^{\prime \prime} \%, 5^{\prime \prime} \%, \&$ BLK

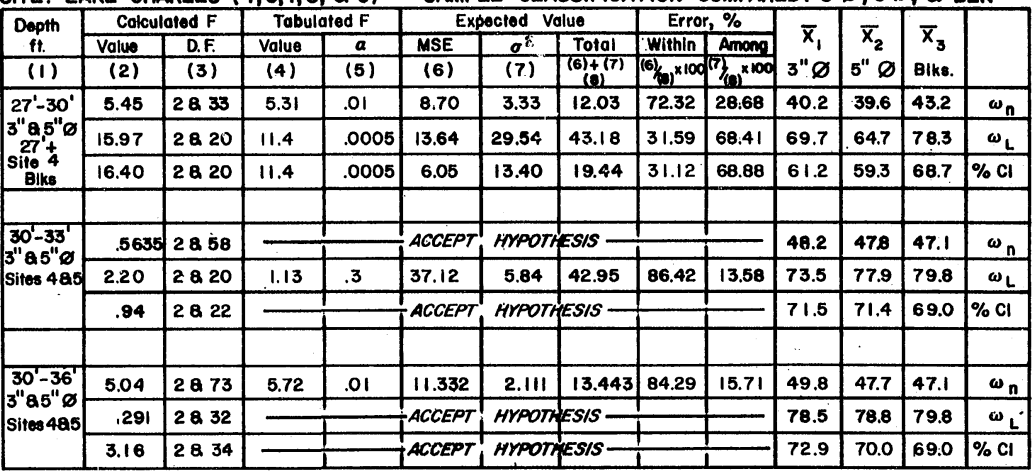

TABLE I5 STATISTICAL ANALYSIS (CRD) 
SITE: LAKE CHARLES $(4,5,7,8,8,9)$

TESTS/SAMPLING SIZE COMPARED: $3 " \varnothing, 5 " \varnothing, 8$ BLK

\begin{tabular}{|c|c|c|c|c|c|c|c|c|c|c|c|c|c|}
\hline \multirow{2}{*}{ Depth } & \multicolumn{2}{|c|}{ Calculated F } & \multicolumn{2}{|c|}{ Tabulated F } & \multicolumn{3}{|c|}{ Expected Value } & \multicolumn{2}{|c|}{ Error \% } & \multirow{3}{*}{$\begin{array}{r}\bar{x}_{1} \\
3^{\prime \prime} \varnothing\end{array}$} & \multirow{3}{*}{$\begin{array}{c}\bar{x}_{2} \\
5^{\prime \prime} \varnothing\end{array}$} & \multirow{3}{*}{$\begin{array}{l}\bar{x}_{3} \\
\text { BLK }\end{array}$} & \\
\hline & Value & D.F. & Value & $a$ & MSE & $\sigma^{2}$ & Total & Within & Among & & & & \\
\hline (1) & (2) & (3) & (4) & (5) & (6) & (7) & ${ }^{(6)}+(8)$ & $6 /(8) \times 100$ & $7 /(0)^{\times 100}$ & & & & \\
\hline $30^{\prime}-33^{\prime}$ & 47.48 & 2062 & 8.65 & .0005 & 10.34 & 33.84 & $.44 ; 18$ & $23: 4$ & 76.6 & 14.62 & $20: 8$ & 24.95 & $\begin{array}{c}\text { w-Test } \\
\text { psi }\end{array}$ \\
\hline $30^{\prime}-36^{\prime}$ & 105.62 & 2 a 77 & 8.37 & .0005 & 9.24 & 43.41 & 52.65 & 17.5 & 82.5 & 13.75 & 20.08 & 24.95 & $\begin{array}{c}\text { UU-Test } \\
\text { psi }\end{array}$ \\
\hline
\end{tabular}

TABLE 16 STATISTICAL ANALYSIS (CRD) 
SITE: LAKE ChARLES $(7,8,89)$

TESTS/SAMPLING SIZE COMPARED: $3^{\prime \prime} \varnothing$ \& $5 " \varnothing$

\begin{tabular}{|c|c|c|c|c|c|c|c|c|c|c|c|c|}
\hline \multirow{2}{*}{$\begin{array}{c}\text { Depth } \\
\mathrm{ft}\end{array}$} & \multicolumn{2}{|c|}{ Calculated F } & \multicolumn{2}{|c|}{ Tabulated F } & \multicolumn{3}{|c|}{ Expected Value } & \multicolumn{2}{|c|}{ Error, \% } & \multirow{3}{*}{$\begin{array}{r}\bar{x}_{1} \\
3^{\prime \prime} \phi \\
\end{array}$} & \multirow{3}{*}{$\begin{array}{c}\bar{x}_{2} \\
5^{\prime \prime} \phi\end{array}$} & \multirow{3}{*}{ Remarks } \\
\hline & Value & D.F. & Value & $a$ & MSE & $\sigma^{2}$ & Total & Within & Among & & & \\
\hline (1) & (2) & (3) & (4) & (5) & (6) & $(7)$ & $(6)+(7)$ & $16 /(0)^{\times 100}$ & $(7) /(6)^{100}$ & & & \\
\hline $27^{\prime}-30^{\prime}$ & 29.63 & 1819 & 17.5 & .0005 & 3.06 & 8.52 & 11.58 & 26 & 74 & 18.42 & 22.62 & UU Teats, pai \\
\hline $30^{\prime}-33^{\prime}$ & 38.17 & 1816 & 18.9 & .0005 & 4.28 & 18.60 & 22.88 & 18.7 & 81.3 & 14.62 & 20.8 & UU Tests, psi \\
\hline $33^{\prime}-36^{\prime}$ & 21.88 & 1813 & 21.1 & .0005 & $3.2 \mathrm{~B}$ & 14.27 & 17.55 & $18.69^{4}$ & 81.31 & 12.95 & 1.8 .41 & UU Tests, psi \\
\hline $36^{\prime}-39$ & 3.53 & 1816 & 3.05 & .10 & 13.07 & 3.87 & 16,94 & 77.15 & 22.85 & 10.97 & 14.25 & UU Tests, psi \\
\hline
\end{tabular}

TABLE 17 STATISTICAL ANALYSIS (CRD) 
F-TEST COMPARATIVE ANALYSIS

\begin{tabular}{|c|c|c|c|c|c|c|c|c|c|c|c|}
\hline \multirow{2}{*}{ SAMPLE } & \multirow{2}{*}{ SITE } & \multicolumn{2}{|c|}{ DEPTH } & \multirow{2}{*}{$\omega_{n}$} & \multirow{2}{*}{$\omega_{L}$} & \multirow{2}{*}{$\% \mathrm{Cl}$} & \multicolumn{3}{|c|}{$\left(\sigma_{1}-\sigma_{3}\right)$} & \multirow{2}{*}{$\begin{array}{l}\text { STORACE } \\
\text { DAYYS }\end{array}$} & \multirow{2}{*}{ SIZE } \\
\hline & & FT & $M$ & & & & PSI & PSF & $N / M^{2}$ & & \\
\hline$C-265 B$ & 7 & $27+$ & $8.23+\mid$ & 40.9 & 71 & 61 & 2065 & 2974 & 989 & 4 & $3^{\prime \prime}$ \\
\hline C-285A & 8 & & & 37.5 & 72 & 65 & 20.62 & 2969 & 987 & 8 & \\
\hline$C-2850$ & 8 & & & - & 72 & 65 & 19.90 & 2866 & 953 & 8 & \\
\hline$C-2604$ & 7 & & & 42.6 & - & - & 19.86 & 2860 & 951 & 4 & \\
\hline$C-2600$ & 7 & & & 42.9 & 81 & 61 & 19.57 & 2818 & 937 & 1 & \\
\hline C-30IA & 9 & & & 34.1 & 66 & 57 & 1910 & 2750 & 914 & 5 & \\
\hline$C-280 \mathrm{~A}$ & 8 & & & 39.9 & 66 & 62 & 18.95 & 2729 & 907 & 7 & \\
\hline C-290A & 8 & & & 38.4 & 68 & 63 & 18.54 & 2670 & 888 & 14 & \\
\hline C-2808 & 8 & & & 44.3 & 66 & 62 & 17.03 & 2452 & 815 & 7 & \\
\hline C-2908: & 8. & & & 46.4 & 68 & 63 & i631 & 2349 & 781 & 14 & \\
\hline c-3018 & 9 & & & 36.8 & 66 & 57 & 15.78 & 2272 & 758 & 5 & \\
\hline c-268A & 7 & & & 38.8 & 71 & 57 & 15.18 & 2186 & 727 & 4 & \\
\hline$C-2558$ & 7 & $2 ?+$ & $8.23+$ & 45.0 & 66 & 60 & 24.18 & 3482 & 1158 & 5 & $5^{\prime \prime}$ \\
\hline$c-2458$ & 7 & & & 39.6 & 62 & 58 & 24.05 & 3463 & 1151 & 8 & \\
\hline$C-250 \mathrm{~A}$ & 7 & & & 38.4 & 62 & 56 & 23.81 & 3429 & 1140 & 5 & \\
\hline$C-2700$ & 8 & & & 41.8 & 70 & 62 & 23.58 & 3396 & 1129 & 8 & \\
\hline$c-2500$ & 7 & & & 39.6 & 59 & 54 & 23.14 & |3332 & 1108 & 5 & \\
\hline$C-2464$ & 7 & & & 41.9 & 67 & 62 & 22.65 & 3262 & 1084 & 8 & \\
\hline C-258A & 7 & & & 40.5 & 64 & 58 & 2180 & $\mid 3139$ & 1044 & 20 & \\
\hline $196 \mathrm{~A}$ & 9 & & & 34.0 & 66 & 61 & 20.50 & 2952 & 981 & 5 & \\
\hline$c-2968$ & 9 & & & 36.0 & 66 & 57 & 19.91 & $2867 \mid$ & 953 & 6 & \\
\hline
\end{tabular}

TABLE 18 STATISTICAL DATA-LAKE CHARLES SITE 
F-TEST COMPARATIVE ANALYSIS

\begin{tabular}{|c|c|c|c|c|c|c|c|c|c|c|c|}
\hline SAMPLE & SITE & DEF & PTH & $a_{n}$ & 1 & $\% \mathrm{Cl}$ & & $\sigma_{1}-\sigma_{3}$ & & & SI7E \\
\hline & & FT & $M$ & & & & PSI & PSF & $\mathrm{N} / \mathrm{M}^{2}$ & DAYS & \\
\hline C-281B & 8 & $30^{+}$ & $9.14+$ & 46.4 & 78 & 68 & 16.71 & 2406 & 800 & 5 & $3^{11}$ \\
\hline C-291A & 8 & & & 47.0 & 71 & 70 & 15.93 & 2294 & 763 & 7 & \\
\hline C-2918 & 8 & & & 46.3 & - & - & 15.90 & 2290 & 761 & 7 & \\
\hline C-281A & 8 & & & 47.0 & 78 & 70 & 15.51 & 2233 & 743 & 5 & \\
\hline C-286A & 8 & & & 49.7 & 64 & 69 & 15.50 & 2232 & 742 & 8 & \\
\hline$C-266 A$ & 7 & & & 50.0 & - & 79 & 15.35 & 2210 & 735 & 4 & \\
\hline$C-2868$ & 8 & & & 48.0 & 64 & 69 & 14.83 & 2136 & 710 & 8 & \\
\hline C-261A & 7 & & & 46.4 & 77 & 69 & 14.25 & 2052 & 682 & 4 & \\
\hline C-302A & 9 & & & 47.9 & 80 & 73 & 13.54 & 1950 & 648 & 4 & \\
\hline$C-3028$ & 9 & & & 46.4 & 80 & 73 & 11.65 & 1678 & 558 & 4 & \\
\hline C-2618 & 7 & & & 52.5 & 82 & 74 & 11.60 & 1670 & 555 & 1 & \\
\hline C-232A & 7 & & & 47.2 & - & - & 8.99 & 1295 & 430 & 67 & \\
\hline$C-2468$ & 7 & $30^{+}$ & $9.14^{+}$ & 41.8 & 78 & 67 & 23.27 & 3351 & 1114 & 6 & $5 "$ \\
\hline$c-2568$ & 7 & & & 44.8 & 73 & 69 & 22.94 & 3303 & 1098 & 5 & \\
\hline$c-2968$ & 9 & & & 45.9 & 87 & 76 & 22.75 & 3276 & 1089 & 5 & \\
\hline$C-268 A$ & 7 & & & 50.8 & 89 & 73 & 22.24 & 3203 & 1086 & 5 & \\
\hline$c-2768$ & 8 & & & 47.9 & 78 & 71 & 18.62 & 2681 & 891 & 7 & \\
\hline$C-2 \pi B A$ & 8 & & & 48.0 & 71 & 62 & 18.61 & 2680 & 891 & 8 & \\
\hline C-25IA & 7 & & & 55.5 & 82 & 69 & 17.15 & 2470 & 821 & 5 & \\
\hline C-2718 & 8 & & & 51.0 & & & 14.70 & 2117 & 704 & 61 & \\
\hline
\end{tabular}

TABLE I9 STATISTICAL DATA-LAKE CHAFLLS SITE 
F-TEST COMPARATIVE ANALYSIS

\begin{tabular}{|c|c|c|c|c|c|c|c|c|c|c|c|}
\hline \multirow{2}{*}{ SAMPLE } & \multirow{2}{*}{ SITE } & \multicolumn{2}{|c|}{ DEPTH } & \multirow{2}{*}{$\omega_{n}$} & \multirow{2}{*}{$\omega_{L}$} & \multirow{2}{*}{$\% \mathrm{Cl}$} & \multicolumn{3}{|c|}{$\left(\sigma_{1}-\sigma_{3}\right)$} & \multirow{2}{*}{$\begin{array}{l}\text { STCOMCE } \\
\text { DAYS }\end{array}$} & \multirow{2}{*}{ SIZE } \\
\hline & & FT & $M$ & & & & \begin{tabular}{l|l|} 
PSI & \\
\end{tabular} & \begin{tabular}{|l|l|} 
PSF \\
\end{tabular} & N/M $M^{2}$ & & \\
\hline C-2628 & 7 & $33+$ & 10.054 & 50.3 & - & - & 15.90 & 2290 & 761 & 1 & $3^{1 t}$ \\
\hline C-303A & 9 & & & 48.2 & 85 & 78 & 14.75 & 2124 & 706 & 4 & \\
\hline C-2928 & 8 & & & 34.9 & - & 73 & $\mid 4.40$ & 2074 & 689 & 7 & \\
\hline$C-287 B$ & 8 & & & 54.3 & 81 & 75 & 14.10 & 2030 & 675 & 7 & \\
\hline C-267B & 7 & & & 51.3 & 82 & 71 & 13.78 & 1984 & 660 & 7 & \\
\hline C-287A & 8 & & & 42.6 & 81 & 78 & 12.22 & 1760 & 585 & 7 & \\
\hline C-2828 & 8 & & & 54.3 & 86 & 79 & 11.45 & 16.49 & 548 & 5 & \\
\hline C-267A & 7 & & & 52.3 & 82 & 71 & 11.45 & 1649 & 548 & 6 & \\
\hline $\mid c-292 A$ & 8 & & & 52.2 & 83 & 75.5 & 11.22 & 1616 & 537 & 7 & \\
\hline c-303e & 9 & & & 50.0 & 82 & 72 & 10.95 & 1577 & 524 & 4 & \\
\hline$C-233 B$ & 7 & & & 54.9 & & & 10.86 & 1564 & 520 & 67 & \\
\hline$C-2478$ & 7 & $33+$ & $1006+$ & 47.7 & 68 & 67 & 20.78 & 2992 & 995 & 9 & $5^{\prime \prime}$ \\
\hline C-2978 & 9 & & & 46.9 & 79 & 71 & i 7.38 & 2503 & 832 & 5 & \\
\hline c-272d & 8 & & & 48.9 & 83 & 69 & $17.0 \mathrm{e}$ & 2460 & 818 & 8 & \\
\hline
\end{tabular}

TABLE 20 STATISTICAL DATA- LAKE CHAPLES SITE 
F-TEST COMPARATIVE AMALYSIS

\begin{tabular}{|c|c|c|c|c|c|c|c|c|c|c|c|}
\hline PE & STE & & PTH & $\omega_{n}$ & $\omega_{1}$ & $\% \mathrm{Cl}$ & & $\sigma_{1}-\sigma$ & & & SRE \\
\hline & & $\overline{F T}$ & $M$ & & & $70 \mathrm{CT}$ & PSI & PSF & त/M2 & ons & \\
\hline C-3048 & 9 & $36^{4}$ & $110.97 t$ & 51.5 & $8 ! !$ & 67 & 13.04 & '1878 & 624 & 5 & $3^{\prime \prime}$ \\
\hline C-234A & 7 & & & 51.0 & 81 & 75 & 12.95 & 1865 & 620 & 17 & \\
\hline$C-2608$ & 7 & & & $66: 4$ & 80 & 75 & 12.61 & 1816 & 604 & 6 & \\
\hline$C-263 \mathrm{~A}$ & 7 & & & 54.9 & 83 & 79 & 12.26 & 1765 & 587 & 6 & \\
\hline c-268A & 7 & & & 86,0 & 80 & 75 & 11.82 & 1703 & 566 & 6 & \\
\hline C-28si & 8 & & & 5.0 & 81 & 75 & 111.55 & 1663 & 853 & 7 & \\
\hline c-28ean & 8 & & & 50.0 & 81 & 75 & 11.21 & 1614 & 637 & 7 & \\
\hline$c-2638$ & 7 & & & 57.8 & 83 & 75 & 10.01 & 1441 & 479 & 6 & \\
\hline$C-2930$ & 8 & & & 58.3 & 75 & 69 & 9.74 & 1403 & 466 & 7 & \\
\hline$c-2038$ & & & & 52.2 & 82 & 73 & 8.53 & 1228 & 408 & 8 & \\
\hline c-293a & 8 & & & 54.5 & 75 & 69 & 6.94 & 999 & 332 & 7 & \\
\hline$c-2498$ & 7 & $36+$ & $10.97+$ & 54.0 & 86 & 72 & 21.52 & 3099 & 1030 & - & 5" \\
\hline$c-2868$ & 7 & & & 51.2 & 74 & 77 & 2084 & 3001 & 998 & 7 & \\
\hline C-248A & 7 & *. & & 50.0 & 73 & 72.5 & 15.82 & 2278 & 757. & 8 & \\
\hline$C-253 A$ & 7 & & & 50.9 & 77 & 69 & 12.24 & 1763 & 586 & 7 & \\
\hline$|C-273 A|$ & 8 & & & 51.6 & 81 & 77 & 11.70 & 1685 & 560 & 8 & \\
\hline C-258A & 7 & & & 50.4 & 80 & 77 & 9.98 & 1437 & 478 & 7 & \\
\hline C-29eA & 9 & & & 82.3 & 88 & 81 & 7.68 & 1106 & 368 & 7 & \\
\hline$\left|\begin{array}{c}C-306 A \\
c-2358\end{array}\right|$ & $\begin{array}{l}9 \\
7\end{array}$ & $39+$ & 111.890 & $\begin{array}{l}53.5 \\
55.5\end{array}$ & $\begin{array}{l}76 \\
77\end{array}$ & $\begin{array}{l}78 \\
72\end{array}$ & $\begin{array}{l}13.14 \\
11.75\end{array}$ & $\begin{array}{l}1892 \\
1692\end{array}$ & $\begin{array}{l}629 \\
663\end{array}$ & 5 & \\
\hline
\end{tabular}

TABLE 2I STATISTICAL DATA - LAKE CHMPLES SITE 
F-TEST COMPARATIVE AMLYYSB

\begin{tabular}{|c|c|c|c|c|c|c|c|c|c|c|c|}
\hline AMPLE & STE & DEP & TH & $\omega_{n}$ & $\boldsymbol{\omega}_{1}$ & $\% \mathrm{Cl}$ & & $\theta_{1}-\sigma_{1}$ & & & SRE \\
\hline & & FT & $M$ & & & & PSI & PSF: & $\mathrm{WN}^{2}$ & Dars & \\
\hline $\begin{array}{l}\text { UN } \\
\text { UN }\end{array}$ & 4 & $27+$ & $8.23+$ & $\begin{array}{l}44.1 \\
43.6\end{array}$ & $\begin{array}{l}76 \\
76\end{array}$ & 69 & \begin{tabular}{|l}
$23: 86$ \\
19.59
\end{tabular} & $\begin{array}{l}3439 \\
2821\end{array}$ & $\begin{array}{r}1143 \\
988\end{array}$ & & BLK \\
\hline 4 & 4 & $27+$ & $8.23+$ & 41.7 & 83 & & 30.16 & 4344. & 1443 & & BLK \\
\hline 4 & & & & 38.4 & & & 28.59 & 4117 & 1368 & & \\
\hline 4 & & & & 40.5 & & & 29.63 & 4267 & 1419 & & \\
\hline 4 & & & & 43.8 & & & 29.24 & 4211 & 1400 & & \\
\hline 4 & & & & & & & 30.53 & 4396. & 1462 & & \\
\hline 4 & & & & 46.4 & 83 & 69 & 30.78 & 4432 & 1474 & & \\
\hline 5 & 4 & $27+$ & $8.23+$ & 42.8 & 76 & 68 & 21.80 & 3151 & 1048 & & BLK \\
\hline 5 & & & & 47.7 & & & 24.34 & 3505 & 1165 & & \\
\hline 5 & & & & 43.6 & & & 25.81 & 3717 & 1236 & & \\
\hline 5 & & & & 440 & & & 27.96 & 4026 & 1339 & & \\
\hline 5 & & & & 44.5 & & & 21.40 & 3082 & 1025 & & \\
\hline 5 & & & & 43.5 & & & 27.99 & 4031 & 1340 & & \\
\hline 6 & & & & 43.0 & 76 & 68 & 28.39 & 4088 & 1359 & & \\
\hline en & 4 & $27+$ & $8.23+$ & 42.3 & $\overline{-}$ & $\bar{z}$ & 25.03 & 3720 & 1237 & & BLK \\
\hline 68 & & & & 41.4 & & & 23.83 & 3432 & 1141 & & \\
\hline $12 A$ & s & $30+$ & $9.14+$ & 489 & 80 & 70 & 2286 & 3292 & 1084 & & LKK \\
\hline 128 & & & & 50.3 & 80 & 70 & 22.25 & 3204 & 1065 & & \\
\hline I3A & 5 & $30+$ & $9.14+$ & 46.1 & 75 & 66 & 23.96 & 3450 & $1: 47$ & & BLK \\
\hline 138 & & & & 49.7 & & & 2420 & 3485 & 1159 & & \\
\hline $13 C$ & & & & 47.3 & 75 & 66 & 25.41 & 3659 & 1217 & & \\
\hline $7 A$ & 5 & $30+$ & $9.14+$ & 49.6 & 80 & 70 & 23.18 & 3338 & 1110 & & BLK \\
\hline 78 & & & & 50.4 & & & 23.32 & 3358 & 1116 & . & \\
\hline $7 C$ & & & & 49.9 & & & 18.30 & 2635 & 876 & & \\
\hline 70 & & & & - & & & 17.42 & 2508 & 834 & & \\
\hline $7 E$ & & & & 48.4 & & & 24.27 & 3496 & 1162 & & \\
\hline $7 F$ & & & & 50.5 & 80 & 70 & 23.38 & 3367 & 1119 & & \\
\hline
\end{tabular}

TABLE 22 STATISTICAL DATA-LAKE CMAPLLS SITE 
F-TEST COMPARATIVE ANALYSIS

\begin{tabular}{|c|c|c|c|c|c|c|c|c|c|c|c|}
\hline \multirow{2}{*}{ SAMPLE } & \multirow{2}{*}{ SITE } & \multicolumn{2}{|c|}{ DEPTH } & \multirow[b]{2}{*}{$\omega_{n}$} & \multirow{2}{*}{$\omega_{L}$} & \multirow{2}{*}{$\% \mathrm{Cl}$} & \multicolumn{3}{|c|}{$\left(\theta_{1}-a_{3}\right)$} & & \multirow{2}{*}{ SIZE } \\
\hline & & FT & $M$ & & & & PSI & PSF & $\mathrm{W} / \mathrm{M}^{2}$ & & \\
\hline 7 & 5 & $30+$ & 9.14 & 49.8 & 80 & 70 & 24.30 & 3499 & 1163 & & BLK \\
\hline 7 & & & & 49.6 & & & 25.54 & 3678 & 1223 & & \\
\hline 7 & & & & 48.4 & & & 18.62 & 2681 & .891 & & \\
\hline 7 & & & & 46.6 & & & 26.23 & 3777 & 1266 & & \\
\hline 7 & & & & 49.0 & & & 26.61 & 3832 & 1274 & & \\
\hline 7 & & & & 47.5 & & & 25.54 & 3678 & 1223 & & \\
\hline 7 & & & & 49.4 & & & 26.73 & 3849 & 1280 & & \\
\hline 7 & & & . & 49.5 & & & 22.43 & 3237 & 1076 & & \\
\hline 7 & & & & 49.6 & 80 & 70 & 31.0 & 4465 & 1495 & & \\
\hline 8 & 5 & $30+$ & 9.14 & - & 86 & 68 & 23.67 & $34 d \mathrm{~B}$ & 1.133 & & BLK \\
\hline 8 & & & & 50.9 & & & 22.32 & 3214 & 1000 & & \\
\hline 8 & & & & 50.3 & & & $21: 06$ & 3148 & 1047 & & \\
\hline 8 & & & & 49.8 & & & 2925 & 4212 & 1400 & & \\
\hline 8 & & & & 50.8 & & & 27.57 & 3970 & 1320 & & \\
\hline 8 & & & & 49.8 & & & 24.90 & 3586 & 1192 & & \\
\hline 8 & & & & - & & & 29.17 & 4200 & 1397 & & \\
\hline 8 & & & & 48.4 & 86 & 68 & 28.42 & 4052 & 1361 & & \\
\hline 10 & 5 & $30+$ & 9.14 & 48.9 & 82 & 72 & 18.45 & 2657 & 883 & & \\
\hline 10 & & & & 50.5 & $\infty 2$ & 72 & 21.64 & 3116. & 1036 & - & \\
\hline
\end{tabular}

TABLE 23 STATISTICAL DATA - LAKE CHARES SITE 


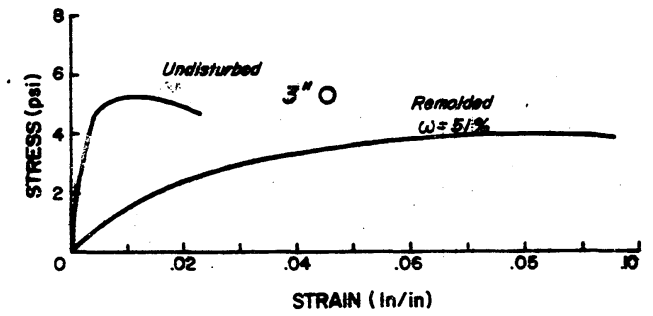

FIGURE IIO LAKE CHARLES - SITE I $B-1, C-1 \mid$ IA, 30-33 FEET (UU TEST) 


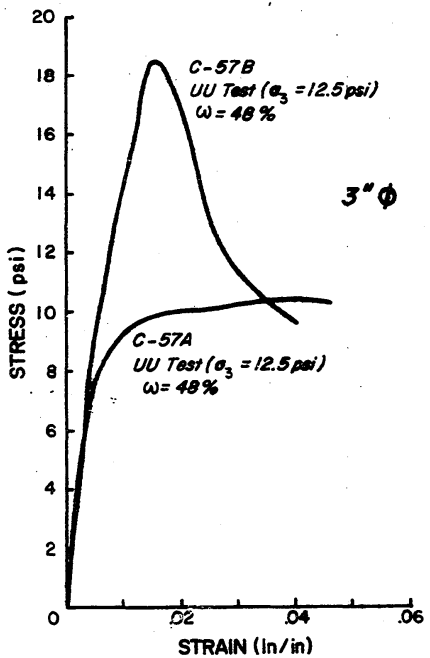

FIGURE III LAKE CHARLES-SITE 3

B-9, C-57, 30-33 FEET 


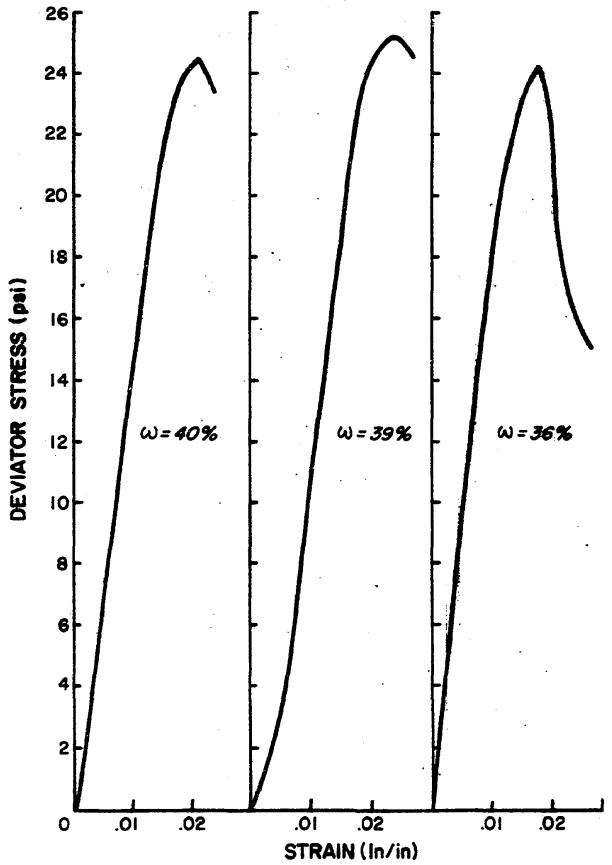

FIGURE II2 UNCONFINED COMPRESSIVE TEST LAKE CHARLES, SITE 4, BLOCK 4, 27 FOOT DEPTH 


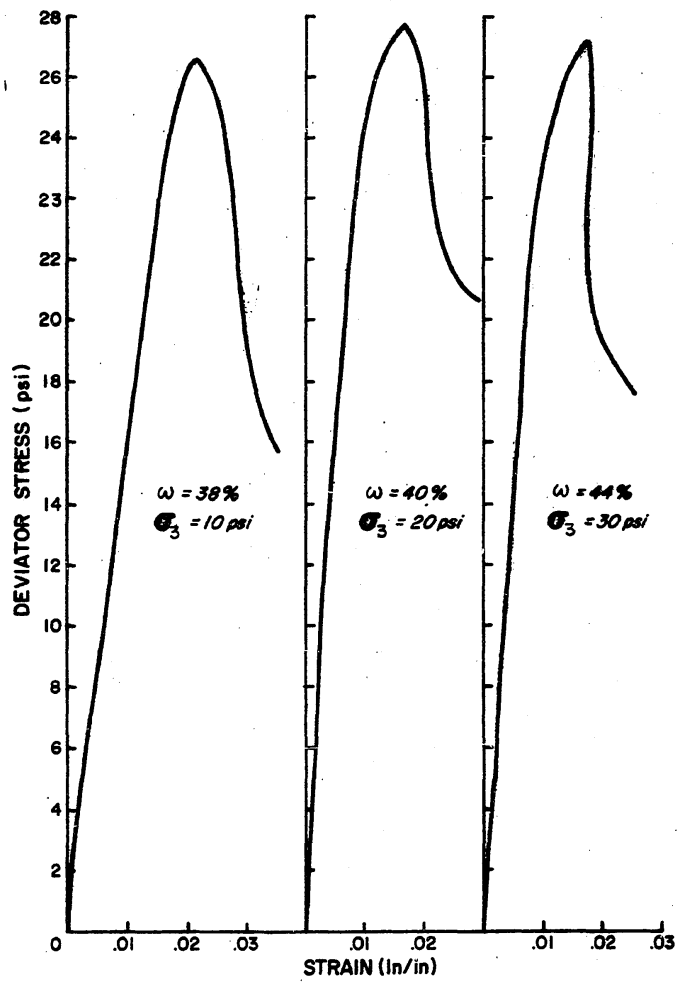

FIGURE IIJ TRIAXIAL COMPRESSIVE TEST LAKE CHARLES, SITE 4, BLOCK 4, 27 FOOT DEPTH 


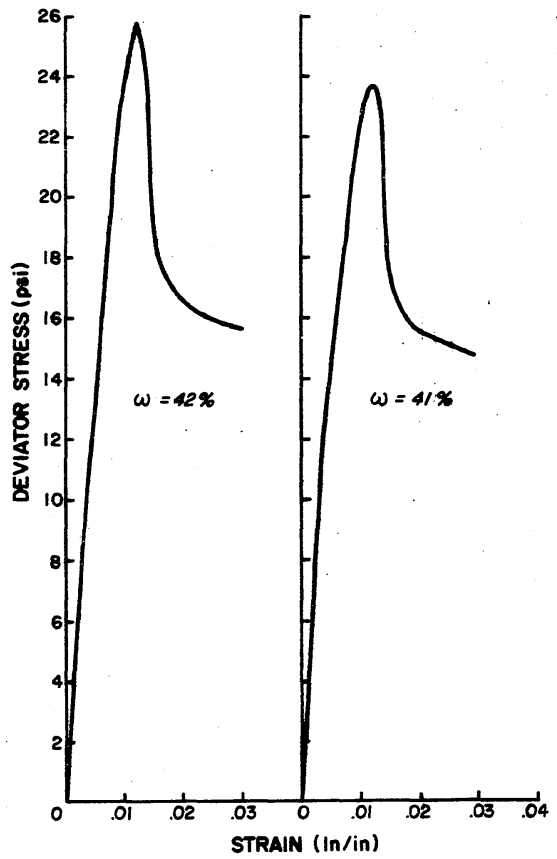

FIGURE II4 TRIAXIAL COMPRESSION TEST ON BLOCK SAMPLES, LAKE CHARLES, SITE 4, BLOCK NO. 6, 27 FT. DEPTH. 


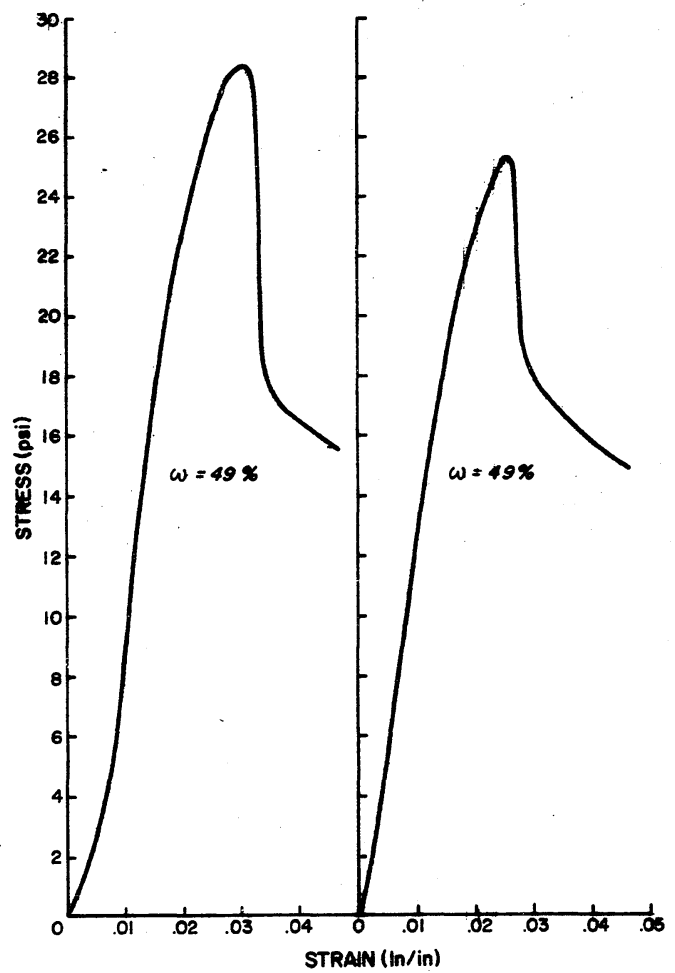

FIGURE 115 UNCONFINED COMPRESSION TEST BLOCK SAMPLES - LAKE CHARLES, SITE 5, BLK NO. 7, 30FT. + DEPTH. 


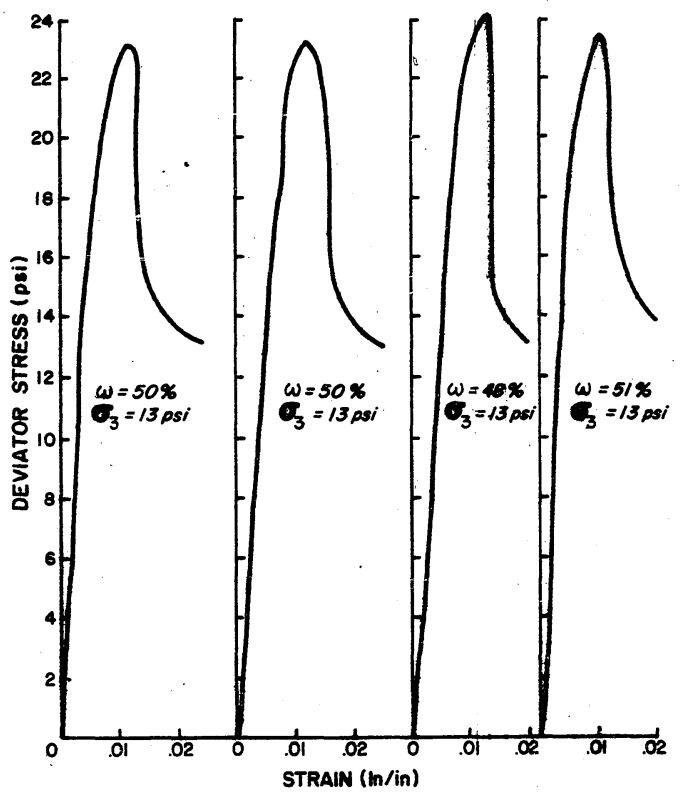

FIGURE IIG TRIAXIAL COMPRESSIVE TEST LAKE CHARLES, SITE 5, BLOCK 7, 30 FOOT DEPTH 


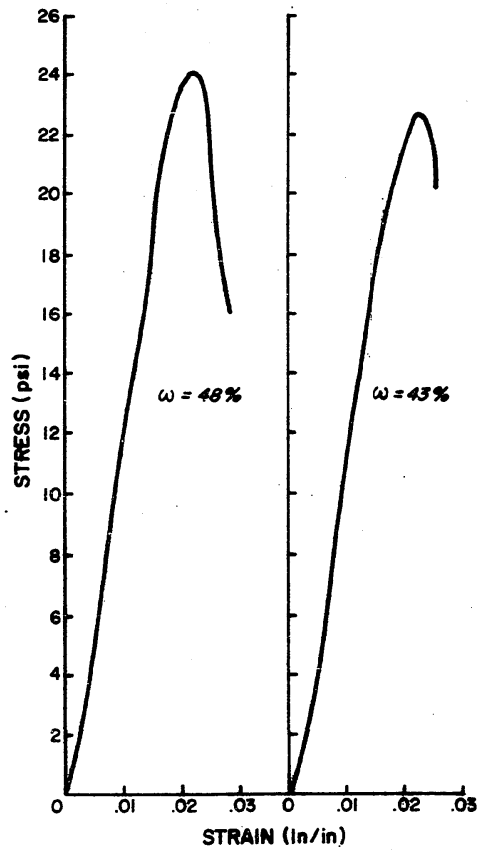

FIGURE 117 UNCONFINED COMPRESSION TEST ON BLOCK SAMPLES, LAKE CHARLES, SITE 5, BLK NO. $8,30 F T+$ DEPTH. 


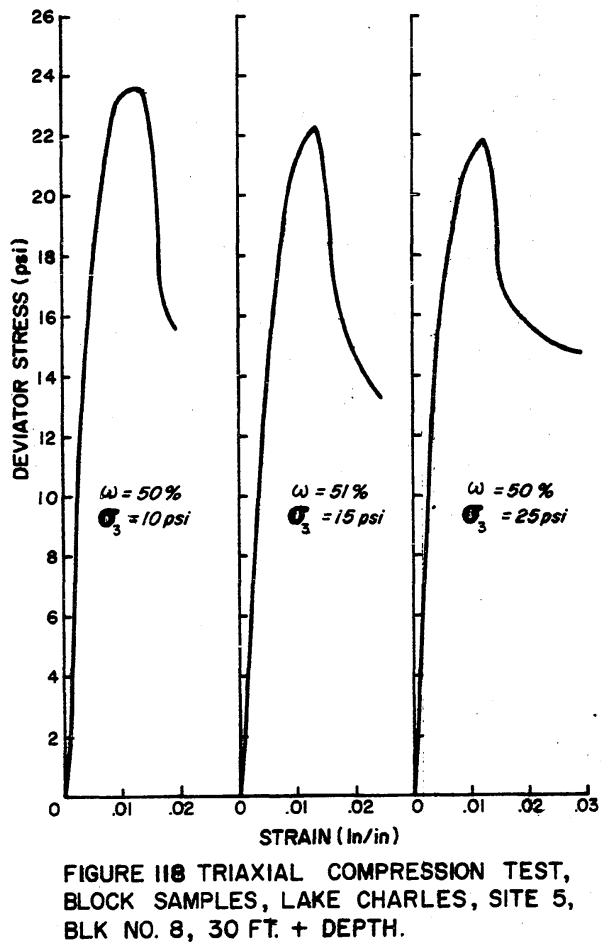




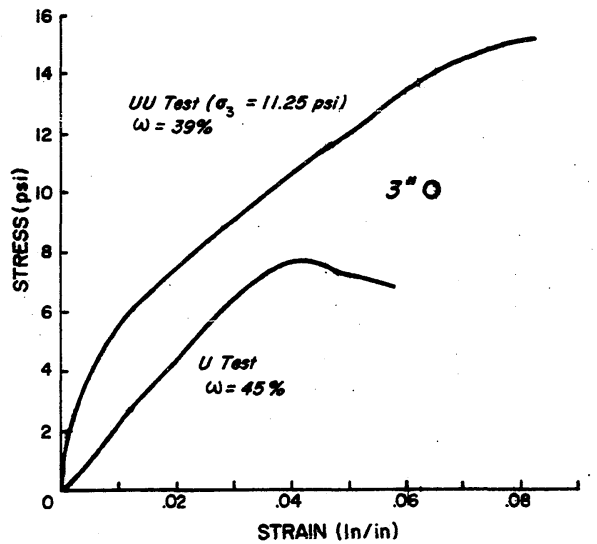

FIGURE II9 LAKE CHARLES-SITE 7

B-18, C-265A, 27 - 30 FEET 


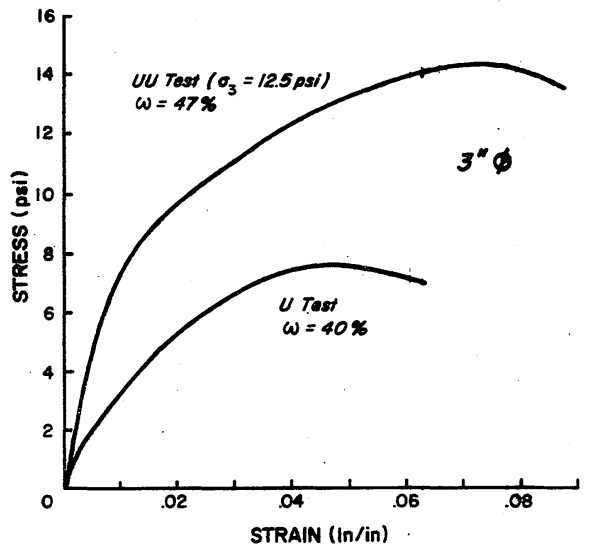

FIGURE 120 LAKE CHARLES - SITE 7 B-17, C-26IA, 30-33 FEET 


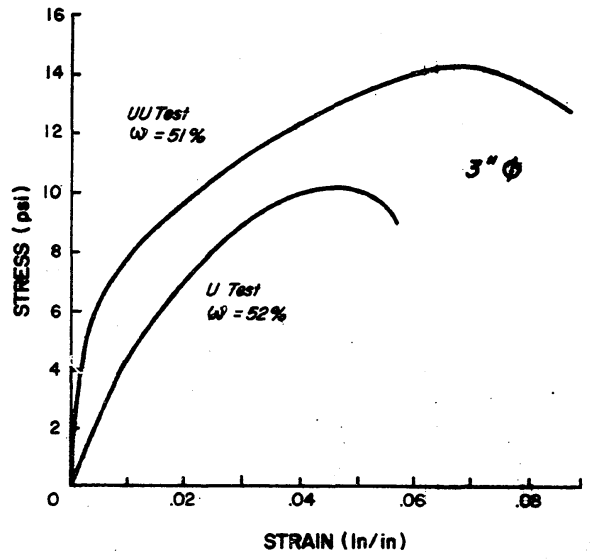

FIGURE I2I LAKE CHARLES-SITE 7 B-12, C-233A, 33-36 FEET 


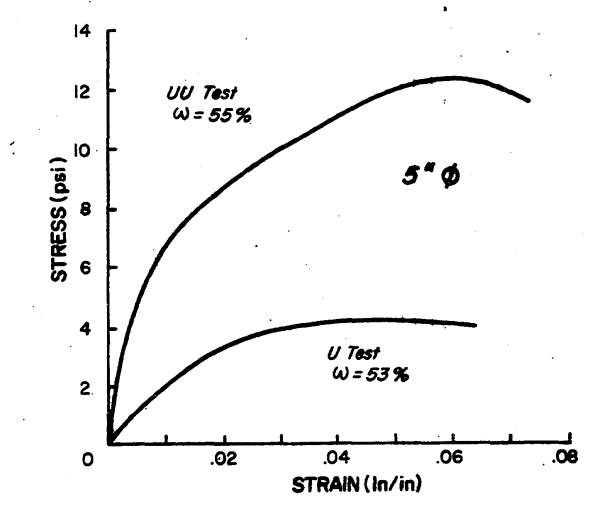

FIGURE 122 LAKE CHARLES - SITE 7 B-17, C-263A, 36-39 FEET 


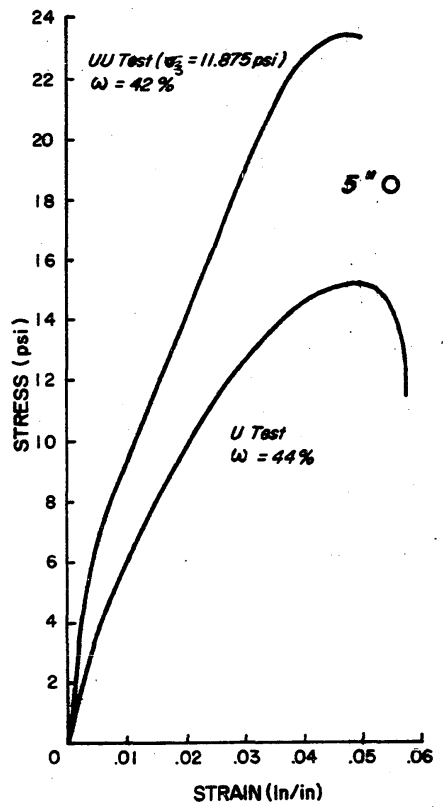

FIGLRE I23 LAKE CHARLES-SITE 8 B-20, C-270B, 27-30 FEET 


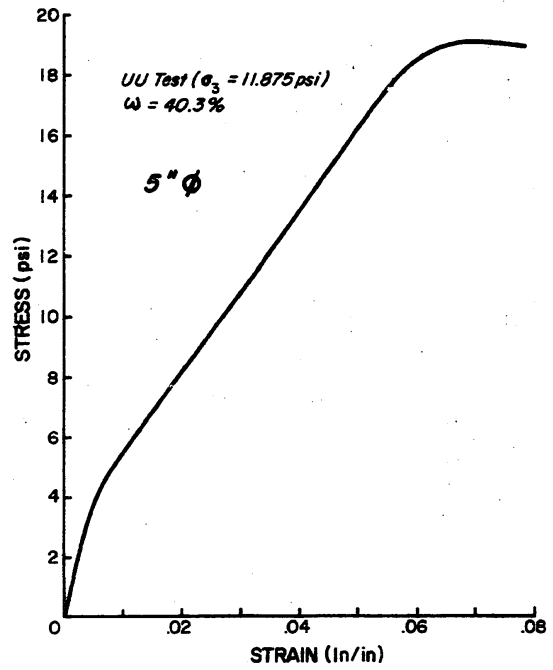

FIGURE 124 LAKE CHARLES-SITE 8 B-2I, C-275A, 27-30 FEET 


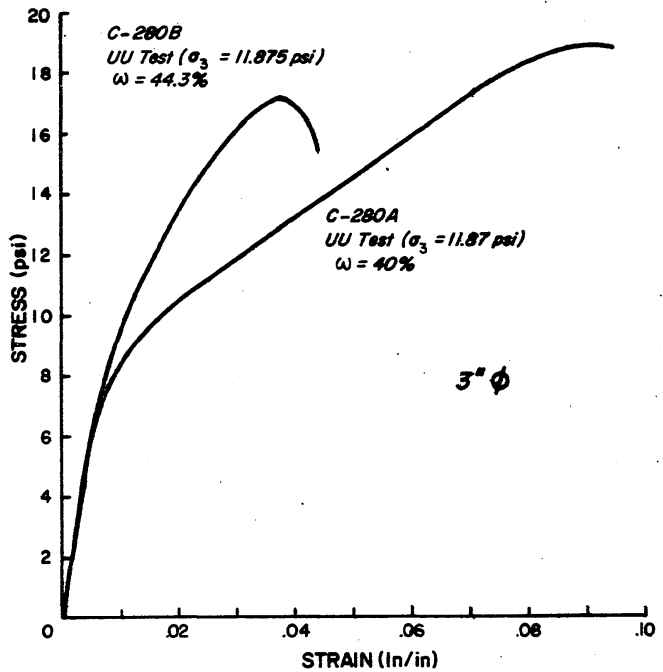

FIGURE 125 LAKE CHARLES - SITE 8 B-22, C-280, 27-30 FEET 


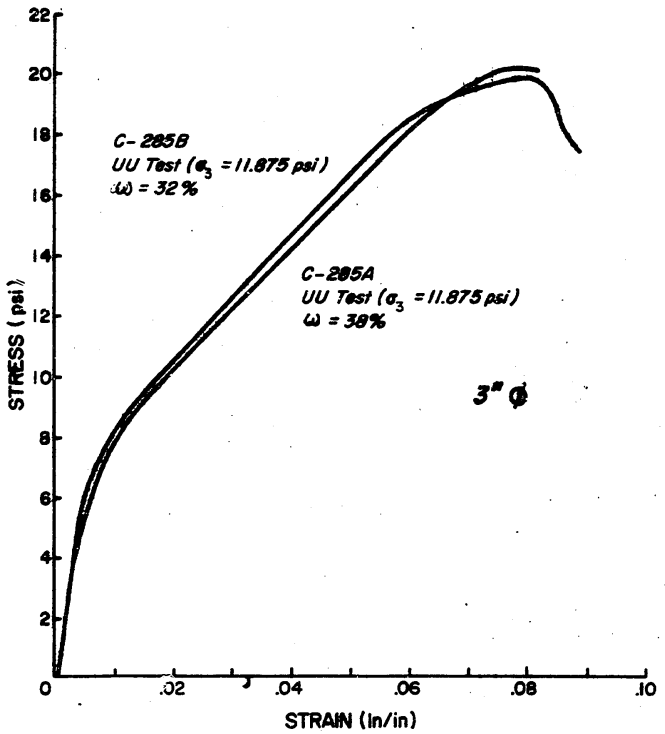

FIGURE IRG LAKE CHARLES-SITE 8 B-23, C-285, 27-30 FEET 


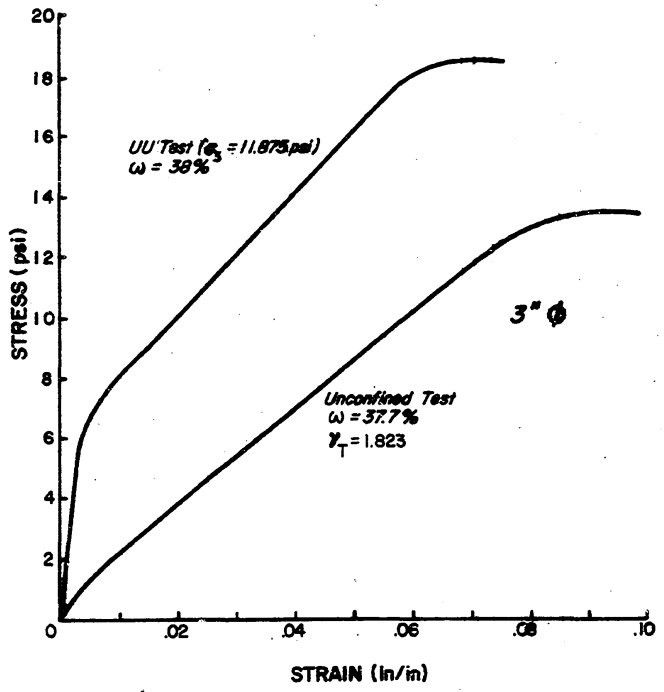

FIGURE PQT' LAKE CHARLES - SITE 8, B-24, C-2904, 27-30 FEET 


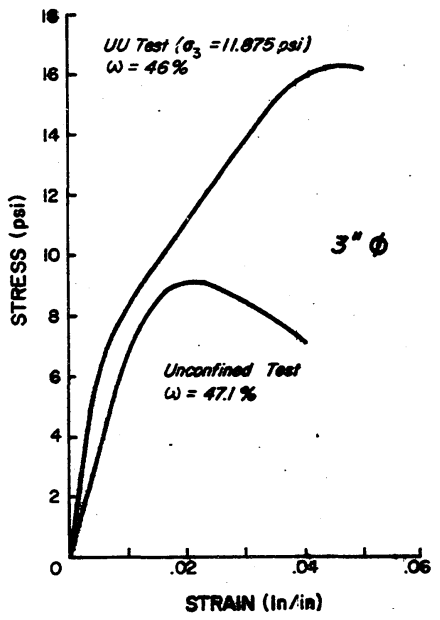

FIGURE IRB LAKE CHARLES-SITE 8, B-24, C-2908, 27-30 FEET 


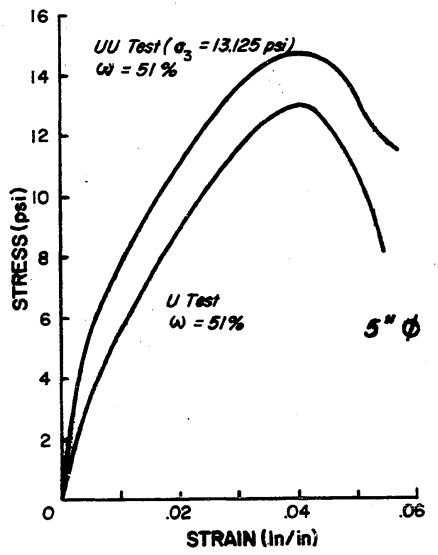

FIGURE 129 LAKE CHARLES-SITE 8 B-20, C-27IB, 30-33 FEET 


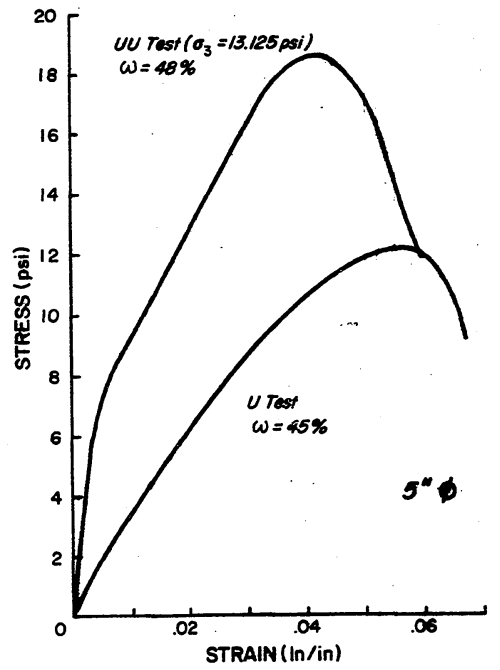

FIGURE I3O LAKE CHARLES-SITE 8 B-2l, C-276A, 30-33 FEET 


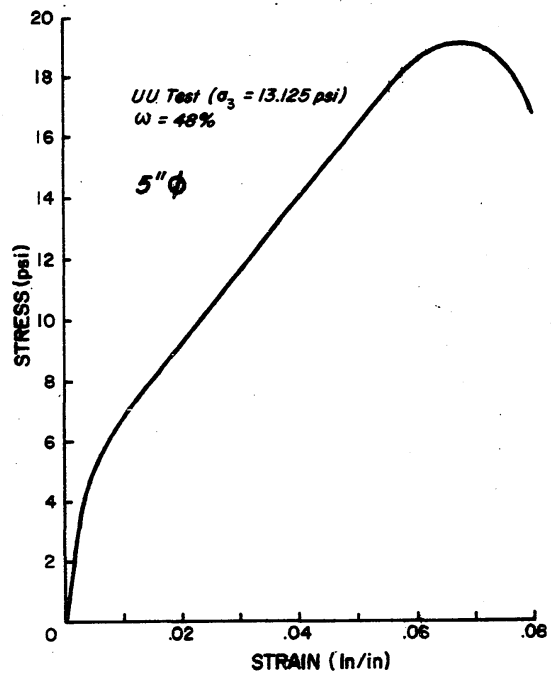

FIGURE I3 LAKE CHARLES - SITE 8 B-2I, C-276B, 30-33 FEET 


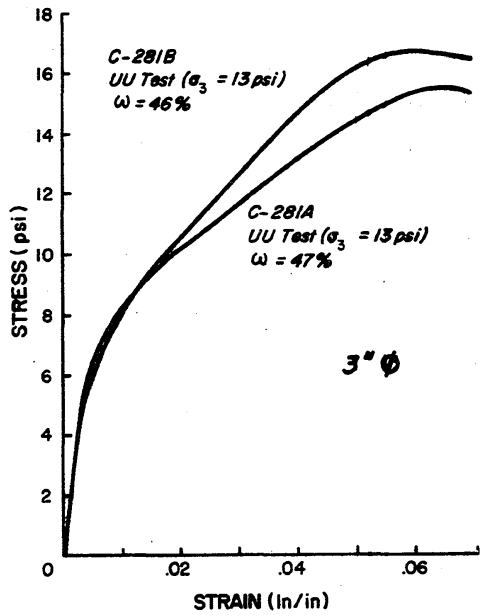

FIGURE I32 LAKE CHARLES-SITE 8 B-22, C-281, 30-33 FEET 


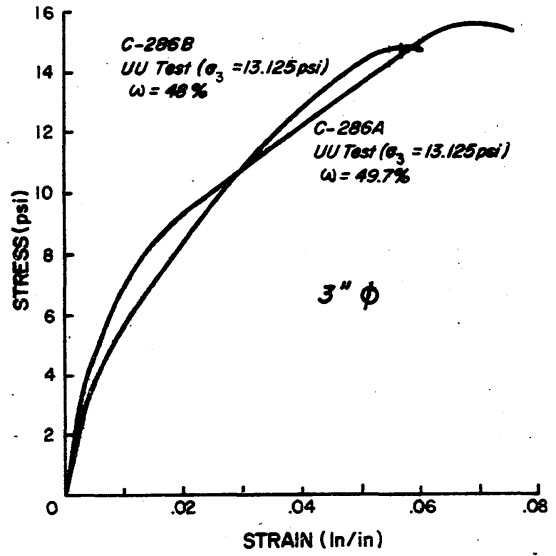

FIGURE I33 LAKE CHARLES - SITE 8 B-23, C-286, 30-33 FEET 


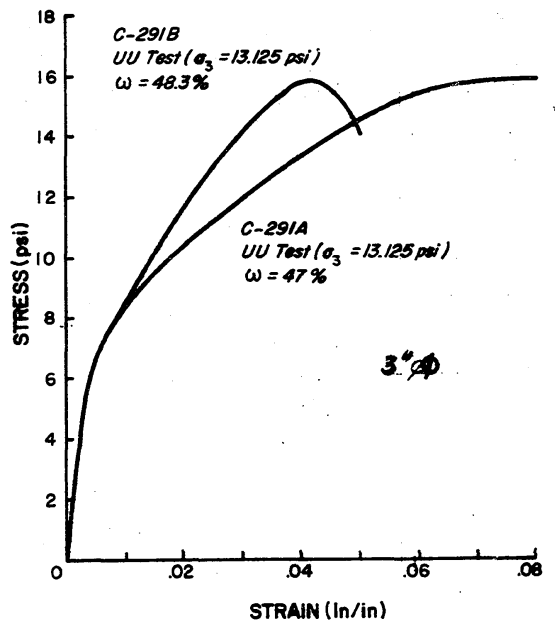

FIGURE I34 LAKE CHARES-SITE 8 B-24, C-29I, 30-33 FEET 


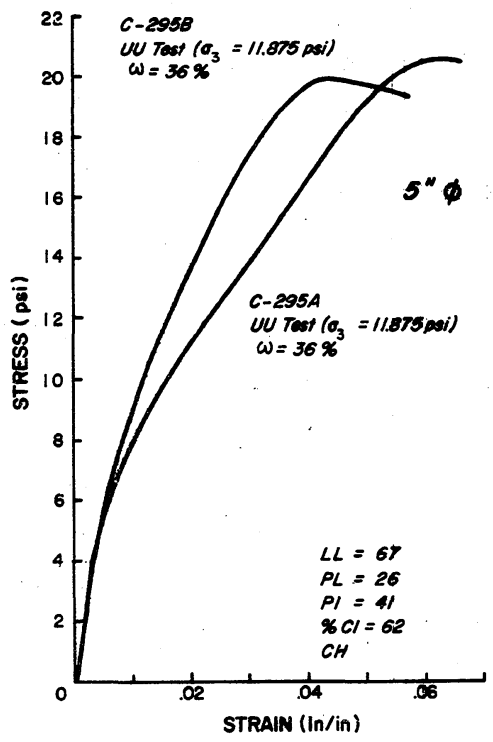

FIGURE I35 LAKE CHARLES-SITE 9

B-25, C-295, 27-30 FEET 


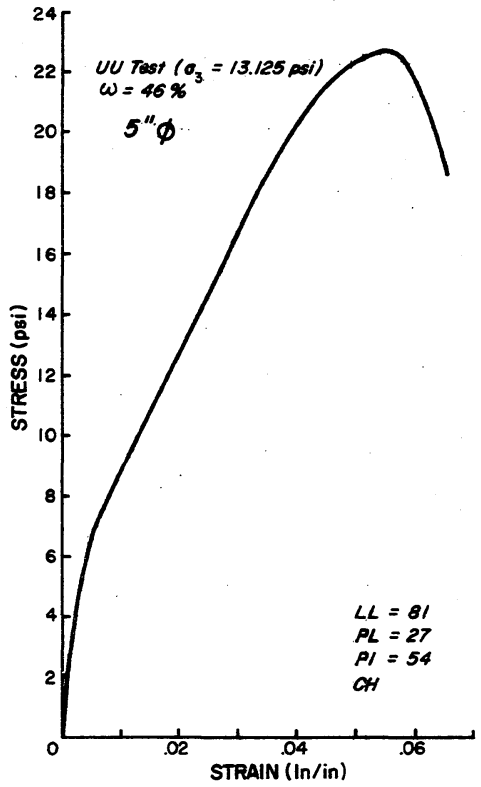

FIQUAE I36 LAKE CHARLES - SITE 9 B-25, C-2968, 30-33 FEET 


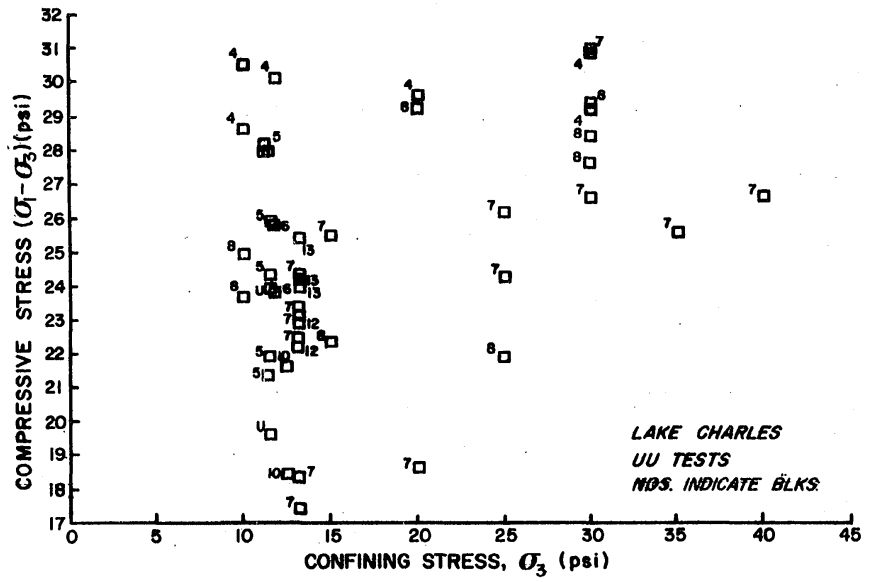

FIGURE 137 UNDRAINED TRIAXIAL TEST LAKE CHARLES, BLOCK SAMPLES, 27-33 FT. DEPTH 


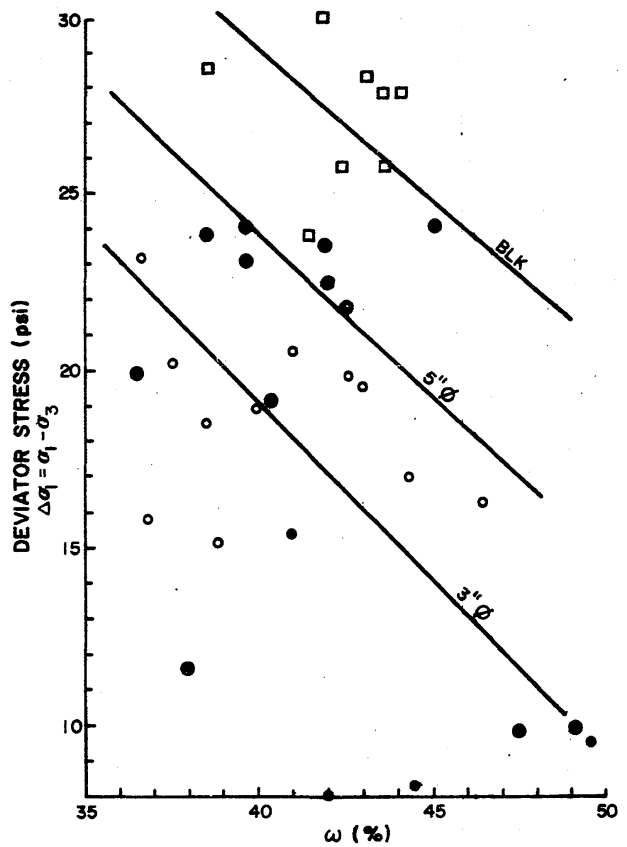

FIGURE I38 TRIAXIAL COMPRESSIVE STRENGTH LAKE CHARLES, SITES I THRU 9, 27-30 FOOT DEPTH 


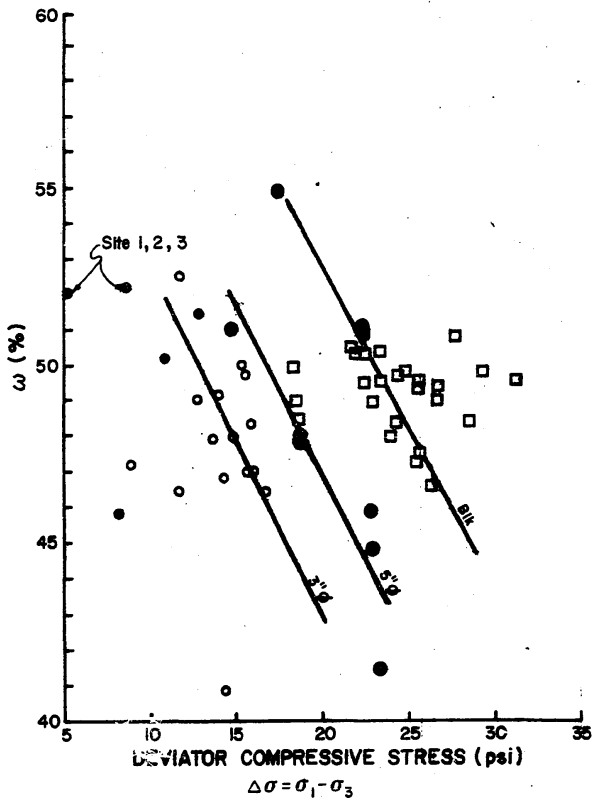

FIGURE I39 TRIAXIAL COMPRESGIVE STRENGTH LAKE CHARLES, SITES I THRU 9, 30-33 FOOT DEPTH 


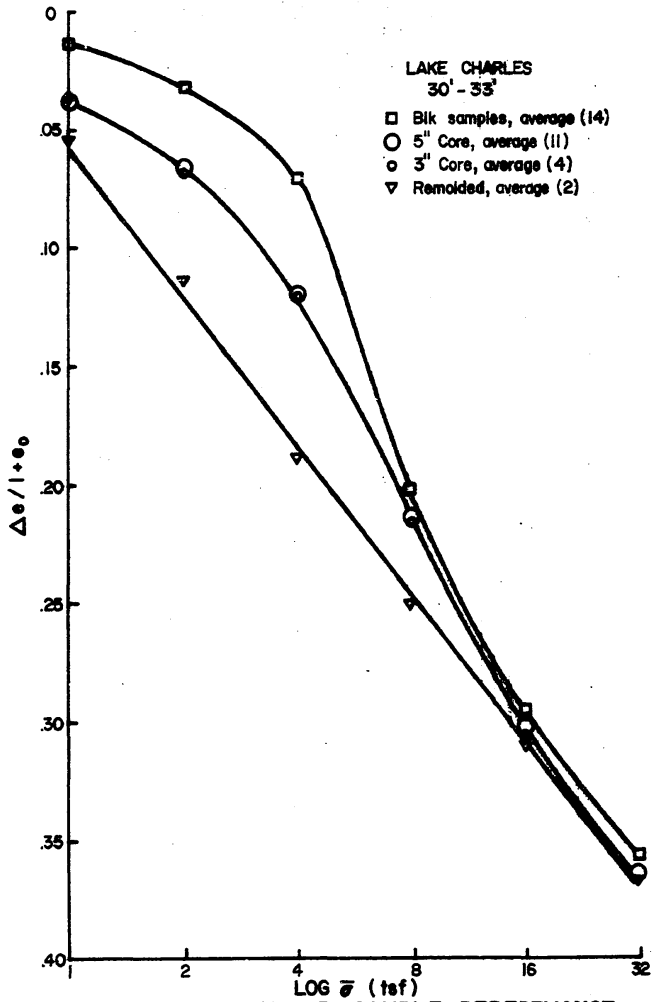

FIGUNE 140 COMPARISON OF SAMPLE PERFORMAME IN CONSOLIDATION TESTS

LAKE CHARLES SITES $I_{2} 2,3$, AND 5 - 30 FOOT DEPTH 


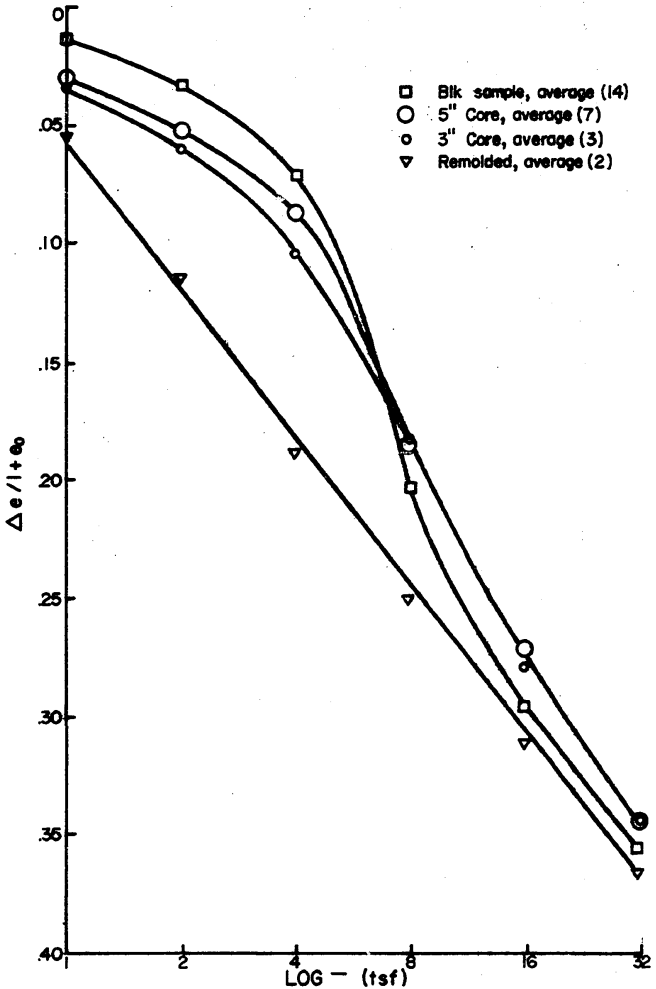

FIGURE 141 COMPARISON OF SAMPLE PERFORMAMCE IN CONSOLIDATION TESTS LAKE CHARLES SITES 5,7,8, AND 9 - 30+FOCT DEPTH 


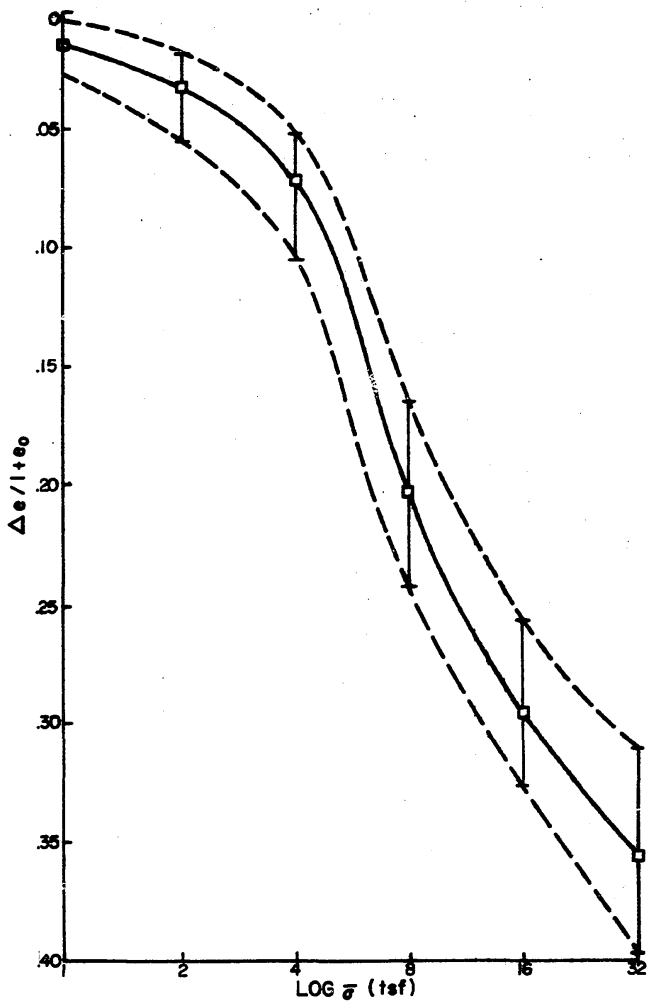

FICURE 142 COMPRESSION CURVE VARAATION

LAKE CHARLES BLOCK SAMPLES-30 FOOT DEPTH 

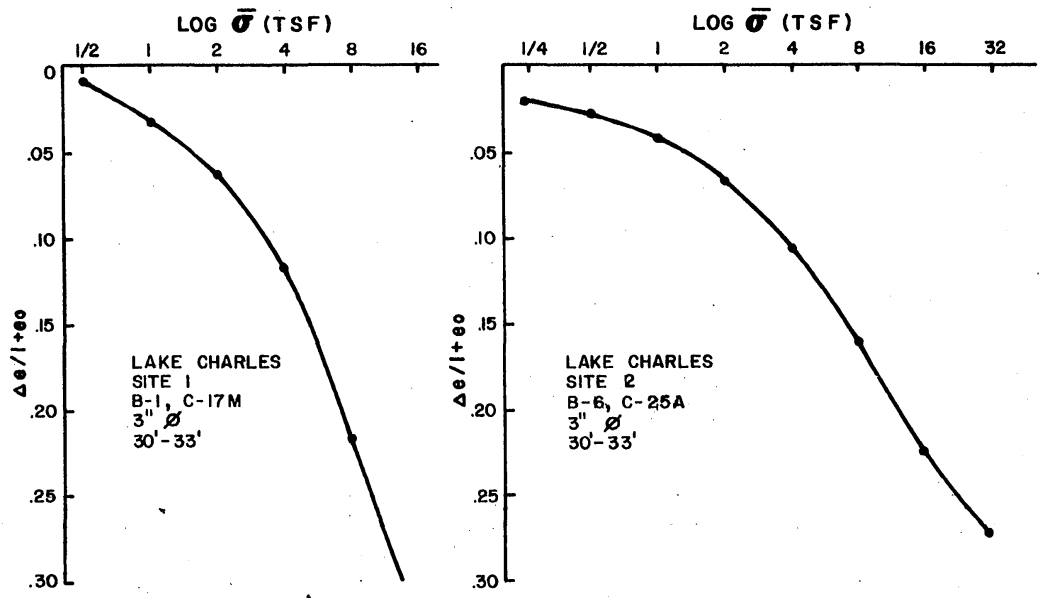

FIGURE 143 COMPRESSION CURVES, CONSOLIDATION TEST - LAKE CHARLES SITE. 

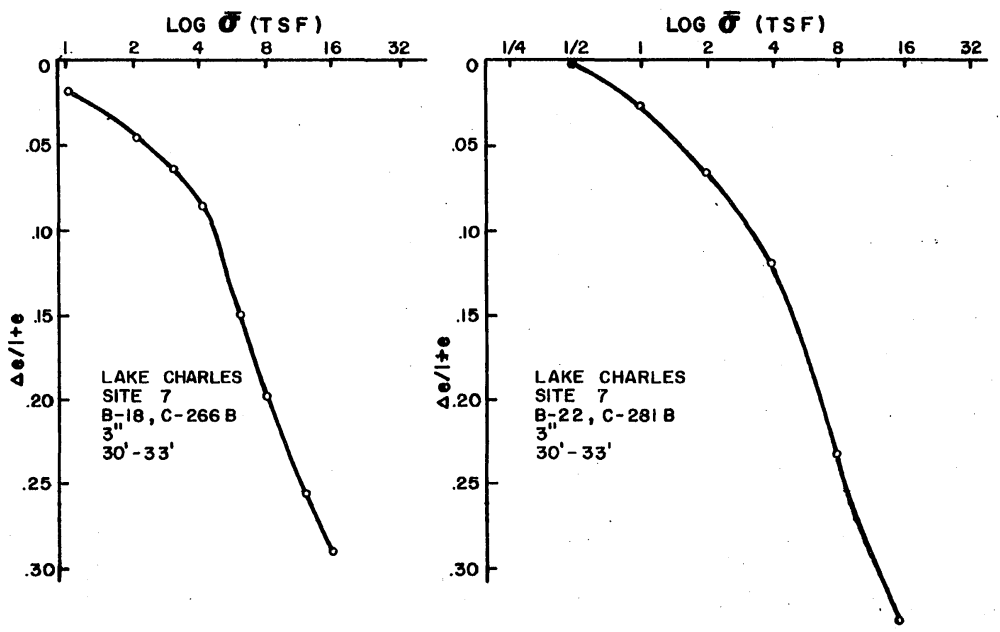

FIOURE 144 COMPRESSION CURVES, CONSOLIDATION TEST - LAKE CHARLES SITE 


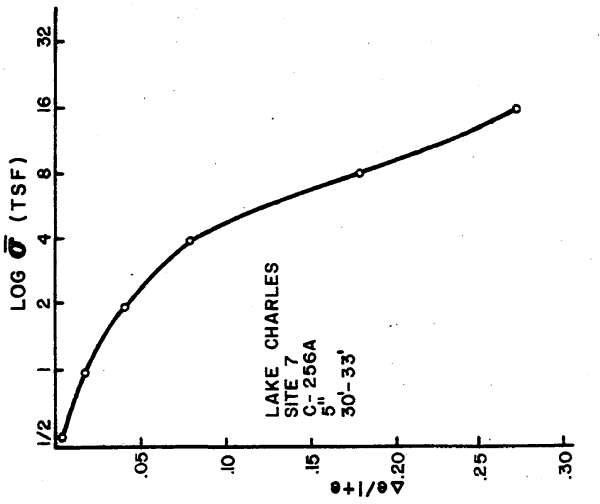

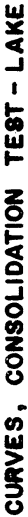

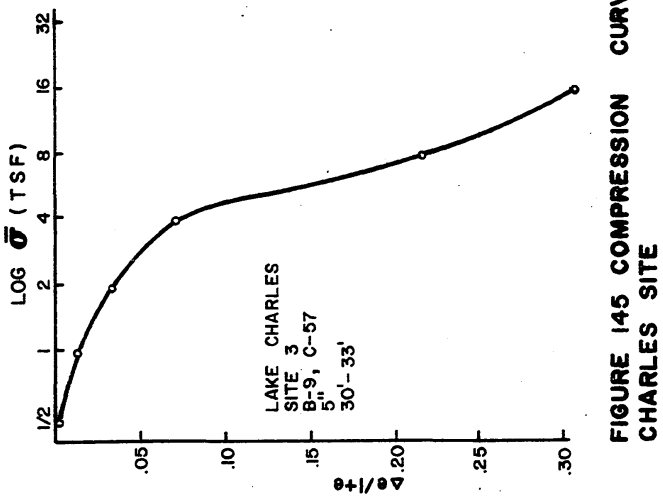



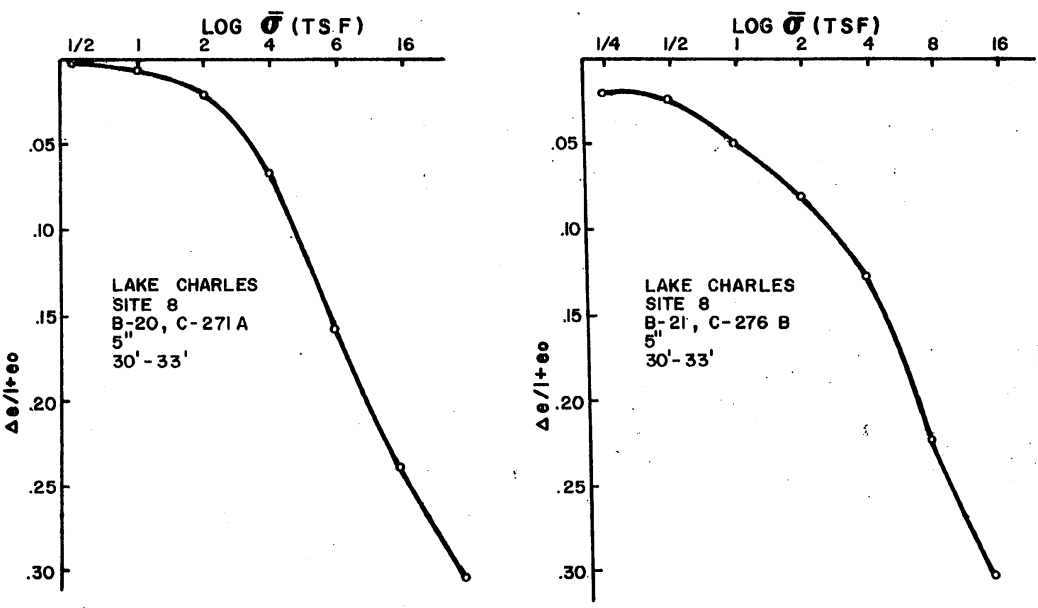

FIGURE 146 COMPRESSION CURVES, CONSOLIDATION TEST - LAKE CHARLES SITE 

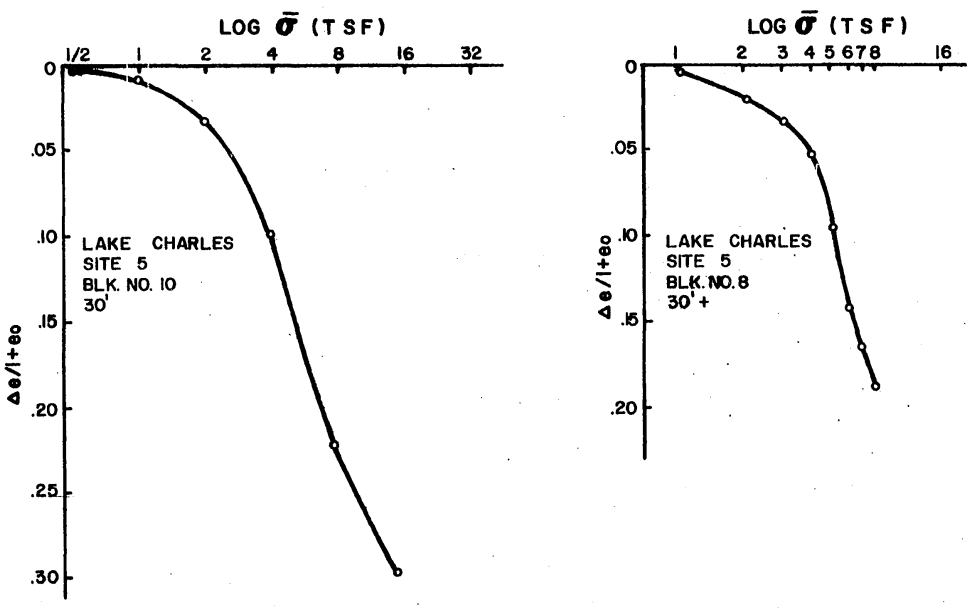

FIGURE 147 COMPRESSHON CURVE8, CONSOLIDATION TEST - LARE CHARLES SITE 


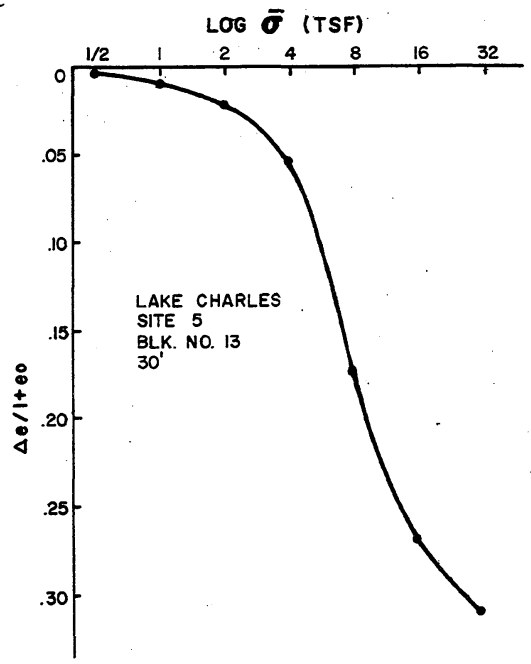

FIGURE 148 COMPRESSION CURVE, CONSOLIDATION TEST - LAKE - CHARLES SITE. 


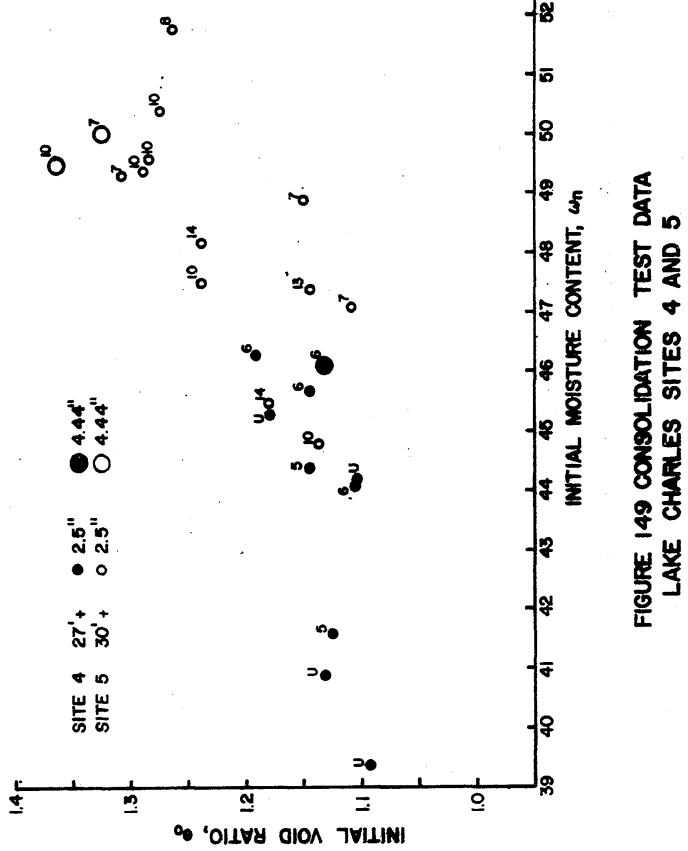




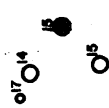

\&
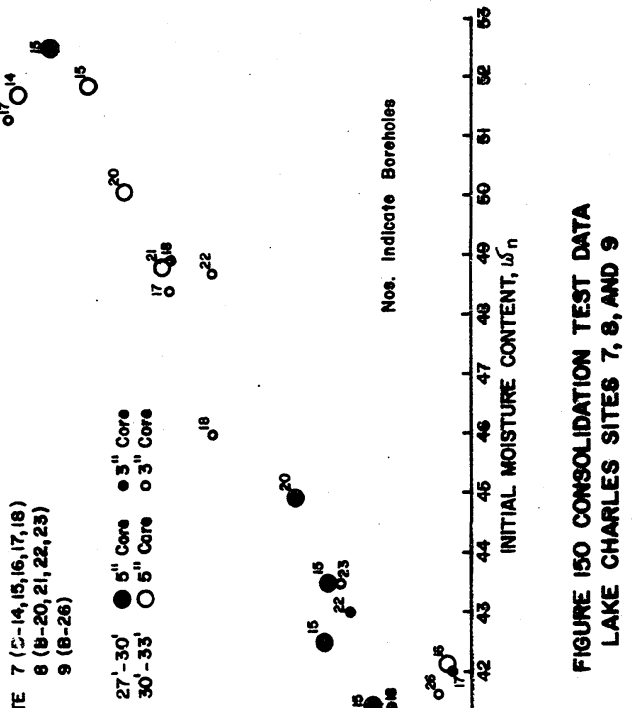

항 융

in

\% ชี

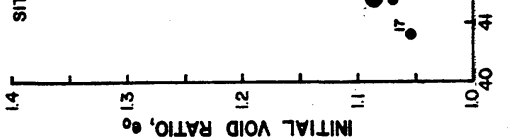




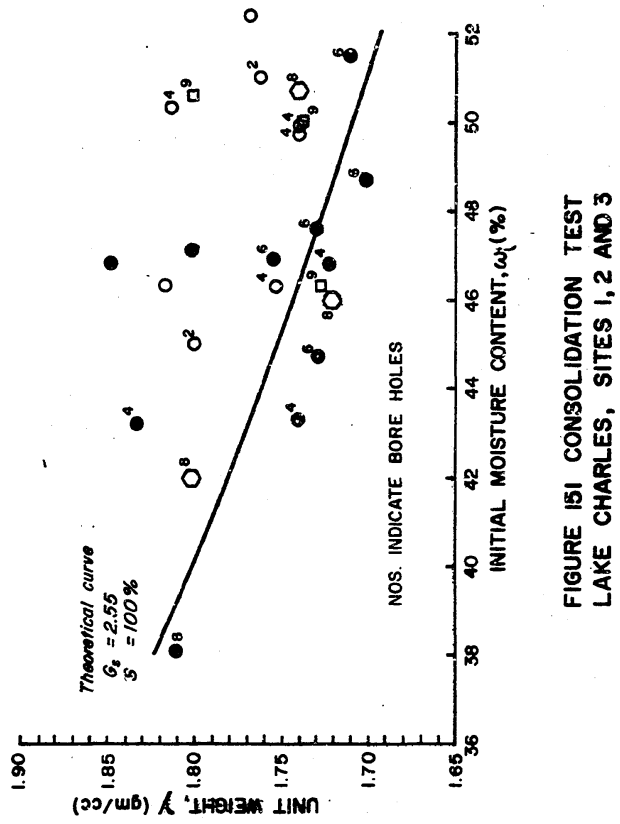




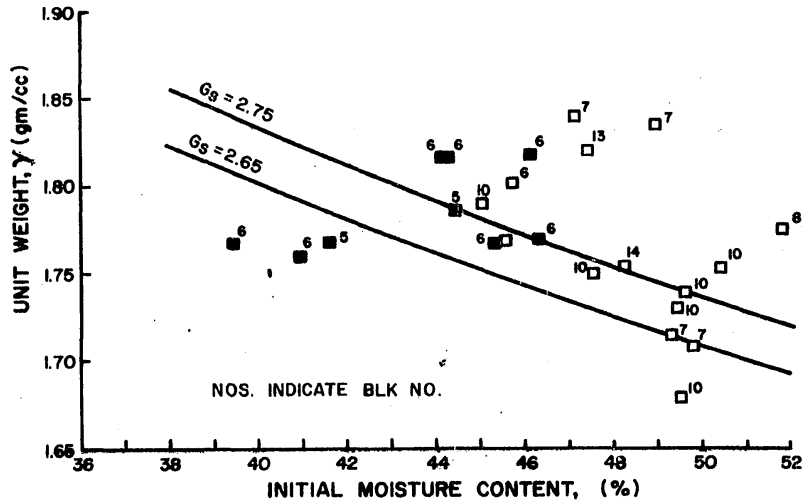

FIOURE IS2 CONSOLIDATION TEST

LAKE CHARLES, SITES 4 AND 5 


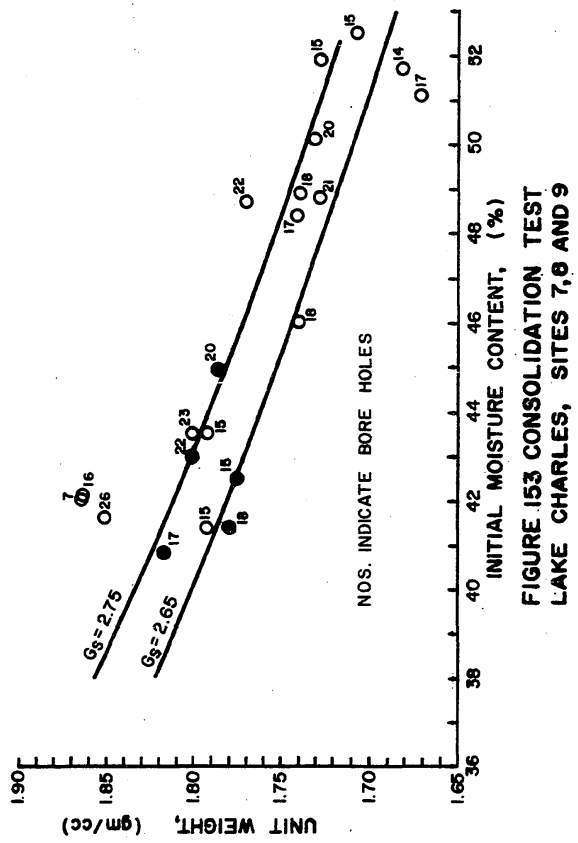




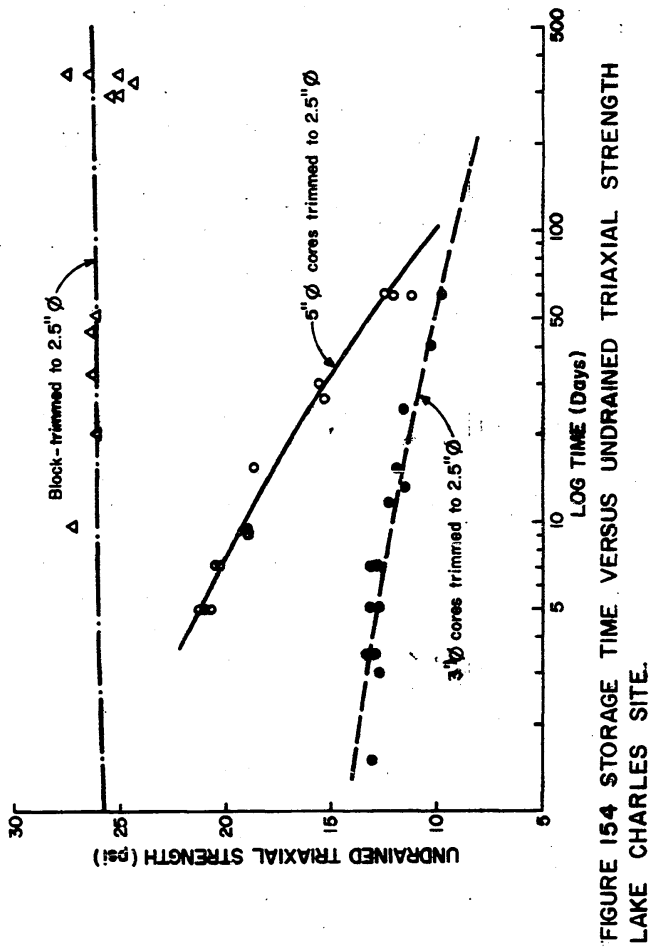




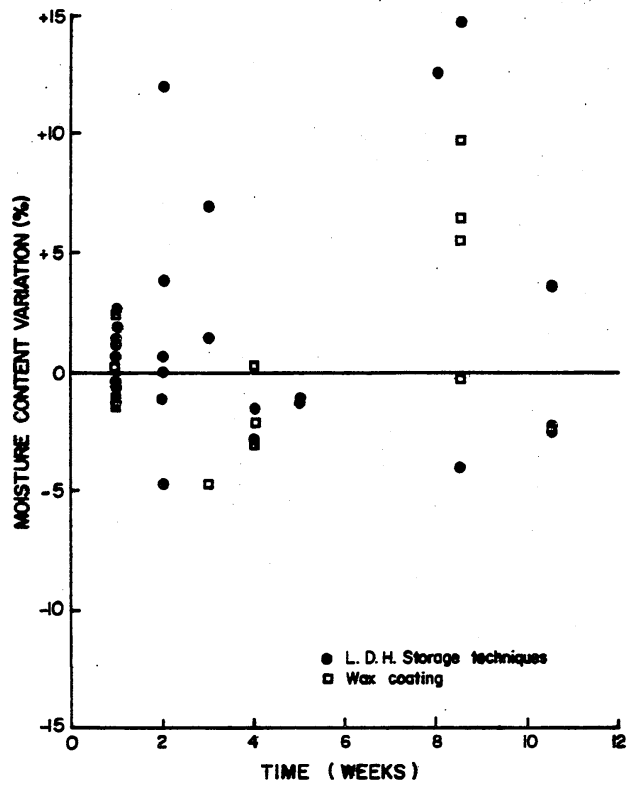

FIEURE 155 MOSTLEE CONTENT MRAATION VS TIME

LAKE CHARLES SITE 


\section{APPENDIX D}

\section{LAPLACE SITE}

325

Reproduced with permission of the copyright owner. Further reproduction prohibited without permission. 


\section{Location: LAPLACE}

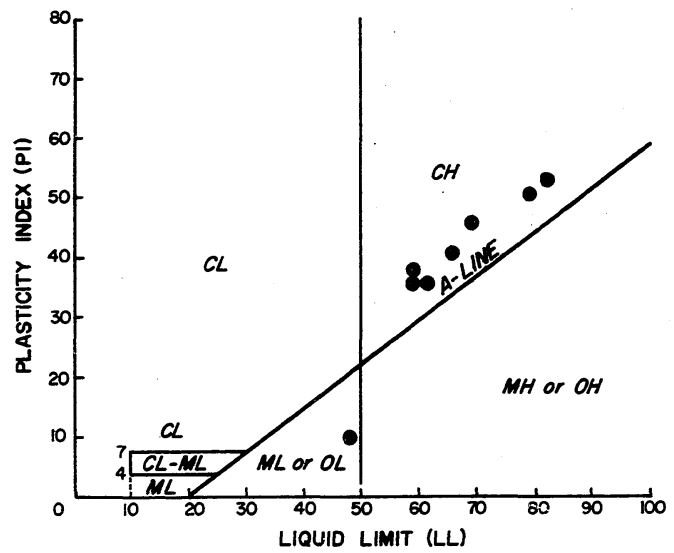

FIGURE 156 MODIFIED PLASTICITY CHART WITH UNIFIED SOIL CLASSIFICATION SYSTEM After USBR, 1963 


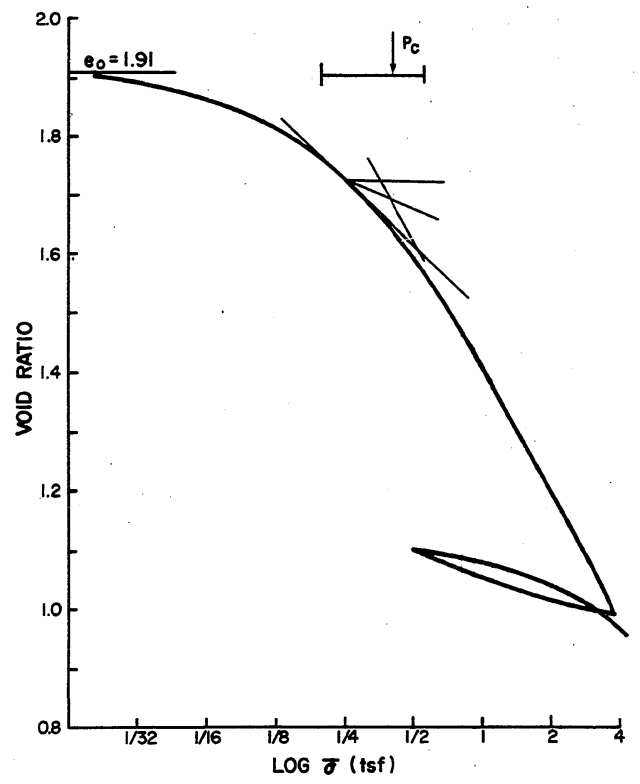

FIGURE 157 LAPLACE SITE - E-LOG - COMPRESSION CURVE 30 FOOT DEPTH 


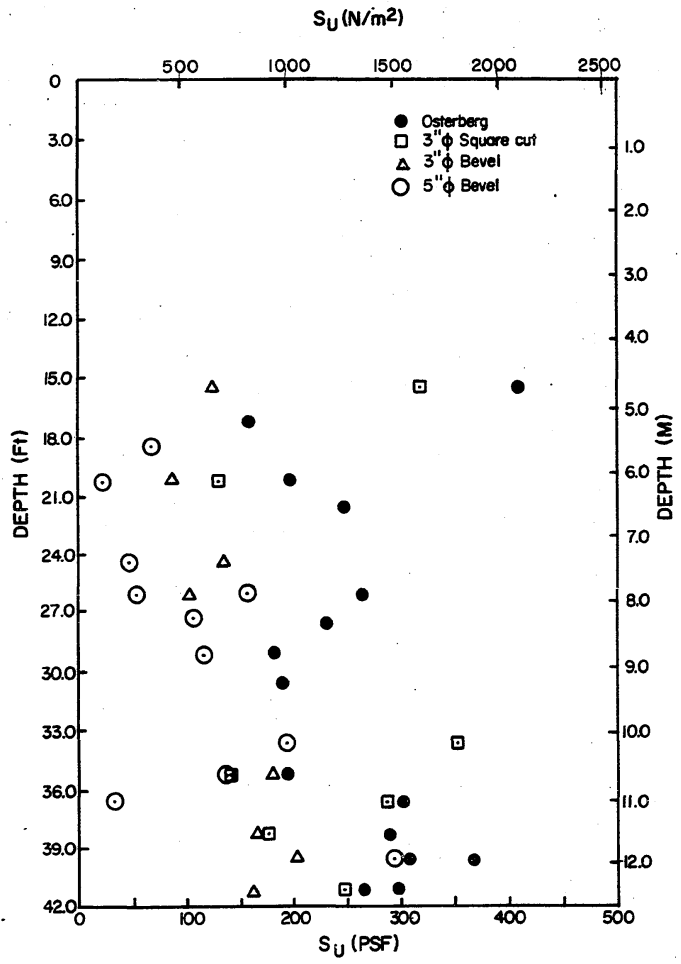

FIGURE 158 LAPLACE SITE UNCONFINED SHEAR STRENGTH VS DEPTH 


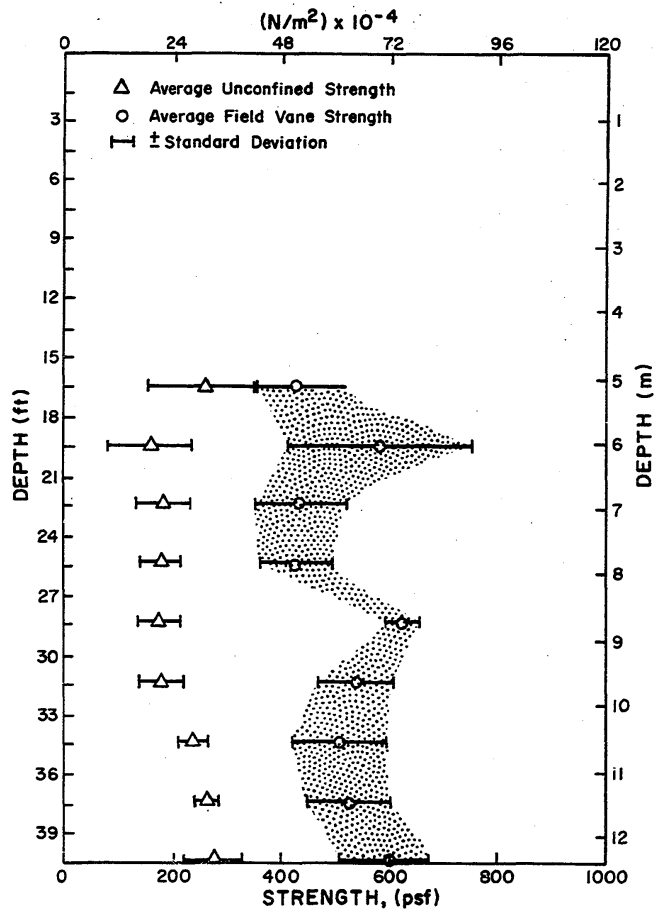

TYPICAL VARIANCE OF UNCONFINED AND

FIELD VANE SHEAR STRENGTHS

(LAPLACE - ORGANIC)

FROM ARMAN, of al 1975

FIGURE $158 \mathrm{~A}$ 


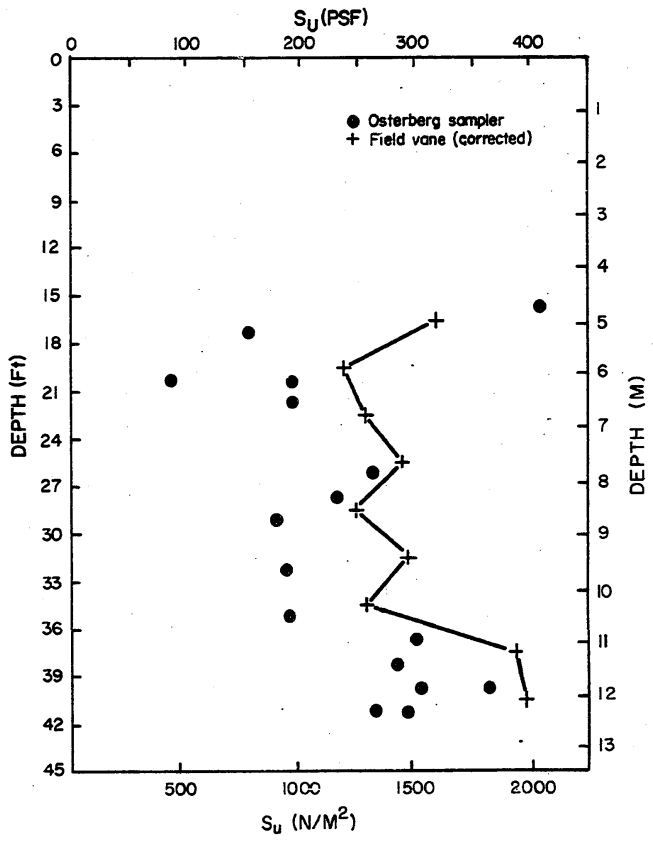

FIGURE 159 LAPLACE SITE DEPTH VS. UNCONFINED SHEAR STRENGTH 

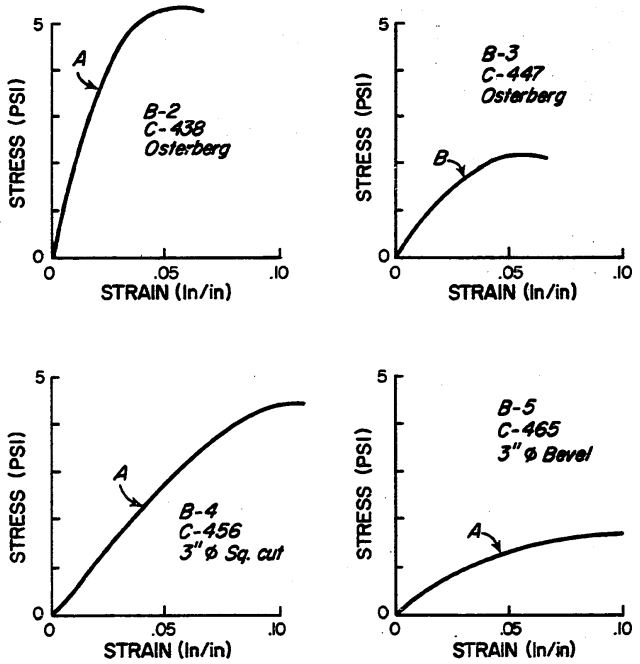

FIGLRE 160 LAPLACE $\left(15^{\prime}-18^{\prime}\right)$ 

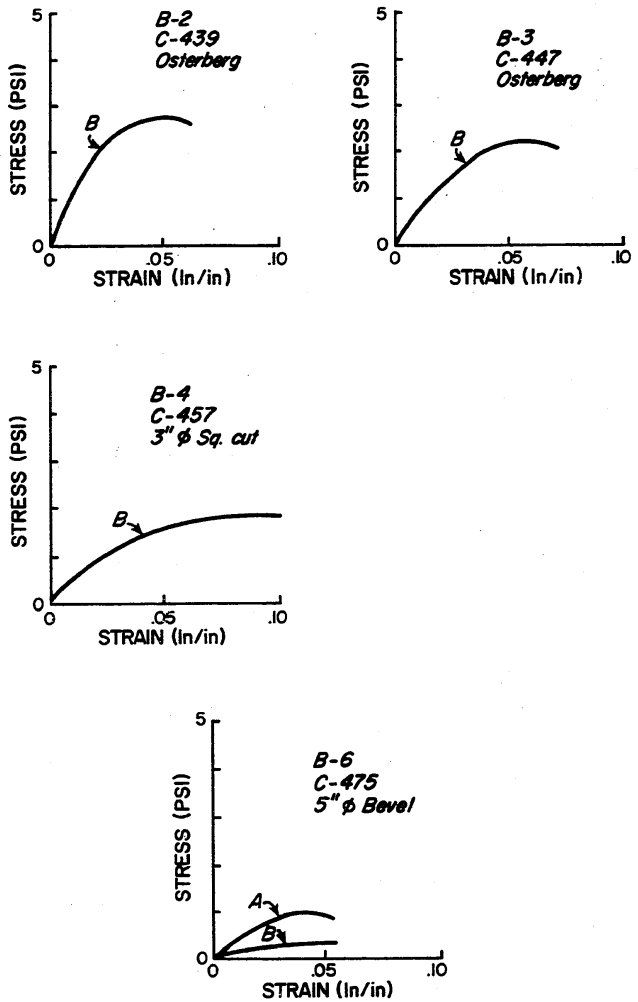

FIGURE I6I LAPLACE $(18 '-2 \mid ')$ 

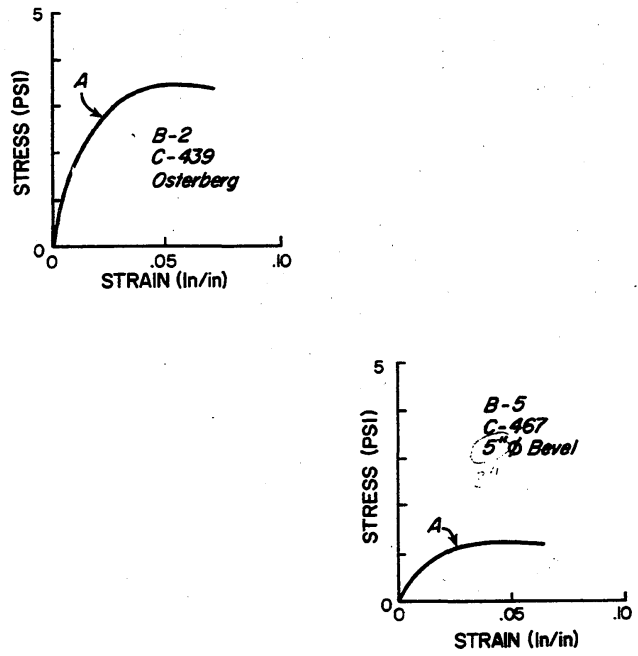

FIGURE I62 LAPLACE (2I' - 24') 

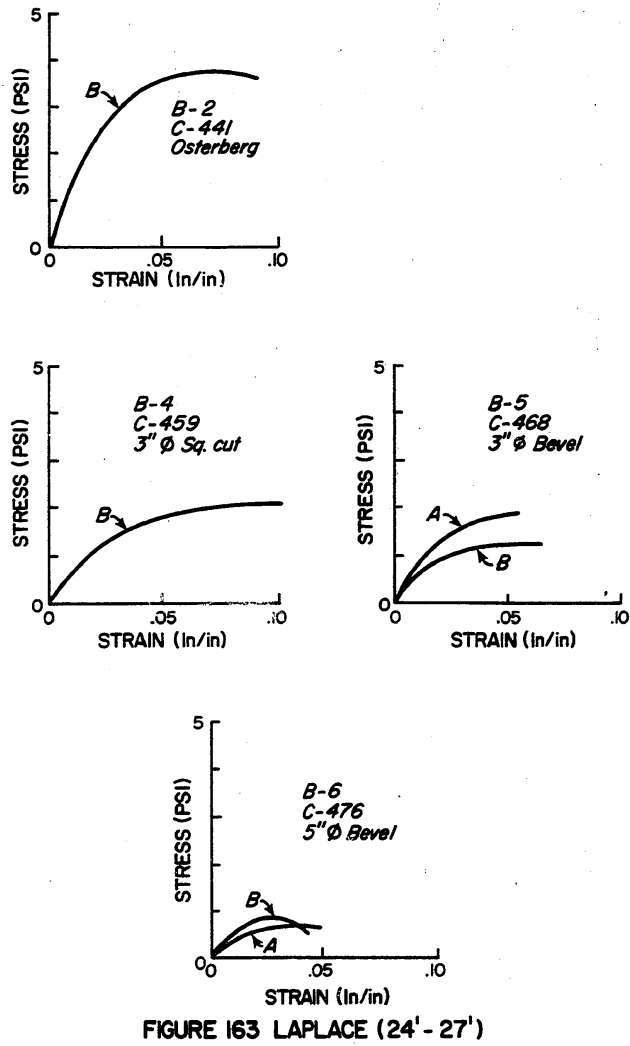

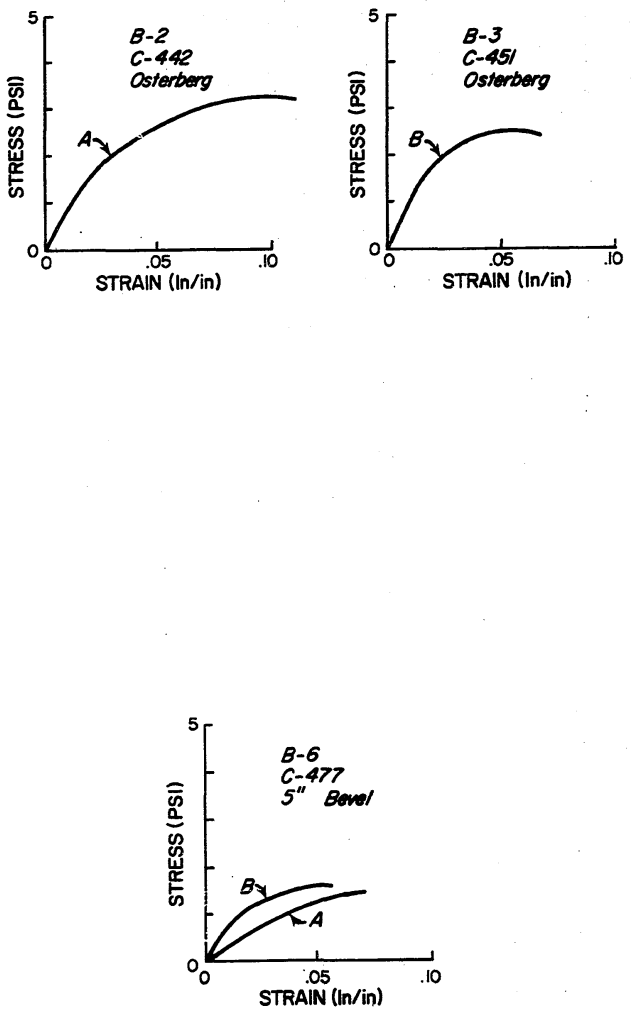

FIGURE 164 LAPLACE $\left(27^{\prime}-30^{\prime}\right)$ 


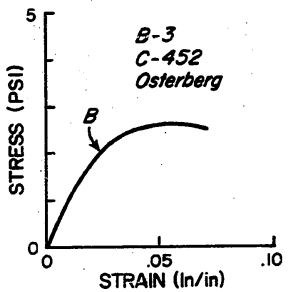

FIGURE 165 LAPLACE $\left(30^{\prime}-33^{\prime}\right)$ 

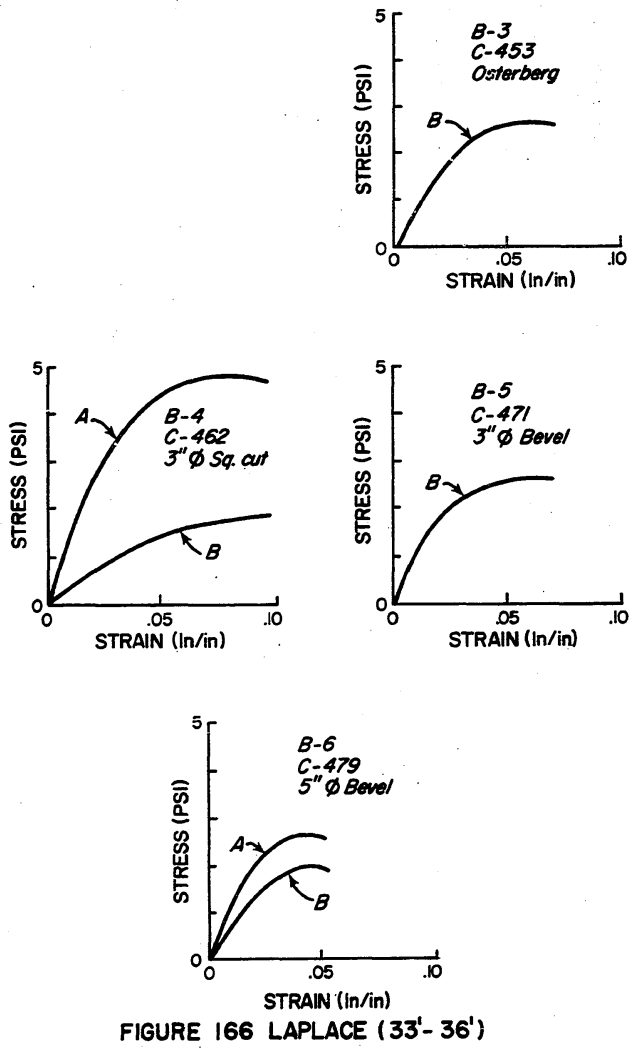

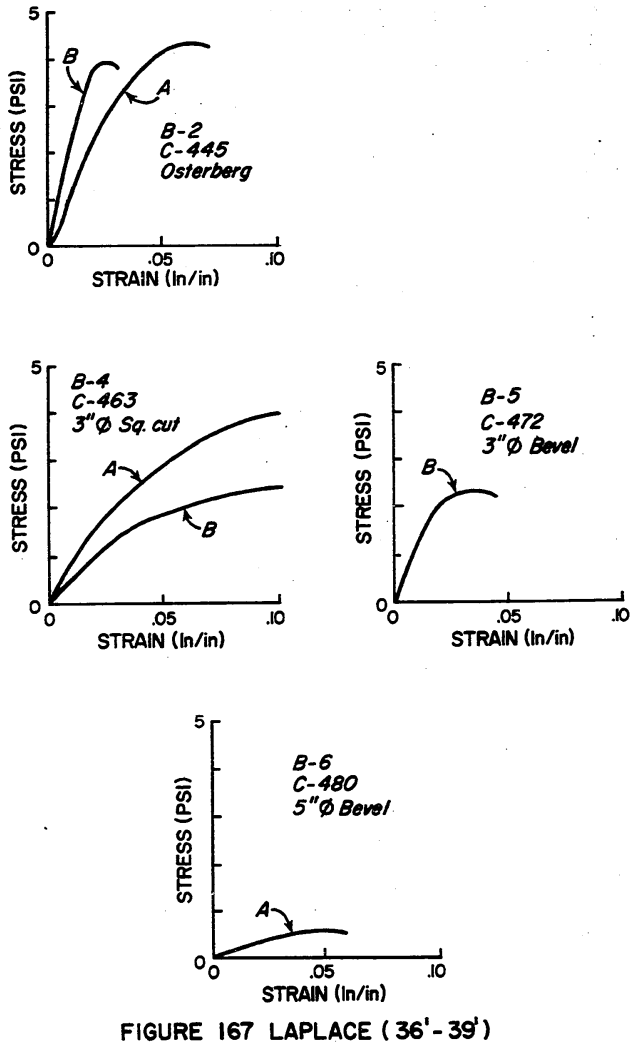

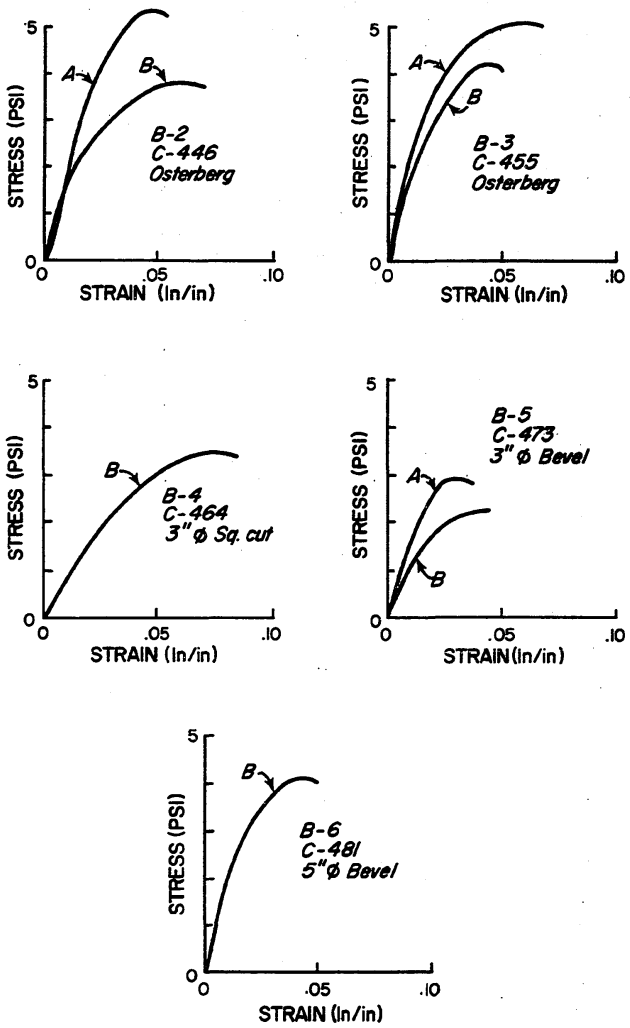

FIGURE 168 LAPLACE $\left(39^{\prime}-42^{\prime}\right)$ 


\author{
APPENDIX E \\ Erwinville Site \\ Houma Site \\ Morgan City Site \\ Benton Site \\ Baton Rouge Site \\ Monroe Site
}

340

Reproduced with permission of the copyright owner. Further reproduction prohibited without permission. 
Location: ERWINVILLE SITE

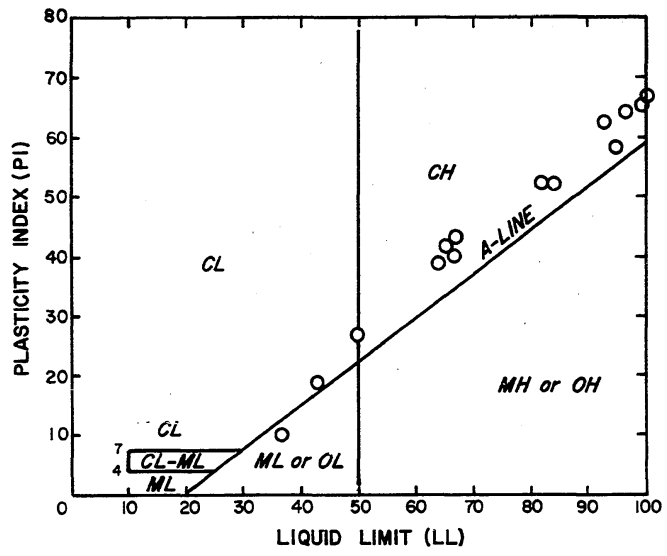

FIGURE 169 MODIFIED PLASTICITY CHART WITH

UNIFIED SOIL CLASSIFICATION SYSTEM

(AFTER USBR 1963) 

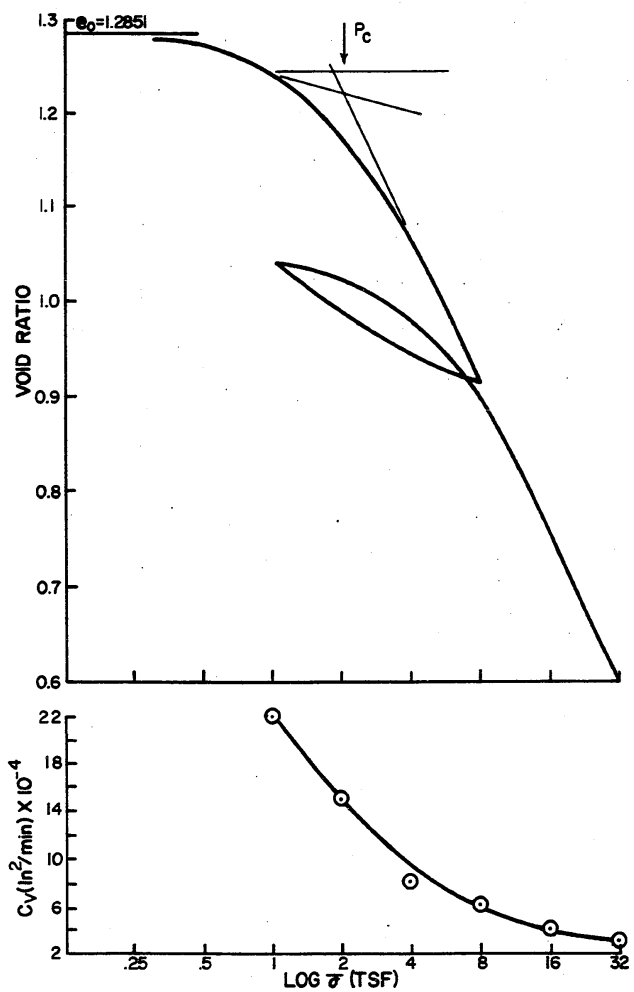

FIGURE 170 CONSOLIDATION TEST - ERWMNVILLE SITE $\left(15^{\prime}-18^{\prime}\right.$ DEPTH) 
Location: HOUMA SITE

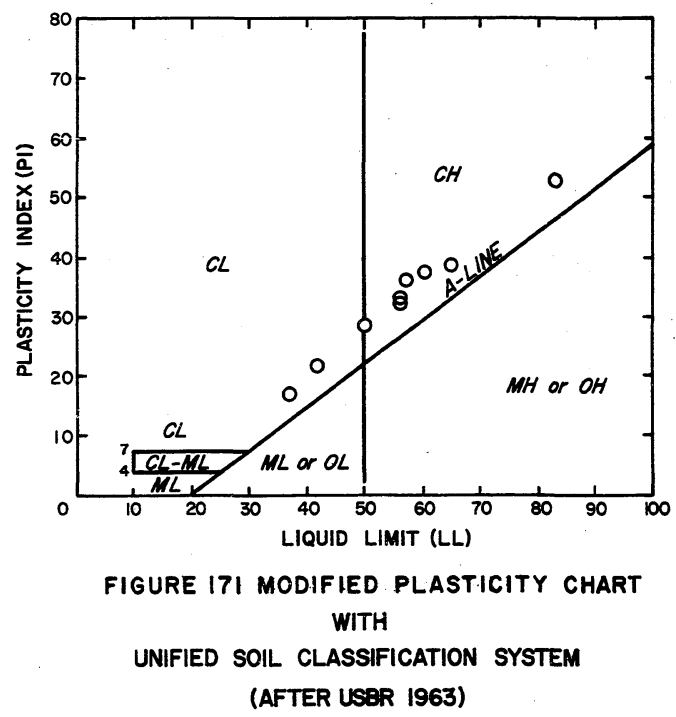




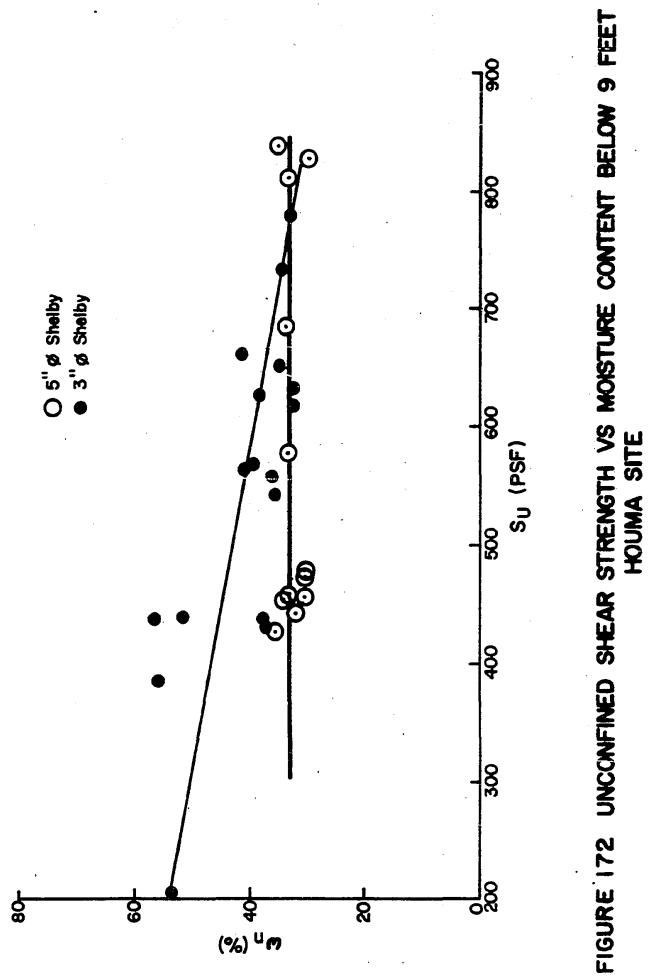



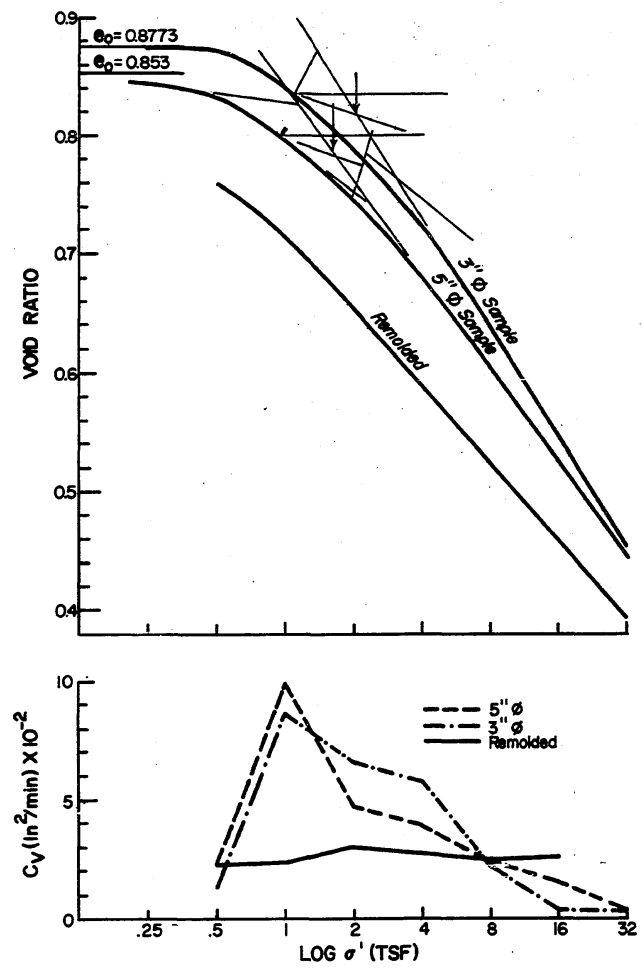

FIGURE I73 CONSOLIDATION TEST - HOMMA SITE (15'-18' DEPTH) 


\section{Location: MORGAN CITY}

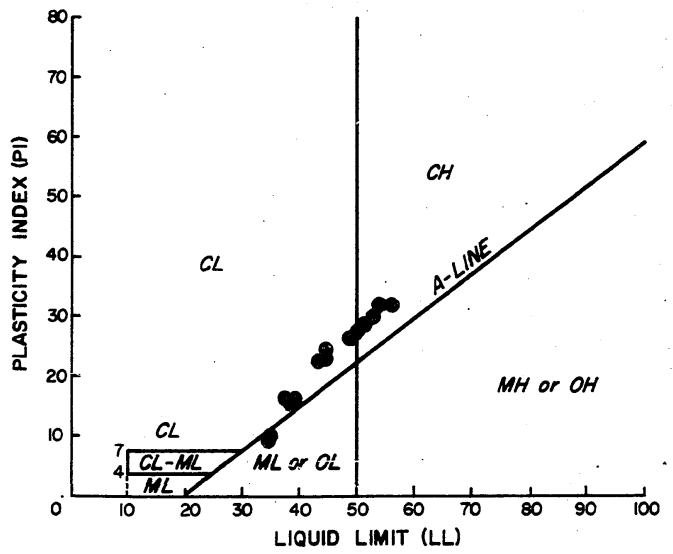

FIGURE 174 MODIFIED PLASTICITY CHART
WITH UNIFIED SOIL CLASSIFICATION SYSTEM

After USBR, 1963 


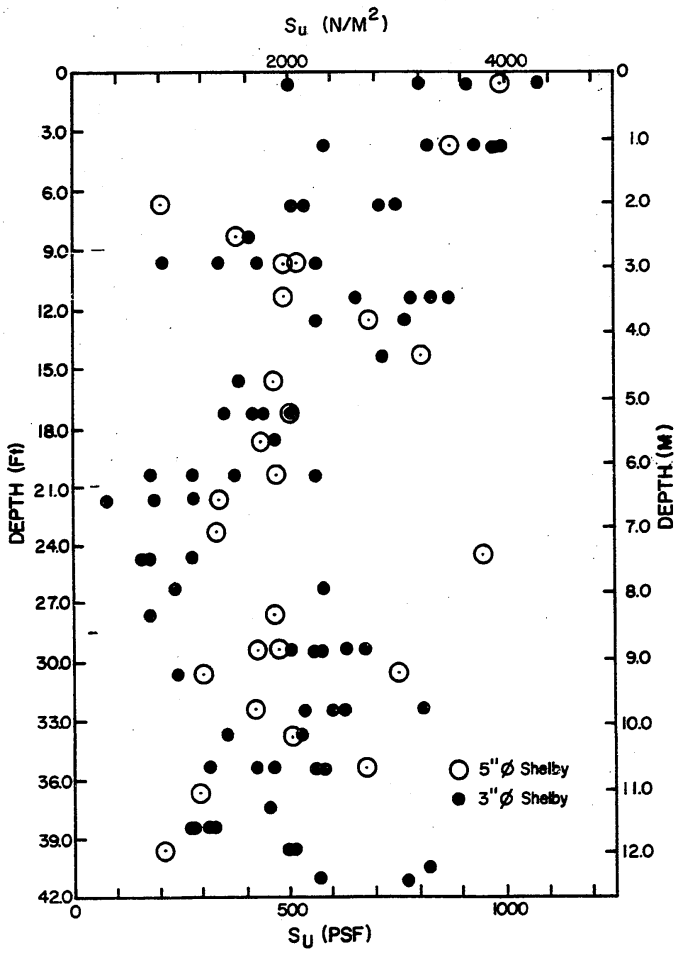

FIGURE 175 DEPTH VS UNCONFNED SHEAR STRENGTH MORGAN CITY SITE 


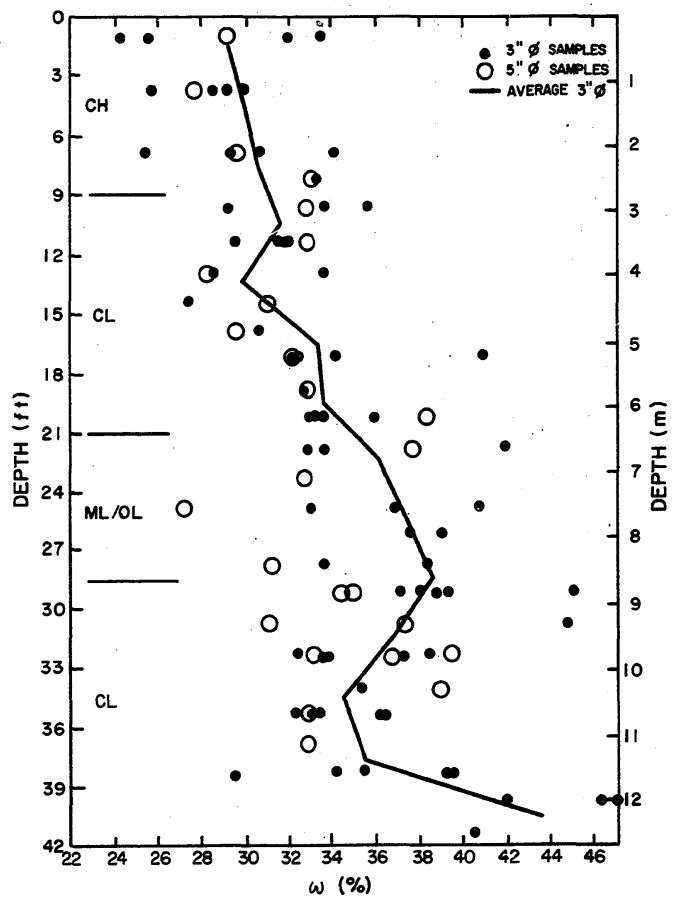

FIGURE I76 MORGAN CITY SITE DEPTH VS NATURAL MOISTURE CONTENT 


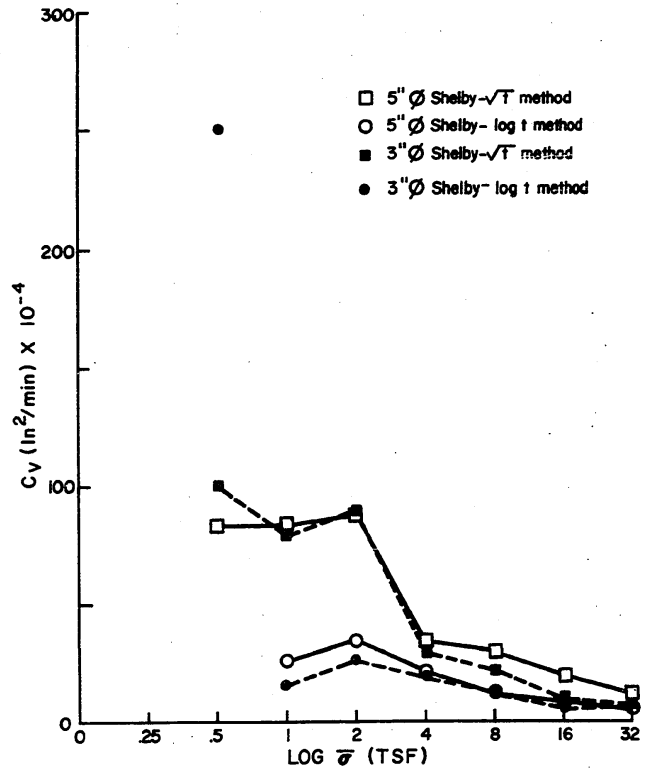

FIGURE 177 COEFFICIENT OF CONSOLIDATION VS PRESSURE MORGAN CITY SITE - $12^{\circ}-15^{\prime}$ DEPTH 


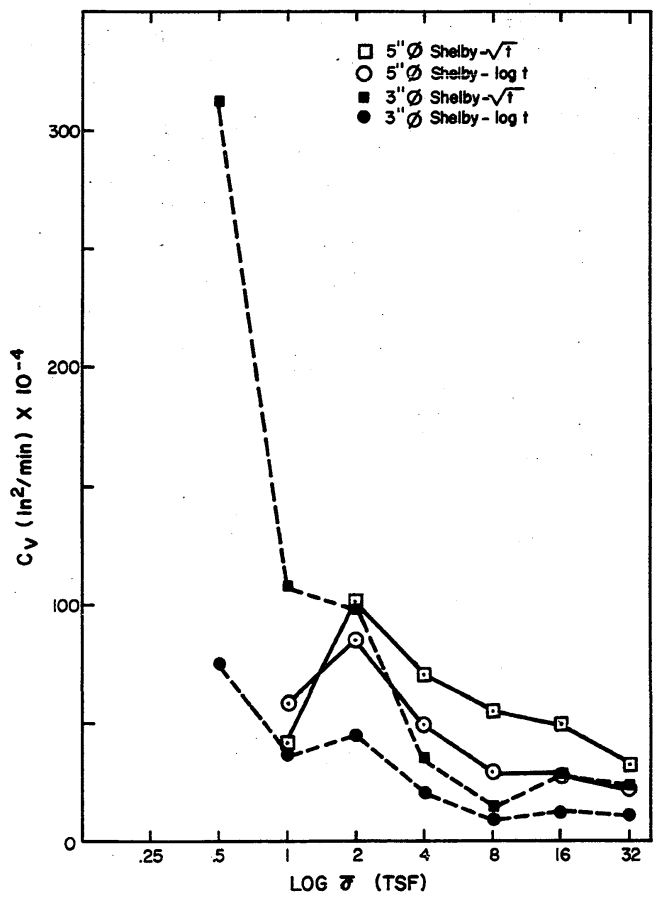

FIGURE I78COEFFICENT OF CONSQLIDATION US PRESSURE MORGAN CITY $\left(30^{\prime}-33^{\prime}\right.$ DEPTH $)$ 


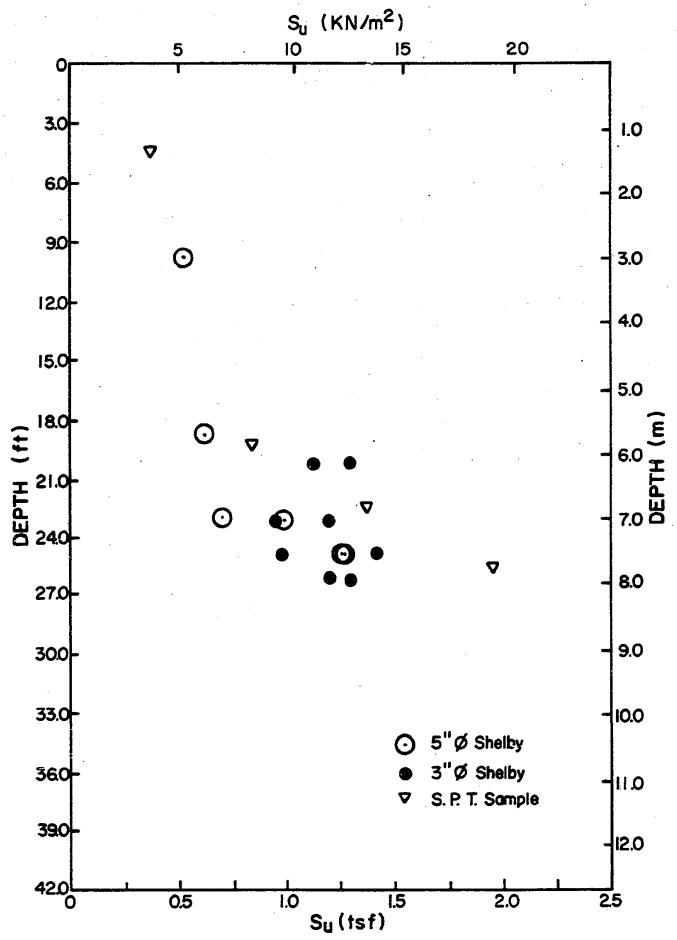

FIGURE 179 DEPTH VS. $S_{U}$ (UNCONFINED SHEAR STRENGTH) BENTON SITE 
Location: BATON ROUGE SITE

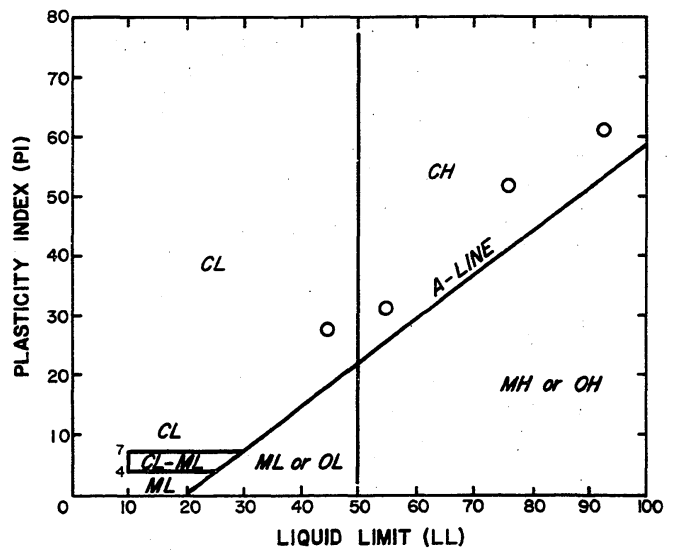

FIGURE 180 MODIFIED PLASTICITY CHART WITH

\section{UNIFIED SOIL CLASSIFICATION SYSTEM \\ (AFTER USBR 1963)}




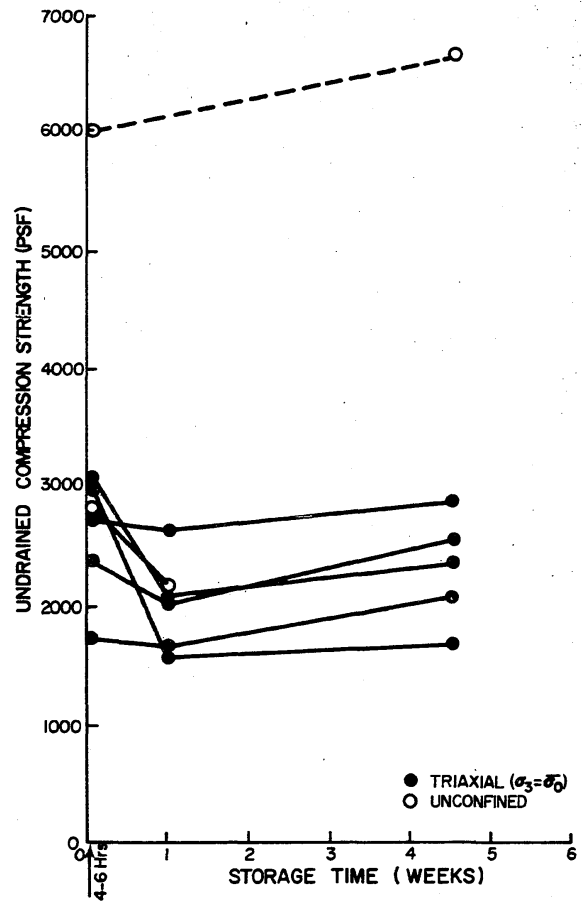

FIGURE I8I STORAGE TIME VS COMPRESSION STRENGTH BATON ROUGE SITE 
Location: MONROE SITE

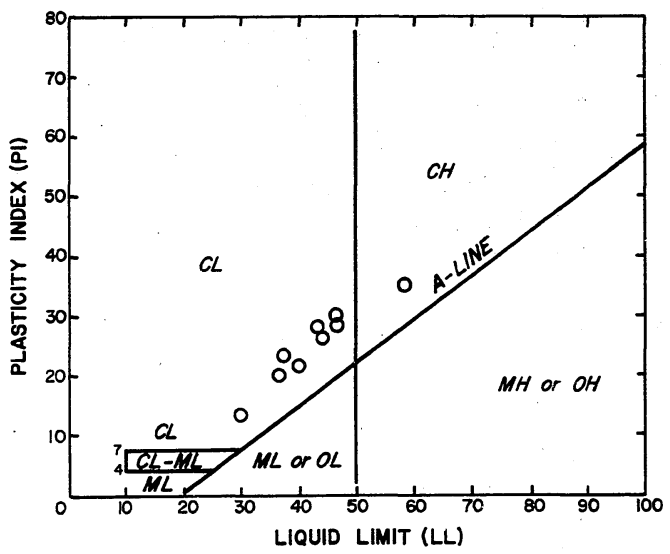

FIGURE I82 MODIFIED PLASTICITY CHART WITH

UNIFIED SOIL CLASSIFICATION SYSTEM

(AFTER USBR 1963) 


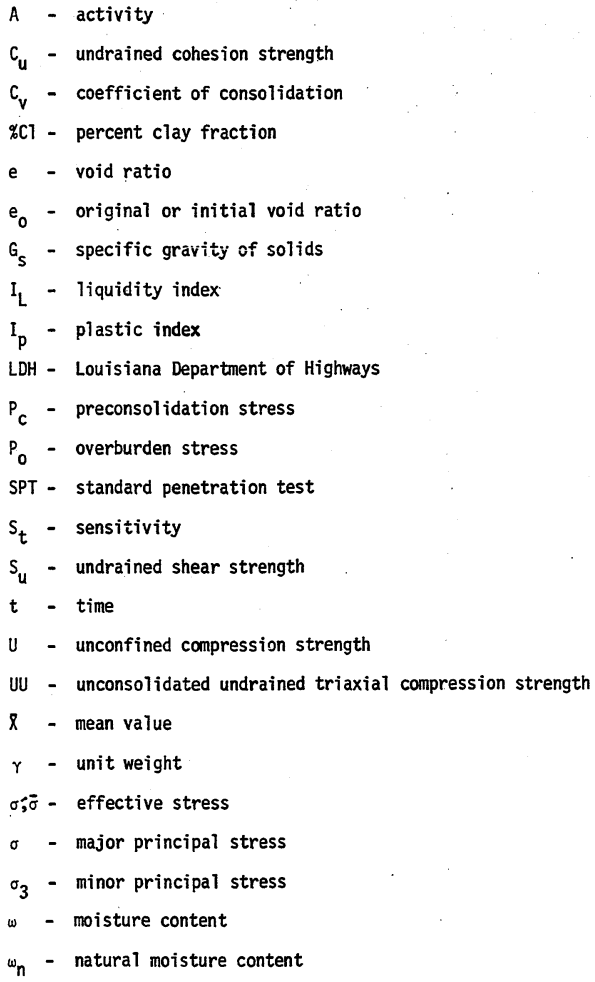


$\omega_{L}$ - liquid limit

$\omega_{p}$ - plastic limit

Other symobls defined where they occur 


\section{BIOGRAPHY.}

Kenneth Louis McManis was born in Lake Charles, Louisiana on October 20, 1941. He received his primary and secondary education in the Lafayette, Louisiana school system. After graduating from high school in 1959, he attended and graduated from the University of Southwestern Louisiana in 1963 with a B.S. degree in civil engineering. Graduate course work included an M.S. degree in civil engineering at Louisiana State University in January, 1966, graduate civil engineering studies at Tulane University in 1968 and he returned to Louisiana State University in 1971 to pursue the Ph.D. degree in civil engineering.

Kenneth McManis was employed in the petroleum offshore industry from 1963 to 1964 and with engineering consuiting firms in the New Orleans area from 1966 to 1968. He is a licensed professional engineer and land surveyor in the state of Louisiana. He was employed in 1968 by Deigado Community Junior College where he is currently Dean of the Engineering and Industrial Technology Division. 


\section{EXAMINATION AND THESIS REPORT}

\section{Candidate: Kenneth Iouis McManis}

\section{Major Field: Civil Engineering}

Title of Thesis: "The Effects of Conventional Soil Sampling Methods on the Ingineering Properties of Cohesive Soils In Louisiana"

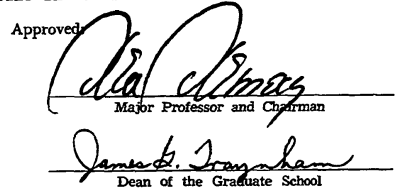

EXAMINING COMMITTEE:

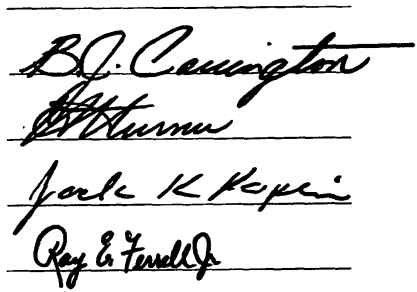

Date of Examination:

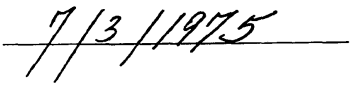

